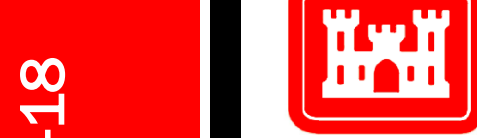

US Army Corps of Engineers $s_{\circledast}$

Engineer Research and

Development Center

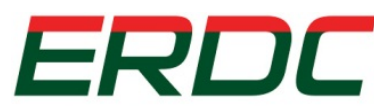

INNOVATIVE SOLUTIONS for a safer, better world

ACSIM Technology Standards Group

\title{
Full-Scale Testing of Thermoplastic Composite I-Beams for Bridges
}

Ghassan K. Al-Chaar, Steven C. Sweeney, Richard G. Lampo,

June 2017

and Marion L. Banko

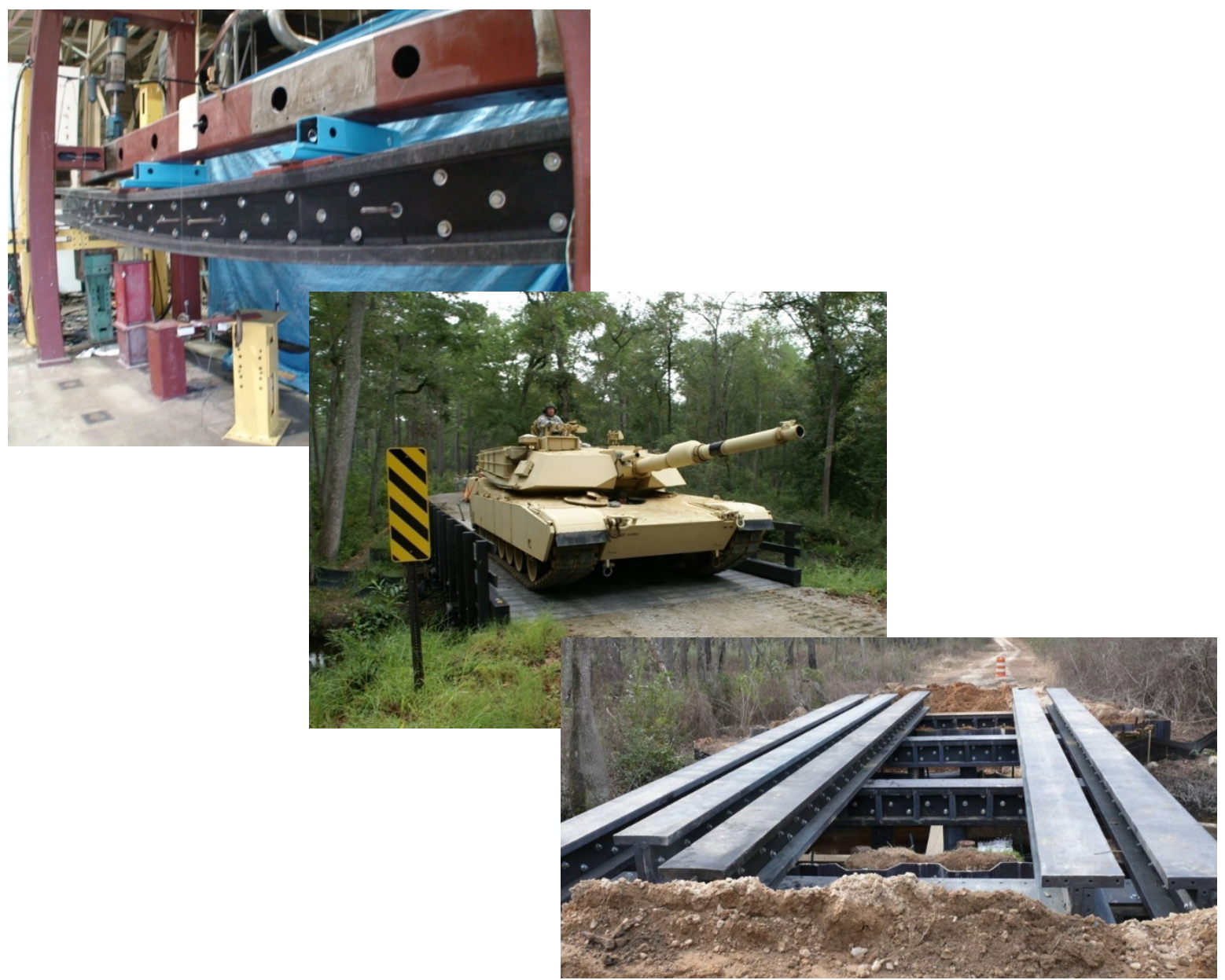


The U.S. Army Engineer Research and Development Center (ERDC) solves the nation's toughest engineering and environmental challenges. ERDC develops innovative solutions in civil and military engineering, geospatial sciences, water resources, and environmental sciences for the Army, the Department of Defense, civilian agencies, and our nation's public good. Find out more at www.erdc.usace.army.mil.

To search for other technical reports published by ERDC, visit the ERDC online library at http://acwc.sdp.sirsi.net/client/default. 


\section{Full-Scale Testing of Thermoplastic Composite I-Beams for Bridges}

Ghassan K. Al-Chaar, Steven C. Sweeney, Richard G. Lampo, and Marion L. Banko Construction Engineering Research Laboratory

U.S. Army Engineer Research and Development Center 2902 Newmark Drive

Champaign, IL 61822

Final report

Approved for public release; distribution is unlimited.

Prepared for Office of the U.S. Army Assistant Chief of Staff for Installation Management (OACSIM)

600 Army Pentagon

Washington, DC 20310

Under Work Item \# 2DB01B, ACSIM Technology Standards Group Evaluation of Technologies 


\section{Abstract}

Bridges are essential to access remote training areas on military installations. Department of Defense (DoD) elements are responsible for maintaining these bridges, which are experiencing significant deterioration of current steel and wood construction. Polymer composite materials that are resistant to corrosion and rot have been demonstrated as beneficial replacements; however, the structural capacity and design considerations for future applications is not known. Structural performance tests were conducted on commercially available, thermoplastic polymer composite Ibeams at U.S. Army Corps of Engineers, Engineer Research and Development Center-Construction Engineering Research Laboratory (ERDCCERL).

Finite element models of the I-beams were used to predict the behavior of the beams and estimate maximum load, displacement, and shear at failure. Then, tests were conducted on actual beams. The thermoplastic beams displayed sudden, brittle failure modes under ultimate loading conditions. The thermoplastic material displayed viscoelastic properties, greater stiffness at higher deflection rates, and load decay under constant and ramped deflections, implying time-dependent deflection under constant load. The beams retained residual deformations after each load cycle.

Therefore, a large capacity-reduction factor is advisable for future strength designs. Follow-on developmental work is recommended that refines material property estimates to create higher efficiency during the design process, yet maintains conservatism.

DISCLAIMER: The contents of this report are not to be used for advertising, publication, or promotional purposes. Citation of trade names does not constitute an official endorsement or approval of the use of such commercial products. All product names and trademarks cited are the property of their respective owners. The findings of this report are not to be construed as an official Department of the Army position unless so designated by other authorized documents.

DESTROY THIS REPORT WHEN NO LONGER NEEDED. DO NOT RETURN IT TO THE ORIGINATOR. 


\section{Contents}

Abstract.............................................................................................................. ii

Figures and Tables...............................................................................................................v

Preface ................................................................................................................ X

Unit Conversion Factors................................................................................................. xi

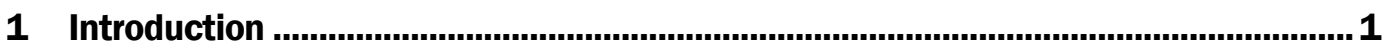

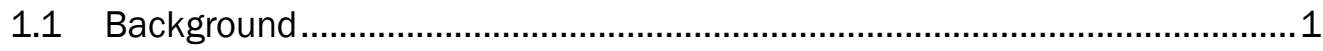

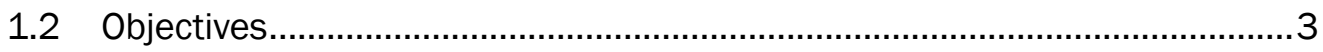

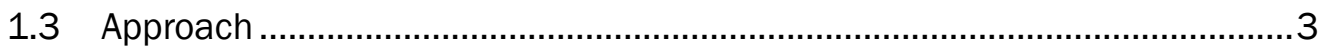

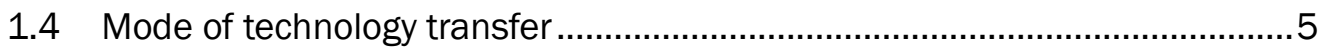

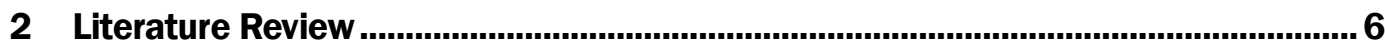

3 Analytical Study of Simply Supported I-Beam with Two Symmetrical Loads ..........11

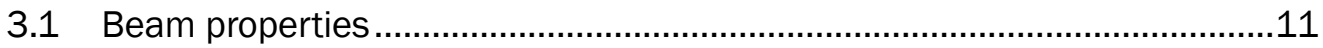

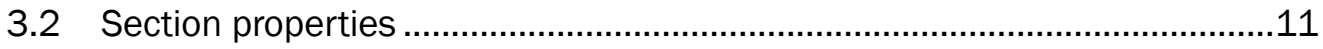

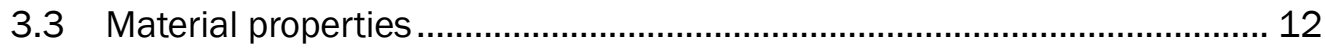

3.4 Load Pideflections............................................................................ 12

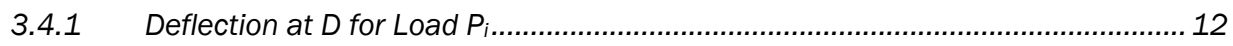

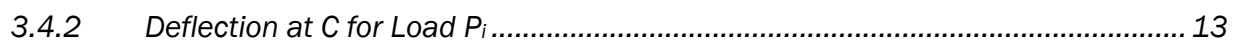

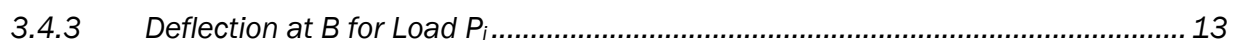

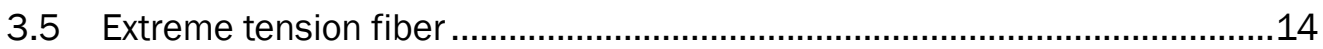

3.5.1 Load at failure of extreme tension fiber ............................................................... 14

3.5.2 Deflection at failure of extreme tension fiber...................................................... 14

3.5.3 Maximum shear stress at failure of extreme tension fiber (Point E) .....................14

3.5.4 Load at failure of extreme compression fiber .................................................... 14

3.5.5 Deflection at failure of extreme compression fiber.............................................. 15

4 Analytical Study of Tests with SAP2000 Models .................................................16

4.1 Beam Configuration \#1 ...........................................................................16

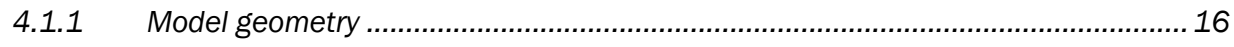

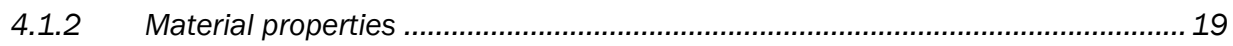

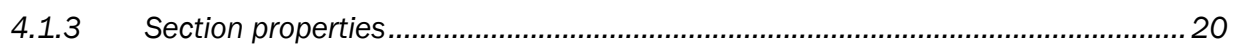

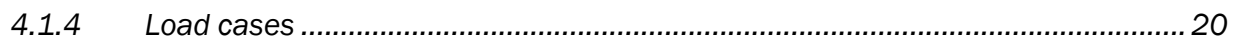

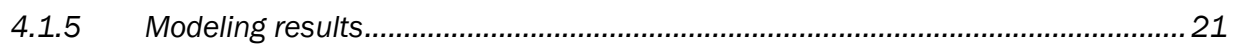

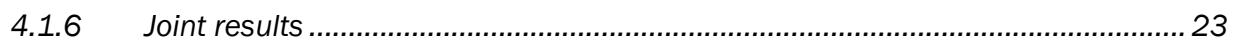

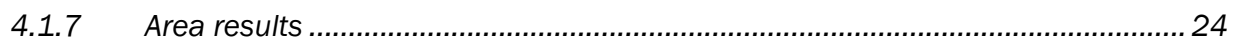

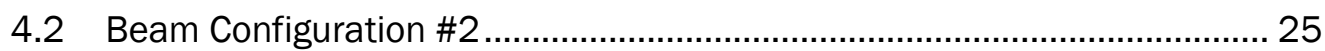

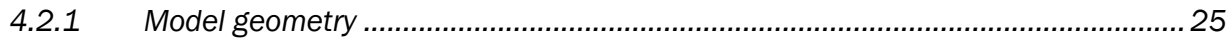

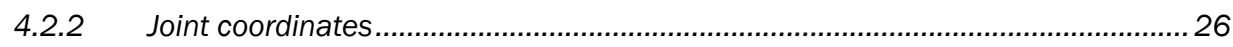

4.2.3 Material properties ........................................................................................ 29 


\begin{tabular}{|c|c|}
\hline 4.2 .4 & 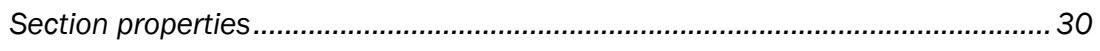 \\
\hline 4.2 .5 & Load cases ... \\
\hline 4.2 .6 & 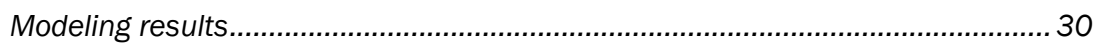 \\
\hline 4.2 .7 & 32 \\
\hline 28 & . \\
\hline
\end{tabular}

5 Mechanical Properties of the Thermoplastic Material .............................................35

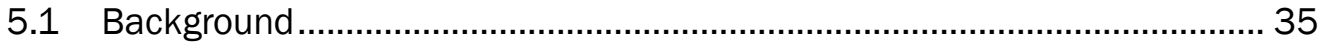

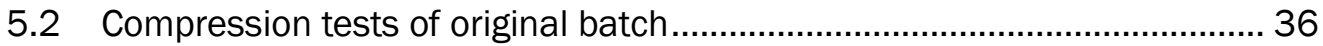

5.3 Tension tests of dog-bone specimens, original batch ................................ 42

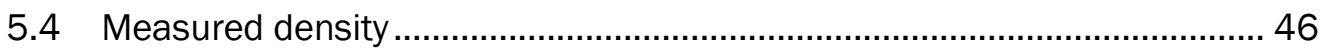

5.5 Compressive testing of specimens from improved batch ........................... 46

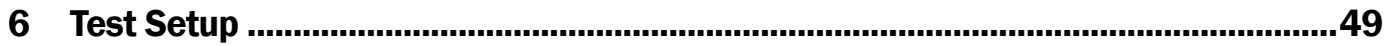

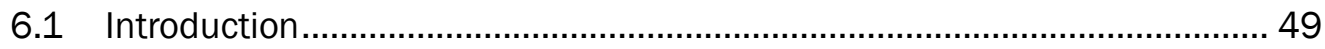

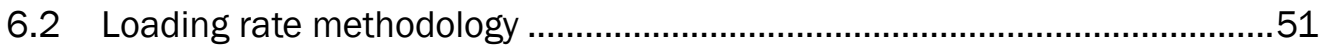

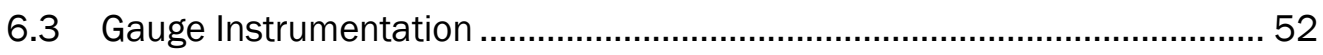

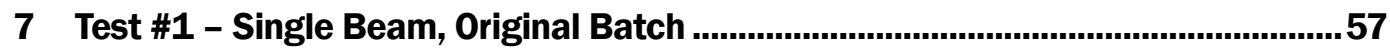

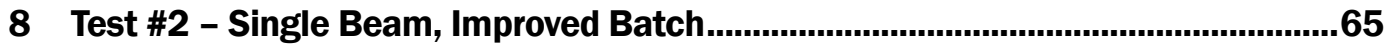

9 Test \#3 - Single Beam, Original Batch ...................................................................

10 Test \#4 - Double Beam, Original Batch ...............................................................80

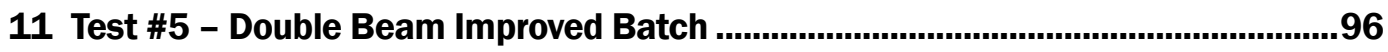

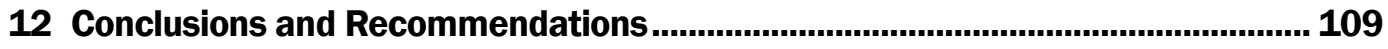

12.1 Test summaries and conclusion........................................................ 109

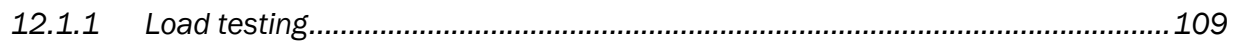

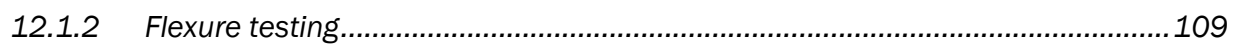

12.1.3 Material properties testing ............................................................................. 110

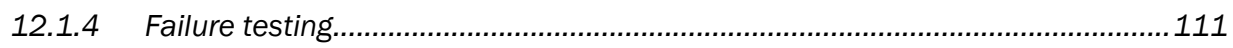

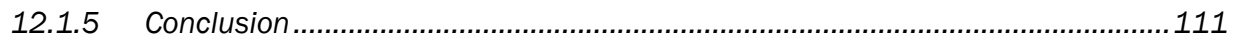

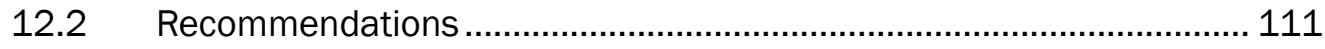

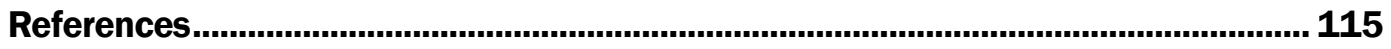




\section{Figures and Tables}

\section{Figures}

Figure 1. Thermoplastic composite l-beams for one of the bridges at Camp Mackall, NC

Figure 2. A U.S. Army Abrams M-1 tank crossing at one of the thermoplastic composite bridges at Camp Mackall, NC.

Figure 3. Nominal beam dimensions (not to scale).

Figure 4. Finite element model for Beam Configuration \#1. Model mesh as generated by SAP 2000 .

Figure 5. Beam plan with critical sections ( $\mathrm{z}=9 \mathrm{in}$.) ....................................................... 17

Figure 6. Beam elevation with critical sections ( $y=9$ in.) ................................................ 17

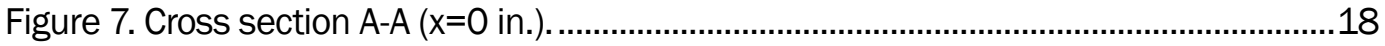

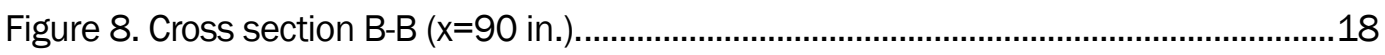

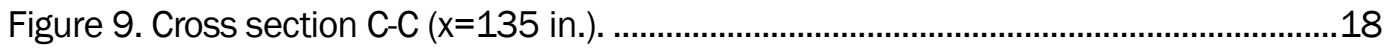

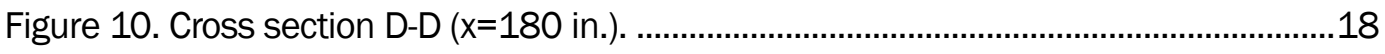

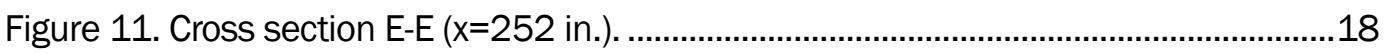

Figure 12. Cross section F-F ( $x=270$ in.)...................................................................

Figure 13. Deformed shape. ..................................................................................... 21

Figure 14. Spectrum of maximum stresses in the beam..................................................22

Figure 15. Spectrum of maximum forces in the beam (elevation). ....................................22

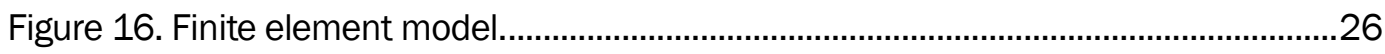

Figure 17. Beam plan indicating critical sections ( $\mathrm{z}=18 \mathrm{in}$.) ............................................26

Figure 18. Beam elevation indicating critical sections ( $y=36$ in.) .......................................2

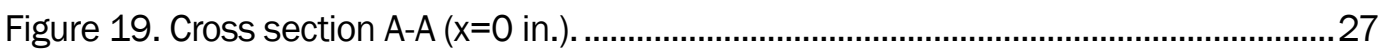

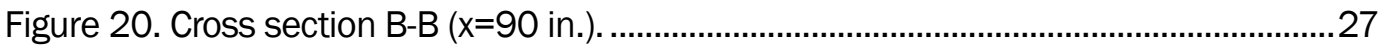

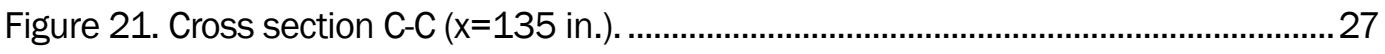

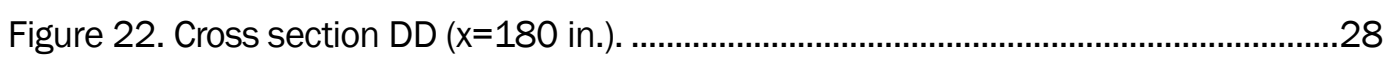

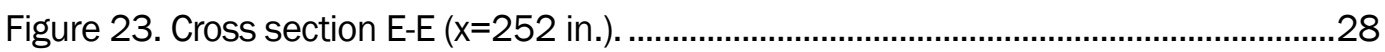

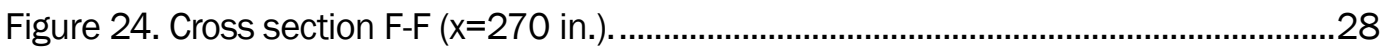

Figure 25. Deformed shape. ............................................................................................31

Figure 26. Spectrum of forces on the beam.................................................................

Figure 27. Spectrum of forces on the beam.................................................................32

Figure 28. Typical section of extruded thermoplastic material in a web or flange, with voids in core outlined by added red box..................................................................35

Figure 29. Cube-shaped specimen to be loaded with layers in series................................37

Figure 30. Cube-shaped specimen to be loaded with layers in parallel. ............................37

Figure 31. Prepared specimens for compression testing, with odd-numbered cubes to be loaded with layers in series, and even-numbered cubes to be loaded with layers in parallel. (Specimen No. 9 is not shown in this photo.) 
Figure 32. Specimens after compression testing.

Figure 33. Test Mark compression machine used to measure ultimate load under compression test. 38

Figure 34. MTS 50-kip extensometer used to measure loading curves. ............................38

Figure 35. Specimen \#9 before testing with extensometer...............................................39

Figure 36. Specimen \#9 after testing with extensometer.................................................39

Figure 37. Cube-shaped specimens, showing modes of failure under compression load.

Figure 38. Stress-strain curves for several specimens. ....................................................42

Figure 39. Nominal dimension of machine-cut dog-bone tension specimens. ...................43

Figure 40. Dog-bone specimen for tensile strength testing...............................................43

Figure 41. Dog bone mounted in MTS million-pound machine.........................................43

Figure 42. Modes of failure for dog-bone specimens........................................................44

Figure 43. Stress-strain curves for selected specimens. .....................................................45

Figure 44. Dog-bone tensile specimens, improved batch................................................. 47

Figure 45. Two T-shaped sections bolted together to form an I-shaped section (left); two I-beams bolted together to form an II-beam (right)...............................................49

Figure 46. Cross-section of beam configurations, showing nominal dimensions. ..............50

Figure 47. A stiffener cut from I-section of 12 in.-deep beam. ...........................................50

Figure 48. Experiment setup.........................................................................................52

Figure 49. Strain and displacement sensor locations for the single beam tests. ..............54

Figure 50. Strain and displacement sensor locations for the double beam (II-

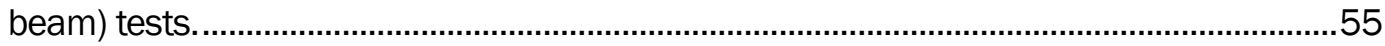

Figure 51. Actuator load versus time. ......................................................................57

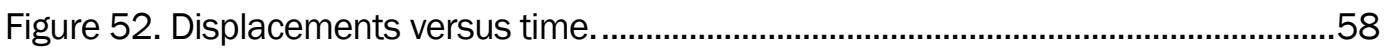

Figure 53. Strain S630, measured near the actuator.....................................................59

Figure 54. Measured strain at midspan bottom fiber........................................................59

Figure 55. Magnitude of measured strains at midspan top fiber. ......................................60

Figure 56. Magnitude of measured strain from gauge rosette versus time.......................61

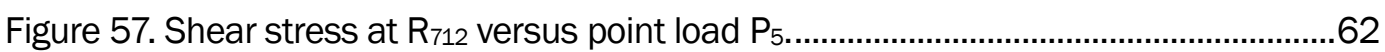

Figure 58. Magnitude of stress-strain curve at midspan bottom fiber...............................62

Figure 59. Magnitude of stress-strain curve at midspan, top fiber.....................................63

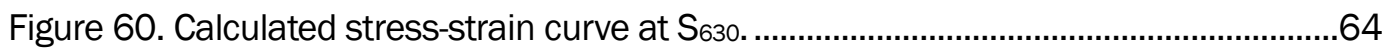

Figure 61. Test \#2 setup...............................................................................................65

Figure 62. Load versus time.......................................................................................6

Figure 63. Displacement versus time.......................................................................67

Figure 64. Measured strain at $\mathrm{S}_{630}$, near the actuator..........................................................67

Figure 65. Measured strains at midspan bottom fiber....................................................68

Figure 66. Measured strain at midspan top fiber versus time...........................................69

Figure 67. Strains measured with R R12 versus time.............................................................. 70 


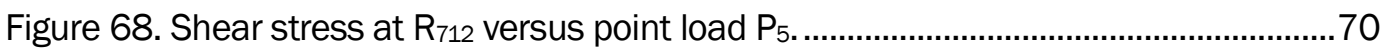

Figure 69. Stress-strain curves at midspan bottom fiber........................................................ 71

Figure 70. Magnitude of stress-strain curves at midspan top fiber...................................72

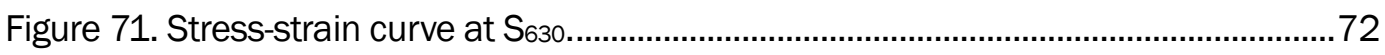

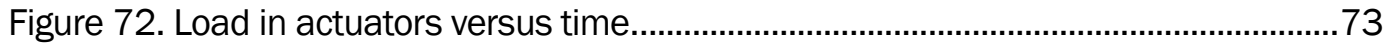

Figure 73. Displacement at the center of the beam......................................................... 74

Figure 74. Magnitudes of strain at the midspan top and bottom fibers. .............................75

Figure 75. Estimated variation of relative compressive and tensile stiffness of

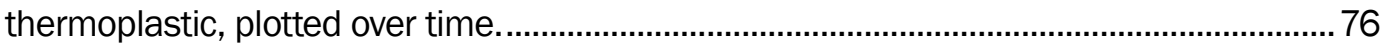

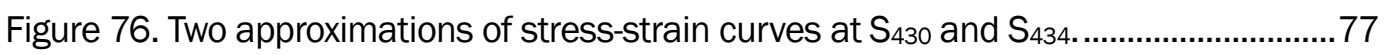

Figure 77. Two approximations of stress-strain curves at $\mathrm{S}_{430}$ and $\mathrm{S}_{434}$ assuming

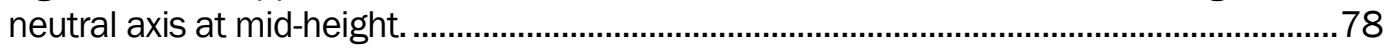

Figure 78. Specimen after failure, with broken section on floor. .........................................79

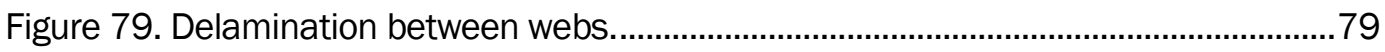

Figure 80. Crack through bolt hole and between flange and web......................................79

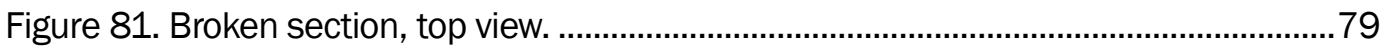

Figure 82. Broken section, west side..............................................................................79

Figure 83. Steps in assembling specimen for Test \#4 .......................................................80

Figure 84. The layout of the stiffeners between the webs of the I-beams...........................81

Figure 85. Test \#4 setup..................................................................................................... 81

Figure 86. Time-variation of point loads....................................................................... 82

Figure 87. Time-variation of point loads, final four cycles. ..............................................82

Figure 88. Displacement over time at loading points......................................................83

Figure 89. Displacement over time at loading points, final four cycles. ..............................84

Figure 90. Displacement over time at midspan bottom fiber.............................................84

Figure 91. Displacement over time at midspan bottom fiber, final four cycles....................85

Figure 92. Displacement of the loading steel beam..........................................................86

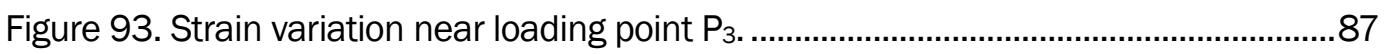

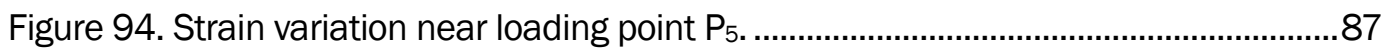

Figure 95. Measured strain at midspan bottom fiber on each l-section. ............................88

Figure 96. Measured strain at midspan top fiber on each I-section. ..................................89

Figure 97. Readings from rosette strain gauges...............................................................89

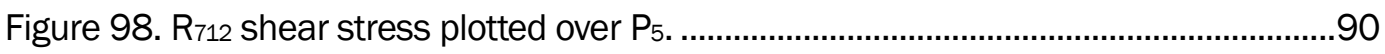

Figure 99. $\mathrm{S}_{430}$ stress-strain curve at midspan bottom fiber. ............................................91

Figure 100. $\mathrm{S}_{494}$ Stress-strain curve at the midspan top fiber...............................................91

Figure 101. $\mathrm{S}_{490}$ stress-strain curve at midspan bottom fiber...........................................92

Figure 102. Excessive deformation without failure.............................................................92

Figure 103. Effect of midspan deflection rate on specimen stiffness. ...............................93

Figure 104. Effect of average midspan deflection rate on average specimen stiffness. 
Figure 105. Effect of normalized midspan deflection rate on normalized specimen stiffness.

Figure 106. Effect of normalized average midspan deflection rate on normalized

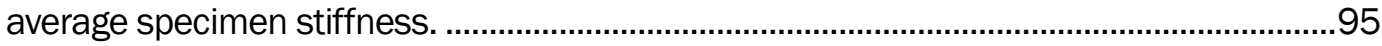

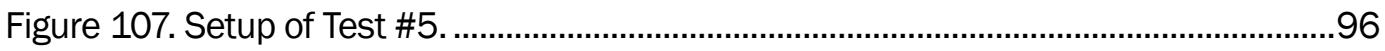

Figure 108. Actuator-only load time histories. ..............................................................97

Figure 109. Approximated total force time histories (preload and actuators). ...................98

Figure 110. Load point displacement under both loading actions.....................................99

Figure 111. Midspan displacement under both loading actions.......................................99

Figure 112. Strain time histories under both loading actions........................................... 100

Figure 113. Strain time histories with S230 multiplied by 10. ............................................ 101

Figure 114. Measured strain at midspan bottom fiber of specimen. ............................... 102

Figure 115. Strain values measured by the rosette R R12..................................................... 102

Figure 116. Calculated shear stresses at $R_{712}$ over time................................................. 103

Figure 117. Actuator point load $P_{5}$ versus calculated shear stresses at $R_{712} \ldots \ldots \ldots \ldots . . . . . . . .104$

Figure 118. Approximate total point load $P_{5}$ versus calculated shear stresses at

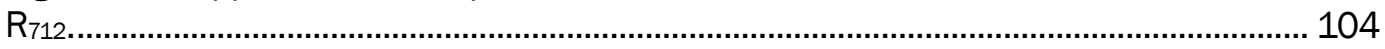

Figure 119. Approximate magnitude of bending stress versus strain at midspan. ......... 105

Figure 120. Brittle failure of the specimen. ..................................................................... 106

Figure 121. Side view of failed specimen, looking west................................................. 106

Figure 122. Oblique view of specimen, cracks in top flange are visible.......................... 107

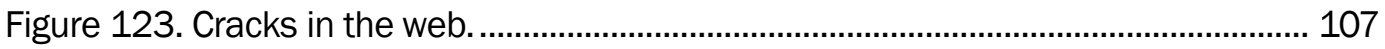

Figure 124. Longitudinal view, looking north............................................................... 107

Figure 125. Flange-web delamination...................................................................... 108

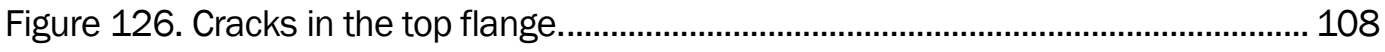

Figure 127. Separation surface between flange and web, shown on flange. .................. 108

Figure 128. Fragments that became airborne due to brittle failure................................. 108

Figure 129. Crack survey............................................................................................... 108

\section{Tables}

Table 1. Calculated values from nominal dimensions........................................................15

Table 2. Global coordinates for joints in Beam Configuration \#1. .....................................19

Table 3. Summary of material properties used in the model for Beam

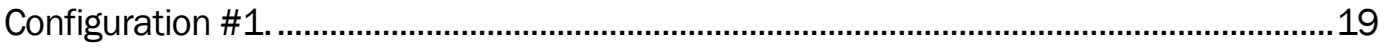

Table 4. Summary of section properties used in the model for Beam

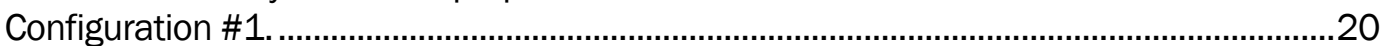

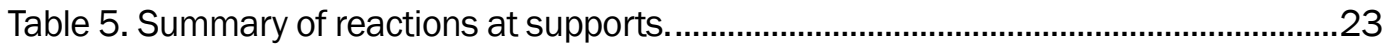

Table 6. Summary of joint displacements and reactions at beam ends. ...........................23

Table 7. Summary of joint displacements beneath loading.................................................23

Table 8. Summary of joint displacements at beam center..................................................24 
Table 9. Summary of element stresses at beam ends....................................................24

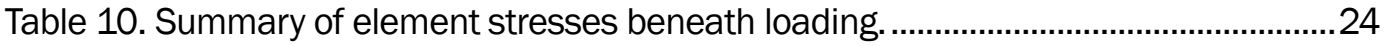

Table 11. Summary of element stresses at beam center.....................................................25

Table 12. Summary of element stresses at the rosette. .....................................................25

Table 13. Summary of global joint coordinates and corresponding cross section.............29

Table 14. Summary of material properties. .......................................................................29

Table 15. Summary of section properties. ….....................................................................30

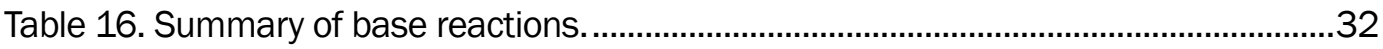

Table 17. Summary of joint displacements and reactions at beam ends............................32

Table 18. Summary of joint displacements beneath loading..............................................33

Table 19. Summary of joint displacement at beam center......................................................33

Table 20. Summary of element stresses at beam ends. ..................................................33

Table 21. Summary of element stresses beneath loading. ....................................................34

Table 22. Summary of element stresses at beam center................................................34

Table 23. Summary of element stresses at the rosette...................................................34

Table 24. Summary of compressive tests on cube-shaped specimens from the original batch.

Table 25. Summary of tension tests on dog-bone specimens from the original

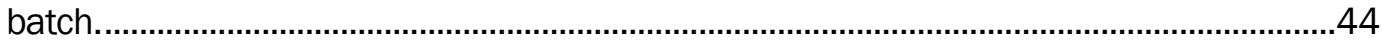

Table 26. Density calculation of original thermoplastic material........................................46

Table 27. Summary of compressive tests on cube-shaped specimens from the improved batch of thermoplastic material. .46

Table 28. Mechanical properties of dog-bone tensile specimens, from improved

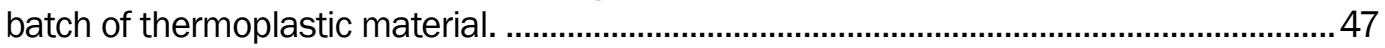

Table 29. Density calculation of improved thermoplastic material.....................................48

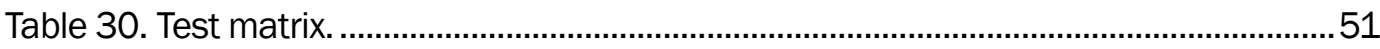

Table 31. List of sensor locations for single I-beam-Tests 1, 2, and 3.............................54

Table 32. List of sensor locations for double II-beams, Tests 4 and 5............................56

Table 33. Measured loads and displacement at the center of the specimens. .............. 113

Table 34. Measured flexural stresses at the center of the beam and the shear stress at 18" in from the support. 


\section{Preface}

This work, "Full-Scale Testing of Thermoplastic Composite I-Beams for Bridges," was conducted under the Technology Standards Group of the Office of the U.S. Army Assistant Chief of Staff for Installation Management (OACSIM) as follow-on support for Installation Technology Transition Program (ITTP) Projects FYo8-16, "Innovative Recycled-Plastic I-Beam Bridge for Vehicular Traffic" and FYo9-31, "Phase II, Load Testing and Tech Transfer for Design for Bridges on Military Installations for Military Vehicles." Funding was provided by OACSIM under Work Item \# 2DBo1B, Technology Standards Group Evaluation of Technologies. The OACSIM Technical Monitor was Mr. Phillip R. Columbus (DAIM-ODF), and the ITTP Program Manager was Ms. Kelly (Dilks) Moon.

The work was performed by the Materials Branch (CEERD-CF-M), Facilities Division (CF), U.S. Army Engineer Research and Development Center, Construction Engineering Research Laboratory (ERDC-CERL). At the time of publication, Ms. Vicki L. VanBlaricum was Chief, CEERD-CF-M; Mr. Donald K. Hicks, was Chief, CEERD-CF; and Mr. Kurt Kinnevan was the Technical Director for Adaptive and Resilient Installations, CEERDCV-ZT. The Deputy Director of ERDC-CERL was Dr. Kirankumar Topudurti, and the Director was Dr. Ilker Adiguzel.

The authors would like to thank Mr. Andrew Steinweg, research assistant, for his contributions to this project and Dr. Thomas J. Nosker, Department of Materials Science and Engineering at Rutgers University in Piscataway, NJ, for reviewing this report and helping to oversee the experimentation documented herein.

The Commander of ERDC was COL Bryan S. Green, and the Director was Dr. David W. Pittman. 


\section{Unit Conversion Factors}

\begin{tabular}{|l|c|l|}
\hline Multiply & \multicolumn{1}{|l|}{ By } & To Obtain \\
\hline cubic feet & 0.02831685 & cubic meters \\
\hline cubic inches & $1.6387064 \mathrm{E}-05$ & cubic meters \\
\hline degrees Fahrenheit & $(\mathrm{F}-32) / 1.8$ & degrees Celsius \\
\hline feet & 0.3048 & meters \\
\hline foot-pounds force & 1.355818 & joules \\
\hline inches & 0.0254 & meters \\
\hline pounds (force) & 4.448222 & newtons \\
\hline pounds (force) per foot & 14.59390 & newtons per meter \\
\hline pounds (force) per inch & 175.1268 & newtons per meter \\
\hline pounds (mass) & 0.45359237 & kilograms \\
\hline square feet & 0.09290304 & square meters \\
\hline square inches & $6.4516 \mathrm{E}-04$ & square meters \\
\hline tons (2,000 pounds, mass) & 907.1847 & kilograms \\
\hline
\end{tabular}


(This page intentionally blank.) 


\section{Introduction}

\subsection{Background}

The Army has installations around the world, and many of these installations utilize bridges as a significant component of their infrastructure. These bridges are exposed to a variety of climate conditions, heavy industrial contaminates, and vehicular loadings resulting in frequent maintenance due to rapid material degradation. These bridges, like those in our national highway system, are experiencing significant deterioration and stability problems from corrosion of steel, cracking and spalling of concrete, and rot, insect attacks, and mold growth of wood.

The Federal Highway Administration (FHWA) Report RD-01-156 states that approximately one quarter of the direct cost of corrosion of bridges is made up of maintenance and capital costs for steel reinforcement, and the Department of Defense (DoD) is responsible for the maintenance of many of these bridges (Koch et al. 2002). Therefore the cost for maintenance and replacement of these bridge infrastructures has a major impact on the Army and its operations. Maintaining serviceable bridges is essential to providing access to the facilities on the post installation and to remote training areas that would otherwise be inaccessible due to rivers, streams, trains, roads, and other geographical obstacles to transportation.

New technologies employing polymer composite materials that are corrosion resistant would be highly beneficial as replacements for traditional materials used for bridges. The validation and implementation of these technologies will improve the ability of DoD installations to sustain the mission and eliminate the potential for premature failure of infrastructure, through the application of these technologies when replacing or rehabilitating corroding bridge structures.

Thermoplastic composites, such as fiber-reinforced, recycled high-density polyethylene plastic lumber and timbers, are an environmentally and economically attractive substitute to current bridge materials, especially wood timbers. Thermoplastic composites are not subject to degradation, do not leach harmful chemical into the soil or groundwater, rarely crack or splinter, and provide great shock-adsorption. Additionally, thermoplastic composites allow for reduced inspection, reduced maintenance, increased 
longevity, and complete recyclability, compared to current bridge materials.

Between 2009 and 2011, three bridges were built at Camp Mackall, North Carolina (a sub-installation to Fort Bragg, North Carolina), using thermoplastic composites for virtually everything, including the support piles and beams. These bridges incorporated an innovative I-beam design that enabled the bridges to support a 71-ton Abrams M-1 tank (Figure 1 and Figure 2), while being cost competitive to a timber or reinforced concrete bridge at the same loading capacity (Commander and Diaz-Alvarez 2010; Lampo et al. 2011; Lampo et al., forthcoming). While these bridges met the designed load requirements, the I-beams used were not loaded to failure in full-scale tests. Knowing the structural behavior of these thermoplastic composite I-beams, including modes of failure, would help engineers to have increased confidence when creating future designs with these components.

Figure 1. Thermoplastic composite I-beams for one of the bridges at Camp Mackall, NC.

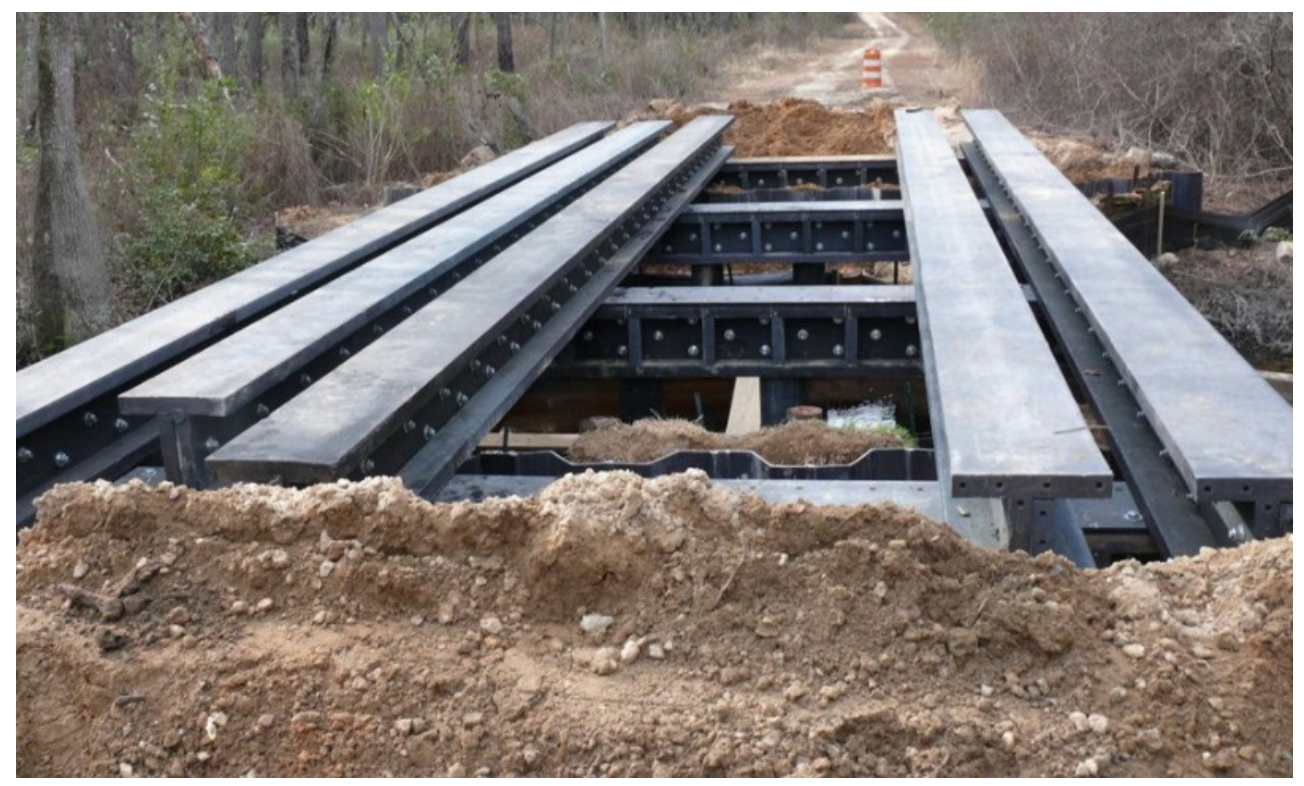


Figure 2. A U.S. Army Abrams M-1 tank crossing at one of the thermoplastic composite bridges at Camp Mackall, NC.

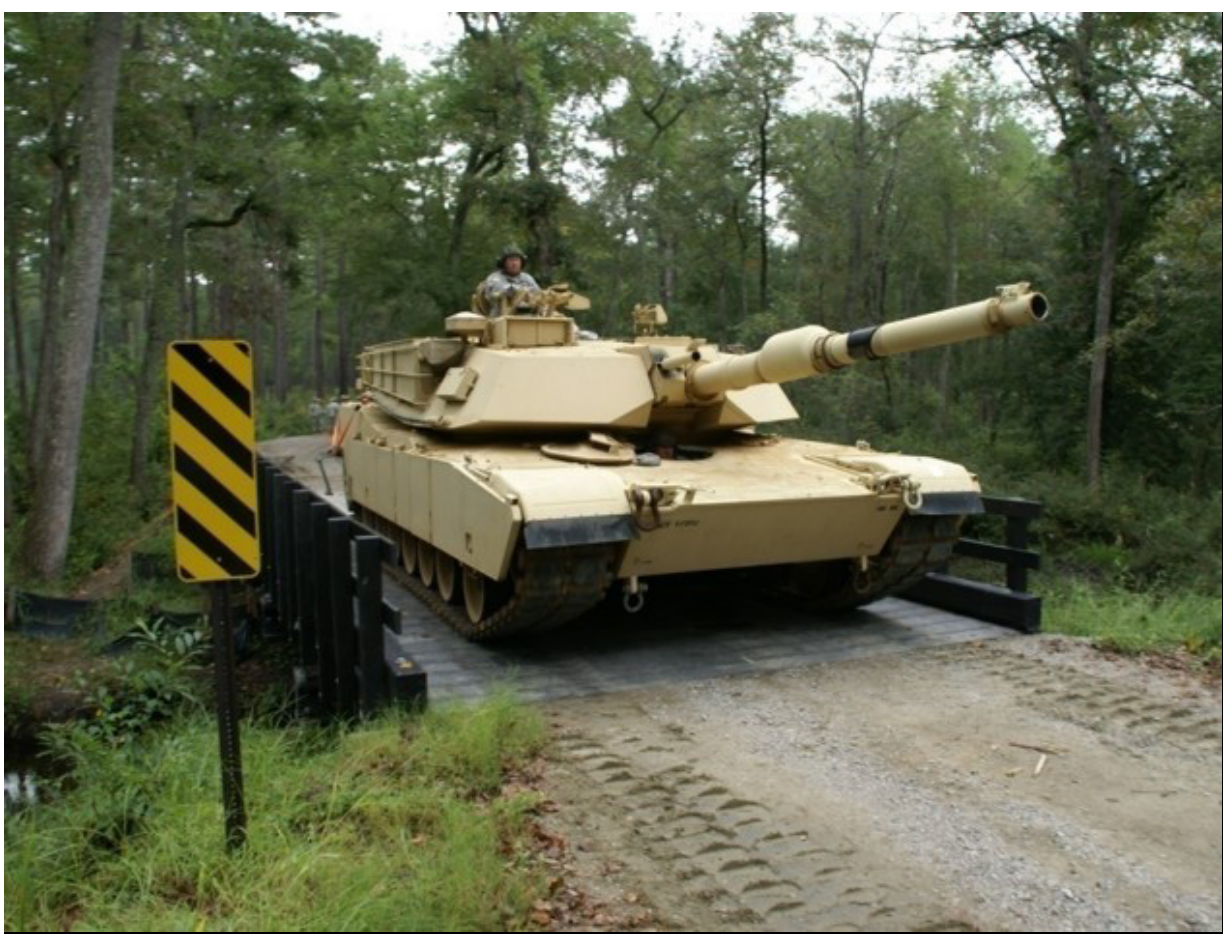

\subsection{Objectives}

The objective of this effort was to evaluate and document the structural performance of full-scale, commercially available thermoplastic I-beams. These I-beams were subjected to typical loading conditions associated with Army installation bridges, in order to determine the components' structural capacity and design considerations for future applications and references.

\subsection{Approach}

The U.S. Army Engineer Research and Development Center-Construction Engineering Research Laboratory (ERDC-CERL) conducted a series of laboratory tests on full-scale thermoplastic composite I-beams. The same commercial manufacturer that supplied the thermoplastic composite ma- 
terials for the bridges at Camp Mackall provided the I-beams used for testing. " Two types of beams were provided-from an original batch and an improved batch (that is, improved formulation) of thermoplastic material. Both types were used for the mechanical property and flexural testing. The properties of each type of beam were held constant for all tests.

Before the tests were conducted, a structural analysis of the I-beam configuration was performed using hand calculations and structural analysis and design software, SAP200o. ${ }^{+}$The structural analysis was conducted to illustrate the expected behavior of the beams under the test conditions and to estimate the maximum load, displacement, and shear at failure.

The beams' thermoplastic material was then subjected to mechanical property tests. Several cube and dog-bone specimens were extracted from each beam type. The cube-shaped specimens underwent compressive tests, and the dog-bone specimens underwent tensile strength tests. These property tests determined the maximum load, stress, and strain of the thermoplastic material.

The I-beams then underwent four-point bending tests to determine ultimate flexural strength. Two I-beam configurations were evaluated for both beam types. The first configuration was two asymmetric T-beam sections bolted together at the webs to form a symmetric I-beam. The second configuration was two I-beam sections bolted together to form a double beam. The beams were subjected to different loading rates to evaluate the effect on the structural behavior. The maximum load, deflection, and strain were measured for each beam tested. A comparison of the experimental and analytical results was completed to determine the structural capacity of the thermoplastic I-beams to be used in future bridge design applications.

\footnotetext{
* Beams were provided by Axion International of New Providence, New Jersey; now Axion Structural Innovations of Zanesville, Ohio.

+ SAP2000 is a graphical modeling software from Computers and Structure, Inc. of California and New York.
} 


\subsection{Mode of technology transfer}

The results of this study are appropriate for follow-on development work that focuses on refinement of material property estimates to create higher efficiency during the design process, while maintaining conservatism.

With successful development work, the technologies documented in this report should be appropriate for reference in a new Unified Facility Criteria (UFC) currently under development regarding the Use of Reinforced Polymer Composite Materials for Bridge Applications. ${ }^{*}$ Future implementation could also include development of a field design guide to assist selection of appropriate thermoplastic materials and structural types for Army tactical bridging.

\footnotetext{
* The UFC under development is part of CPC Program Project F15-AR08, "Engineering Guidance for Fiber Reinforced Polymer Composites for Bridge Applications;" anticipate report availability in FY18. Information in this report also relates to work currently underway in another CPC Program Project F16AR09, "Thermoplastic Composite Materials for Highway, Training, and Military Bridging Applications in Extreme Environments."
} 


\section{Literature Review}

The U.S. Army ERDC and Bridge Diagnostics, Inc. (BDI) investigated field load testing of a new bridge constructed of recycled plastic lumber (RPL) and calculating its load ratings (Commander and Diaz-Alvarez 2010). The bridge is a new three-span structure constructed entirely of RPL. Instrumentation for the load tests included strain transducers, vertical displacement sensors, and foil strain gauges placed at 94 locations on the bridge deck, deck support beams, and pile foundations. Load tests were performed with a 72 kip dump truck and 144 kip M1 tank crossing the RPL Bridge. Results indicated the structure generally performed in a normal linear-elastic manner. Relatively small viscoelastic responses were observed with the M1 tank. A long-duration static test with the tank showed that it took several minutes for deflections to stop moving while the bridge was loaded, and a similar amount of time for the measurements to return to zero after the load was removed. The testing behavior appeared consistent with the material properties of RPL and the intended design, though strain and displacement magnitudes were relatively high due to the low modulus of elasticity.

Jim Sheldon evaluated the performance of deckboard samples of nominal $2 \times 4$ in (2012). Three board specimens were tested with five replicate samples for each specimen. The compression side of each board was identified for testing. Specimens were stored in an ambient lab atmosphere of $70-75$ ${ }^{\circ} \mathrm{F}$ and $40 \%-50 \%$ relative humidity. The bending tests were conducted according to methods described in ASTM D6109 (2013). The specimens were weighed and measured, then mounted in a universal test machine such that the on-center support span was 24 in., and it could be symmetrically loaded at $8 \mathrm{in}$. from the supports. A displacement transducer was mounted to record the midspan deflection and was loaded at a uniform crosshead $(\mathrm{C} / \mathrm{H})$ speed of $0.71 \mathrm{in}$. per minute until the sample was no longer able to sustain the increasing load. The load and deflection were continuously monitored. A typical failure consisted of excessive deflection, and none of the samples ruptured. The ultimate strength of the specimens was 1,420 pound force (lbf) at failure, with 421 psi modulus of rupture (MOR). 
WECC, Inc. * conducted replacement of an existing wood timber bridge with a thermoplastic composite bridge of similar design. Budget constraints can limit repairs to critical timber and steel structures, so thermoplastic composite beams allow a comparatively cost-effective solution that is resistant to environmental degradation (chemical and biological). The bridge had a span length of $58 \mathrm{ft}-4 \mathrm{in}$., and five bents with $12 \mathrm{ft}$ and $10 \mathrm{ft}$ nominal spacing between each, secured with 30 composite piles in total. The live load intended for the bridge structure was HS 25 truck load and 79-ton tank. The RPL piles were designed with a capacity of 20 tons with a safety factor of 3, driven 15-20 ft below road surface elevation. Piles and bridge materials were of post-consumer recycled commingled plastics, fasteners were of hot-dipped galvanized steel. Since thermoplastic material performance is based on the quality and mix of raw materials from various sources, delays can be expected in acquisition based on quality of the current material and the physical properties required for the end product. Long-term advantages to using the material appear to be significant benefits to construction cost, material cost, maintenance cost, and useful life duration.

Nassim Uddin and Abdul Moeed Abro (2007) investigated the design and manufacturing of low-cost, high-performance thermoplastic composite bridge superstructures. They conducted a finite element analysis to investigate stiffness and strength of the fiber-reinforced plastic structural system, an alternative bridge construction material primarily chosen for its corrosion resistance and durability when compared to aluminum, concrete, or steel. Based on the structural demands of highway traffic, the deck system was carefully designed for structural efficiency and manufacturing ease. Stiffness is the main governing factor which controls design, so the use of curved panels (sine ribs) enabled nonplanar core configurations to increase performance of the bridge deck system. They specified three types of vehicular loading: design truck, design tandem, and design lane loads. The dynamic nature of moving vehicular loads was addressed by imposing a dynamic load allowance factor. The truck and tandem were placed for maximum deflection. When compared to two other designs of similar nature, the composite system has a higher self-weight and dead-to-

\footnotetext{
* WECC, Inc. is a diverse construction company located in Fayetteville, NC. The firm was contracted by ERDC-CERL to produce a third (longer) bridge at Camp Mackall (contract number W9132T-10-c-0033 to “Replace Failing Bridge T-8520," awarded 1 July 2010.
} 
live load ratio but could result in better low-cost bridge deck sections based on manufacturing and material cost comparisons.

Lampo, Sweeney, Wilcoski, Hock, Chiarito, and Diaz-Alvarez of ERDC and Nosker of the Rutgers University School of Engineering investigated thermoplastic composites as degradation-resistant material systems for timber bridge designs (Lampo et al. 2009). Plastic lumber is an attractive substitute for natural wood because it diverts waste from landfills and is inherently resistant to moisture, rot, and insects. While as strong as an equivalent-sized piece of wood, original plastic lumber products had an elastic modulus at least an order of magnitude less than even the most common wood species in construction. This lack of elasticity was resolved when manufacturers began incorporating fibers into the formulation to produce a reinforced thermoplastic composite lumber with higher elastic modulus. Because it does not use toxic chemical treatments, this material is a viable alternative material to treated wood. When subject to temperature change, plastic lumber expands and contracts to a greater extent than wood or steel, so design features must be incorporated to allow for these thermal changes. Appropriate design considerations and material formulation would enable these materials to be used in high-intensity load-bearing applications for all types of structures, despite property differences between thermoplastic composite materials and treated wood.

M.G. McLaren Consulting Engineers designed a structure for an existing wood timber bridge to demonstrate applications of structural-grade plastic lumber (Lampo et al. 2009). A $25 \mathrm{ft}$ long x 261/2 ft wide plastic lumber bridge sits on six steel girders that supported the original wooden bridge; the new bridge was designed to carry light vehicular traffic. The structure was designed using a protocol developed for plastic lumber as part of the ASTM standards. The safety capacity is more than 30 tons over the entire structure, structural grade plastic lumber $3 \times 12$ boards incorporating polystyrene for stiffness were the main support joists over the steel girders. The decking was $3 \times 12$ plastic lumber (standard grade), and the bridge was constructed with standard woodworking power tools and fasteners. Slotted connections were made between the plastic lumber joists and steel girders to allow for thermal expansion and contraction of the plastic lumber independent from the steel girders. A typical treated-wood bridge structure would need to be replaced every $15 \mathrm{yr}$, with biannual inspections and maintenance, while the plastic lumber bridge is expected to last $50 \mathrm{yr}$ with minimal maintenance. The plastic lumber cost is more than double 
the cost for a replacement wood bridge, but lifecycle cost analysis showed the plastic lumber bridge would begin to pay for itself in less than $8 \mathrm{yr}$, and diverted 13,00o lb of waste plastics from landfills.

M.G. McLaren Consulting Engineers also conducted a demonstration project to investigate whether reinforced plastic lumber may be used to construct laminated beams and arches for bridges, as wood can be (Assis 2010). In these cases, smaller-dimension lumber is used to make built-up beams and arches in a more efficient and cost-effective use of materials. The bridge was constructed with a laminated $2 \times 8$ arched top chord and 8 x 8 glass fiber-reinforced plastic lumber bottom chord. There were five equally spaced vertical supports as well as cross bracing to the top and bottom of each vertical support. The bridge was constructed using no heavy equipment and only needed to be designed for $\mathrm{H}-1 \mathrm{O}$ loading (10-ton), but was designed and tested for $\mathrm{H}-15$ loading (15-ton). Under the load of a 32,000-lb dump truck, the bridge's maximum deflection was 1.2 in., which is very acceptable for such structures.

Another project by M.G. McLaren Consulting Engineers in collaboration with Rutgers University was an all-plastic lumber, wide-flange bridge designed for class $\mathrm{H}-2 \mathrm{O}$ (20 ton) loading (Assis 2010). The wide-flange beam design reduced the time and material requirements for the construction of a bridge with the same load capacity using conventional joist and beam construction significantly. Although the project costs were not fully analyzed and documented, reduced labor time for completion suggests that the wide flange design is competitive on a first-cost basis with conventional treated wood, and life-cycle considerations make the design even more advantageous.

Fink, Gillespie Jr., and Ersoy (2000) of the Army Research Laboratory published an article on the thermal degradation effects on consolidation and bonding in the thermoplastic fiber-placement process . The effects of elevated temperature exposure during thermoplastic placement on bonding and consolidation were investigated for AS4/polyetherketoneketone (PEKK) composite. They found that, as a general rule, at higher temperatures and slower deposition velocities, higher shear bond strengths (SBSs) were obtained. Void content decreased when the torch temperature was increased. However, at high torch temperatures and long dwell times, the tradeoff of polymer degradation that occurs prevents full-strength development during the fiber placement process. 
Qi and Boyce of the Department of Mechanical Engineering at the Massachusetts Institute of Technology studied the stress-strain behavior of thermoplastic polyurethanes (2005). The substantially nonlinear stress-strain behavior of thermoplastic polyurethanes exhibits strong hysteresis, rate dependence, and cyclic softening. They conducted a series of uniaxial compression tests to quantitatively identify these features. Specimens were subjected to constant true strain rate loading-unloading cycles. The testing showed thermoplastic polyurethanes exhibit very complicated stressstrain behavior, confirming the qualities of strong rate dependence, hysteresis, and softening, which was evident upon reloading. This complicated behavior impedes a simple phenomenological curve-fit model and necessitates a physically based constitutive model. 


\section{Analytical Study of Simply Supported I- Beam with Two Symmetrical Loads}

This chapter details the analytical hand calculations performed for a general thermoplastic I-Beam configuration and material properties undergoing third point loading (Figure 3). The calculations were used to identify the expected beam behavior, load capacity at the extreme tension and compression fibers, and deflection at various points. Table 1 provides a summary of the calculated deflections along the beam for various applied loads. The results of the hand calculations will be used as validation of the tested behavior of the beam.

Figure 3. Nominal beam dimensions (not to scale).

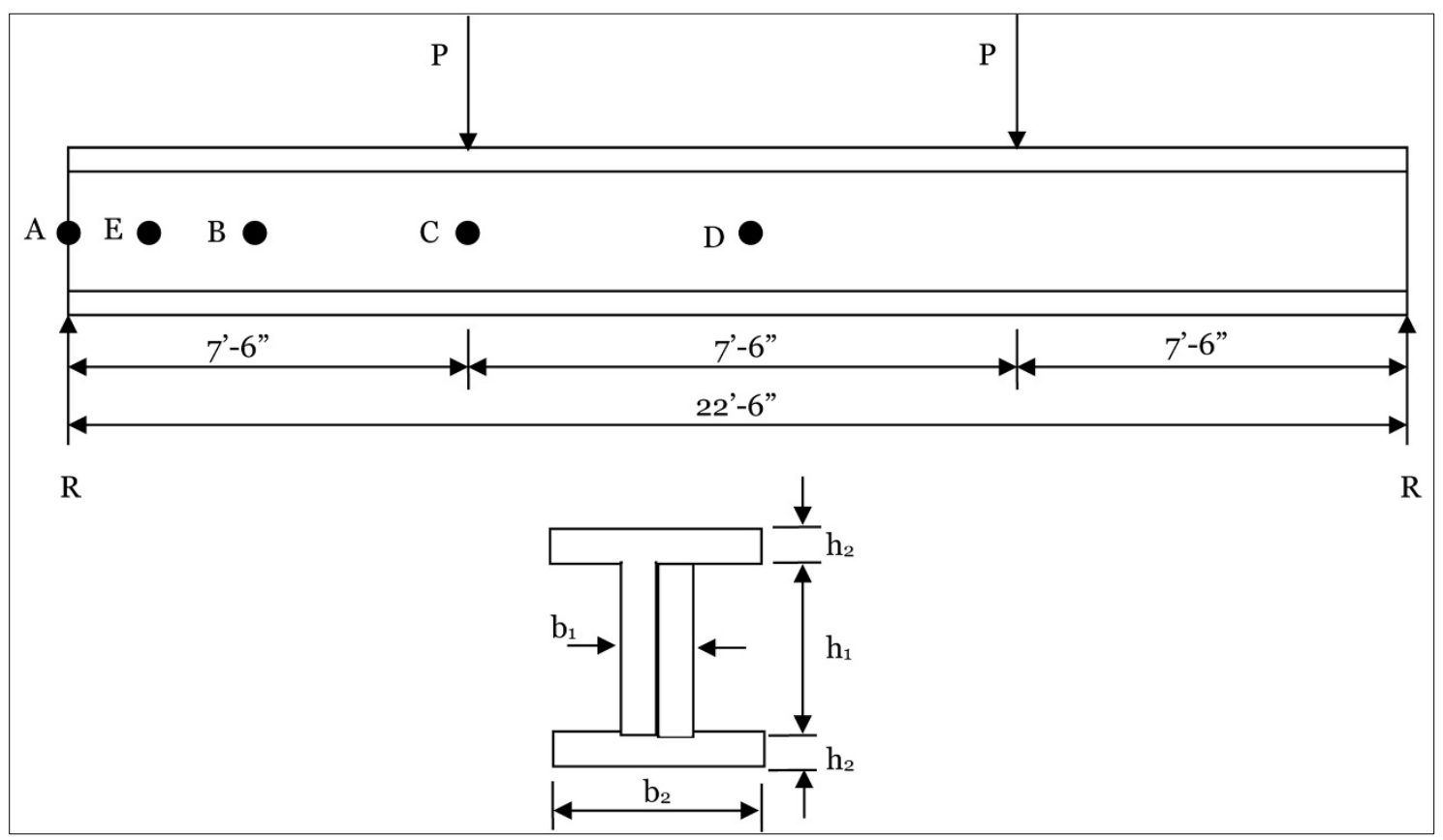

\subsection{Beam properties}

$$
|\mathrm{AB}|=45^{\prime \prime} \quad|\mathrm{AC}|=90^{\prime \prime} \quad|\mathrm{AD}|=135^{\prime \prime} \quad|\mathrm{AE}|=18^{\prime \prime} \quad \mathrm{L}=270^{\prime \prime}
$$

\subsection{Section properties}

$$
\begin{gathered}
h_{1}=12 " \quad h_{2}=3 " \quad b_{1}=6 " \quad b_{2}=18 " \\
I=\sum\left(\frac{b h^{3}}{12}+A d^{2}\right)
\end{gathered}
$$




$$
\begin{gathered}
I=\frac{b_{1} h_{1}{ }^{3}}{12}+2\left[\frac{b_{2} h_{2}{ }^{3}}{12}+b_{2} h_{2}\left(\frac{h_{1}+h_{2}}{2}\right)^{2}\right]=\frac{6 \times 12^{3}}{12}+2\left[\frac{18 \times 3^{3}}{12}+18 \times 3 \times 7.5^{2}\right]=7020 \mathrm{in}^{4} \\
S=\frac{I}{y}=\frac{7020 \mathrm{in}^{4}}{9 \mathrm{in}}=780 \mathrm{in}^{3} \\
Q_{\text {centroid }}=2\left[\frac{b_{1} h_{1}{ }^{2}}{8}+b_{2} h_{2}\left(\frac{h_{1}+h_{2}}{2}\right)\right]=2\left[\frac{6 \times 12^{2}}{8}+18 \times 3 \times 7.5\right]=1026 \mathrm{in}^{3}
\end{gathered}
$$

\subsection{Material properties}

$$
E=350 k s i \quad \sigma_{M a x, T}=2 k s i \quad \sigma_{M a x, C}=5 k s i
$$

\subsection{Load $P_{i}$ deflections}

\subsubsection{Deflection at $D$ for Load $P_{i}$}

$$
\begin{gathered}
\Delta_{D}=\frac{P a}{24 E I}\left(3 L^{2}-4 a^{2}\right), \text { where } a=|\mathrm{AC}| \\
\text { Let } \Delta \mathrm{D}=1^{\prime \prime} \\
1^{\prime \prime}=\frac{P \times 90^{\prime \prime}}{24 \times 350 k \operatorname{si} \times 7020 \text { in }^{4}}\left[3\left(270^{\prime \prime}\right)^{2}-4\left(90^{\prime \prime}\right)^{2}\right] \\
P_{1^{\prime \prime}}=3.517 \mathrm{~K} \\
P_{2^{\prime \prime}}=7.034 \mathrm{~K} \\
P_{3^{\prime \prime}}=10.551 \mathrm{~K} \\
P_{4^{\prime \prime}}=14.068 \mathrm{~K} \\
P_{5^{\prime \prime}}=17.585 \mathrm{~K} \\
P_{6^{\prime \prime}}=21.101 \mathrm{~K}
\end{gathered}
$$




\subsubsection{Deflection at $C$ for Load $P_{i}$}

$$
\begin{gathered}
\Delta_{C}=\frac{P_{i} b}{6 E I}\left(3 L a-3 a^{2}-b^{2}\right), \text { where } \mathrm{a}=\mathrm{b}=|\mathrm{AC}| \\
\Delta_{C_{1}}=\frac{3.517 K \times 90^{\prime \prime}}{6 \times 350 k \sin \times 7020 \mathrm{in}^{4}}\left[\left(3 \times 270^{\prime \prime} \times 90^{\prime \prime}\right)-\left(3 \times\left(90^{\prime \prime}\right)^{2}\right)-\left(90^{\prime \prime}\right)^{2}\right] \\
\Delta_{C_{1}}=0.870^{\prime \prime} \\
\Delta_{C_{2}}=1.739^{\prime \prime} \\
\Delta_{C_{3}}=2.609^{\prime \prime} \\
\Delta_{C_{4}}=3.478^{\prime \prime} \\
\Delta_{C_{5}}=4.348^{\prime \prime} \\
\Delta_{C_{6}}=5.218 "
\end{gathered}
$$

\subsubsection{Deflection at B for Load $P_{i}$}

$$
\begin{gathered}
\Delta_{B}=\frac{P_{i} b}{6 E I}\left(3 L a-3 a^{2}-b^{2}\right), \text { where } \mathrm{a}=|\mathrm{AC}| \text { and } \mathrm{b}=|\mathrm{AB}| \\
\Delta_{B_{1}}=\frac{3.517 \mathrm{~K} \times 45^{\prime \prime}}{6 \times 350 k \operatorname{si} \times 7020 \mathrm{in}^{4}}\left[\left(3 \times 270^{\prime \prime} \times 90^{\prime \prime}\right)-\left(3 \times\left(90^{\prime \prime}\right)^{2}\right)-\left(45^{\prime \prime}\right)^{2}\right] \\
\Delta_{B_{1}}=0.500^{\prime \prime} \\
\Delta_{B_{2}}=1.000^{\prime \prime} \\
\Delta_{B_{3}}=1.500^{\prime \prime} \\
\Delta_{B_{4}}=2.000^{\prime \prime} \\
\Delta_{B_{5}}=2.500^{\prime \prime} \\
\Delta_{B_{6}}=3.000^{\prime \prime}
\end{gathered}
$$




\subsection{Extreme tension fiber}

3.5.1 Load at failure of extreme tension fiber

$$
\begin{gathered}
\sigma_{\operatorname{Max}, T}=\frac{M}{S} \quad M=P a, \text { where } \mathrm{a}=|\mathrm{AC}| \\
\sigma_{M a x, T}=2 \mathrm{ksi}=\frac{P a}{S}=\frac{P \times 90^{\prime \prime}}{780 \mathrm{in}^{3}} \quad \Rightarrow \quad P_{\operatorname{Max}, T}=17.333 \mathrm{~K}
\end{gathered}
$$

\subsubsection{Deflection at failure of extreme tension fiber}

$$
\begin{aligned}
& \Delta_{D_{\text {Max }, T}}=\frac{17.333 \mathrm{~K} \times 90^{\prime \prime}}{24 \times 350 k \operatorname{si} \times 7020 \mathrm{in}^{4}}\left[3(270 ")^{2}-4\left(90^{\prime \prime}\right)^{2}\right] \\
& \Delta_{D_{\text {Max }, T}}=4.929^{\prime \prime} \\
& \Delta_{C_{\text {Max }, T}}=\frac{17.333 K \times 90^{\prime \prime}}{6 \times 350 k \operatorname{si}^{2} 7020 \mathrm{in}^{4}}\left[\left(3 \times 270^{\prime \prime} \times 90^{\prime \prime}\right)-\left(3 \times\left(90^{\prime \prime}\right)^{2}\right)-\left(90^{\prime \prime}\right)^{2}\right] \\
& \Delta_{C_{M a x, T}}=4.286^{\prime \prime} \\
& \Delta_{B_{M a x, T}}=\frac{17.333 K \times 45^{\prime \prime}}{6 \times 350 k s i \times 7020 \text { in }^{4}}\left[\left(3 \times 270^{\prime \prime} \times 90^{\prime \prime}\right)-\left(3 \times\left(90^{\prime \prime}\right)^{2}\right)-\left(45^{\prime \prime}\right)^{2}\right] \\
& \Delta_{B_{M a x, T}}=2.464^{\prime \prime}
\end{aligned}
$$

\subsubsection{Maximum shear stress at failure of extreme tension fiber} (Point E)

$$
\tau_{\text {max }, T @ E}=\frac{P_{\max , T} Q_{\text {centroid }}}{I b_{1}}=\frac{17.333 \mathrm{~K} \times 1026 \mathrm{in}^{3}}{7020 \mathrm{in}^{4} \times 6^{\prime \prime}}=0.422 \mathrm{ksi}
$$

\subsubsection{Load at failure of extreme compression fiber}

$$
\begin{array}{cc}
\sigma_{\operatorname{Max}, C}=\frac{M}{S} & M=P a \\
\sigma_{M a x, C}=5 \mathrm{ksi}=\frac{P a}{S}=\frac{P \times 90^{\prime \prime}}{780 \mathrm{in}^{3}} \quad \Rightarrow \quad P_{\operatorname{Max}, C}=43.333 \mathrm{~K}
\end{array}
$$




\subsubsection{Deflection at failure of extreme compression fiber}

$$
\begin{aligned}
& \Delta_{D_{M a x, C}}=\frac{43.333 \mathrm{~K} \times 90 "}{24 \times 350 \mathrm{ksi} \times 7020 \mathrm{in}^{4}}\left[3(270 ")^{2}-4\left(90^{\prime \prime}\right)^{2}\right] \\
& \Delta_{D_{M a x, C}}=12.321 " \\
& \Delta_{C_{\text {Max }, C}}=\frac{43.333 K \times 90^{\prime \prime}}{6 \times 350 k \operatorname{si} \times 7020 \text { in }^{4}}\left[(3 \times 270 " \times 90 ")-\left(3 \times(90 ")^{2}\right)-\left(90^{\prime \prime}\right)^{2}\right] \\
& \Delta_{C_{\text {Max }, C}}=10.714^{\prime \prime} \\
& \Delta_{B_{\text {Max }, C}}=\frac{43.333 \mathrm{~K} \times 45^{\prime \prime}}{6 \times 350 \mathrm{si} \times 7020 \mathrm{in}^{4}}\left[\left(3 \times 270^{\prime \prime} \times 90^{\prime \prime}\right)-\left(3 \times\left(90^{\prime \prime}\right)^{2}\right)-\left(45^{\prime \prime}\right)^{2}\right] \\
& \Delta_{B_{M a x, C}}=6.161^{\prime \prime}
\end{aligned}
$$

Table 1. Calculated values from nominal dimensions.

\begin{tabular}{|l|l|l|l|l|l|}
\hline $\mathrm{P}$ (kips) & $\Delta \mathrm{D}$ (in.) & $\Delta \mathrm{C}$ (in.) & $\Delta \mathrm{B}$ (in.) & Tmax, $(\mathrm{ksi})$ & Notes \\
\hline 3.517 & 1.000 & 0.870 & 0.500 & & \\
\hline 7.034 & 2.000 & 1.740 & 1.000 & & \\
\hline 10.551 & 3.000 & 2.609 & 1.500 & & \\
\hline 14.068 & 4.000 & 3.478 & 2.000 & & \\
\hline $17.333(\max , \mathrm{T})$ & 4.929 & 4.286 & 2.464 & 0.422 & Point of failure \\
\hline 17.585 & 5.000 & 4.348 & 2.500 & & \\
\hline 21.101 & 6.000 & 5.218 & 3.000 & & \\
\hline $43.333(\max , \mathrm{C})$ & 12.321 & 10.714 & 6.161 & & \\
\hline
\end{tabular}




\section{Analytical Study of Tests with SAP2000 Models}

This chapter describes the analytical SAP2000 ${ }^{\circledR}$ models created for two beam configurations. The first configuration was two asymmetric T-beam sections bolted together at the webs to form a symmetric I-beam. The second configuration was two I-beam sections bolted together to form a double I-beam. Analyses of these models were used to identify the typical reactions of the beams under testing conditions. Because models were derived from the current testing conditions and limitations of the beam, the result was validation of the true behavior of the beam under testing conditions for the current project.

\subsection{Beam Configuration \#1}

\subsubsection{Model geometry}

Model geometry information included items such as joint coordinates, joint restraints, and element connectivity. The $\mathrm{x}$-axis is in the direction of the span, the $y$-axis is in the lateral direction, and the $\mathrm{z}$-axis is in the vertical direction. This model was meshed by using SAP200o's generalized (polygonal) meshing tool, with a maximum square mesh of 3 in. (Figure 4).

Output joint coordinates were established at various locations along the beam and within the cross section. Each section had seven possible output coordinates: three along each flange, and one in the center of the web. This testing was concerned with the fibers that would undergo the most extreme conditions, so output information was accumulated from six critical sections along the beam, shown in Figure 5 and Figure 6. Each beam section, with its distinct coordinates, is identified in Figure 7-Figure 12. In Table 2, the global coordinates of each joint are specified, based on the joint's location with respect to the $\mathrm{x}, \mathrm{y}$, and $\mathrm{z}$ axes. 
Figure 4. Finite element model for Beam Configuration \#1. Model mesh as generated by SAP2000.

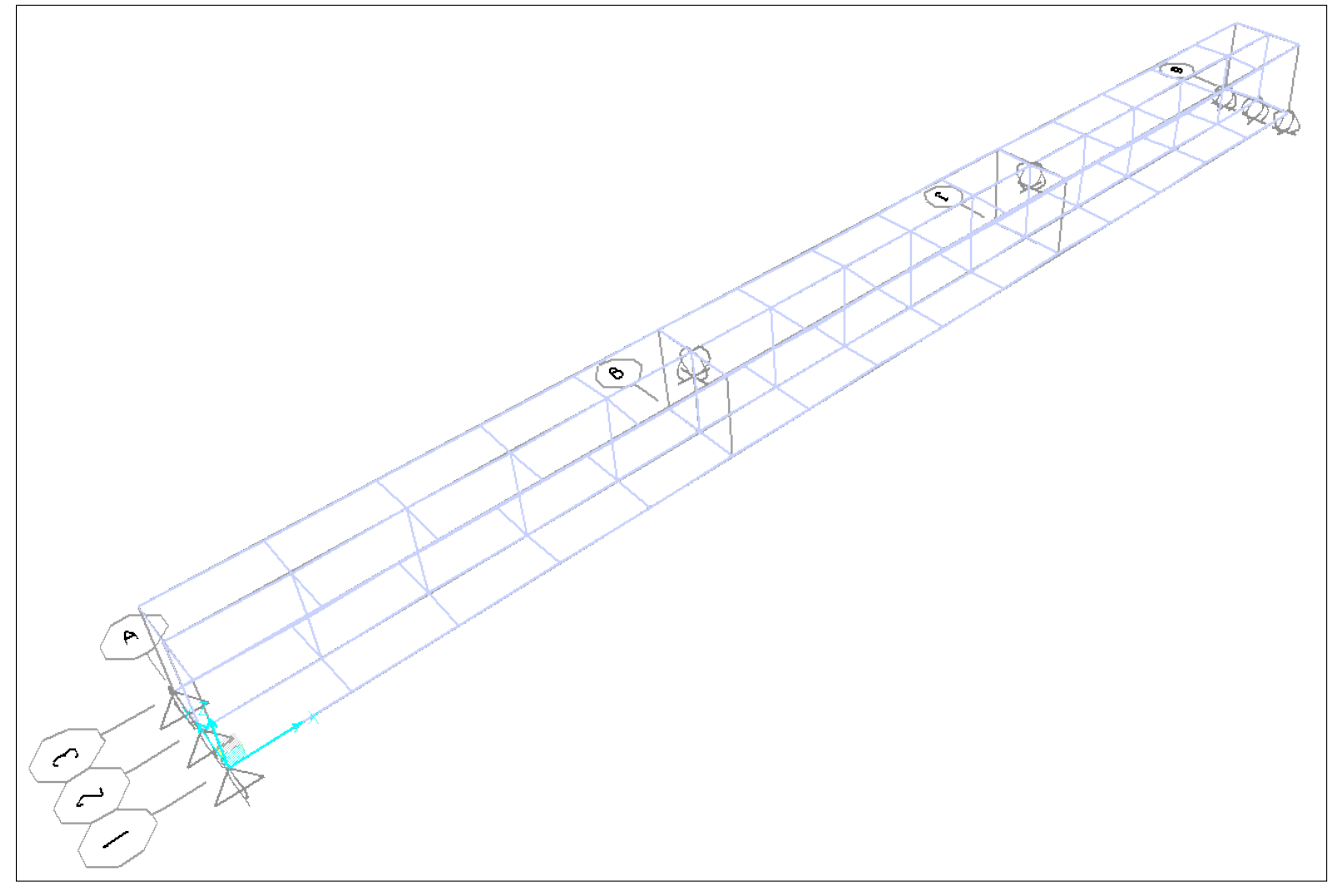

Figure 5. Beam plan with critical sections ( $\mathrm{z}=9 \mathrm{in}$.).

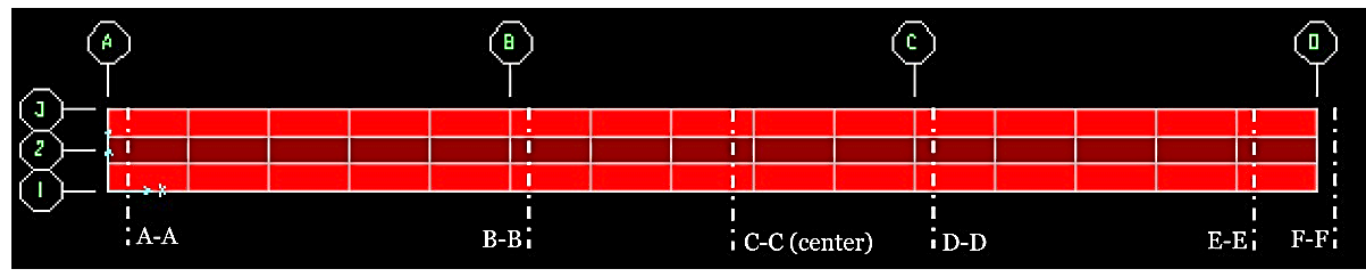

Figure 6. Beam elevation with critical sections ( $y=9$ in.).

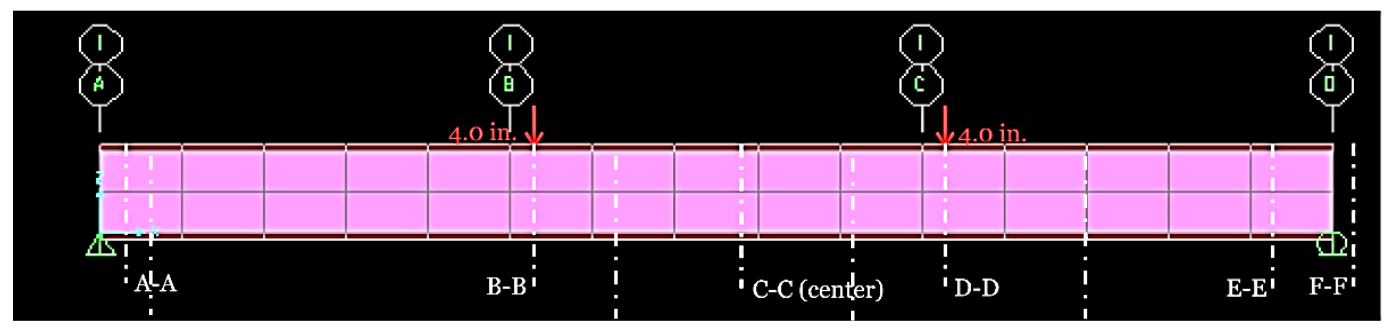


Figure 7. Cross section $A-A(x=0$ in.). Figure 8. Cross section $B-B(x=90$ in.).
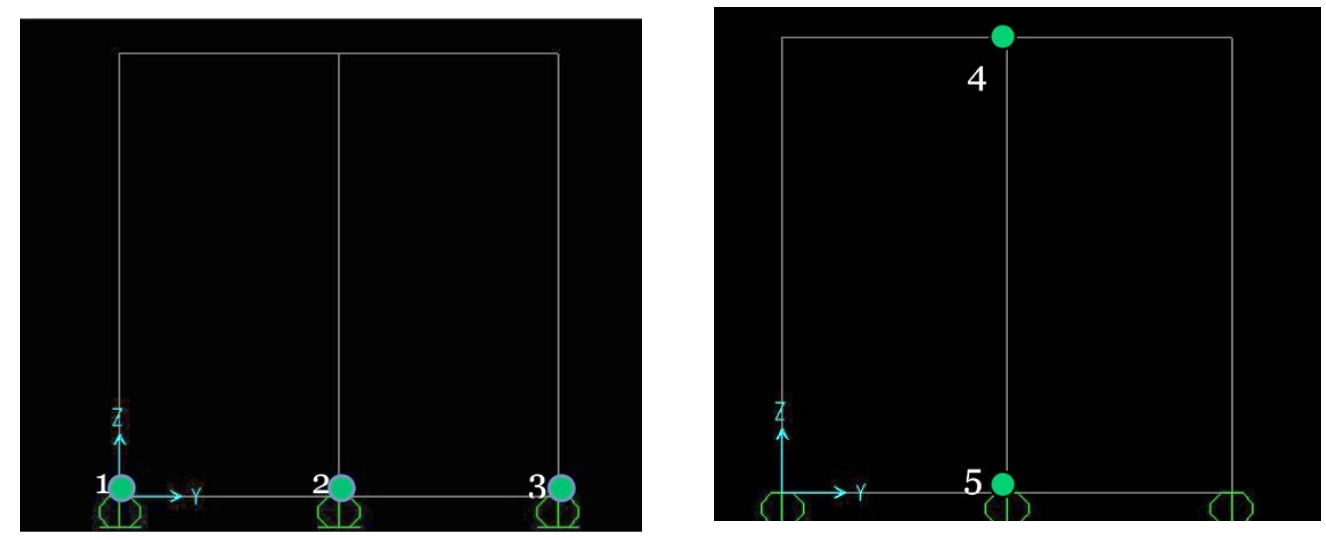

Figure 9. Cross section $C-C(x=135$ in.). Figure 10. Cross section $D-D(x=180$ in.).
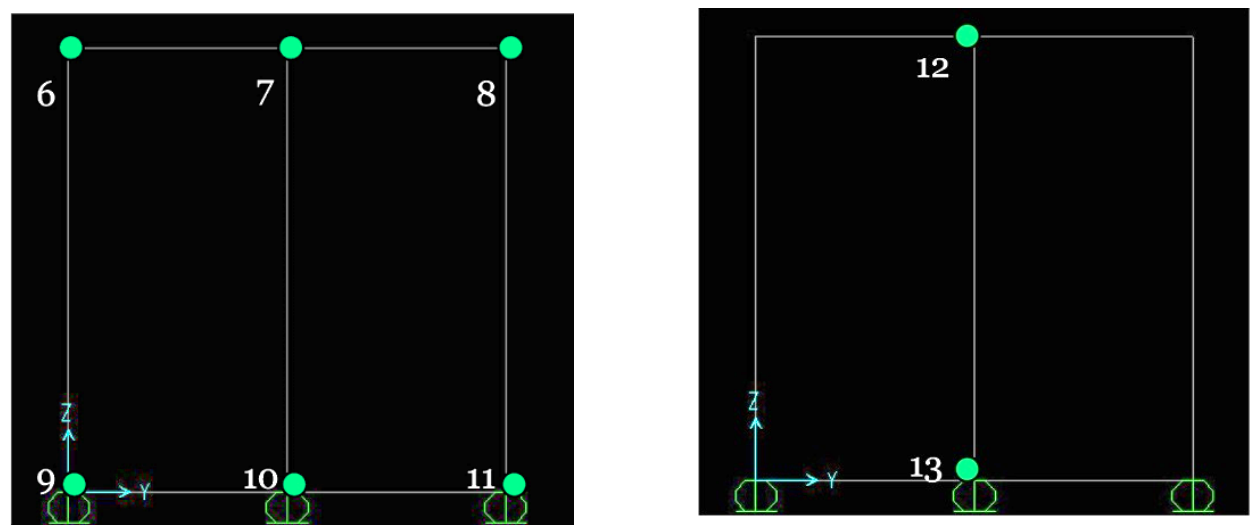

Figure 11. Cross section $E-E(x=252$ in.). Figure 12. Cross section F-F ( $x=270$ in.).
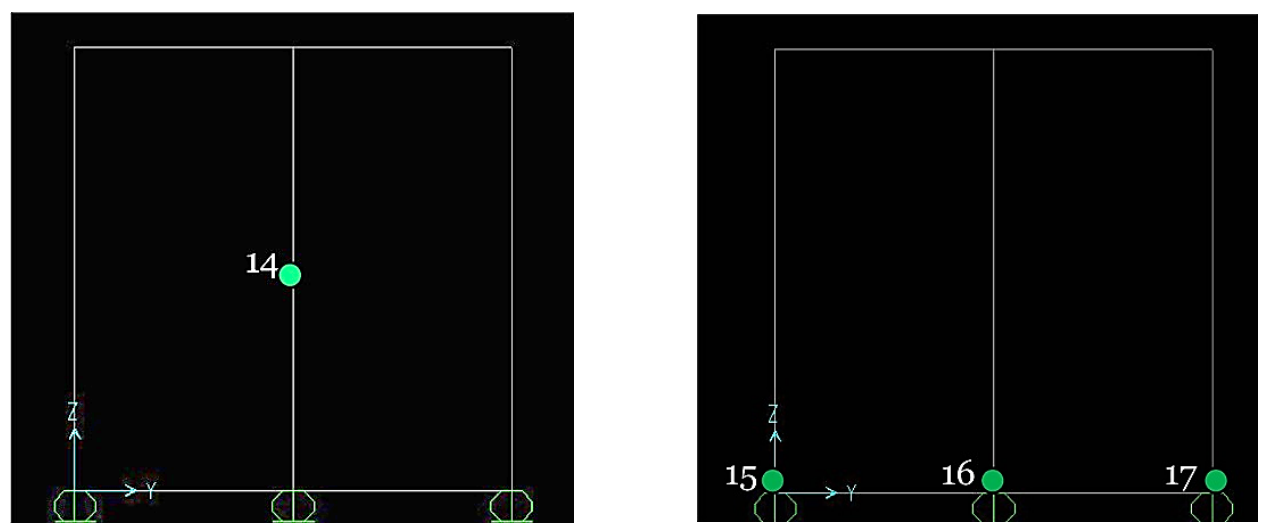
Table 2. Global coordinates for joints in Beam Configuration \#1.

\begin{tabular}{|l|l|r|r|r|}
\hline Joint & $\begin{array}{l}\text { Cross } \\
\text { Section }\end{array}$ & X (in.) & Y (in.) & Z (in.) \\
\hline 1 & A-A & 0.0 & 0.0 & 0.0 \\
\hline 2 & A-A & 0.0 & 9.0 & 0.0 \\
\hline 3 & A-A & 0.0 & 18.0 & 0.0 \\
\hline 4 & B-B & 90.0 & 9.0 & 18.0 \\
\hline 5 & B-B & 90.0 & 9.0 & 0.0 \\
\hline 6 & C-C & 135.0 & 0.0 & 18.0 \\
\hline 7 & C-C & 135.0 & 9.0 & 18.0 \\
\hline 8 & C-C & 135.0 & 18.0 & 18.0 \\
\hline 9 & C-C & 135.0 & 0.0 & 0.0 \\
\hline 10 & C-C & 135.0 & 9.0 & 0.0 \\
\hline 11 & C-C & 135.0 & 18.0 & 0.0 \\
\hline 12 & D-D & 180.0 & 9.0 & 18.0 \\
\hline 13 & D-D & 180.0 & 9.0 & 0.0 \\
\hline 14 & E-E & 252.0 & 9.0 & 9.0 \\
\hline 15 & F-F & 270.0 & 0.0 & 0.0 \\
\hline 16 & F-F & 270.0 & 9.0 & 0.0 \\
\hline 17 & F-F & 270.0 & 18.0 & 0.0 \\
\hline
\end{tabular}

\subsubsection{Material properties}

Material properties provide information for materials used in the model. In the model, only one materiality was present, the thermoplastic composite material (thermoplastic); its properties are specified in Table 3.

Table 3. Summary of material properties used in the model for Beam Configuration \#1.

\begin{tabular}{|c|c|c|c|c|c|c|}
\hline Material & $\begin{array}{l}\text { Unit Weight } \\
\text { (kip/in.2) }\end{array}$ & $\begin{array}{l}\text { Unit Mass } \\
\left(\mathrm{kips}^{2} / \mathrm{in}^{4}\right)\end{array}$ & \begin{tabular}{|l} 
Elastic \\
Modulus \\
(kip/in.2 ${ }^{2}$ )
\end{tabular} & $\begin{array}{l}\text { Shear Modulus } \\
\text { (kip/in.2) }\end{array}$ & $\begin{array}{l}\text { Poisson } \\
\text { Ratio }\end{array}$ & $\mathrm{A} 1$ (1/F) \\
\hline Thermoplastic & 3.347 E-05 & 8.670 E-08 & 388.0 & 145.86 & 0.33 & $7.50 \mathrm{E}-05$ \\
\hline
\end{tabular}




\subsubsection{Section properties}

Section properties identify specifications for objects used in the model. Table 4 identifies the cross-sectional thicknesses of the member, with significance to bending and stress capacities. All sections were modeled as thin shells of thermoplastic material.

Table 4. Summary of section properties used in the model for Beam Configuration \#1.

\begin{tabular}{|l|l|l|l|l|l|l|l|l|l|l|l|l|}
\hline Section & $\begin{array}{l}\text { Thickness } \\
\text { (in.) }\end{array}$ & $\begin{array}{l}\text { Bend } \\
\text { Thickness } \\
\text { (in.) }\end{array}$ & $\begin{array}{l}\mathrm{F}_{11} \\
\text { Mod }\end{array}$ & $\begin{array}{l}\mathrm{F}_{22} \\
\text { Mod }\end{array}$ & $\begin{array}{l}\mathrm{F}_{12} \\
\text { Mod }\end{array}$ & $\begin{array}{l}\mathbf{M}_{11} \\
\text { Mod }\end{array}$ & $\begin{array}{l}\mathbf{M}_{22} \\
\text { Mod }\end{array}$ & $\begin{array}{l}\mathbf{M}_{12} \\
\text { Mod }\end{array}$ & $\begin{array}{l}\mathrm{V}_{13} \\
\text { Mod }\end{array}$ & $\begin{array}{l}\mathrm{V}_{23} \\
\text { Mod }\end{array}$ & $\begin{array}{l}\text { M } \\
\text { Mod }\end{array}$ & $\begin{array}{l}\text { W } \\
\text { Mod }\end{array}$ \\
\hline Flange & 3.0 & 3.0 & 1.0 & 1.0 & 1.0 & 1.0 & 1.0 & 1.0 & 1.0 & 1.0 & 1.0 & 1.0 \\
\hline Web & 6.0 & 6.0 & 1.0 & 1.0 & 1.0 & 1.0 & 1.0 & 1.0 & 1.0 & 1.0 & 1.0 & 1.0 \\
\hline
\end{tabular}

\subsubsection{Load cases}

Loading information, as applied to the model, represented the loading conditions during Beam Test \#1. In the model, the beam was restrained at both ends (pin and roller) and loaded at two points symmetrically along the beam, each point 45 in. from the center line of the beam, as shown in Figure 13. A dead load displacement of 4.0 in. was applied in the negative $\mathrm{Z}$ direction at each loading location. A self-weight multiplier of 1.0 was used to account for the weight of the beam. Shear and moment were established based on the applied displacements. 
Figure 13. Deformed shape.

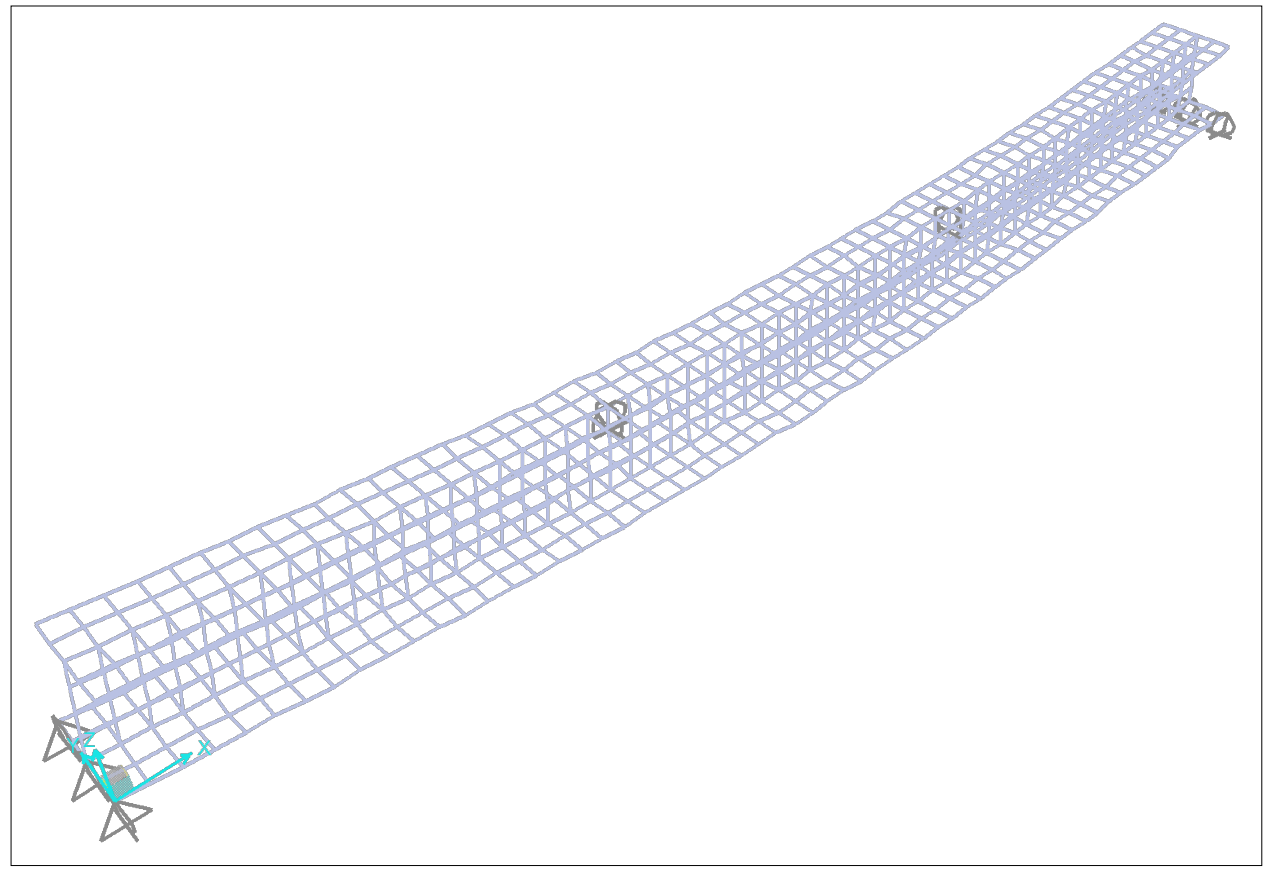

\subsubsection{Modeling results}

Modeling results included items such as the shear, moment, and reaction values that resulted from the applied displacements (Figure 14 and Figure 15). Note that all horizontal reactions at the pin support cancel each other, resulting in an effective reaction of o.o kips (Table 5). 
Figure 14. Spectrum of maximum stresses in the beam.

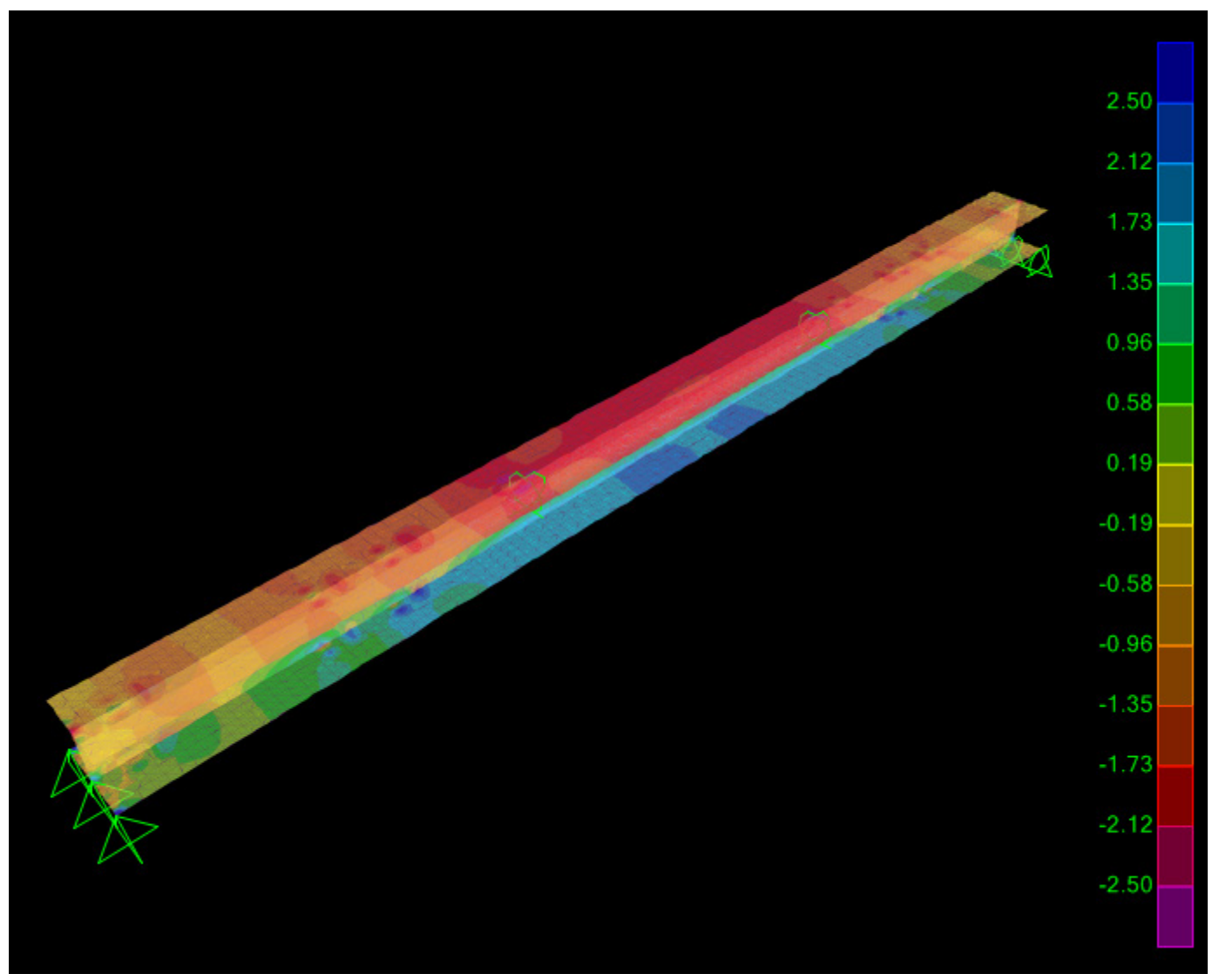

Figure 15. Spectrum of maximum forces in the beam (elevation).

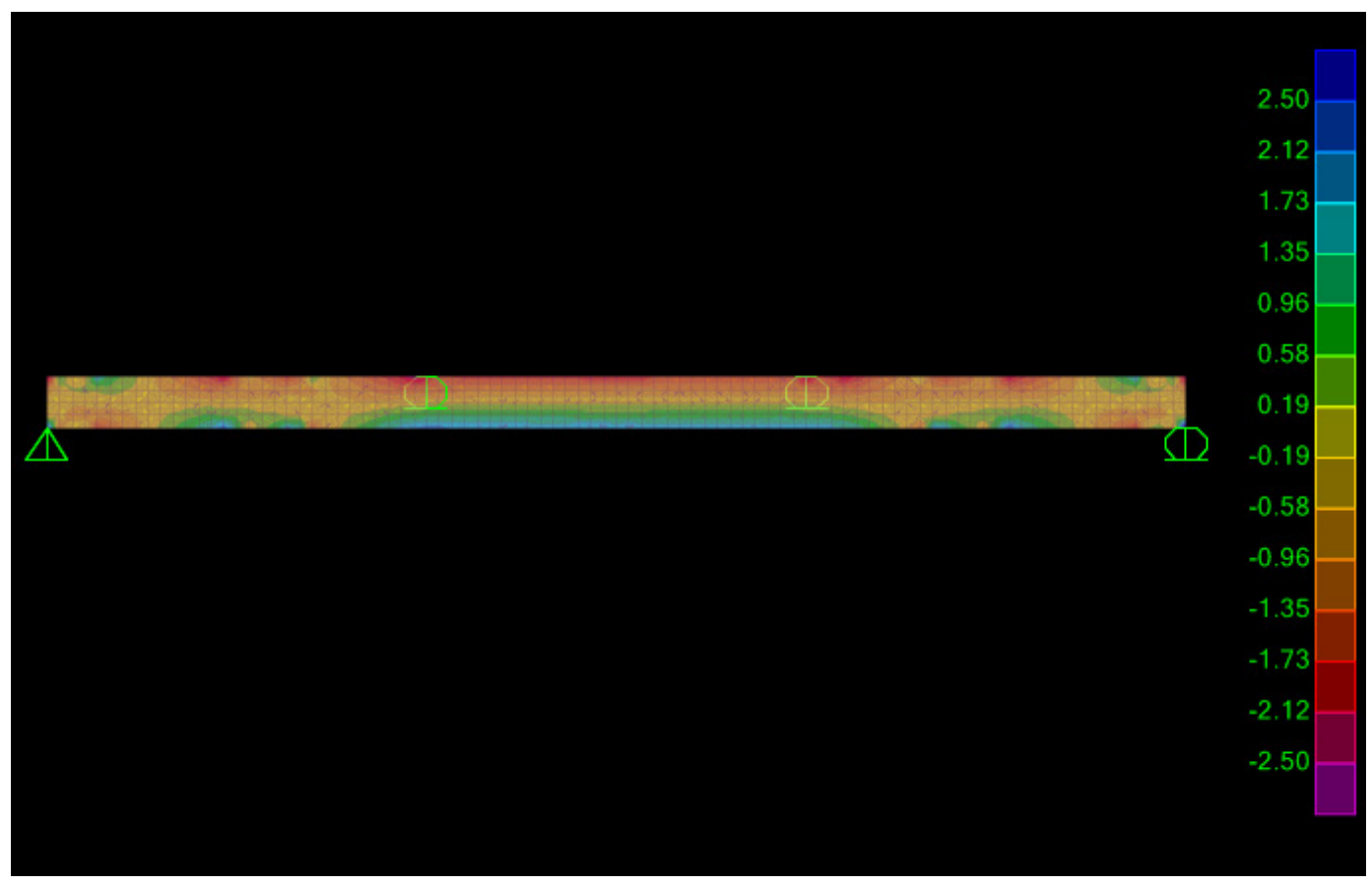


Table 5. Summary of reactions at supports.

\begin{tabular}{|l|l|l|l|l|l|l|}
\hline Output Case & $F_{x}(k i p)$ & $F_{y}(k i p)$ & $F_{z}(k i p)$ & $M_{x}(k i p-i n)$ & $M_{y}$ (kip-in) & $M_{z}$ (kip-in) \\
\hline Point loads & 0.00 & 0.00 & 40.43 & 14.64 & -219.61 & 0.00 \\
\hline
\end{tabular}

\subsubsection{Joint results}

Joint results included the displacements and reactions which occurred at each joint throughout the beam, under the specified loading and selfweight of the beam. The results have been separated into charts below, based on their corresponding cross section (Table 6-Table 8). Similar cross sections were included within the same chart for ease of data comparison.

Table 6. Summary of joint displacements and reactions at beam ends.

\begin{tabular}{|l|l|r|r|r|r|r|}
\hline Joint & Cross Section & Ux (in.) & Uz (in.) & Fx (kip) & Fz (kip) & M (kip-in) \\
\hline 1 & A-A & 0.00 & 0.00 & -2.191 & 0.318 & 0.00 \\
\hline 2 & A-A & 0.00 & 0.00 & 4.382 & 15.69 & 0.00 \\
\hline 3 & A-A & 0.00 & 0.00 & -2.191 & 0.318 & 0.00 \\
\hline 15 & F-F & 0.53 & 0.00 & 0.00 & -0.243 & 0.00 \\
\hline 16 & F-F & 0.56 & 0.00 & 0.00 & 14.59 & 0.00 \\
\hline 17 & F-F & 0.53 & 0.00 & 0.00 & -0.243 & 0.00 \\
\hline
\end{tabular}

Table 7. Summary of joint displacements beneath loading.

\begin{tabular}{|l|l|l|l|}
\hline Joint & Cross Section & $U_{x}$ (in.) & $U_{z}$ (in.) \\
\hline 4 & B-B & 0.42 & -4.00 \\
\hline 5 & B-B & 0.09 & -3.99 \\
\hline 12 & D-D & 0.13 & -4.00 \\
\hline 13 & D-D & 0.39 & -3.88 \\
\hline
\end{tabular}


Table 8. Summary of joint displacements at beam center.

\begin{tabular}{|l|l|l|l|}
\hline Joint & Cross Section & $U_{x}$ (in.) & $U_{z}$ (in.) \\
\hline 6 & C-C & 0.27 & -4.608 \\
\hline 7 & C-C & 0.27 & -4.600 \\
\hline 8 & C-C & 0.27 & -4.608 \\
\hline 9 & C-C & 0.27 & -4.610 \\
\hline 10 & C-C & 0.27 & -4.598 \\
\hline 11 & C-C & 0.27 & -4.610 \\
\hline
\end{tabular}

\subsubsection{Area results}

This section provides results based on the forces and stresses of the affected cross-sectional areas. In Table 9-Table 12, the joints are identified to indicate the exact location on the cross section from which the data was collected.

Table 9. Summary of element stresses at beam ends.

\begin{tabular}{|c|c|c|c|c|c|c|c|}
\hline Joint & $\begin{array}{l}\text { Cross } \\
\text { Section }\end{array}$ & $\begin{array}{l}\sigma_{11} \text { Top } \\
\text { (kip/in²) }\end{array}$ & $\begin{array}{l}\sigma_{22} \text { Top } \\
\text { (kip/in²) }\end{array}$ & $\begin{array}{l}\sigma_{12} \text { Top } \\
\text { (kip/in²) }\end{array}$ & $\begin{array}{l}\sigma_{11} \\
\text { Bottom } \\
\left(\mathrm{kip} / \mathrm{in}^{2}\right)\end{array}$ & $\begin{array}{l}\sigma_{22} \\
\text { Bottom } \\
\left(\mathrm{kip} / \mathrm{in}^{2}\right)\end{array}$ & $\begin{array}{l}\sigma_{12} \\
\text { Bottom } \\
\left(\mathrm{kip} / \mathrm{in}^{2}\right)\end{array}$ \\
\hline 1 & A-A & -2.306 & -0.529 & 0.508 & 4.012 & 0.781 & -0.925 \\
\hline 2 & $A-A$ & -1.990 & 0.237 & -0.119 & 3.896 & 0.920 & 0.654 \\
\hline 3 & A-A & -2.305 & -0.529 & -0.508 & 4.012 & 0.781 & 0.925 \\
\hline 15 & F-F & -0.007 & 0.481 & 0.026 & 0.039 & -0.827 & -0.090 \\
\hline 16 & F-F & -2.978 & 0.312 & 0.206 & 5.840 & 1.516 & -0.981 \\
\hline 17 & F-F & -0.006 & 0.481 & -0.026 & 0.039 & -0.827 & 0.090 \\
\hline
\end{tabular}

Table 10. Summary of element stresses beneath loading.

\begin{tabular}{|c|c|c|c|c|c|c|c|}
\hline Joint & $\begin{array}{l}\text { Cross } \\
\text { Section }\end{array}$ & $\begin{array}{l}\sigma_{11} \text { Top } \\
\left(\mathrm{kip} / \mathrm{in}^{2}\right)\end{array}$ & $\begin{array}{l}\sigma_{22} \text { Top } \\
\left(\mathrm{kip} / \mathrm{in}^{2}\right)\end{array}$ & $\begin{array}{l}\sigma_{12} \text { Top } \\
\left(\mathrm{kip} / \mathrm{in}^{2}\right)\end{array}$ & $\begin{array}{l}\sigma_{11} \\
\text { Bottom } \\
\left(\mathrm{kip} / \mathrm{in}^{2}\right)\end{array}$ & $\begin{array}{l}\sigma_{22} \\
\text { Bottom } \\
\left(\mathrm{kip} / \mathrm{in}^{2}\right)\end{array}$ & $\begin{array}{l}\sigma_{12} \\
\text { Bottom } \\
\left(\mathrm{kip} / \mathrm{in}^{2}\right)\end{array}$ \\
\hline 4 & B-B & -5.357 & 2.686 & -0.578 & -5.518 & -1.819 & -0.052 \\
\hline 5 & B-B & 1.820 & 0.154 & 0.020 & 1.820 & 0.154 & 0.020 \\
\hline 12 & $D-D$ & -2.835 & 2.072 & 0.317 & -4.653 & -1.556 & 0.016 \\
\hline 13 & D-D & 1.539 & -0.003 & 0.000 & 1.069 & 0.003 & -0.001 \\
\hline
\end{tabular}


Table 11. Summary of element stresses at beam center.

\begin{tabular}{|c|c|c|c|c|c|c|c|}
\hline Joint & $\begin{array}{l}\text { Cross } \\
\text { Section }\end{array}$ & $\begin{array}{l}\sigma_{11} \text { Top } \\
\left(\mathrm{kip} / \mathrm{in}^{2} \text { ) }\right.\end{array}$ & $\begin{array}{l}\sigma_{22} \text { Top } \\
\left(\mathrm{kip} / \mathrm{in}^{2}\right)\end{array}$ & $\begin{array}{l}\sigma_{12} \text { Top } \\
\text { (kip/in²) }\end{array}$ & $\begin{array}{l}\sigma_{11} \\
\text { Bottom } \\
\left(\mathrm{kip} / \mathrm{in}^{2}\right)\end{array}$ & $\begin{array}{l}\sigma_{22} \\
\text { Bottom } \\
\left(\mathrm{kip} / \mathrm{in}^{2}\right)\end{array}$ & $\begin{array}{l}\sigma_{12} \\
\text { Bottom } \\
\left(\mathrm{kip} / \mathrm{in}^{2}\right)\end{array}$ \\
\hline 6 & $\mathrm{C}-\mathrm{C}$ & -1.135 & 0.000 & 0.001 & -1.797 & 0.000 & -0.001 \\
\hline 7 & $\mathrm{C}-\mathrm{C}$ & -1.247 & -0.062 & -0.006 & -1.872 & 0.023 & 0.010 \\
\hline 8 & $C-C$ & -1.135 & 0.000 & -0.001 & -1.797 & 0.000 & 0.001 \\
\hline 9 & $\mathrm{C}-\mathrm{C}$ & 1.671 & -0.002 & 0.003 & 0.962 & -0.002 & 0.004 \\
\hline 10 & $\mathrm{C}-\mathrm{C}$ & 1.888 & -0.120 & -0.017 & 1.270 & 0.080 & 0.009 \\
\hline 11 & $\mathrm{C}-\mathrm{C}$ & 1.671 & -0.002 & -0.003 & 0.962 & -0.002 & -0.004 \\
\hline
\end{tabular}

Table 12. Summary of element stresses at the rosette.

\begin{tabular}{|c|c|c|c|c|c|c|c|}
\hline Joint & $\begin{array}{l}\text { Cross } \\
\text { Section }\end{array}$ & $\begin{array}{l}\sigma_{11} \text { Top } \\
\left(\mathrm{kip} / \mathrm{in}^{2}\right)\end{array}$ & $\begin{array}{l}\sigma_{22} \text { Top } \\
\left(\mathrm{kip} / \mathrm{in}^{2}\right)\end{array}$ & $\begin{array}{l}\sigma_{12} \text { Top } \\
\left(\mathrm{kip} / \mathrm{in}^{2}\right)\end{array}$ & $\begin{array}{l}\sigma_{11} \\
\text { Bottom } \\
\left(\mathrm{kip} / \mathrm{in}^{2}\right)\end{array}$ & $\begin{array}{l}\sigma_{22} \\
\text { Bottom } \\
\left(\mathrm{kip} / \mathrm{in}^{2}\right)\end{array}$ & $\begin{array}{l}\sigma_{12} \\
\text { Bottom } \\
(\text { kip/in }\end{array}$ \\
\hline 14 & E-E & -0.048 & -0.048 & -0.277 & -0.048 & -0.048 & -0.277 \\
\hline
\end{tabular}

\subsection{Beam Configuration \#2}

This section describes the analytical SAP200o models created for Beam Configuration \#2, which is used to identify the typical reactions of each beam under testing conditions. This model was derived from the testing conditions and limitations of the beam, and the model allowed us to validate the true behavior of the beam under these conditions.

\subsubsection{Model geometry}

Model geometry information again included items such as joint coordinates, joint restraints, and element connectivity. The $\mathrm{x}$-axis is in the direction of the span, the y-plane is in the lateral direction, and the z-axis is the vertical. This beam was meshed using SAP200o's maximum mesh size tool. The beam webs and flanges were modeled with a square mesh with a maximum size of 3 in., while the stiffeners were modeled with a square mesh with a maximum size of 2 in. (Figure 16). 
Figure 16. Finite element model.

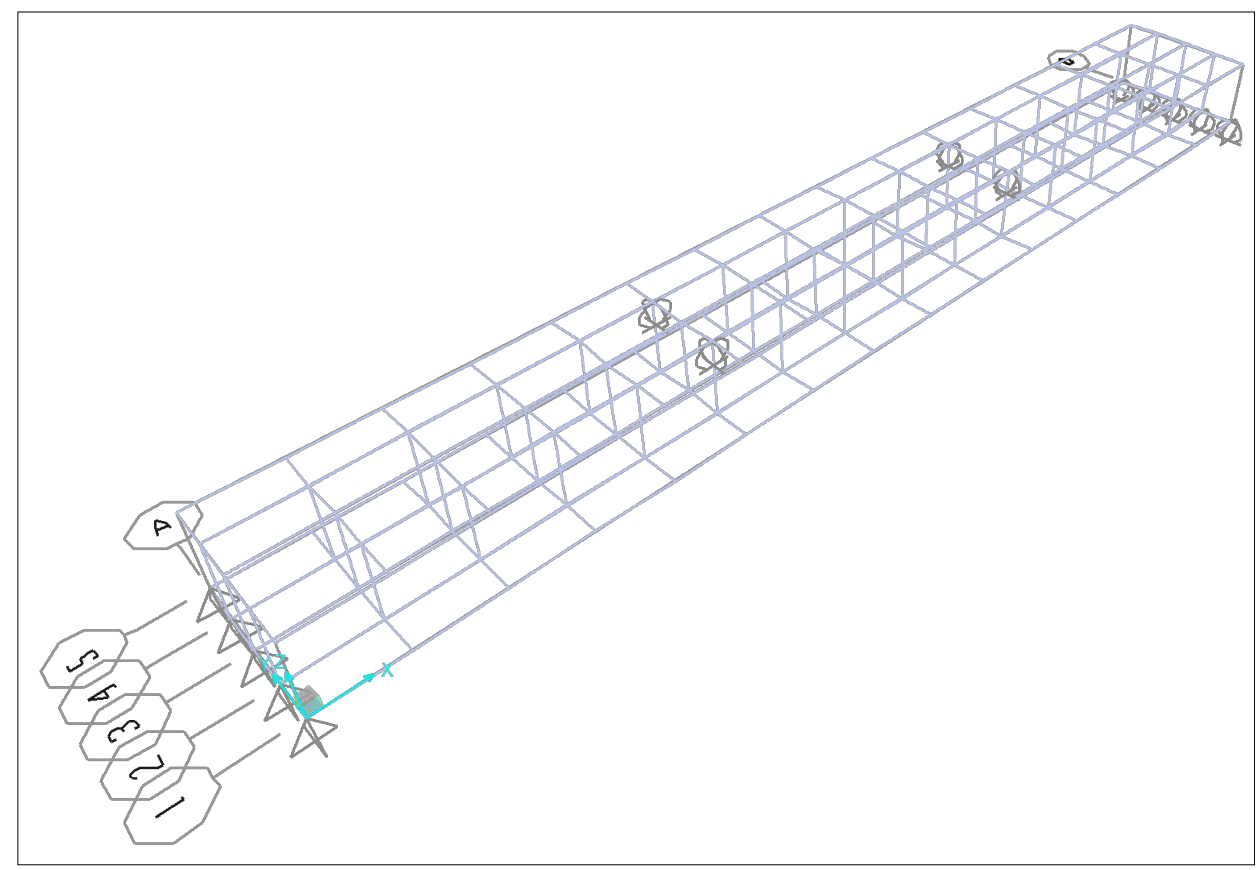

\subsubsection{Joint coordinates}

The double beam was constructed by fastening two single beams together through their webs. The cross section can be seen in the Figures below. Additionally, thermoplastic stiffeners were included in the model at 9-inch spacing throughout the interior cavity of the double beam. Joint coordinates were established based on cross sections taken at various locations along the beam. Each section had 12 coordinates: five along each flange and one in the center of each web. For testing, a concern was that the fibers would undergo the most extreme conditions, so we accumulated output information was accumulated from six critical sections along the beam shown in Figure 17 and Figure 18. Each section, with its distinct coordinates, is identified in Figure 19-Figure 24. In Table 13, the global coordinates of each joint are specified based on its location with respect to the $\mathrm{x}$, $\mathrm{y}$, and $\mathrm{z}$ axes.

Figure 17. Beam plan indicating critical sections ( $z=18$ in.).

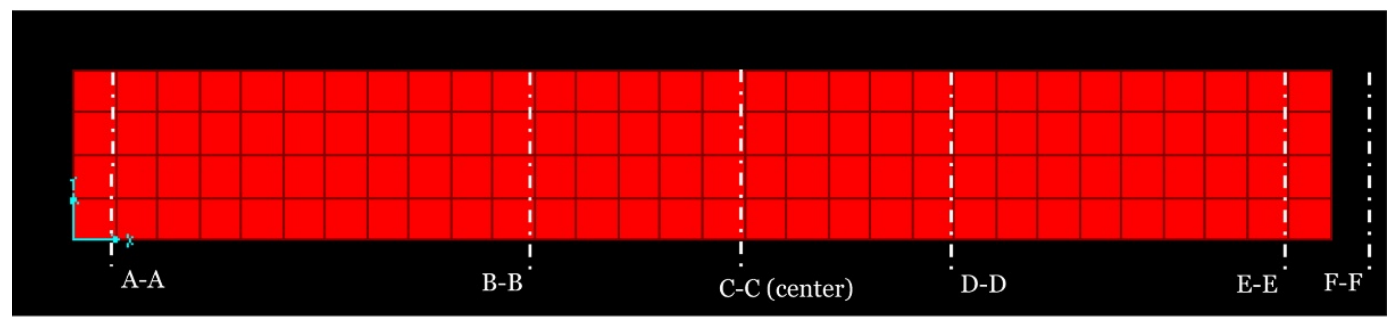


Figure 18. Beam elevation indicating critical sections ( $y=36$ in.).

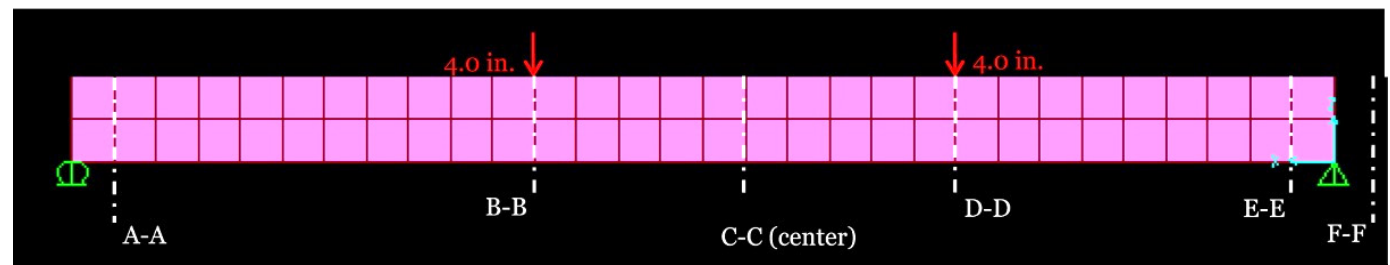

Figure 19. Cross section $A-A(x=0$ in.).

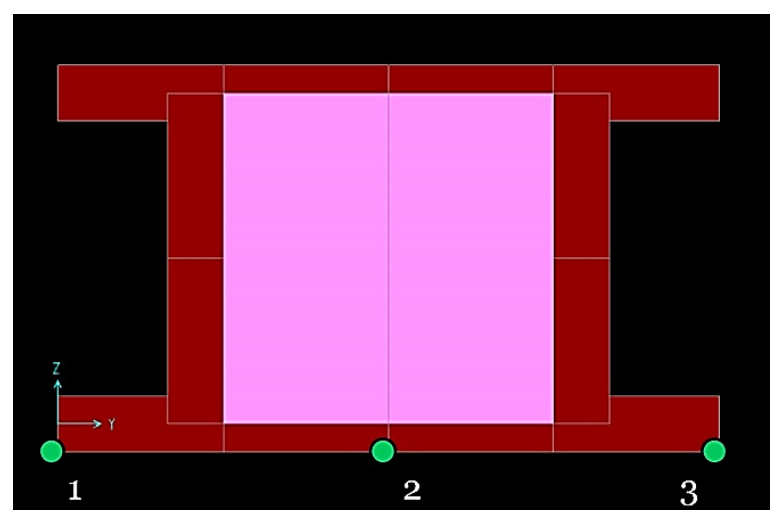

Figure 20. Cross section $B-B(x=90$ in.).

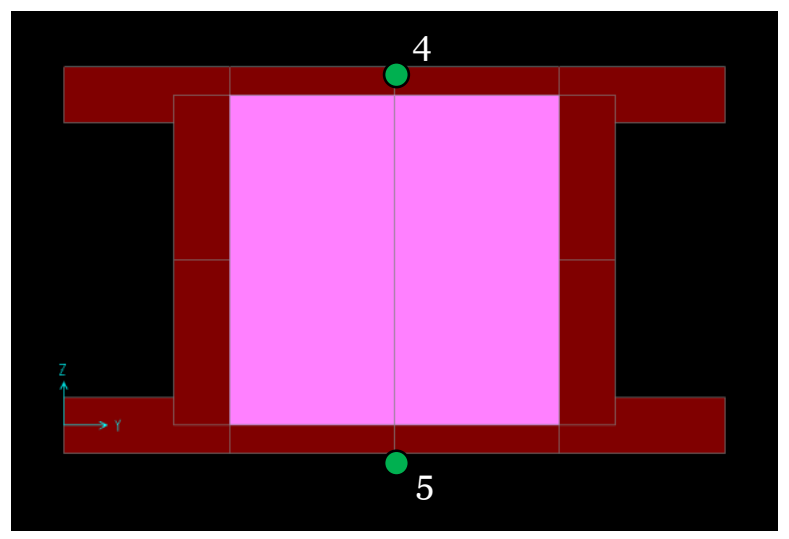

Figure 21. Cross section $C-C(x=135$ in.).

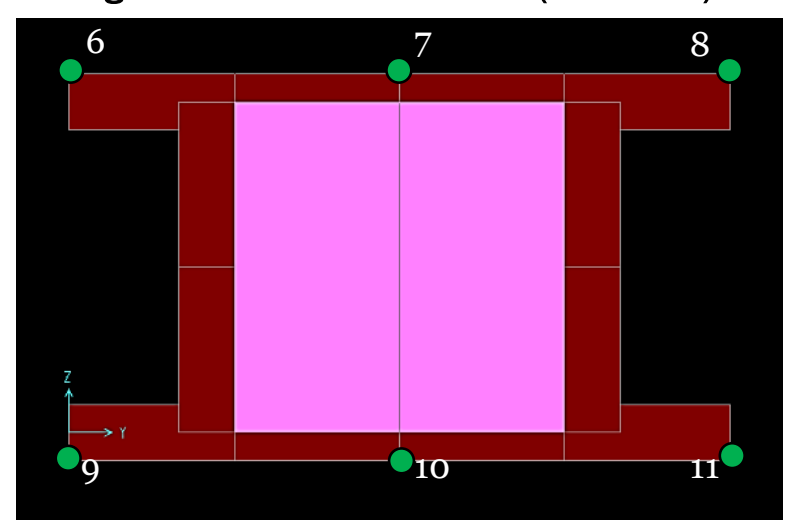


Figure 22. Cross section DD ( $x=180$ in.).

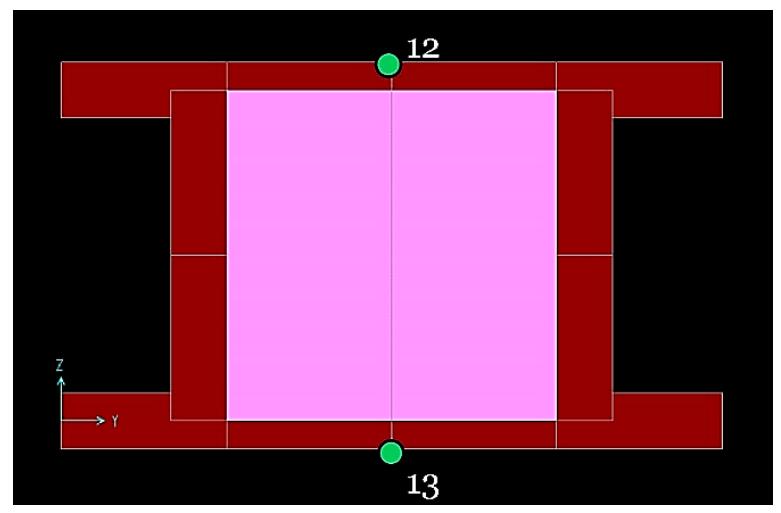

Figure 23. Cross section $E-E(x=252$ in.).

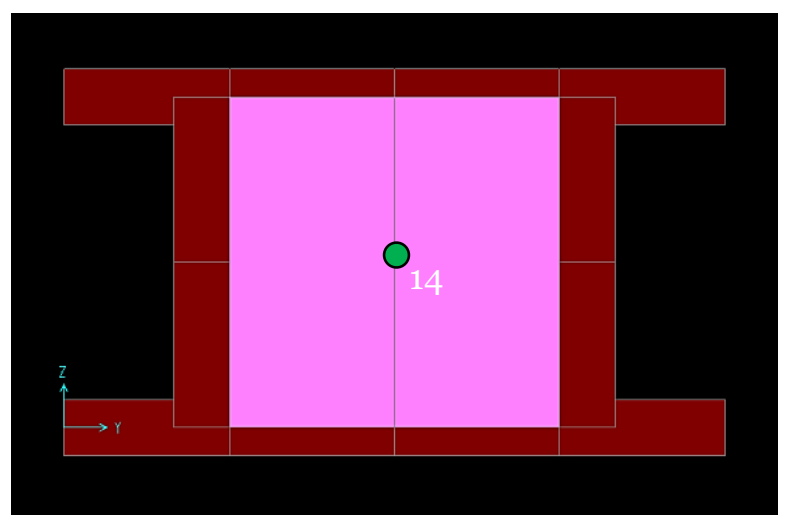

Figure 24. Cross section F-F ( $x=270$ in.).

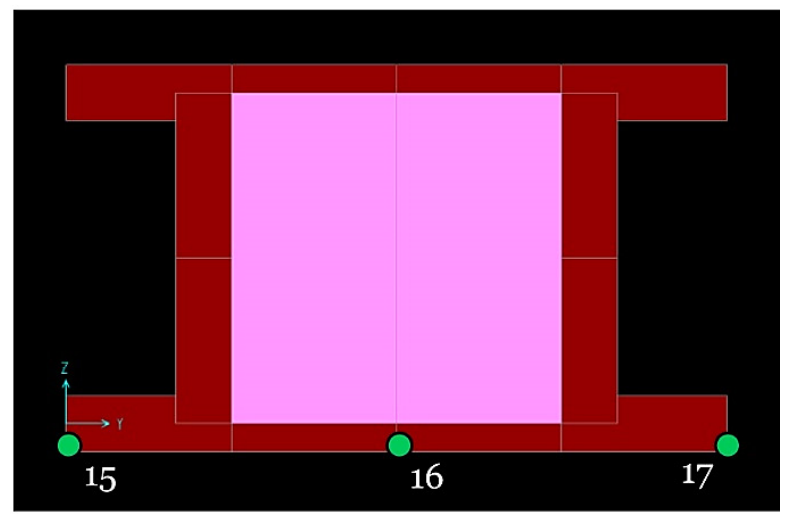


Table 13. Summary of global joint coordinates and corresponding cross section.

\begin{tabular}{|l|l|l|l|l|}
\hline \multirow{2}{*}{ Joint } & \multirow{2}{*}{$\begin{array}{l}\text { Cross } \\
\text { Section }\end{array}$} & \multicolumn{3}{|c|}{ Global Coordinates } \\
\cline { 3 - 5 } & X (in.) & Y (in.) & Z (in.) \\
\hline 1 & A-A & 0.0 & 0.0 & 0.0 \\
\hline 2 & A-A & 0.0 & 18.0 & 0.0 \\
\hline 3 & A-A & 0.0 & 36.0 & 0.0 \\
\hline 4 & B-B & 90.0 & 18.0 & 18.0 \\
\hline 5 & B-B & 90.0 & 18.0 & 0.0 \\
\hline 6 & C-C & 135.0 & 0.0 & 18.0 \\
\hline 7 & C-C & 135.0 & 18.0 & 18.0 \\
\hline 8 & C-C & 135.0 & 36.0 & 18.0 \\
\hline 9 & C-C & 135.0 & 0.0 & 0.0 \\
\hline 10 & C-C & 135.0 & 18.0 & 0.0 \\
\hline 11 & C-C & 135.0 & 36.0 & 0.0 \\
\hline 12 & D-D & 180.0 & 18.0 & 18.0 \\
\hline 13 & D-D & 180.0 & 18.0 & 0.0 \\
\hline 14 & E-E & 252.0 & 9.0 & 9.0 \\
\hline 15 & F-F & 270.0 & 0.0 & 0.0 \\
\hline 16 & F-F & 270.0 & 18.0 & 0.0 \\
\hline 17 & F-F & 270.0 & 36.0 & 0.0 \\
\hline
\end{tabular}

\subsubsection{Material properties}

Material properties provide information for materials used in the model. In the model, only one materiality was present, the thermoplastic composite material (thermoplastic); its properties are specified in Table 14.

Table 14. Summary of material properties.

\begin{tabular}{|c|c|c|c|c|c|c|}
\hline Material & $\begin{array}{l}\text { Unit Weight } \\
\text { (kip/in.2) }\end{array}$ & 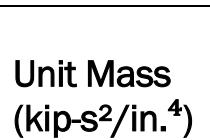 & $\begin{array}{l}\text { Elastic Modulus } \\
\text { (kip/in. }^{2} \text { ) }\end{array}$ & $\begin{array}{l}\text { Shear } \\
\text { Modulus } \\
\text { (kip/in. }^{2} \text { ) }\end{array}$ & $\begin{array}{l}\text { Poisson } \\
\text { Ratio }\end{array}$ & $\mathrm{A} 1(1 / \mathrm{F})$ \\
\hline Thermoplastic & 3.347 E-05 & 8.670 E-08 & 388.0 & 145.86 & 0.33 & $7.50 \mathrm{E}-05$ \\
\hline
\end{tabular}




\subsubsection{Section properties}

Section properties identify specifications for objects used in the model. Table 15 identifies the cross-sectional thicknesses of the member, with significance to bending and stress capacities. All sections were modeled as thin shells of thermoplastic material.

Table 15. Summary of section properties.

\begin{tabular}{|l|l|l|l|l|l|l|l|l|l|l|l|l|}
\hline Section & $\begin{array}{l}\text { Thickness } \\
\text { (in.) }\end{array}$ & $\begin{array}{l}\text { Bend } \\
\text { Thickness } \\
\text { (in.) }\end{array}$ & $\begin{array}{l}\mathbf{F}_{11} \\
\text { Mod }\end{array}$ & $\begin{array}{l}\mathbf{F}_{22} \\
\text { Mod }\end{array}$ & $\begin{array}{l}\mathbf{F}_{12} \\
\text { Mod }\end{array}$ & $\begin{array}{l}\mathbf{M}_{11} \\
\text { Mod }\end{array}$ & $\begin{array}{l}\mathbf{M}_{22} \\
\text { Mod }\end{array}$ & $\begin{array}{l}\mathbf{M}_{12} \\
\mathbf{M o d}\end{array}$ & $\begin{array}{l}\mathbf{V}_{13} \\
\text { Mod }\end{array}$ & $\begin{array}{l}\mathbf{V}_{23} \\
\text { Mod }\end{array}$ & $\begin{array}{l}\text { M } \\
\text { Mod }\end{array}$ & $\begin{array}{l}\text { W } \\
\text { Mod }\end{array}$ \\
\hline Flange & 3.0 & 3.0 & 1.0 & 1.0 & 1.0 & 1.0 & 1.0 & 1.0 & 1.0 & 1.0 & 1.0 & 1.0 \\
\hline Stiffener & 2.0 & 2.0 & 1.0 & 1.0 & 1.0 & 1.0 & 1.0 & 1.0 & 1.0 & 1.0 & 1.0 & 1.0 \\
\hline Web & 6.0 & 6.0 & 1.0 & 1.0 & 1.0 & 1.0 & 1.0 & 1.0 & 1.0 & 1.0 & 1.0 & 1.0 \\
\hline
\end{tabular}

\subsubsection{Load cases}

This section provides loading information, as applied to the model. The load patterns created in the SAP model represent the loading conditions during Beam Configuration \#2. In the model, the beam was restrained at both ends (pin and roller) and loaded at two points symmetrically along the beam, each 45 in. from the center line of the beam, as shown in Figure 25. Designed as a dead load with a self-weight multiplier of 1.0, each point load was applied as 4.0 in. in the negative $\mathrm{Z}$ direction. This load was derived from the calculated maximum load the beam could withstand before rupture, and the model allowed validation of the beam's true behavior under these conditions. Shear and moment were established based on the two point loads and the self-weight of the beam.

\subsubsection{Modeling results}

This section provides modeling results, including items such as the shear and moment reactions at the base of the beam (Figure 26 and Figure 27). Note that all horizontal reactions at the pin support cancel each other, resulting in an effective reaction of o.o kips (Table 16). 
Figure 25. Deformed shape.

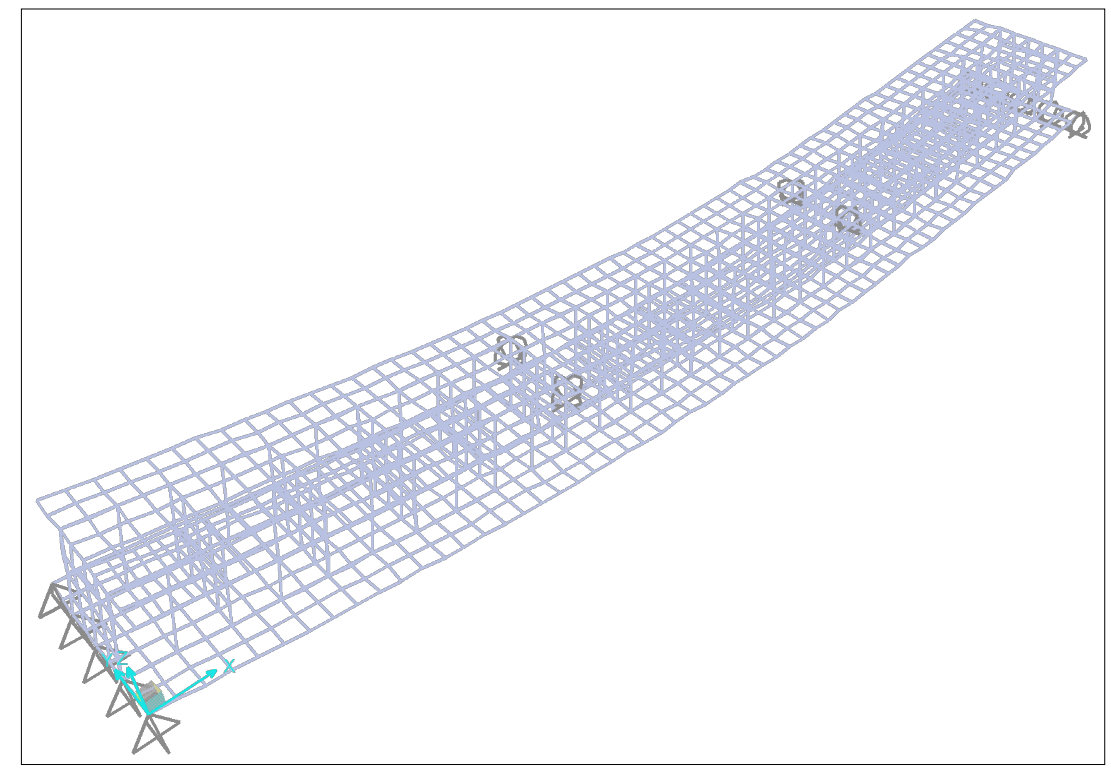

Figure 26. Spectrum of forces on the beam.

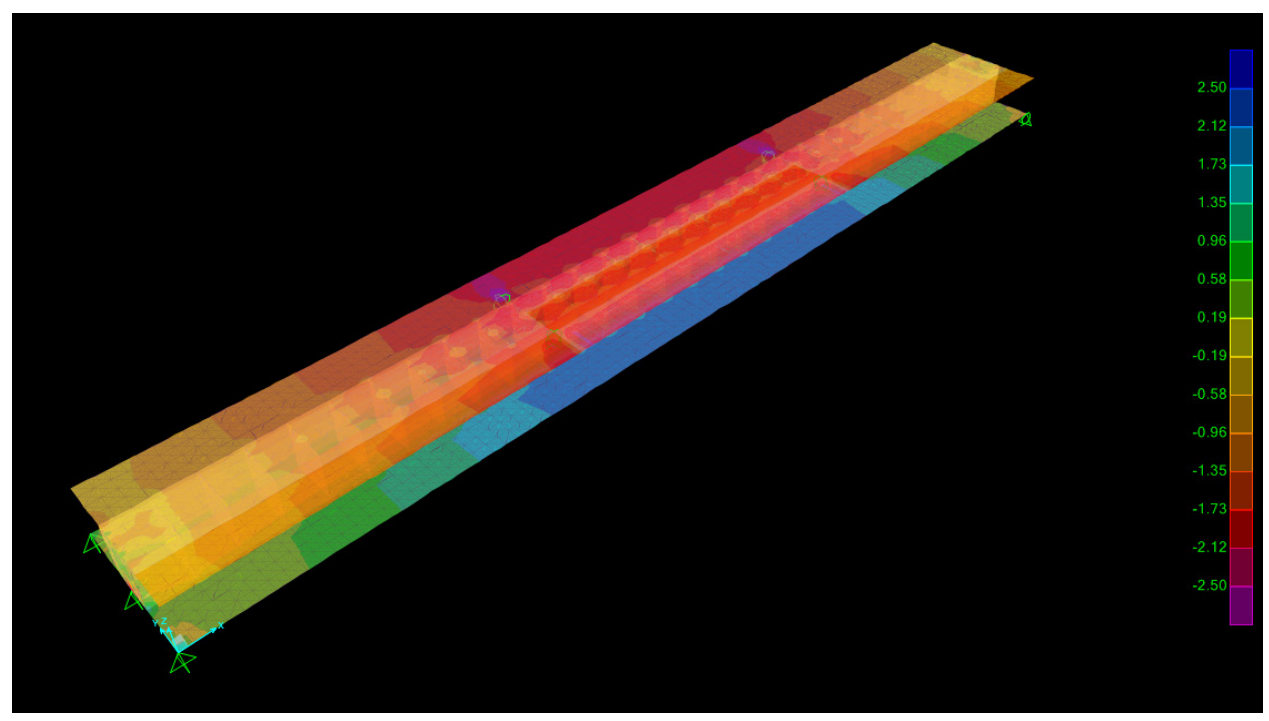


Figure 27. Spectrum of forces on the beam.

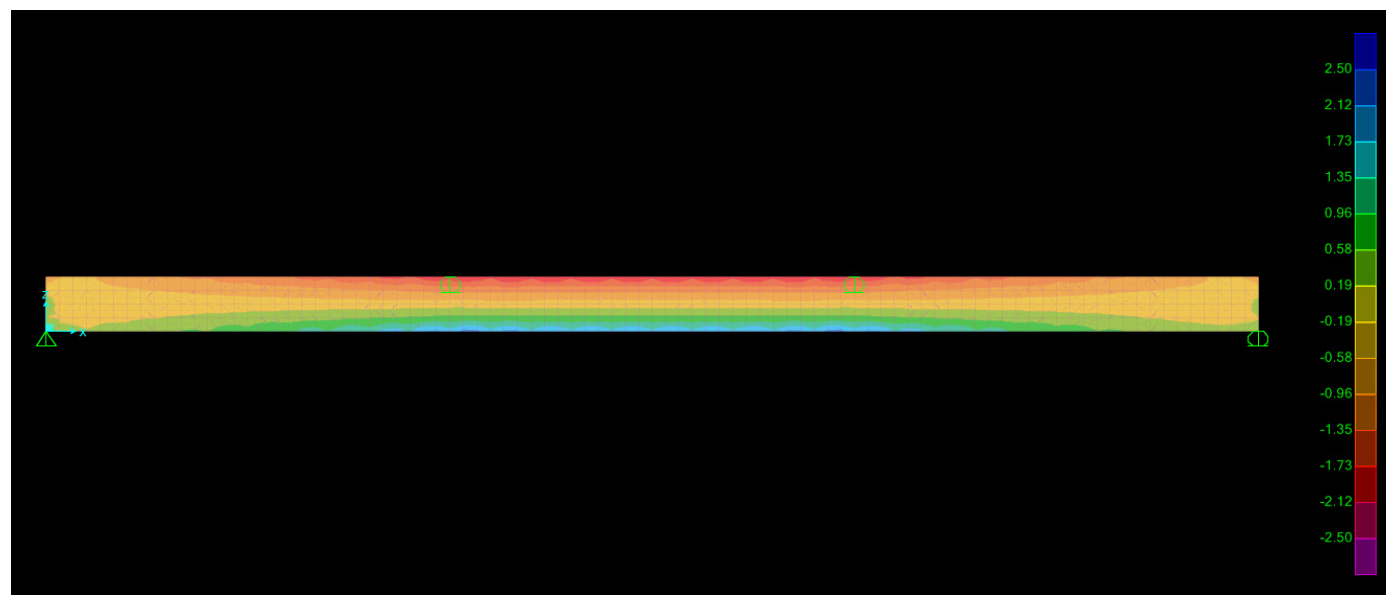

Table 16. Summary of base reactions.

\begin{tabular}{|l|l|l|l|l|l|l|}
\hline Output Case & $F_{x}($ kip) & $F_{y}($ kip) & $F_{z}$ (kip) & $M_{x}$ (kip-in.) & $M_{y}$ (kip-in.) & $M_{z}$ (kip-in.) \\
\hline Point Loads & 0.00 & 0.00 & 52.40 & 63.94 & -479.56 & 0.00 \\
\hline
\end{tabular}

\subsubsection{Joint results}

Joint results include the displacements and reactions which occurred at each joint throughout the beam, under specified loading and self-weight of the beam. The results have been separated into charts below in Table 17Table 19, based on their corresponding cross section. Similar cross sections were identified in the same chart for ease of data comparison.*

Table 17. Summary of joint displacements and reactions at beam ends.

\begin{tabular}{|l|l|l|l|l|l|l|}
\hline Joint & Cross Section & $\mathrm{U}_{\mathrm{x}}$ (in.) & $\mathrm{U}_{\mathrm{z}}$ (in.) & $\mathrm{F}_{\mathrm{x}}$ (kip) & $\mathrm{F}_{\mathbf{z}}$ (kip) & $\mathrm{M}$ (kip-in.) \\
\hline 1 & A-A & 0.00 & 0.00 & -0.741 & 1.365 & 0.00 \\
\hline 2 & A-A & 0.00 & 0.00 & 1.481 & 31.62 & 0.00 \\
\hline 3 & A-A & 0.00 & 0.00 & -0.741 & -1.365 & 0.00 \\
\hline 15 & F-F & 0.568 & 0.00 & 0.00 & 1.228 & 0.00 \\
\hline 16 & F-F & 0.578 & 0.00 & 0.00 & 31.88 & 0.00 \\
\hline 17 & F-F & 0.568 & 0.00 & 0.00 & 1.228 & 0.00 \\
\hline
\end{tabular}

\footnotetext{
* Note that Joint 14 is in cross section E-E, which does not fall under any of the categories (labeled in captions) for Table 17-19.
} 
Table 18. Summary of joint displacements beneath loading.

\begin{tabular}{|l|l|l|l|}
\hline Joint & Cross Section & $U_{x}$ (in.) & $U_{z}$ (in.) \\
\hline 4 & B-B & 0.438 & -3.979 \\
\hline 5 & B-B & 0.136 & -3.977 \\
\hline 12 & D-D & 0.136 & -3.979 \\
\hline 13 & D-D & 0.438 & -3.977 \\
\hline
\end{tabular}

Table 19. Summary of joint displacement at beam center.

\begin{tabular}{|l|l|l|l|}
\hline Joint & Cross Section & $\mathrm{U}_{\mathrm{x}}$ (in.) & $\mathrm{U}_{\mathrm{z}}$ (in.) \\
\hline 6 & C-C & 0.287 & -4.576 \\
\hline 7 & C-C & 0.287 & -4.548 \\
\hline 8 & C-C & 0.287 & -4.576 \\
\hline 9 & C-C & 0.287 & -4.576 \\
\hline 10 & C-C & 0.287 & -4.547 \\
\hline 11 & C-C & 0.287 & -4.576 \\
\hline
\end{tabular}

\subsubsection{Area results}

This section provides results based on the forces and stresses of the affected cross sectional areas. In Table 20-Table 23, the joints are identified to indicate the exact location on a cross section where the data has been collected from.

Table 20. Summary of element stresses at beam ends.

\begin{tabular}{|c|c|c|c|c|c|c|c|}
\hline Joint & $\begin{array}{l}\text { Cross } \\
\text { Section }\end{array}$ & $\begin{array}{l}\sigma_{11} \text { Top } \\
\text { (kip/in. }{ }^{2} \text { ) }\end{array}$ & $\begin{array}{l}\sigma_{22} \text { Top } \\
\text { (kip/in.2) }\end{array}$ & $\begin{array}{l}\sigma_{12} \text { Top } \\
\text { (kip/in. }{ }^{2} \text { ) }\end{array}$ & $\begin{array}{l}\sigma_{11} \\
\text { Bottom } \\
\text { (kip/in.2) }\end{array}$ & $\begin{array}{l}\sigma_{22} \\
\text { Bottom } \\
\left(\text { kip/in.2 }{ }^{2}\right)\end{array}$ & $\begin{array}{l}\sigma_{12} \\
\text { Bottom } \\
\text { (kip/in. }^{2} \text { ) }\end{array}$ \\
\hline 1 & A-A & -0.637 & -1.027 & -0.044 & 1.025 & 1.749 & -0.196 \\
\hline 2 & $A-A$ & -2.549 & -5.697 & -0.445 & -2.709 & -5.125 & -0.410 \\
\hline 3 & A-A & -0.637 & -1.027 & 0.044 & 1.025 & 1.749 & 0.196 \\
\hline 15 & F-F & -0.052 & -0.774 & 0.181 & 0.016 & 1.345 & -0.063 \\
\hline 16 & F-F & -1.524 & 0.483 & -0.821 & -4.463 & -1.718 & -2.373 \\
\hline 17 & F-F & -0.052 & -0.774 & -0.181 & 0.016 & 1.345 & 0.063 \\
\hline
\end{tabular}


Table 21. Summary of element stresses beneath loading.

\begin{tabular}{|c|c|c|c|c|c|c|c|}
\hline Joint & $\begin{array}{l}\text { Cross } \\
\text { Section }\end{array}$ & $\begin{array}{l}\sigma_{11} \text { Top } \\
\text { (kip/in. }{ }^{2} \text { ) }\end{array}$ & $\begin{array}{l}\sigma_{22} \text { Top } \\
\text { (kip/in. }{ }^{2} \text { ) }\end{array}$ & $\begin{array}{l}\sigma_{12} \text { Top } \\
\text { (kip/in. }{ }^{2} \text { ) }\end{array}$ & $\begin{array}{l}\sigma_{11} \\
\text { Bottom } \\
\text { (kip/in.2) }\end{array}$ & $\begin{array}{l}\sigma_{22} \\
\text { Bottom } \\
\text { (kip/in.2) }\end{array}$ & $\begin{array}{l}\sigma_{12} \\
\text { Bottom } \\
(\text { kip/in.2) }\end{array}$ \\
\hline 4 & B-B & -2.211 & -0.113 & -0.010 & -0.963 & -0.013 & 0.002 \\
\hline 5 & B-B & 1.232 & -0.095 & 0.013 & 2.047 & 0.221 & -0.021 \\
\hline 12 & D-D & -1.972 & -0.035 & 0.015 & -1.290 & -0.121 & -0.007 \\
\hline 13 & D-D & 1.232 & -0.095 & -0.013 & 2.285 & 0.299 & 0.004 \\
\hline
\end{tabular}

Table 22. Summary of element stresses at beam center.

\begin{tabular}{|c|c|c|c|c|c|c|c|}
\hline Joint & $\begin{array}{l}\text { Cross } \\
\text { Section }\end{array}$ & $\begin{array}{l}\sigma_{11} \text { Top } \\
\text { (kip/in. }{ }^{2} \text { ) }\end{array}$ & $\begin{array}{l}\sigma_{22} \text { Top } \\
\text { (kip/in. }{ }^{2} \text { ) }\end{array}$ & $\begin{array}{l}\sigma_{12} \text { Top } \\
\text { (kip/in. }{ }^{2} \text { ) }\end{array}$ & $\begin{array}{l}\sigma_{11} \\
\text { Bottom } \\
\text { (kip/in.2) }\end{array}$ & $\begin{array}{l}\sigma_{22} \\
\text { Bottom } \\
\text { (kip/in.2 }{ }^{2} \text { ) }\end{array}$ & $\begin{array}{l}\sigma_{12} \\
\text { Bottom } \\
\text { (kip/in.2) }\end{array}$ \\
\hline 6 & $\mathrm{C}-\mathrm{C}$ & -1.946 & 0.000 & 0.000 & -1.303 & 0.000 & 0.000 \\
\hline 7 & C-C & -2.026 & -0.119 & -0.003 & -1.249 & 0.052 & 0.003 \\
\hline 8 & $\mathrm{C}-\mathrm{C}$ & -1.946 & 0.000 & 0.000 & -1.303 & 0.000 & 0.000 \\
\hline 9 & $\mathrm{C}-\mathrm{C}$ & 1.301 & 0.000 & 0.000 & 1.950 & 0.000 & 0.000 \\
\hline 10 & C-C & 1.249 & -0.050 & -0.002 & 2.024 & 0.119 & 0.002 \\
\hline 11 & C-C & 1.301 & 0.000 & 0.000 & 1.950 & 0.000 & 0.000 \\
\hline
\end{tabular}

Table 23. Summary of element stresses at the rosette.

\begin{tabular}{|c|c|c|c|c|c|c|c|}
\hline Joint & $\begin{array}{l}\text { Cross } \\
\text { Section }\end{array}$ & $\begin{array}{l}\sigma_{11} \text { Top } \\
\text { (kip/in.2) }\end{array}$ & $\begin{array}{l}\sigma_{22} \text { Top } \\
\text { (kip/in. }{ }^{2} \text { ) }\end{array}$ & $\begin{array}{l}\sigma_{12} \text { Top } \\
\text { (kip/in.2) }\end{array}$ & $\begin{array}{l}\sigma_{11} \\
\text { Bottom } \\
\text { (kip/in.2) }\end{array}$ & $\begin{array}{l}\sigma_{22} \\
\text { Bottom } \\
\text { (kip/in. }{ }^{2} \text { ) }\end{array}$ & $\begin{array}{l}\sigma_{12} \\
\text { Bottom } \\
\text { (kip/in. }{ }^{2} \text { ) }\end{array}$ \\
\hline 14 & E-E & -.009 & -0.009 & 0.203 & -.0155 & 0.0480 & 0.220 \\
\hline
\end{tabular}




\section{Mechanical Properties of the Thermoplastic Material}

\subsection{Background}

Nine cube-shaped specimens and six dog bone-shaped specimens were cut from a section of T-beam from the original batch of thermoplastic material. Voids with an average size of about $2 \mathrm{~mm}$ and a maximum size of $4.4 \mathrm{~mm}$ were observed in the section. These voids were concentrated in an approximately $1.2 \mathrm{in}$. thick layer at the core of each element in the beam cross section. Figure 28 shows a typical section in a web or flange of extruded thermoplastic material. The marked core of the section (red outline) contained voids, while outside layers (about $0.8 \mathrm{in}$. thick) were almost free from visible voids. Mechanical testing specimens contained a single void-filled layer sandwiched between two exterior layers that were free of voids. Therefore, the mechanical tests provided capacities from a combination of the two materials.

Figure 28. Typical section of extruded thermoplastic material in a web or flange, with voids in core outlined by added red box.

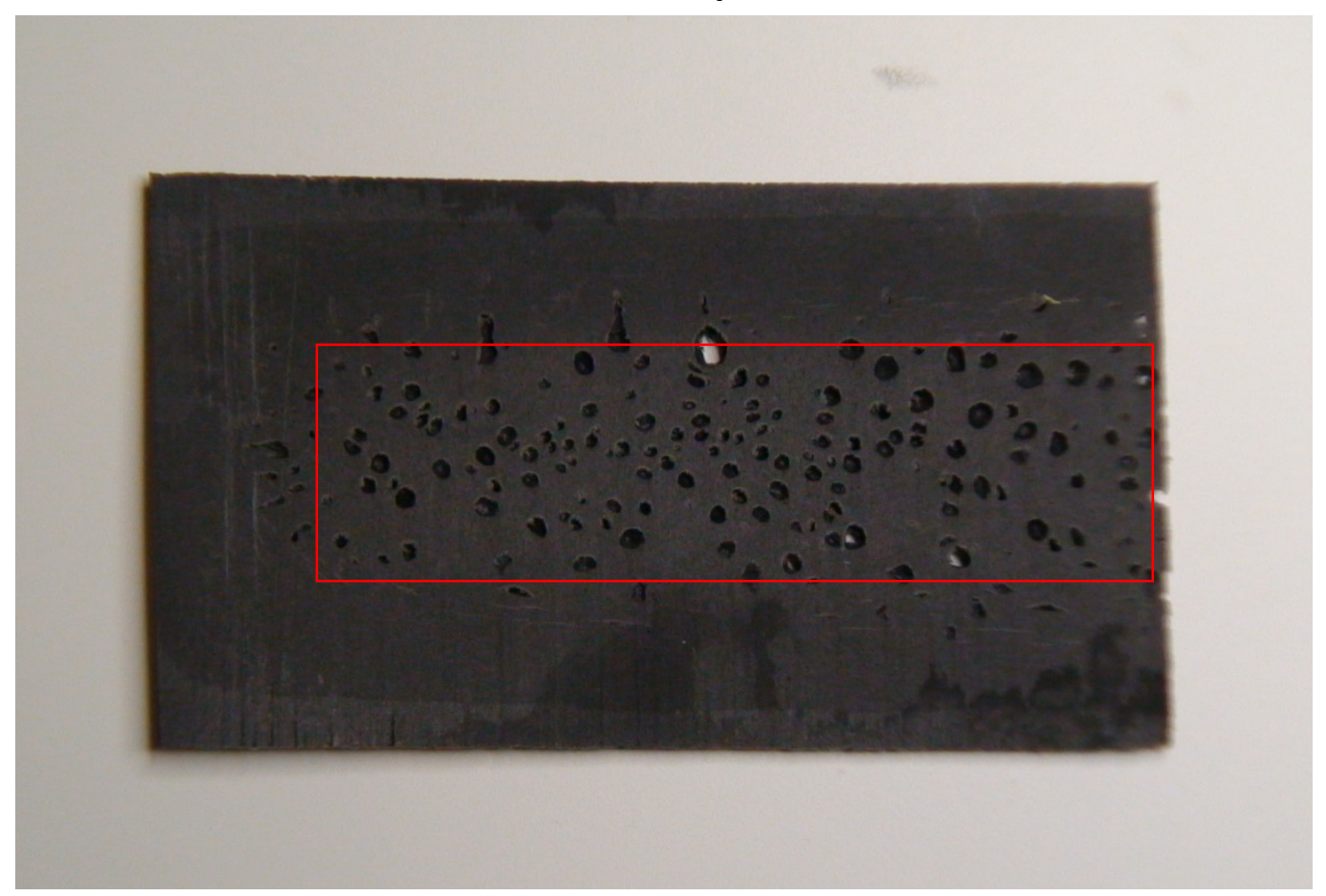




\subsection{Compression tests of original batch}

Each compression specimen consisted of a 3 in. cube. Cubes were compression-tested in two groups, based on the orientation of the different layers in the specimen. The first group (Group I) was tested such that the layers were loaded in series. Cubes with odd numbers $(1,3,5,7$, and 9) are in this group. Figure 29 shows Specimen \#1 as an example of Group I specimens.

In Group II, each specimen was oriented such that the layers were loaded in parallel. Specimens labeled 2, 4, 6, and 8 belong to this group. Figure 30 shows sample No. 2 as an example of Group II specimens.

Figure 31 shows specimens 1 through 8 prepared for compression testing. 
Figure 29. Cube-shaped specimen to be loaded with layers in series.

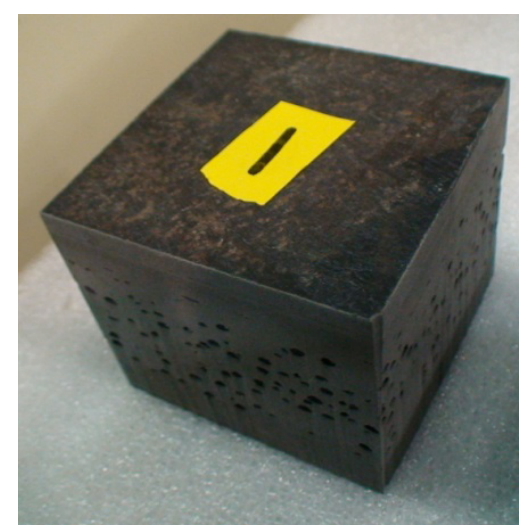

Figure 30. Cube-shaped specimen to be loaded with layers in parallel.

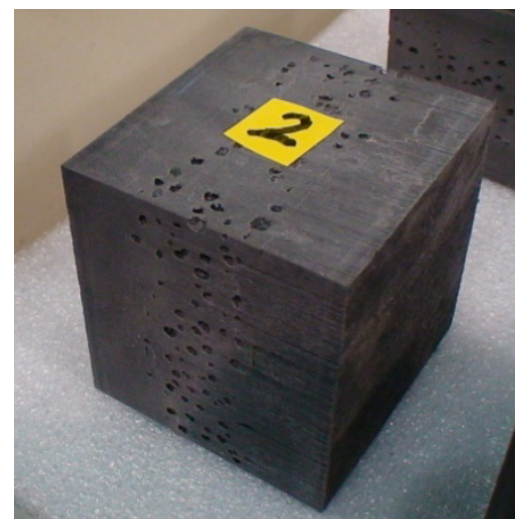

Figure 31. Prepared specimens for compression testing, with odd-numbered cubes to be loaded with layers in series, and even-numbered cubes to be loaded with layers in parallel. (Specimen No. 9 is not shown in this photo.)

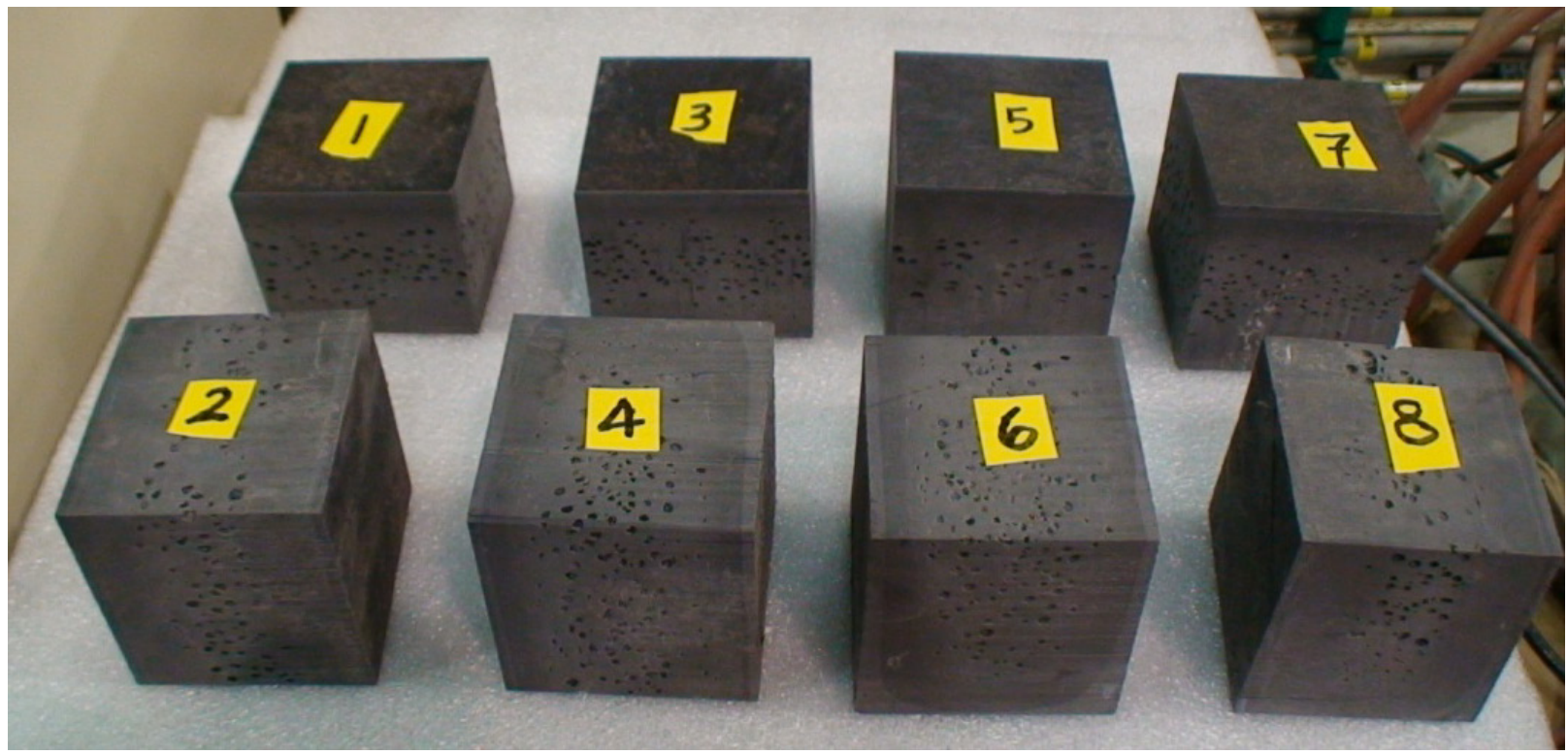

Figure 32 shows all specimens after testing. Figure 33 shows a specimen in the Test Mark compression machine, which was used to apply a ramped displacement load to each compression specimen and to measure the corresponding force. An extensometer was also used to measure strain during testing of selected specimens (\#7 and \#9; Figure 34). 
Figure 32. Specimens after compression testing.

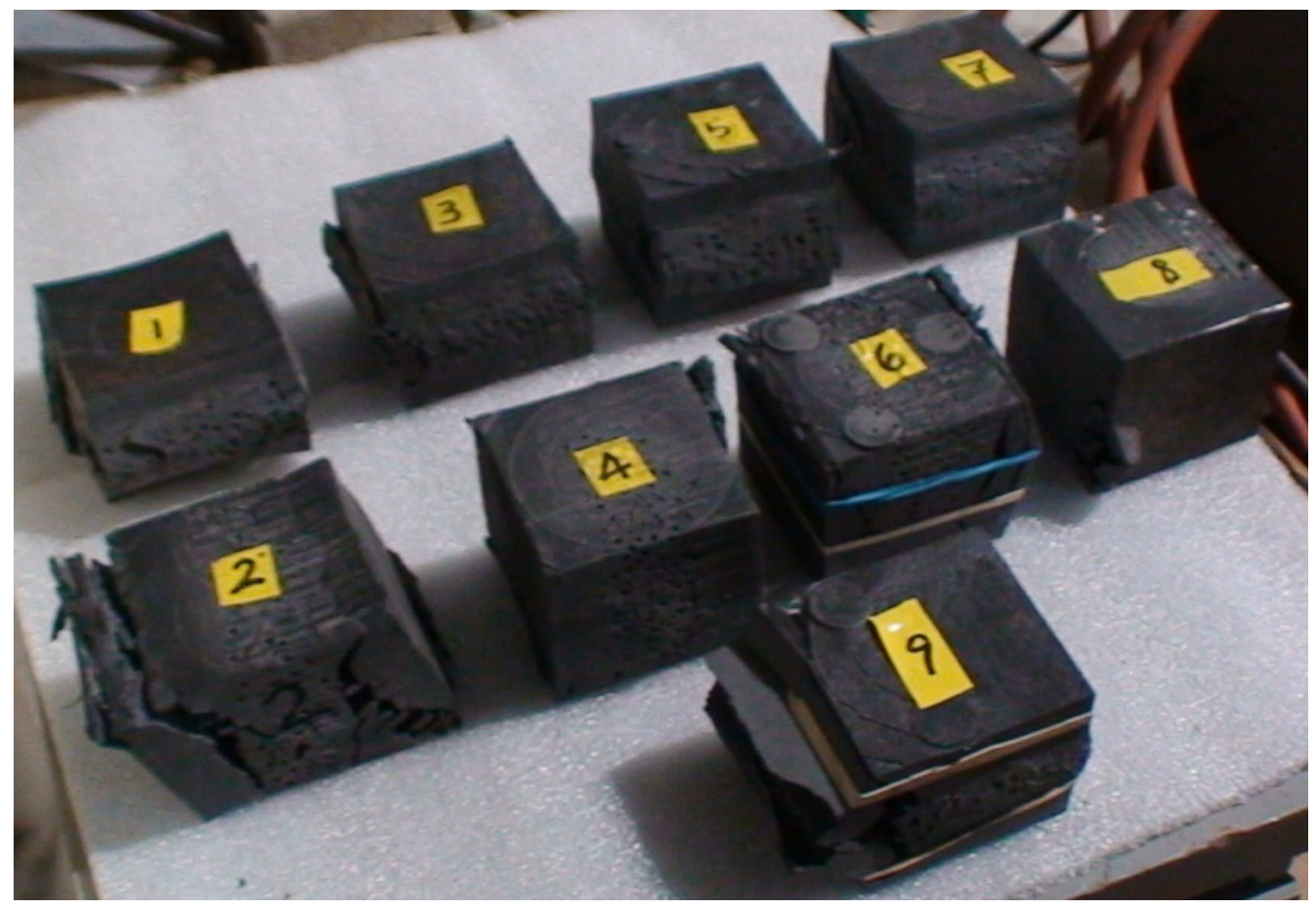

Figure 33. Test Mark compression machine used to measure ultimate load under compression test.

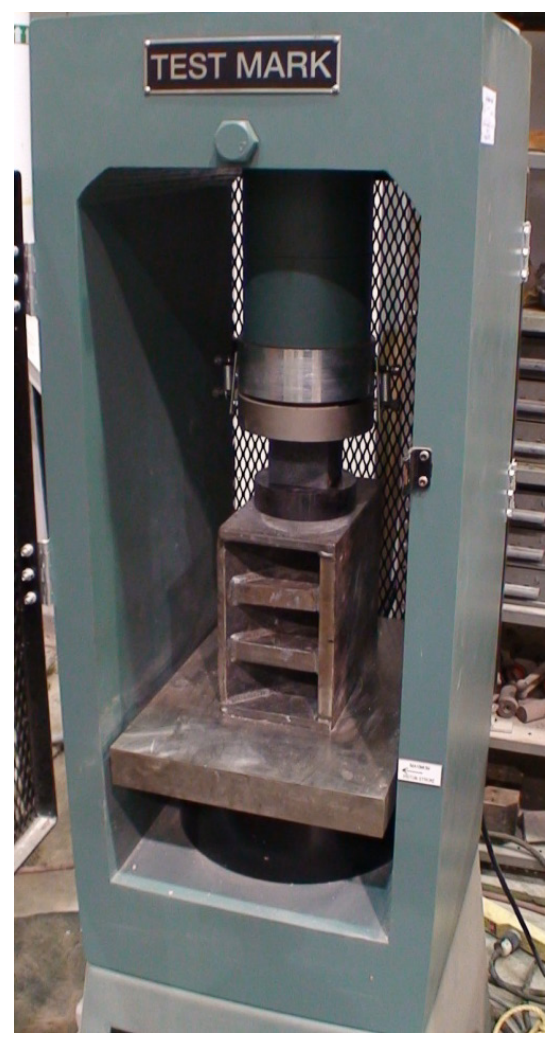

Figure 34. MTS 50-kip extensometer used to measure loading curves.

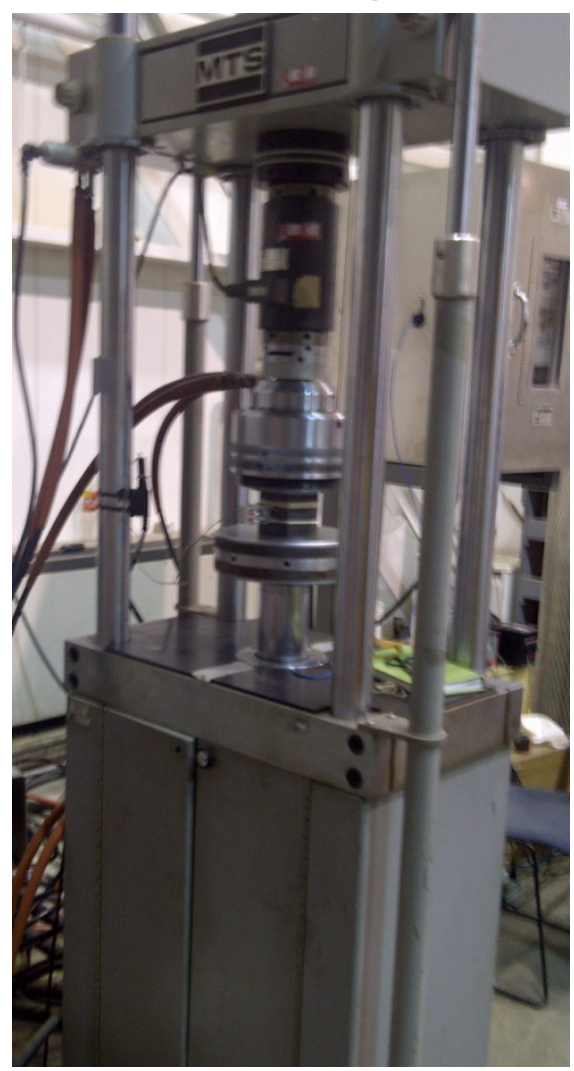


The strain values at maximum load in specimens \#7 and \#9 were measured by using an extensometer, to be 0.109 and $0.098 \mathrm{in}$./in. respectively. The average strain for the two specimens at ultimate strength was 0.104 in./in. Figure 35 and Figure 36 show specimen \#9 before and after testing with an extensometer.

Figure 37 shows modes of failure of all compression specimens. The predominate mode of failure of Group I (layers in series) was observed to be crushing of the void-filled core. The dominant failure mode for Group II (layers in parallel) is delamination between interior and exterior layers and buckling of the specimen.

The results of the compression tests in the original batch are summarized in Table 24, which shows the overall average compressive strength as 4,402 psi. The average maximum stress for Group I is 4,310 psi, and the average stress for Group II is 4,494 psi. Group II is stronger than Group I by about $4.25 \%$ due to the orientation of the layers in the specimen with respect to the applied load and the lower stiffness and strength of the core.

Figure 35. Specimen \#9 before testing with extensometer.

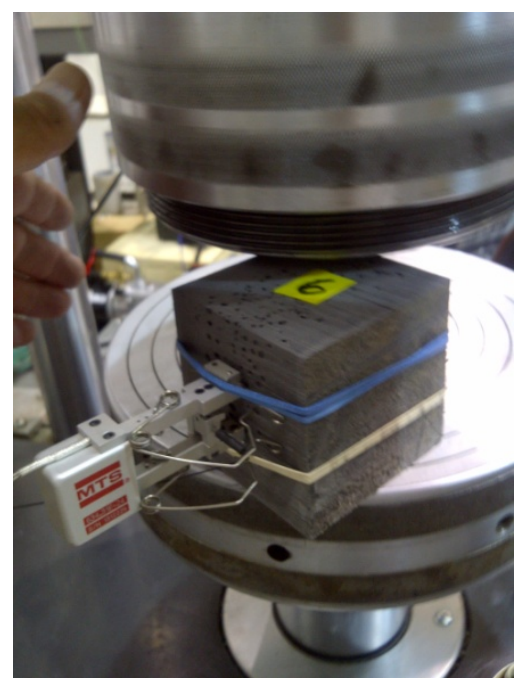

Figure 36. Specimen \#9 after testing with extensometer.

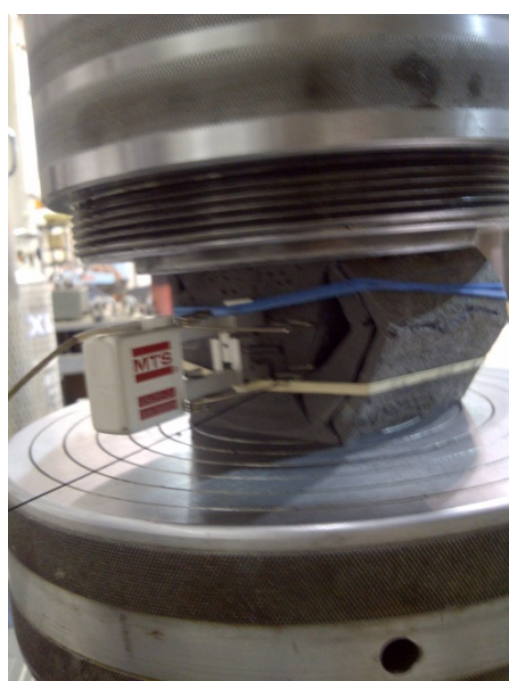


Figure 37. Cube-shaped specimens, showing modes of failure under compression load.

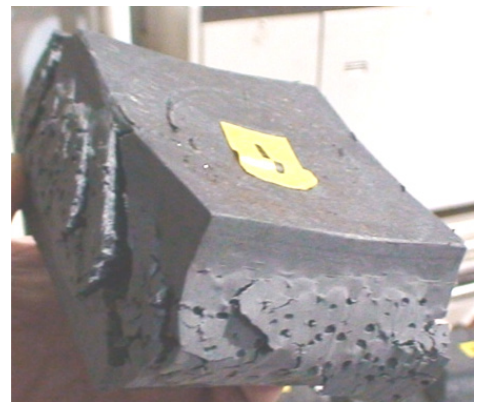

Specimen 1

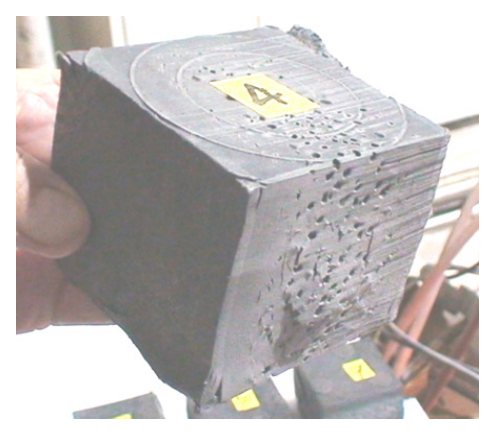

Specimen 4

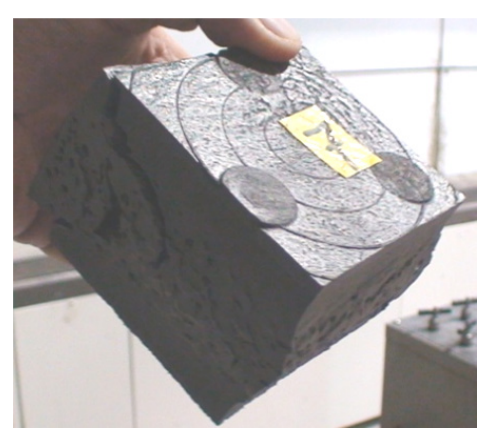

Specimen 7

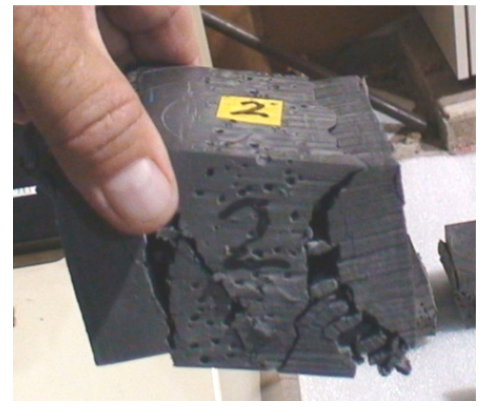

Specimen 2

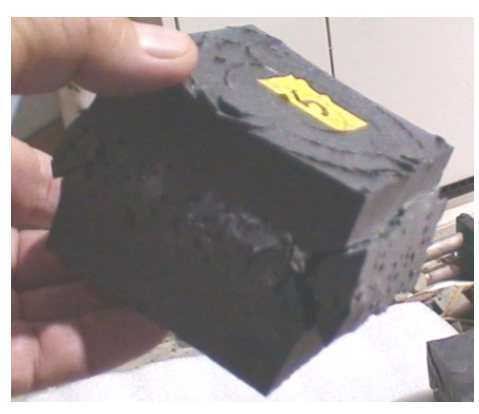

Specimen 5

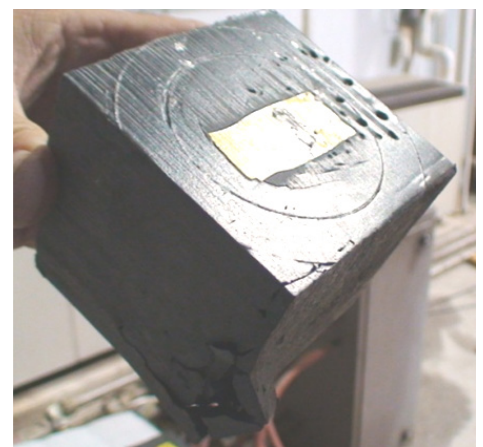

Specimen 8

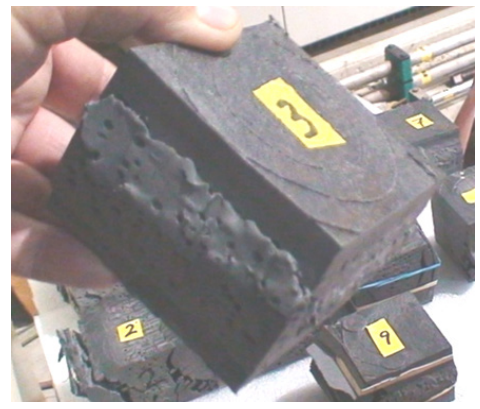

Specimen 3
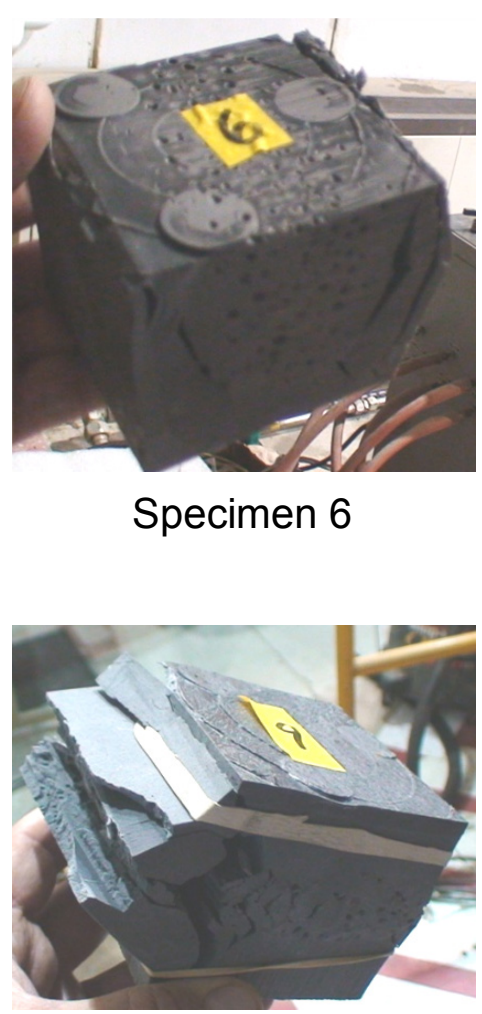

Specimen 9 
Table 24. Summary of compressive tests on cube-shaped specimens from the original batch.

\begin{tabular}{|c|c|c|c|c|c|c|c|c|}
\hline Specimen & $\begin{array}{l}\text { Orientation } \\
\text { of Loading }\end{array}$ & $\begin{array}{l}\text { Width } \\
\text { (in.) }\end{array}$ & $\begin{array}{l}\text { Depth } \\
\text { (in.) }\end{array}$ & $\begin{array}{l}\text { Height } \\
\text { (in.) }\end{array}$ & $\begin{array}{l}\text { Area } \\
\text { (in. }^{2} \text { ) }\end{array}$ & $\begin{array}{l}\text { Load } \\
\text { (lb) }\end{array}$ & $\begin{array}{l}\text { Stress } \\
\text { (psi) }\end{array}$ & $\begin{array}{l}\text { Strain } \\
\text { at Peak } \\
\text { in./in. }\end{array}$ \\
\hline 1 & $\begin{array}{l}\text { Layers in } \\
\text { series }\end{array}$ & 3.01 & 3.00 & 2.60 & 9.04 & 50,720 & 5,613 & N/A \\
\hline 2 & $\begin{array}{l}\text { Layers in } \\
\text { parallel }\end{array}$ & 2.84 & 3.02 & 3.01 & 8.57 & 38,160 & 4,455 & N/A \\
\hline 3 & \multicolumn{8}{|l|}{ Bad test } \\
\hline 4 & $\begin{array}{l}\text { Layers in } \\
\text { parallel }\end{array}$ & 2.85 & 2.86 & 2.99 & 8.14 & 39,681 & 4,873 & N/A \\
\hline 5 & $\begin{array}{l}\text { Layers in } \\
\text { series }\end{array}$ & 3.00 & 3.00 & 2.84 & 9.01 & 34,606 & 3,841 & N/A \\
\hline 6 & $\begin{array}{l}\text { Layers in } \\
\text { parallel }\end{array}$ & 2.85 & 2.96 & 2.99 & 8.43 & 34,350 & 4,076 & N/A \\
\hline 7 & $\begin{array}{l}\text { Layers in } \\
\text { series }\end{array}$ & 3.00 & 3.00 & 2.85 & 9.00 & 37,519 & 3,574 & 0.109 \\
\hline 8 & $\begin{array}{l}\text { Layers in } \\
\text { parallel }\end{array}$ & 2.98 & 2.84 & 2.96 & 8.46 & 38,680 & 4,570 & $\begin{array}{l}\text { Bad } \\
\text { data }\end{array}$ \\
\hline 9 & $\begin{array}{l}\text { Layers in } \\
\text { series }\end{array}$ & 3.00 & 3.01 & 2.84 & 8.55 & 36,018 & 4,213 & 0.098 \\
\hline \multicolumn{7}{|c|}{ Average stress } & \multicolumn{2}{|l|}{4,402} \\
\hline
\end{tabular}

The stress-strain curves of the original batch specimens are presented in Figure 38 for four specimens: \#4, \#5, \#7, and \#9. From these curves, the modulus of elasticity (E) was estimated to be $388 \mathrm{ksi}$. 
Figure 38. Stress-strain curves for several specimens.
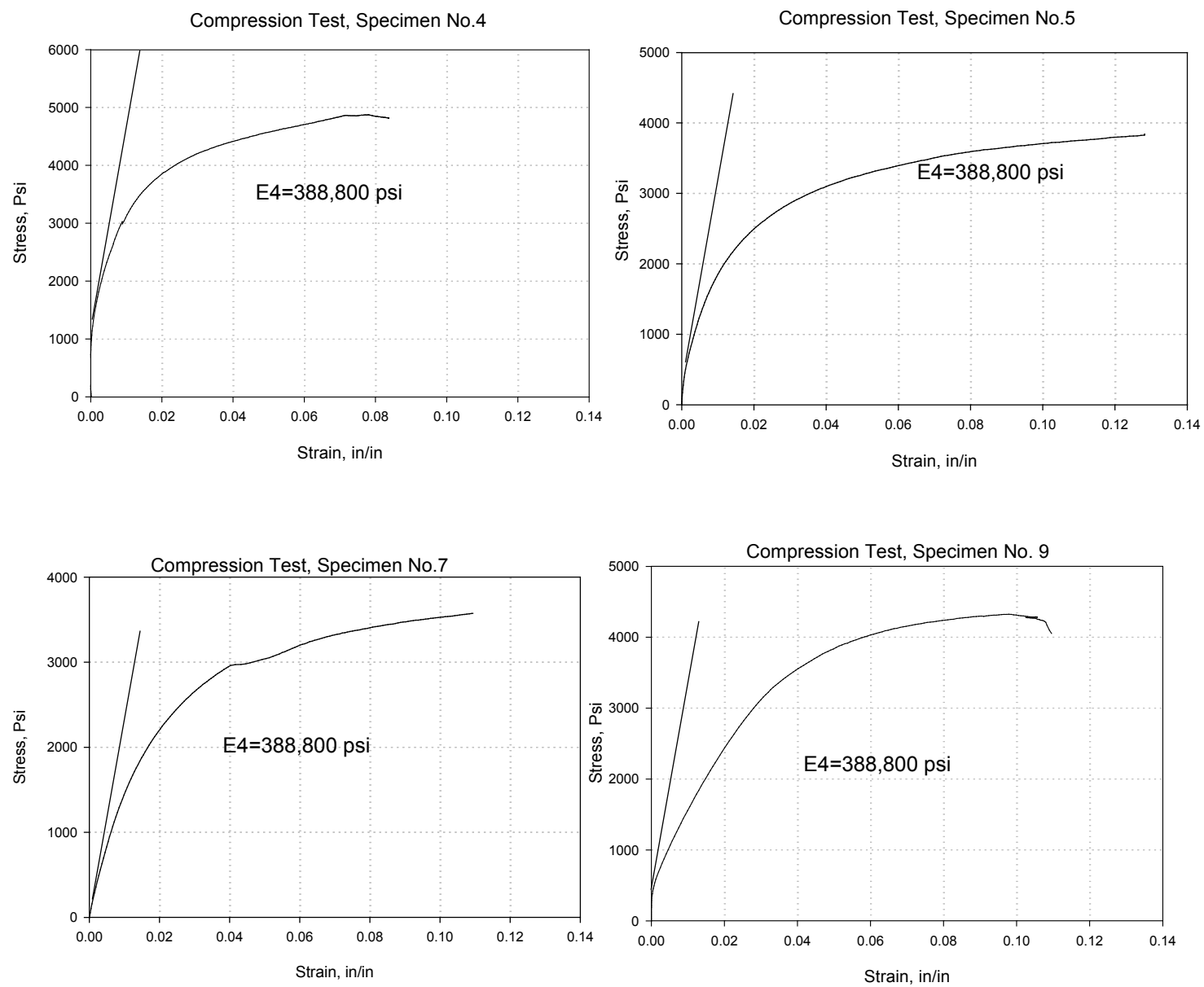

\subsection{Tension tests of dog-bone specimens, original batch}

Six specimens were cut from a beam that was similar to those which were tested in flexure later in this project. The specimens were machine cut per ASTM D638-10, "Standard Test method for Tensile Properties of Plastic." Dimensions of dog-bone specimens for tension strength testing are shown in Figure 39. Figure 40 shows a typical specimen.

Figure 41 shows the specimens positioned in the MTS Million Pound machine ready for testing. All tension specimens were loaded at $0.1 \mathrm{in}$. per minute with layers in parallel. The modes of failure are shown in Figure 42. Specimens \# 2 and \# 5 failed near the grip due to excessive clamping load from the jaws of the machine. These two tests were considered bad tests and were omitted from calculations. 
Figure 39. Nominal dimension of machine-cut dog-bone tension specimens.

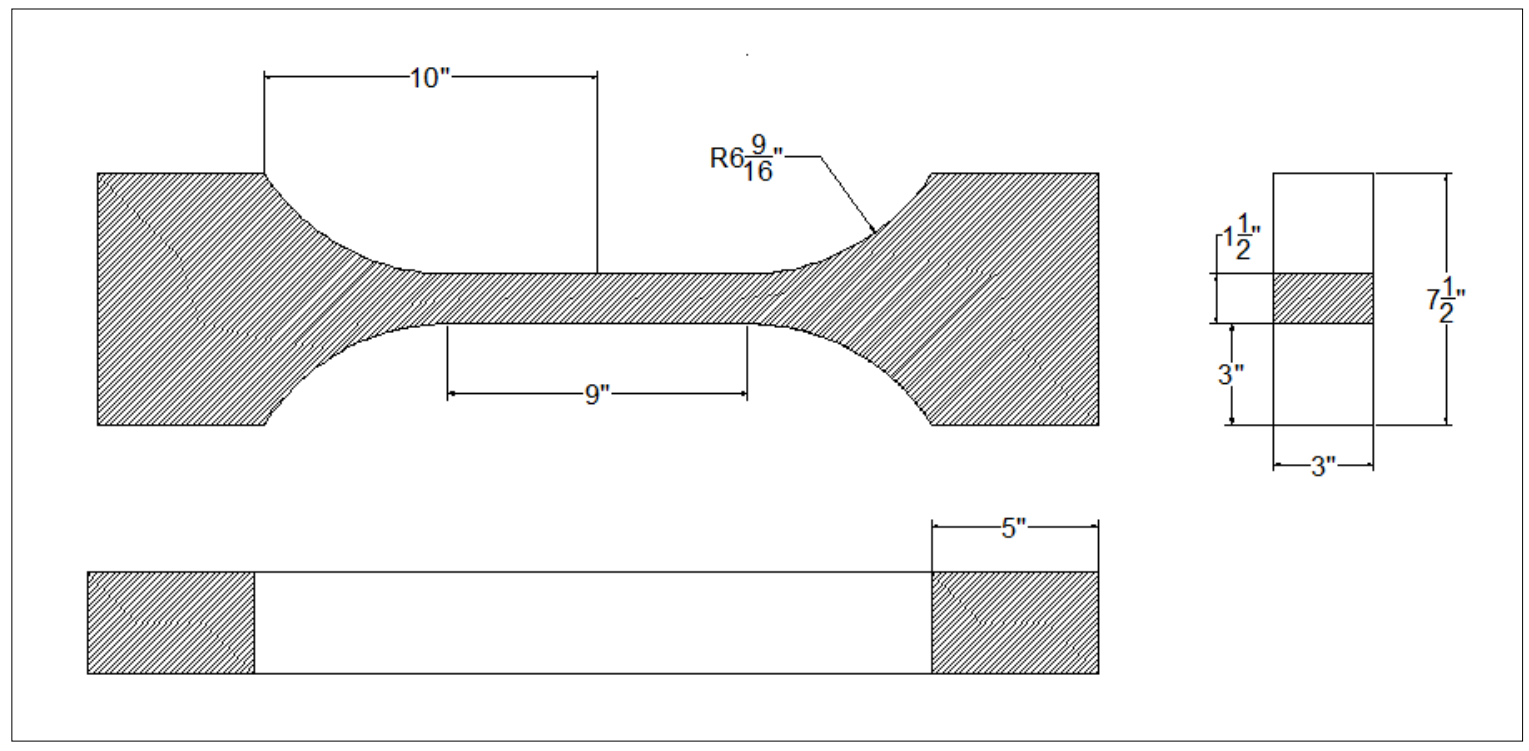

Figure 40. Dog-bone specimen for tensile strength testing.

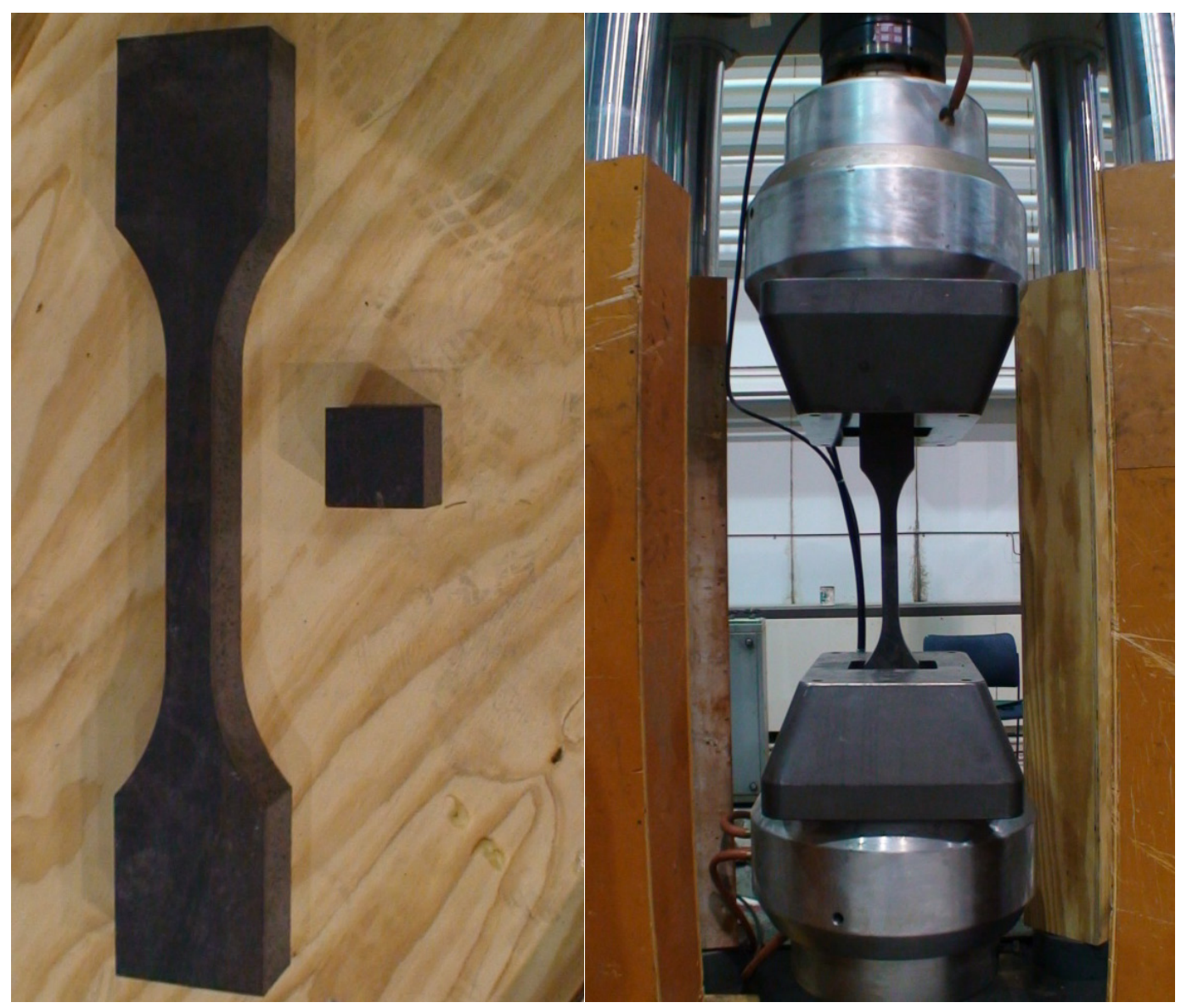

Figure 41. Dog bone mounted in MTS million-pound machine. 
Figure 42. Modes of failure for dog-bone specimens.

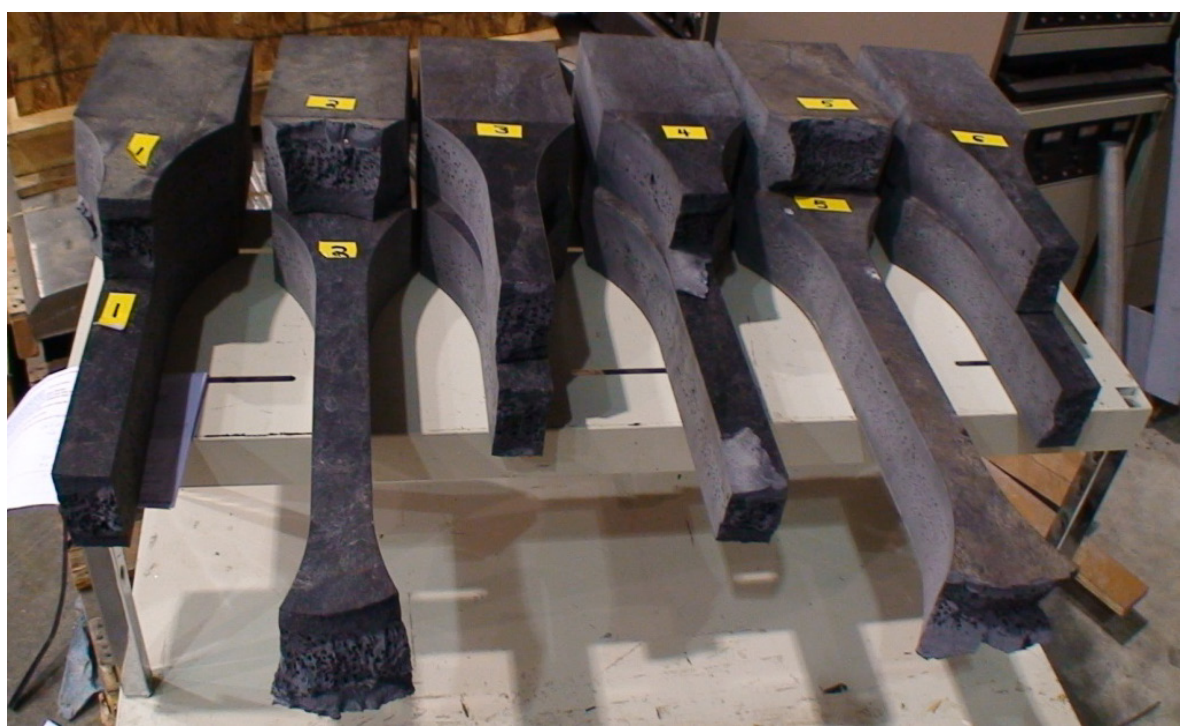

Tension test results are summarized in Table 25, with "bad test" failures shaded in gray. The average tensile strength is 2,059 psi, based on specimens \#1, \#3, \#4, and \#6. An extensometer was used to measure the strain at peak strength of specimens \#3 and \#4, which were found to be 0.0164 and 0.0113 , respectively. Strains reported for specimens \#1 and \#6 were measured by the MTS machine. These values are not as accurate as those measured directly with the extensometer. Stress-strain curves for specimens \#3 and \#4 are shown in Figure 43. From these measurements, the tensile modulus of elasticity can be estimated to be about $300 \mathrm{ksi}$.

Table 25. Summary of tension tests on dog-bone specimens from the original batch.

\begin{tabular}{|l|l|l|l|l|l|l|l|}
\hline $\begin{array}{l}\text { Specimen } \\
\text { No. }\end{array}$ & $\begin{array}{l}\text { Width } \\
\text { (in.) }\end{array}$ & $\begin{array}{l}\text { Depth } \\
\text { (in.) }\end{array}$ & $\begin{array}{l}\text { Area } \\
\text { (in. }{ }^{2}\end{array}$ & $\begin{array}{l}\text { Load } \\
\text { (lb) }\end{array}$ & $\begin{array}{l}\text { Stress } \\
\text { (psi) }\end{array}$ & $\begin{array}{l}\text { Strain at } \\
\text { peak } \\
\text { in./in. }\end{array}$ & Remarks \\
\hline 1 & 1.497 & 2.865 & 4.289 & 9,898 & 2,308 & 0.2884 & - \\
\hline 2 & 1.500 & 2.872 & 4.308 & 7,925 & 1,840 & 0.1741 & Bad test failed near the grip \\
\hline 3 & 1.494 & 2.610 & 3.899 & 8,427 & 2,161 & 0.0164 & - \\
\hline 4 & 1.496 & 2.671 & 3.996 & 8,563 & 2,143 & 0.0113 & - \\
\hline 5 & 1.499 & 2.851 & 4.274 & 5,986 & 1,401 & 0.0055 & Bad test failure near the grip \\
\hline 6 & 1.504 & 2.604 & 3.916 & 9,798 & 2,502 & 0.2524 & - \\
\hline
\end{tabular}


Figure 43. Stress-strain curves for selected specimens.
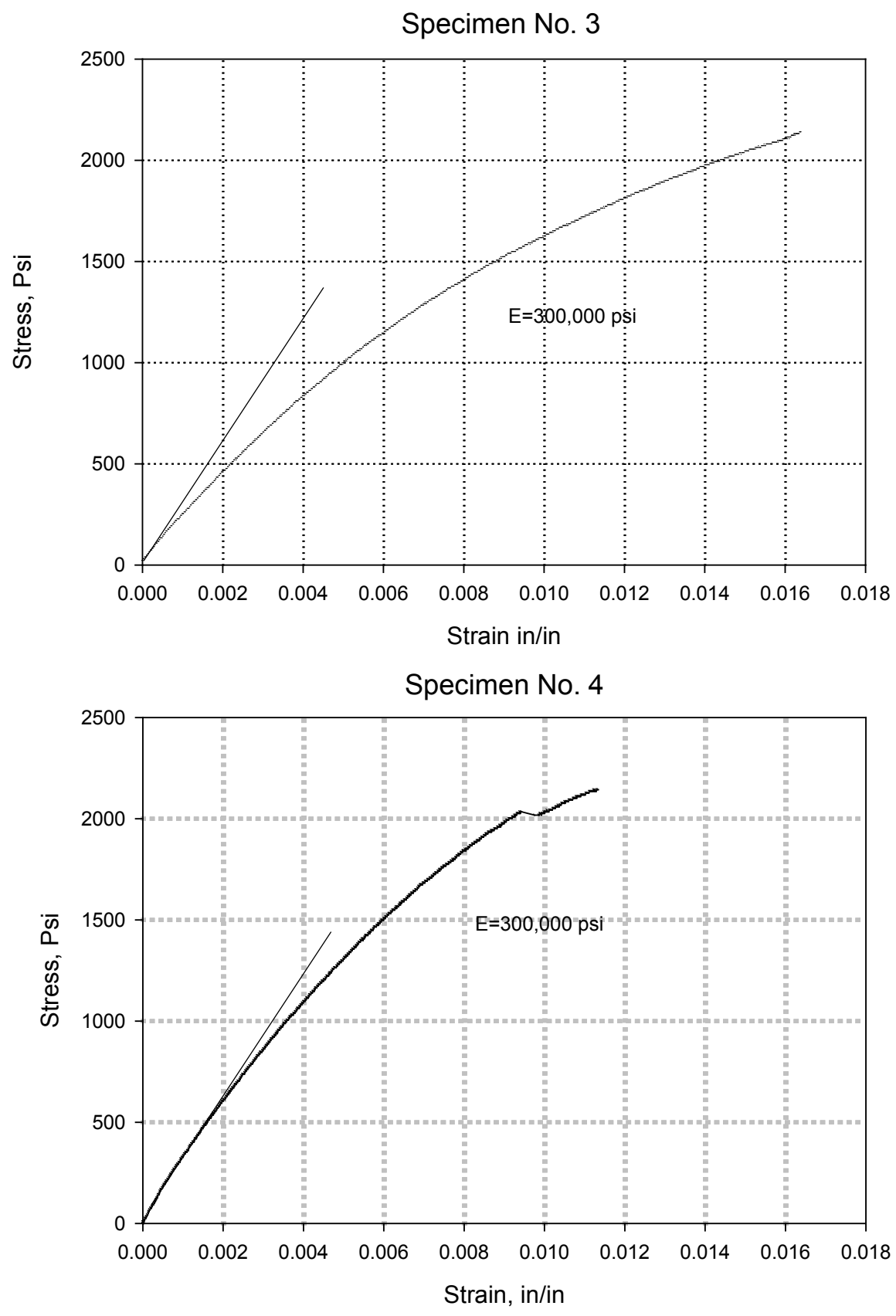


\subsection{Measured density}

To determine the density of the original thermoplastic material, cube specimens were cut from a beam, similar to the beams tested later in this report. The results of the density calculations are shown in Table 26.

Table 26. Density calculation of original thermoplastic material.

\begin{tabular}{|l|l|l|l|l|l|l|l|}
\hline $\begin{array}{l}\text { Specimen } \\
\text { No. }\end{array}$ & $\begin{array}{l}\text { Width } \\
\text { (in.) }\end{array}$ & $\begin{array}{l}\text { Depth } \\
\text { (in.) }\end{array}$ & $\begin{array}{l}\text { Height } \\
\text { (in.) }\end{array}$ & $\begin{array}{l}\text { Volume } \\
\text { (in. }{ }^{3}\end{array}$ & $\begin{array}{l}\text { Weight } \\
\text { (g) }\end{array}$ & $\begin{array}{l}\text { Weight } \\
\text { (lb) }\end{array}$ & $\begin{array}{l}\text { Density } \\
\left.\text { (lb/ft }{ }^{3}\right)\end{array}$ \\
\hline 5 & 3.00 & 3.00 & 2.84 & 25.6 & 388.70 & 0.86 & 57.9 \\
\hline 6 & 2.85 & 2.96 & 2.99 & 25.2 & 401.70 & 0.89 & 60.7 \\
\hline 7 & 3.00 & 3.00 & 2.85 & 25.7 & 378.90 & 0.84 & 56.3 \\
\hline 8 & 2.98 & 2.84 & 2.96 & 25.1 & 418.90 & 0.92 & 63.7 \\
\hline \multicolumn{7}{|l|}{ Average density } \\
\hline
\end{tabular}

\subsection{Compressive testing of specimens from improved batch}

Specimens were cut from a thermoplastic beam that was similar to the beams that were tested later in this project. Each specimen was extracted from either the flange or the web, at the extreme or central fibers. With samples from various locations within the cross section, compressive test results were used to identify the modular compressive strength with the specimen layers loaded, in series or in parallel, at each location. The results of the compressive test are recorded below in Table 27.

Table 27. Summary of compressive tests on cube-shaped specimens from the improved batch of thermoplastic material.

\begin{tabular}{|l|l|l|l|l|l|l|l|}
\hline $\begin{array}{l}\text { Specimen } \\
\text { No. }\end{array}$ & $\begin{array}{l}\text { Orientation of } \\
\text { Loading }\end{array}$ & $\begin{array}{l}\text { Width } \\
\text { (in.) }\end{array}$ & $\begin{array}{l}\text { Depth } \\
\text { (in.) }\end{array}$ & $\begin{array}{l}\text { Height } \\
\text { (in.) }\end{array}$ & $\begin{array}{l}\text { Area } \\
\text { (in }{ }^{2}\end{array}$ & $\begin{array}{l}\text { Load } \\
\text { (lb) }\end{array}$ & $\begin{array}{l}\text { Stress } \\
\text { (psi) }\end{array}$ \\
\hline 1 & Layers in series & 3.003 & 3.008 & 2.926 & 9.033 & 34,490 & 3,818 \\
\hline 4 & Layers in parallel & 3.022 & 3.011 & 3.004 & 9.099 & 47,910 & 5,265 \\
\hline 5 & Layers in series & 3.006 & 3.005 & 2.877 & 9.033 & 43,550 & 4,821 \\
\hline 6 & Layers in parallel & 2.881 & 3.011 & 3.005 & 8.675 & 37,120 & 4,279 \\
\hline \multicolumn{7}{|l|}{ Average stress }
\end{tabular}

Eight specimens were cut from a thermoplastic beam from the improved batch that was similar to those which were tested in flexure later in this project (Figure 44). The specimens were machine cut per ASTM D638-10, "Standard Test method for Tensile Properties of Plastic." All tension specimens were loaded at 0.1 in per minute with layers in parallel. 
Figure 44. Dog-bone tensile specimens, improved batch.

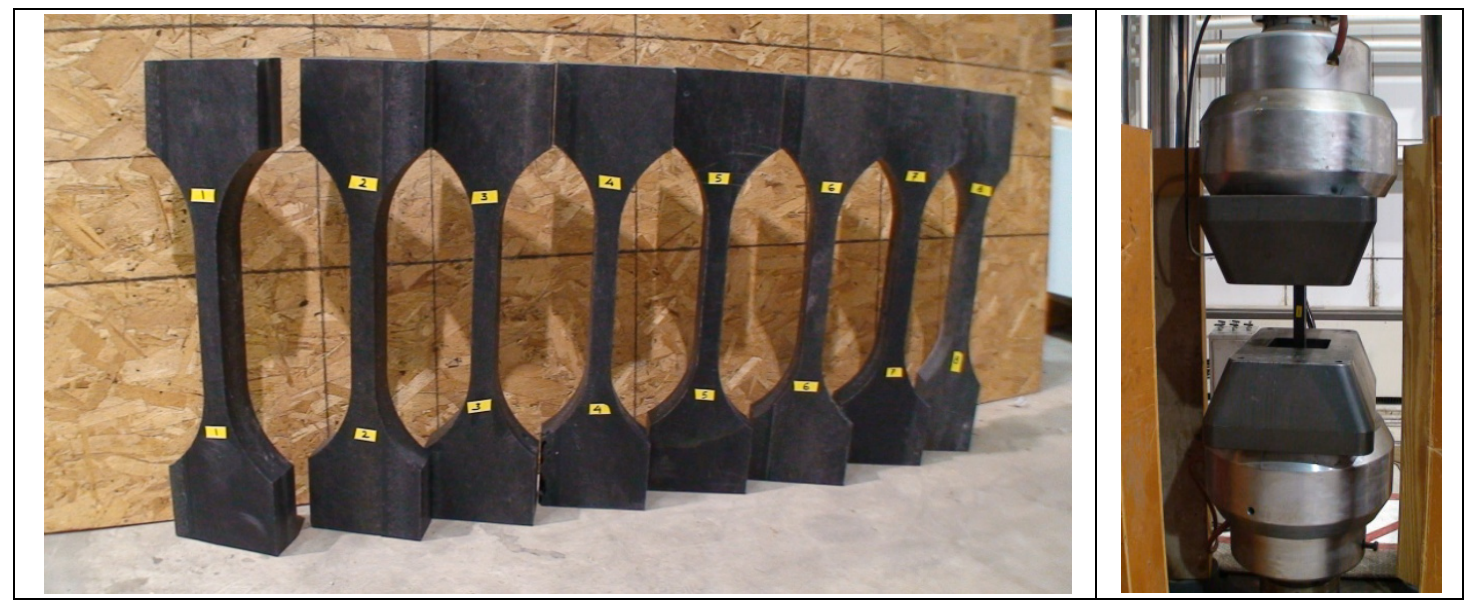

Tension test results are summarized in Table 28, with "bad test" failures shaded in gray. The average tensile strength is 2,304 psi, based on specimens \#3- \#7.

Table 28. Mechanical properties of dog-bone tensile specimens, from improved batch of thermoplastic material.

\begin{tabular}{|l|l|l|l|l|l|l|l|}
\hline $\begin{array}{l}\text { Specimen } \\
\text { No. }\end{array}$ & $\begin{array}{l}\text { Width } \\
\text { (in.) }\end{array}$ & $\begin{array}{l}\text { Depth } \\
\text { (in.) }\end{array}$ & $\begin{array}{l}\text { Area } \\
\text { (in }{ }^{2}\end{array}$ & $\begin{array}{l}\text { Load } \\
\text { (lb) }\end{array}$ & $\begin{array}{l}\text { Stress } \\
\text { (psi) }\end{array}$ & $\begin{array}{l}\text { Void } \\
\text { Area }\end{array}$ & Remarks \\
\hline 1 & 1.520 & 2.920 & 4.438 & 11,135 & 2,509 & & $\begin{array}{l}\text { Bad test, failed near the } \\
\text { grip }\end{array}$ \\
\hline 2 & 1.520 & 2.890 & 4.393 & 11,135 & 2,535 & & $\begin{array}{l}\text { Bad test, failed near the } \\
\text { grip }\end{array}$ \\
\hline 3 & 1.507 & 2.870 & 4.325 & 9,864 & 2,281 & & Load rate $=0.1$ inch/min \\
\hline 4 & 1.514 & 2.900 & 3.744 & 8,894 & 2,376 & 0.6468 & Rate $=0.1$ inch/min \\
\hline 5 & 1.509 & 2.856 & 4.108 & 9,463 & 2,304 & 0.202 & Rate $=0.1$ inch/min \\
\hline 6 & 1.510 & 2.903 & 3.798 & 10,132 & 2,668 & 0.586 & Rate $=1.0$ inch/min \\
\hline 7 & 1.510 & 2.860 & 3.884 & 7,356 & 1,894 & 0.4344 & Rate $=0.01$ inch/min \\
\hline 8 & 1.495 & 2.826 & 4.225 & 8,326 & 1,971 & & $\begin{array}{l}\text { Bad test, failed near the } \\
\text { grip }\end{array}$ \\
\hline \multicolumn{7}{|l|}{ Average stress } \\
\hline
\end{tabular}

The density of the improved thermoplastic material was calculated from cube specimens that were cut from an improved batch beam, similar to the beams tested later in this report. The results of the density calculations are shown in Table 29. 
Table 29. Density calculation of improved thermoplastic material.

\begin{tabular}{|l|l|l|l|l|l|l|l|l|}
\hline $\begin{array}{l}\text { Specimen } \\
\text { No. }\end{array}$ & $\begin{array}{l}\text { Orientation of } \\
\text { Loading }\end{array}$ & $\begin{array}{l}\text { Width } \\
\text { (in.) }\end{array}$ & $\begin{array}{l}\text { Depth } \\
\text { (in.) }\end{array}$ & $\begin{array}{l}\text { Height } \\
\text { (in.) }\end{array}$ & $\begin{array}{l}\text { Volume } \\
\left(\text { (n }^{3}\right)\end{array}$ & $\begin{array}{l}\text { Weight } \\
\text { (g) }\end{array}$ & $\begin{array}{l}\text { Weight } \\
\text { (lb) }\end{array}$ & $\begin{array}{l}\text { Density } \\
\left(\mathrm{lb}_{\mathrm{ft}} \text { ) }\right.\end{array}$ \\
\hline 1 & $\begin{array}{l}\text { Perpendicular } \\
\text { to the face }\end{array}$ & 3.00 & 3.01 & 2.93 & 26.43 & 421.59 & 0.93 & 60.77 \\
\hline 2 & $\begin{array}{l}\text { Parallel to the } \\
\text { face }\end{array}$ & 3.01 & 3.01 & 3.01 & 27.23 & 421.95 & 0.93 & 59.02 \\
\hline 3 & $\begin{array}{l}\text { Perpendicular } \\
\text { to the face }\end{array}$ & 3.01 & 3.01 & 2.88 & 26.04 & 379.55 & 0.84 & 55.53 \\
\hline 4 & $\begin{array}{l}\text { Parallel to the } \\
\text { face }\end{array}$ & 3.02 & 3.01 & 3.00 & 27.33 & 427.45 & 0.94 & 59.57 \\
\hline 5 & $\begin{array}{l}\text { Perpendicular } \\
\text { to the face }\end{array}$ & 3.01 & 3.01 & 2.88 & 25.99 & 383.05 & 0.84 & 56.15 \\
\hline 6 & $\begin{array}{l}\text { Parallel to the } \\
\text { face }\end{array}$ & 2.88 & 3.01 & 3.01 & 26.07 & 382.98 & 0.84 & 55.97 \\
\hline Average density
\end{tabular}




\section{Test Setup}

\subsection{Introduction}

In total, five thermoplastic beams were tested. The test beams consisted of two configurations. In the first configuration, three of the five tested beams were a symmetric I-shape, formed when two asymmetric T-shaped sections were bolted web-to-web (Figure 45, left). For the second configuration, two of the test beams consisted of two I-shaped sections that were bolted together with threaded rods (using four asymmetric T-shapes in total) to form a double I-beam (i.e., II-beam), as shown in Figure 45, right. The nominal dimensions of the beam cross sections are shown in Figure 46.

Figure 45. Two T-shaped sections bolted together to form an I-shaped section (left); two I-beams bolted together to form an II-beam (right).
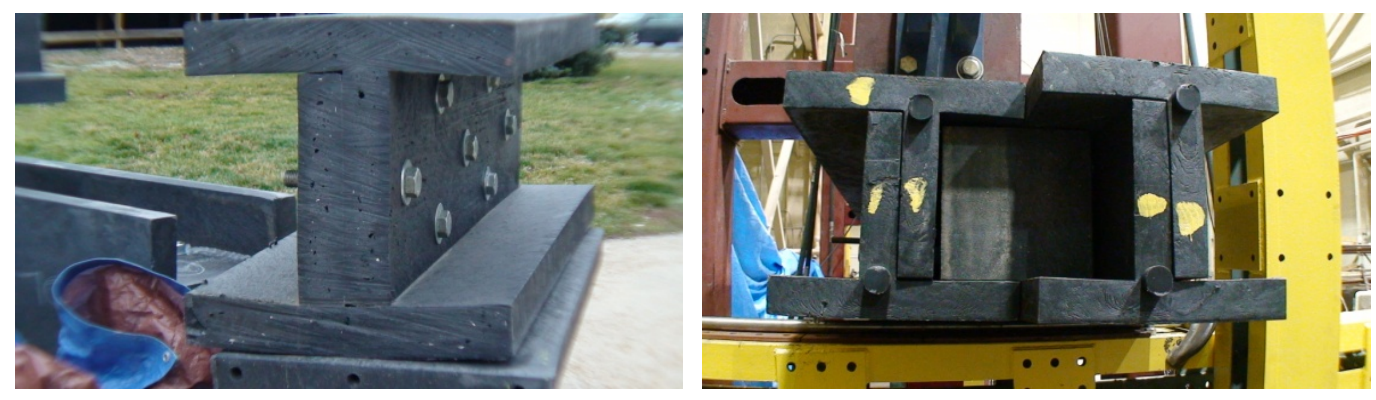

The manufacturer provided two batches of materials, and each was used in testing. One is referred to as the "original batch" and the other is the "improved batch." In providing the improved batch, manufacturer's representatives revealed there had been a change to the original specimen's composition that they believed enhanced the strength and the quality of the material.

As stated, the series of tests conducted covered both material batches and both configurations of beams (I and II) sections. The II-beams were stiffened with 12 in. deep thermoplastic sections inserted between two adjacent beams. See Figure 47 for the shape of the stiffener section used.

Different loading rates were used during testing to determine the effect of loads on the structural behavior of the beams. Of the five tests conducted, there were two single-web (I) beam and one double-web (II) beam of the 
original batch, and one single-web beam and one double-web beam of improved batch of thermoplastic materials.

Figure 46. Cross-section of beam configurations, showing nominal dimensions.

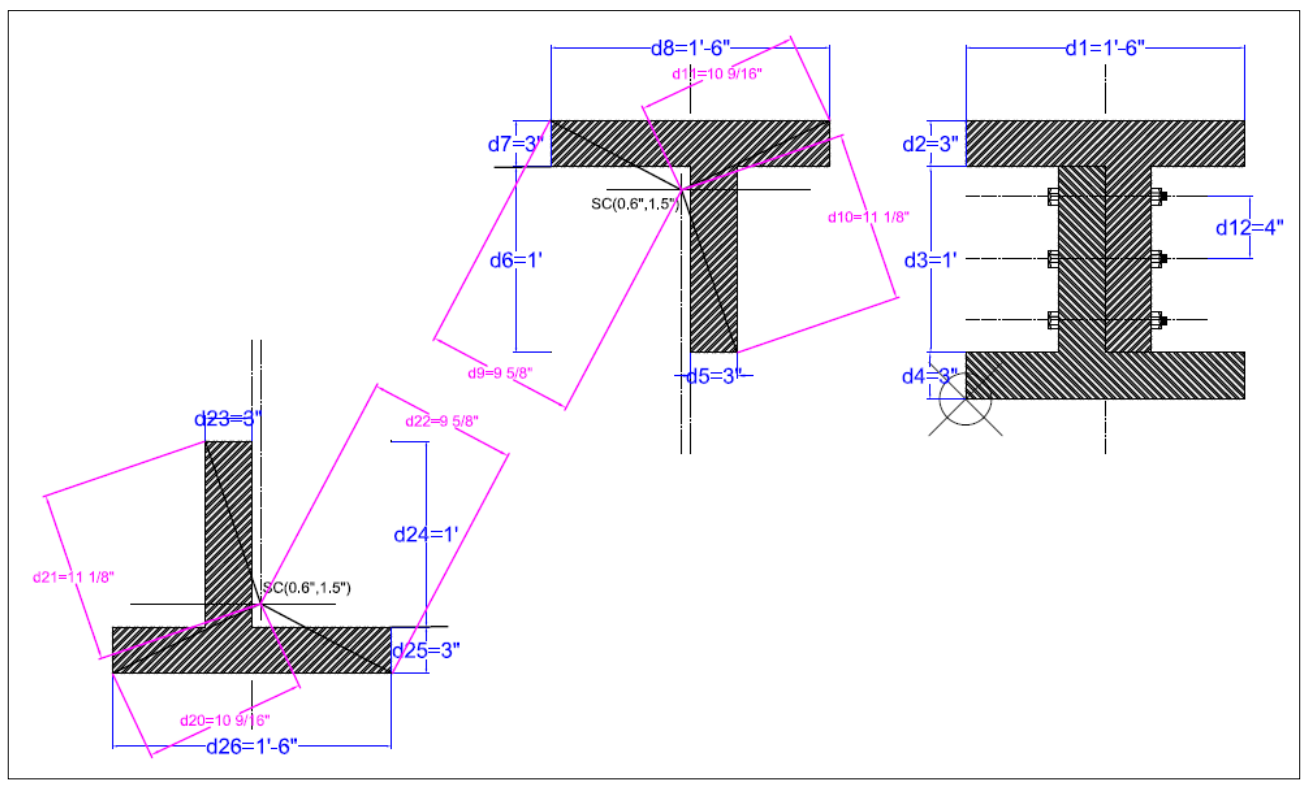

Figure 47. A stiffener cut from I-section of 12 in.-deep beam.

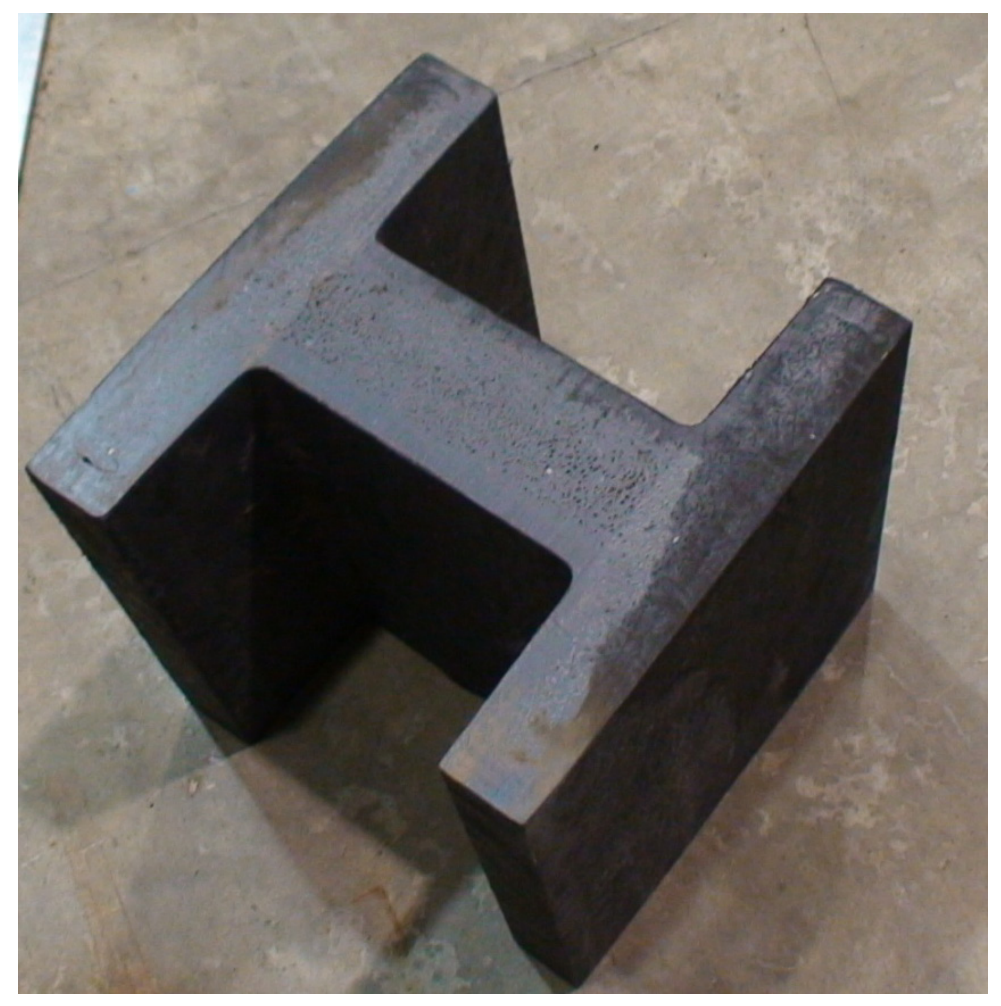

The series of tests studied the structural behavior of these selected beam configurations and materials, using the matrix given in Table 30. 
Table 30. Test matrix.

\begin{tabular}{|c|c|c|c|c|}
\hline Test No. & Section & Batch & Run & $\begin{array}{l}\text { Loading Rate (in. } \\
\text { per minute) }\end{array}$ \\
\hline 1 & 1 & Original & 1 & 0.83 \\
\hline 2 & 1 & Improved & $\begin{array}{l}1 \\
2 \\
3\end{array}$ & $\begin{array}{l}0.83 \\
0.83 \\
0.83\end{array}$ \\
\hline 3 & I & Original & $\begin{array}{l}1 \\
2\end{array}$ & $\begin{array}{l}0.83 \times 10 \\
0.83 \times 10\end{array}$ \\
\hline 4 & II & Original & $\begin{array}{l}1 \\
2 \\
3\end{array}$ & $\begin{array}{l}0.83 \\
0.83 \times 10 \\
0.83 \times 20\end{array}$ \\
\hline 5 & II & Improved & $\begin{array}{l}1 \\
2 \text { (failure) }\end{array}$ & $\begin{array}{l}0.83 \\
0.83\end{array}$ \\
\hline
\end{tabular}

\subsection{Loading rate methodology}

The thermoplastic beam was mounted on a steel frame. At each end, the beam was supported by a 1.75 in. diameter steel roller. The span between each support was $22 \mathrm{ft}-6$ in., as shown in Figure 48. The rollers were laid across a steel beam that was bolted to a steel column at each end. The beam underwent monotonic loading by vertical loads at $\mathrm{L} / 3$ and $2 \mathrm{~L} / 3$. The specimen was tested in flexure as a beam in flat mode. The load was applied progressively until a strain of 3 in./in. was achieved or until failure of the beam, in accordance with ASTM D6109-10 (Section 10.1.4), which states that the rate of $\mathrm{C} / \mathrm{H}$ motion should be as follows in Equation 16, and the machine should be set as close as possible for a load span of one-third of the support span.

$$
R=\frac{0.185 Z\left(L^{2}\right)}{d}
$$

where:

$$
\begin{aligned}
& \mathrm{R}=\text { rate of } \mathrm{C} / \mathrm{H} \text { motion (in. per minute) } \\
& \mathrm{L}=\text { support span (in.) } \\
& \mathrm{D}=\text { depth of beam (in.) }
\end{aligned}
$$




\section{$\mathrm{Z}=$ prescribed rate of straining of outer fibers (0.01 in./in. per minute)}

From the calculation of Equation 1, a rate of $\mathrm{C} / \mathrm{H}$ motion is determined to be equal to $0.8325 \mathrm{in}$. per minute for a $22.5 \mathrm{ft}$ support span and an $18 \mathrm{in}$. beam depth.

In a similar test in another project (Sheldon 2012), a C/H speed of $0.71 \mathrm{in}$. per minute was used in an ASTM D6109 test of the deckboard samples; the test span for this case was $24 \mathrm{ft}$ and nominal length was 32 in.

Given this $\mathrm{C} / \mathrm{H}$ motion, load cells within the actuators recorded the applied load, while a series of displacement sensors recorded the displacement of the beam in the vertical direction. The actuators used in this project have a capacity of 50 kips and a maximum stroke of 6 in. Sensors were also applied to measure and record the strain at several areas on the beam. Application of these sensors is explained below in section 6.3.

Figure 48. Experiment setup.

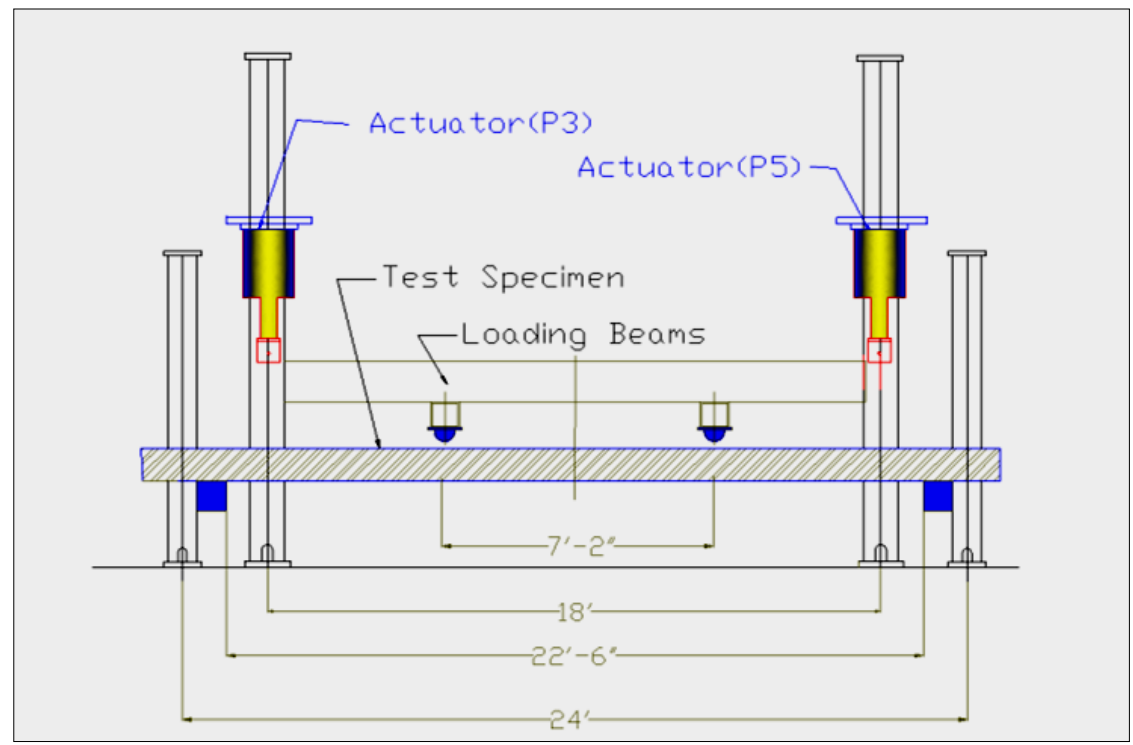

\subsection{Gauge Instrumentation}

To prepare the beam for data acquisition, the surface was thoroughly sanded with an acidic solution at the locations where strain gauges were to be attached. After the surface was neutralized, epoxy was applied over the strain gauge for a thorough bond with the beam, to ensure accurate data was recorded. Wires were soldered to the nodes of each strain gauge, and 
gauges were tested for resistance within the system. Strain gauges were installed at various locations on the extreme fibers along the top and bottom flanges of the beam.

After the beam was set in place within the support structure, data cables were attached from the strain gauge wires to the leads to quantify and record their output. J-hooks were also installed at four locations on the underside of the bottom flange and connected to displacement gauges for monitoring displacement of the beam. The displacement gauges were located similarly to the strain gauges, where the most extreme deformation would occur.

The data collected by the actuators (applied load), strain gauges, and displacement gauges were integral to understanding the behavior of thermoplastic material in beams under progressive loading. The flexural properties determined by these test methods are especially useful for research and development, quality control, acceptance or rejection under specifications, and other purposes (ASTM D6109).

Tests were conducted on beams with two different cross sections. Tests 13 were conducted on single-beam cross sections (I-beams). Tests 4-5 were conducted on double beams (II-beams). Installation locations of strain and displacement gauges are designated according to their placement in the $\mathrm{x}$, $\mathrm{y}$, and $\mathrm{z}$ planes of the beam. Each beam was appropriately designated and can be seen below in Figure 49 and Figure 50. Location descriptions can be found in Table 31 and Table 32. 
Figure 49. Strain and displacement sensor locations for the single beam tests.

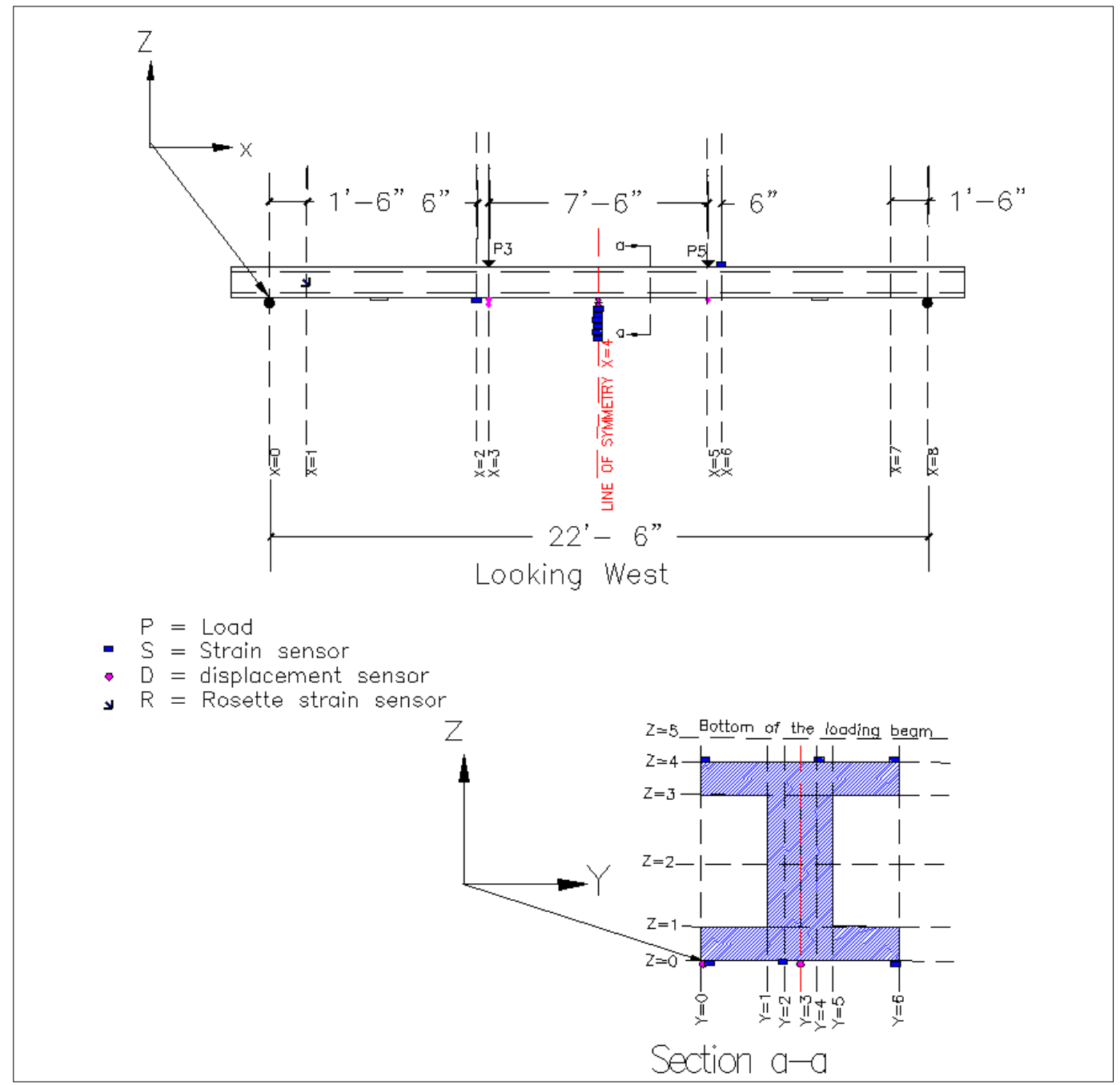

Table 31. List of sensor locations for single I-beam-Tests 1, 2, and 3.

\begin{tabular}{|l|l|l|l|}
\hline Sensor No. & Sensor Type & Name & Location Description \\
\hline 1 & Load & $\mathrm{P}_{3}$ & $3 \mathrm{ft}-9$ in. south of midspan \\
\hline 2 & Load & $\mathrm{P}_{5}$ & $3 \mathrm{ft}-9$ in. north of midspan \\
\hline 3 & Displacement & $\mathrm{D}_{3,3,0}$ & Below the north actuator \\
\hline 4 & Displacement & $\mathrm{D}_{4,0,0}$ & Midspan lower east corner of the bottom flange \\
\hline 5 & Displacement & $\mathrm{D}_{4,3,0}$ & Midspan center of bottom of section \\
\hline 6 & Displacement & $\mathrm{D}_{5,3,0}$ & Below the south actuator \\
\hline 7 & Displacement & $\mathrm{D}_{4,3,5}$ & Midspan of steel loading beam section \\
\hline 8 & Strain & $\mathrm{S}_{2,3,4}$ & Top fiber, 6 in. south of the south actuator \\
\hline 9 & Strain & $\mathrm{S}_{4,0,0}$ & Midspan, bottom east corner \\
\hline
\end{tabular}




\begin{tabular}{|l|l|l|l|}
\hline Sensor No. & Sensor Type & Name & Location Description \\
\hline 10 & Strain & $S_{4,0,4}$ & Midspan, top east corner \\
\hline 11 & Strain & $S_{4,2,0}$ & $\begin{array}{l}\text { Midspan bottom fiber, aligned with east web } \\
\text { centerline }\end{array}$ \\
\hline 12 & Strain & $S_{4,4,4}$ & $\begin{array}{l}\text { Midspan top fiber, aligned with west web } \\
\text { centerline }\end{array}$ \\
\hline 13 & Strain & $S_{4,6,0}$ & Midspan bottom fiber, west corner \\
\hline 14 & Strain & $S_{4,6,4}$ & Midspan top fiber, west corner \\
\hline 15 & Strain & $S_{6,3,0}$ & 6 in. north of the south actuator \\
\hline 16 & Rosette strain & $R(h)_{7,1,2}$ & $\begin{array}{l}18 \text { in. from the south support, midheight of east } \\
\text { surface of the web }\end{array}$ \\
\hline 17 & Rosette strain & $R(d)_{7,1,2}$ & Same \\
\hline 18 & Rosette strain & $R(v)_{7,1,2}$ & Same \\
\hline
\end{tabular}

Figure 50. Strain and displacement sensor locations for the double beam (II-beam) tests.

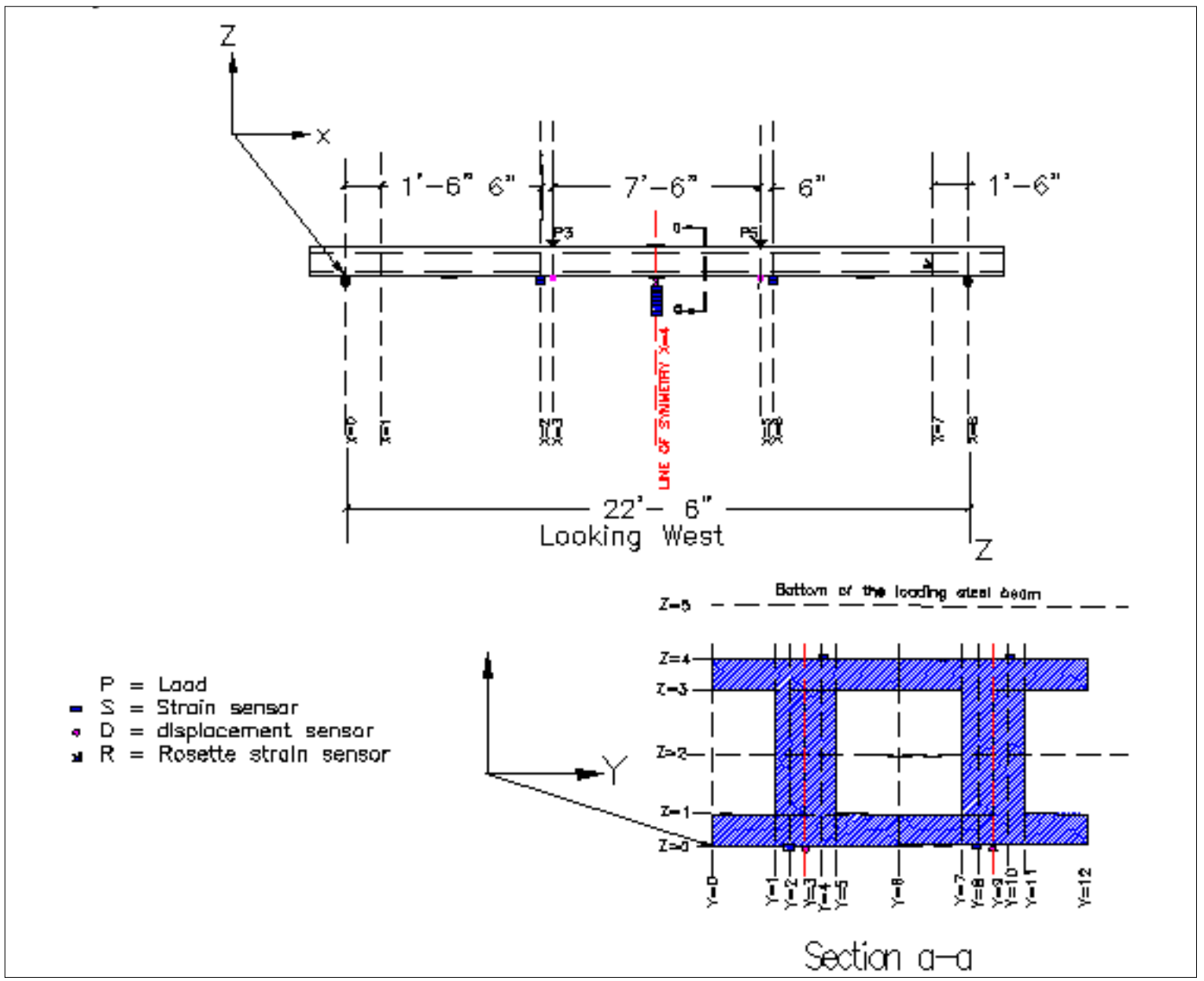


Table 32. List of sensor locations for double II-beams, Tests 4 and 5.

\begin{tabular}{|l|l|l|l|}
\hline Number & Sensor Type & Name & Location Description \\
\hline 1 & Load & $\mathrm{P}_{3}$ & $3 \mathrm{ft}-9$ in. south of midspan \\
\hline 2 & Load & $\mathrm{P}_{5}$ & $3 \mathrm{ft}-9$ in. north of midspan \\
\hline 3 & Displacement & $\mathrm{D}_{3,3,0}$ & Below the north actuator \\
\hline 4 & Displacement & $\mathrm{D}_{4,3,0}$ & Midspan, center of bottom of east section \\
\hline 5 & Displacement & $\mathrm{D}_{4,9,0}$ & Midspan, center of bottom of west section \\
\hline 6 & Displacement & $\mathrm{D}_{5,3,0}$ & Below the south actuator \\
\hline 7 & Displacement & $\mathrm{D}_{4,3,5}$ & Midspan of steel loading beam \\
\hline 8 & Strain & $\mathrm{S}_{2,3,0}$ & 6 in. south of the south actuator \\
\hline 9 & Strain & $\mathrm{S}_{2,9,4}$ & Center of top fiber of west section, 6 in. south of the south \\
\hline 10 & Strain & $\mathrm{S}_{4,3,0}$ & Midspan, center of bottom fiber of east section \\
\hline 11 & Strain & $\mathrm{S}_{4,3,4}$ & Midspan, center of top fiber of east section \\
\hline 12 & Strain & $\mathrm{S}_{4,9,0}$ & Midspan, center of bottom fiber of west section \\
\hline 13 & Strain & $\mathrm{S}_{4,9,4}$ & Midspan, center of top fiber of west section \\
\hline 14 & Strain & $\mathrm{S}_{6,6,4}$ & 6 in. north of the south actuator, between I-sections \\
\hline 15 & Strain & $\mathrm{S}_{6,9,0}$ & 6 in. north of the south actuator, bottom of west section \\
\hline 16 & Rosette strain & $\left.\mathrm{R}_{(\mathrm{h}}\right)_{7,1,2}$ & 18 in. from south support, midheight of web's east surface \\
\hline 17 & Rosette strain & $\left.\mathrm{R}_{(\mathrm{d})}\right)_{7,1,2}$ & Same \\
\hline 18 & Rosette strain & $\left.\mathrm{R}_{(\mathrm{v}}\right)_{7,1,2}$ & Same \\
\hline
\end{tabular}




\section{Test \#1 - Single Beam, Original Batch}

This test was carried out on a $22 \mathrm{ft}-6 \mathrm{in}$. single I-beam from the original batch of thermoplastic material. The section consisted of two nonsymmetrical T-beams bolted web-to-web to form a symmetrical I-shaped section.

The beam was loaded with two point loads, $\mathrm{P}_{3}$ and $\mathrm{P}_{5}$, at a distance $\mathrm{L} / 3$ from the south and north supports, respectively. To control the failure mechanism of the beam and protect the actuators, the application of actuator loads was displacement-controlled instead of force-controlled. As shown in Figure 51, the measured force time histories in the two actuators were close enough to approximate a 4-point bending test setup. The duration of the experiment was about 350 seconds at an actuator loading rate of 0.8325 in. per minute.

Figure 51. Actuator load versus time.

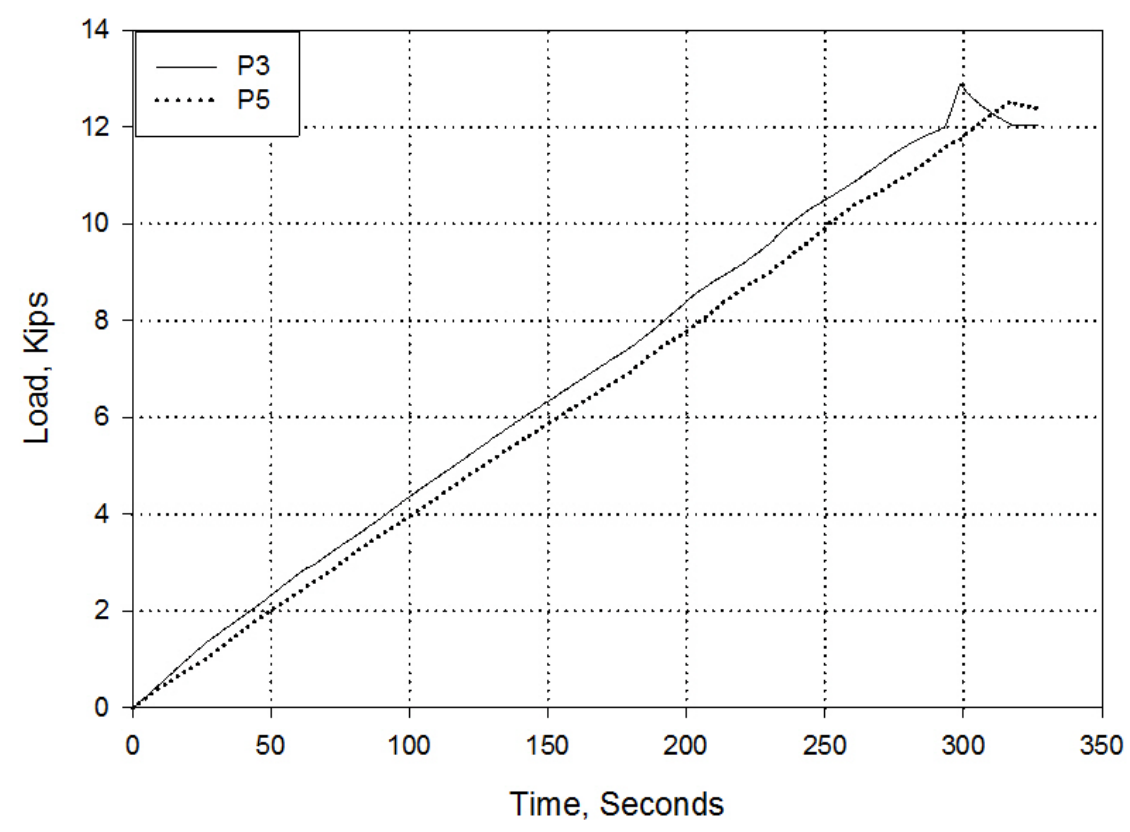

The beam was instrumented with four displacement gauges. Displacement gauge $\mathrm{D}_{33}$ was placed $\mathrm{L} /{ }_{3}$ from the south support (beneath point load $\mathrm{P}_{3}$ ). $\mathrm{D}_{530}$ was located $\mathrm{L} / 3$ from the north support (beneath point load $\mathrm{P}_{5}$ ). The deflections at these two points were close to identical, as expected. Two displacement gauges were installed at midspan (x-location 4). One dis- 
placement gauge, $\mathrm{D}_{430}$, was placed at the center of the bottom flange. Another gauge, $\mathrm{D}_{400}$, was installed at the outside corner of the bottom flange. Figure 52 shows that the deformation measured from $\mathrm{D}_{400}$ and $\mathrm{D}_{430}$ are very close, which means that very little rotation about the $\mathrm{x}$-axis occurred in the beam during loading.

Since the actuators were not directly connected to the specimen, the measured deflection rate of the specimens should be compared to one another. This specimen underwent a midspan deflection rate of about 0.9 in. per minute.

Figure 52. Displacements versus time.

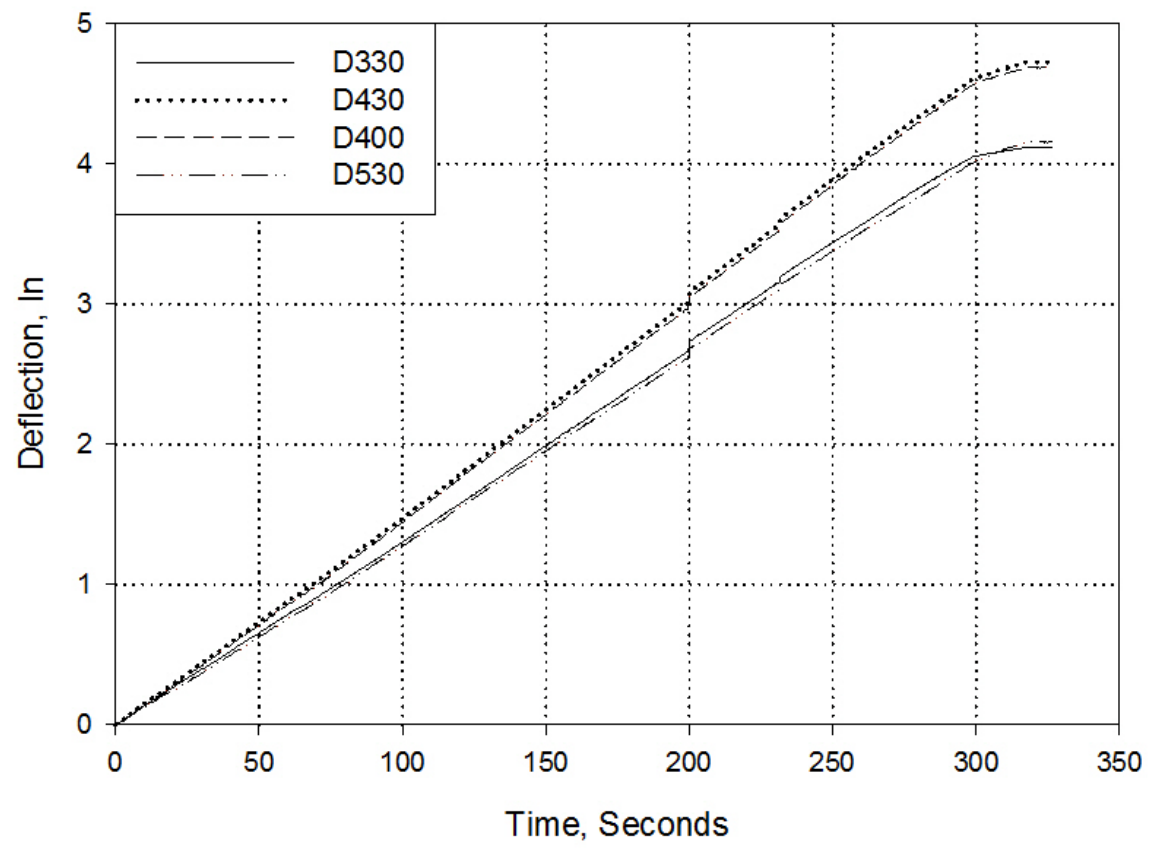

Strain gauge $\mathrm{S}_{630}$ was installed at a section 6 in. (in the $\mathrm{x}$-direction) outside one of the point loads. This section was chosen for its high shear and flexural stresses. The strain curve for the location of $\mathbf{S}_{630}$ is shown in Figure 53. The maximum deflection in the beam was expected at midspan, while the critical section of the beam for flexural strength was expected somewhere near one of the point loads, since the two loads were not exactly identical. 
Figure 53. Strain $\mathrm{S}_{630}$, measured near the actuator.

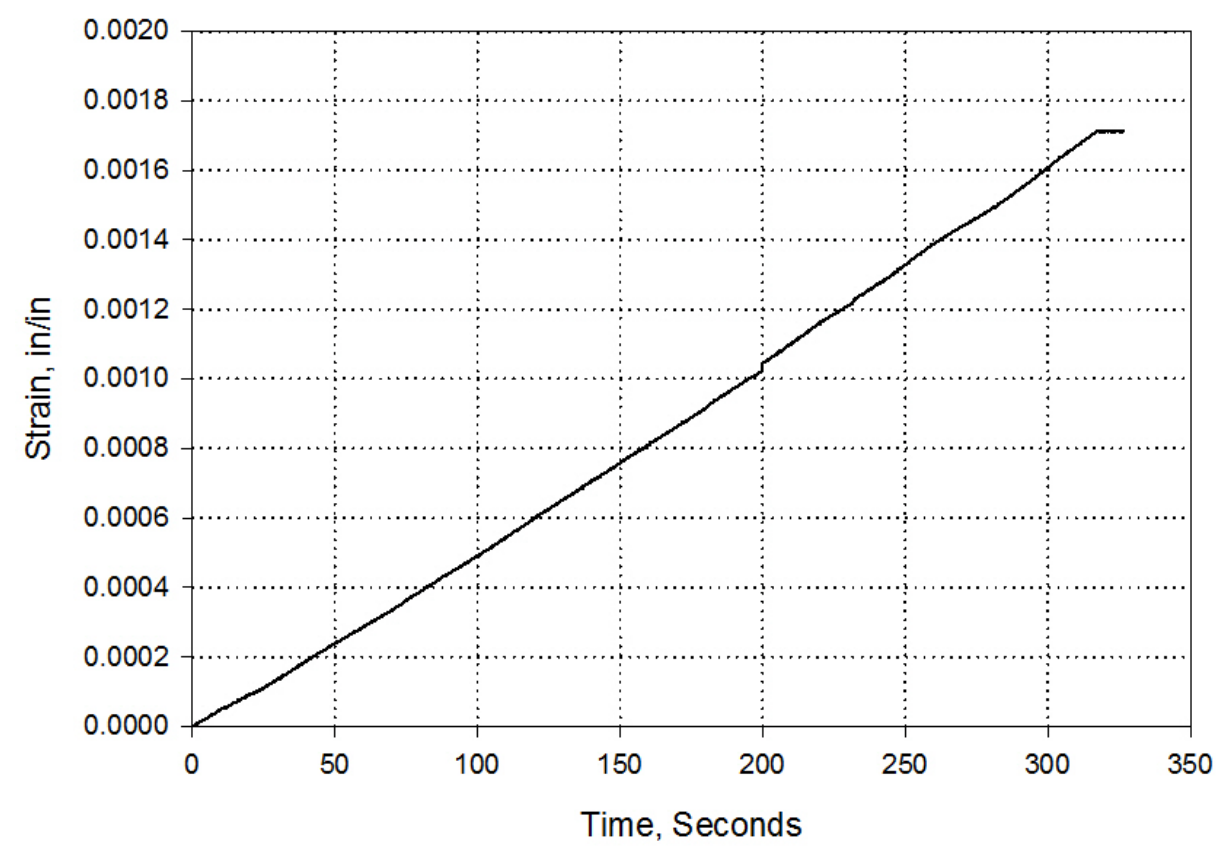

The bottom surface of the beam was instrumented at midspan with three strain gauges: $\mathrm{S}_{400}, \mathrm{~S}_{420}$, and $\mathrm{S}_{460}$. The maximum measured strains of these gauges, as shown in Figure 54, are 0.0017, 0.0018, and 0.0017, respectively. These strain readings are also close to those in Figure 55, which implies that curvature, and therefore moment, is approximately equal at midspan and just outside of the point load $\mathrm{P}_{5}$.

Figure 54. Measured strain at midspan bottom fiber.

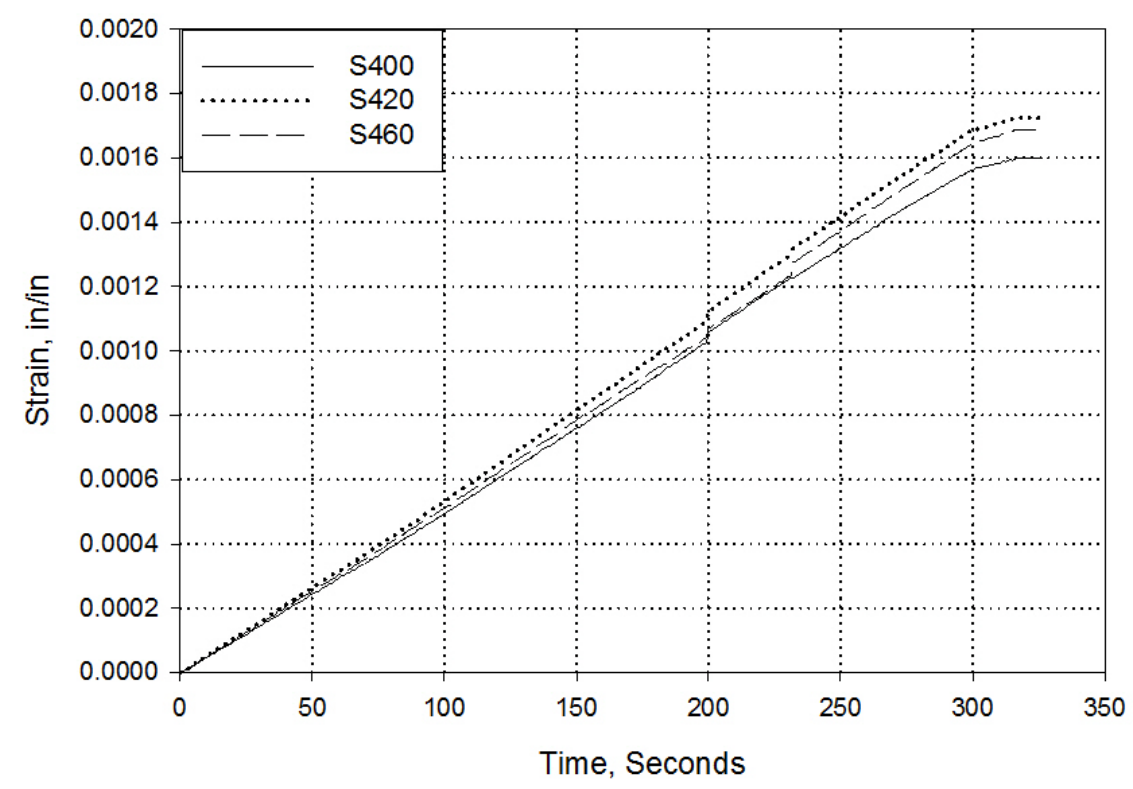


The top surface of the beam was instrumented with three strain gauges: $\mathrm{S}_{404}, \mathrm{~S}_{444}$, and $\mathrm{S}_{464}$. However, $\mathrm{S}_{404}$ did not record useful data. The maximum strains measured with gauges $\mathrm{S}_{444}$ and $\mathrm{S}_{464}$ were about 0.0017 and 0.00155, respectively, as shown in Figure 55. There is some skew between the strains that were measured on top and bottom, which could indicate that the beam flexed about a neutral axis above the section midheight.

Figure 55. Magnitude of measured strains at midspan top fiber.

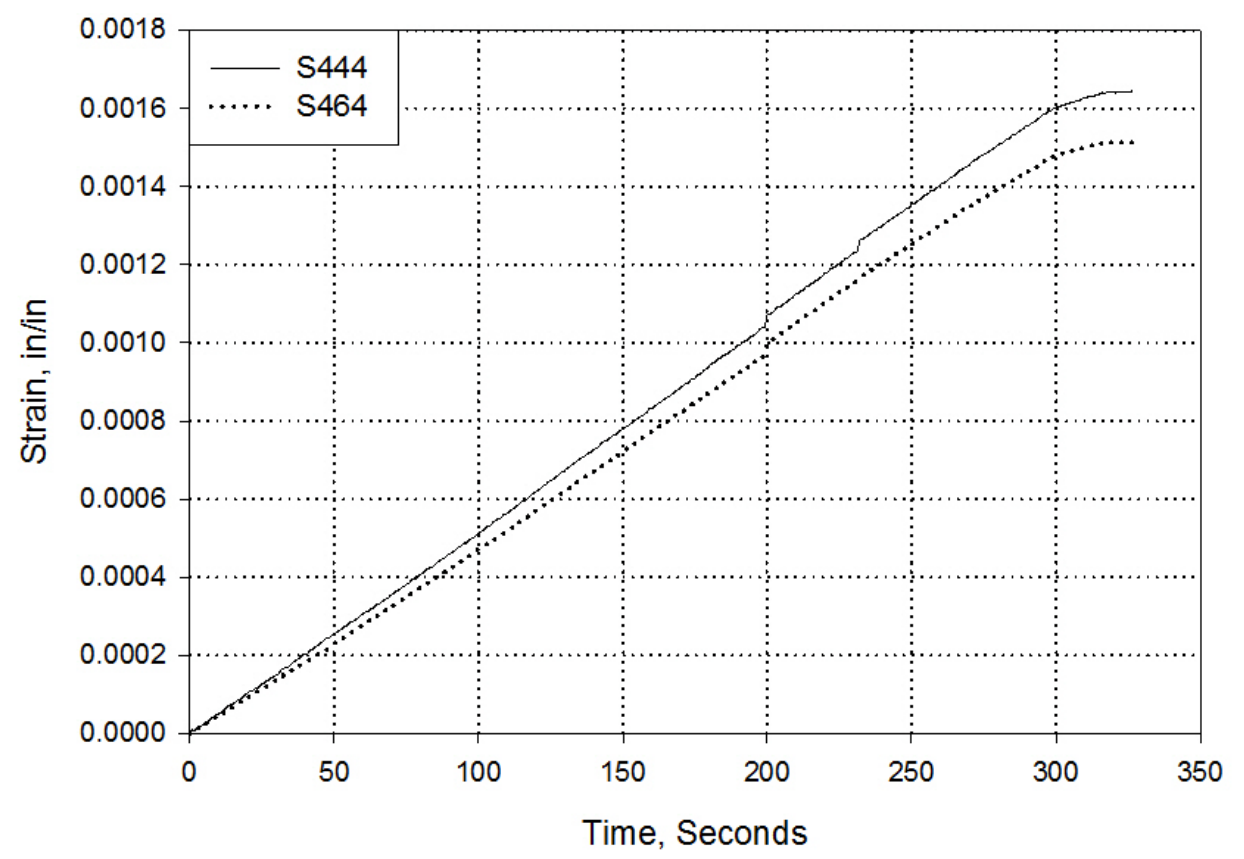

A rosette strain gauge, $R_{712}$, was installed at the section midheight, 18 in. from the north support. This is a location with high shear stress and low flexural stress. The diagonal strain gauge recorded the highest values, as expected, while the flexural-induced horizontal strain was small. The recorded vertical strain was also small. Figure 56 shows the curves of all three gauges in the rosette strain gauge. The maximum strain recorded in the diagonal gauge $\left(\varepsilon_{d}\right)$ was $0.0012 \mathrm{in}$./in., or about two-thirds the recorded maximum flexural value of $0.0018 \mathrm{in}$./in. This shows that, while failure may be dominated by flexure, the beam experiences significant shearing action. 
Figure 56. Magnitude of measured strain from gauge rosette versus time.

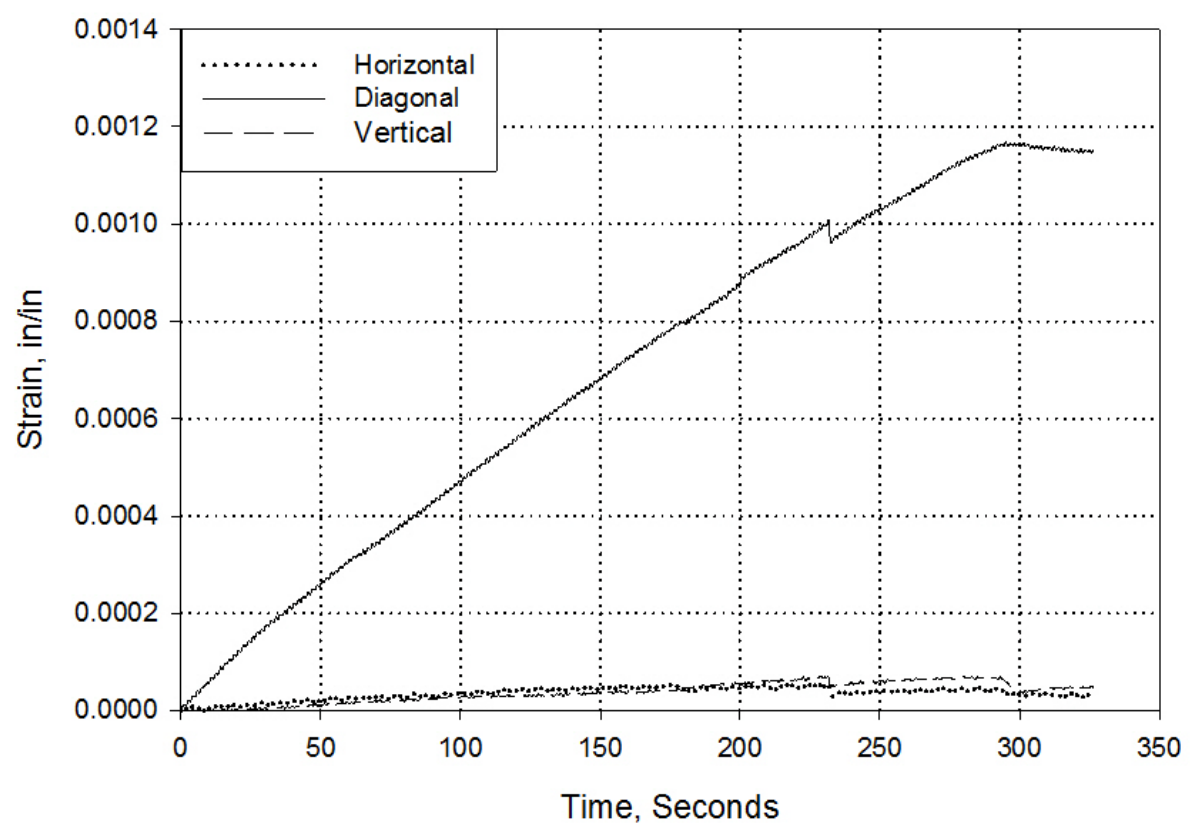

Shear stress can be approximated from the data recorded by the rosette strain gauge that consists of three strain gauges: one horizontal $\left(\varepsilon_{h}\right)$, one vertical $\left(\varepsilon_{v}\right)$ and one at a $45^{\circ}$ diagonal $\left(\varepsilon_{d}\right)$.

$$
\tau=\frac{E}{2(1+v)}\left[2 \varepsilon_{d}-\left(\varepsilon_{h}+\varepsilon_{v}\right)\right]
$$

Where:

$$
\begin{aligned}
& \mathrm{E}=\text { modulus of elasticity } \\
& v=\text { Poisson's ratio }
\end{aligned}
$$

The calculated shear stress-to-point load relationship is shown in Figure 57 , with a maximum shear stress value of $0.357 \mathrm{ksi}$.

In Figure 58, the strains measured with $\mathrm{S}_{400}, \mathrm{~S}_{420}$, and $\mathrm{S}_{460}$ at the midspan bottom fiber are plotted against the corresponding stress, which was approximated from the measured loads and the section properties of the beam. The maximum calculated stress magnitudes at x-positions 4 and 6 are $1.43 \mathrm{ksi}$ and $1.33 \mathrm{ksi}$, respectively. 
Figure 57. Shear stress at $R_{712}$ versus point load $P_{5}$.

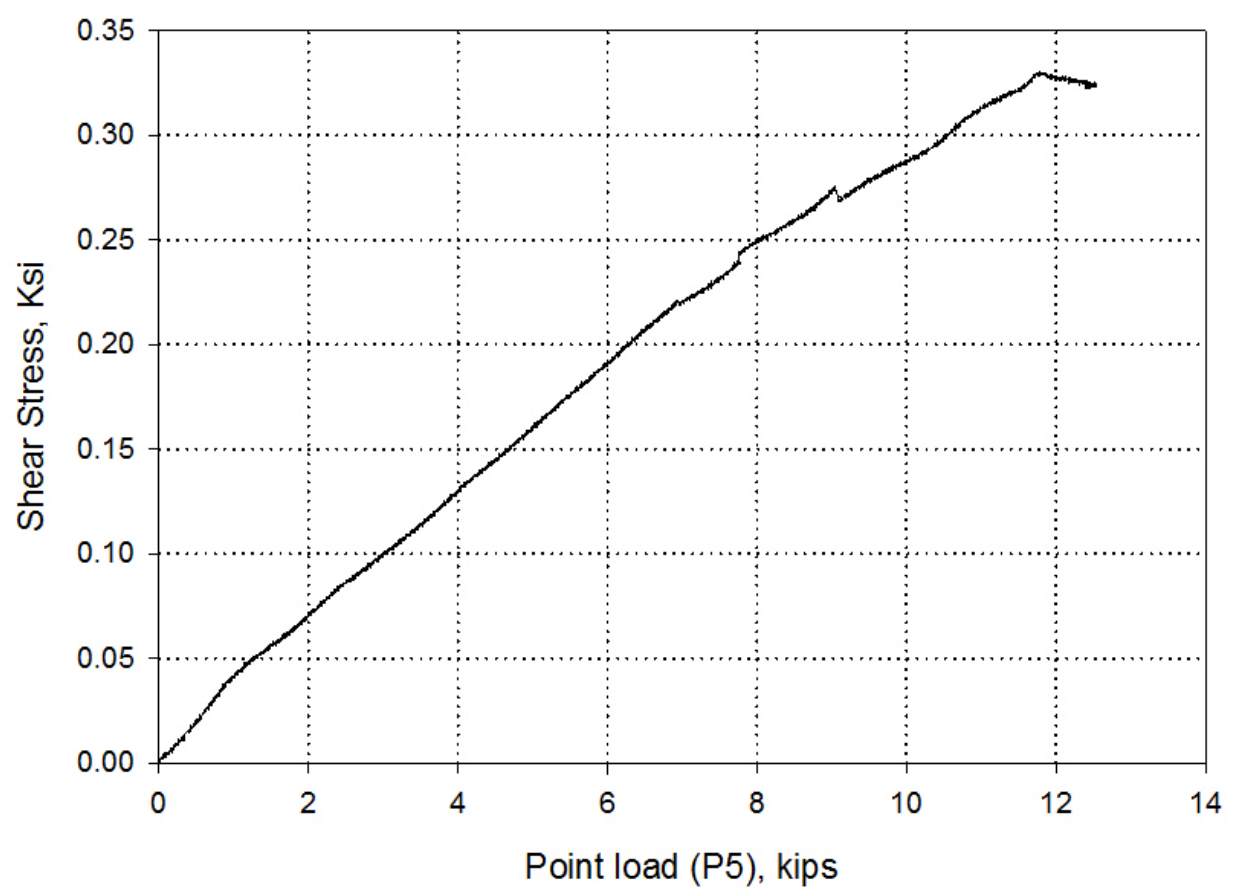

Figure 58. Magnitude of stress-strain curve at midspan bottom fiber.

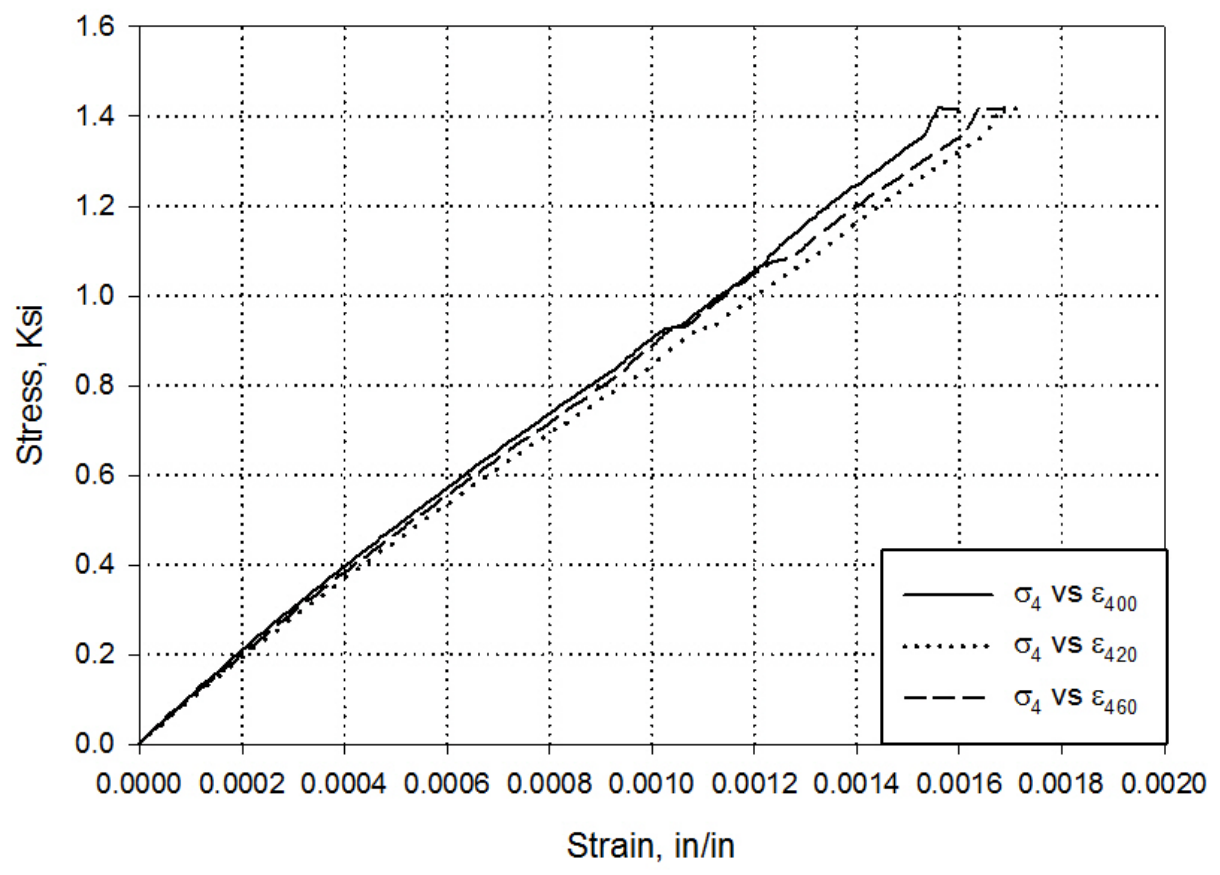

In Figure 59, the strains measured with $\mathrm{S}_{444}$ and $\mathrm{S}_{464}$ at the top fiber at midspan are plotted against the corresponding stress at the bottom fiber, which was calculated in Figure 58. 
Figure 59. Magnitude of stress-strain curve at midspan, top fiber.

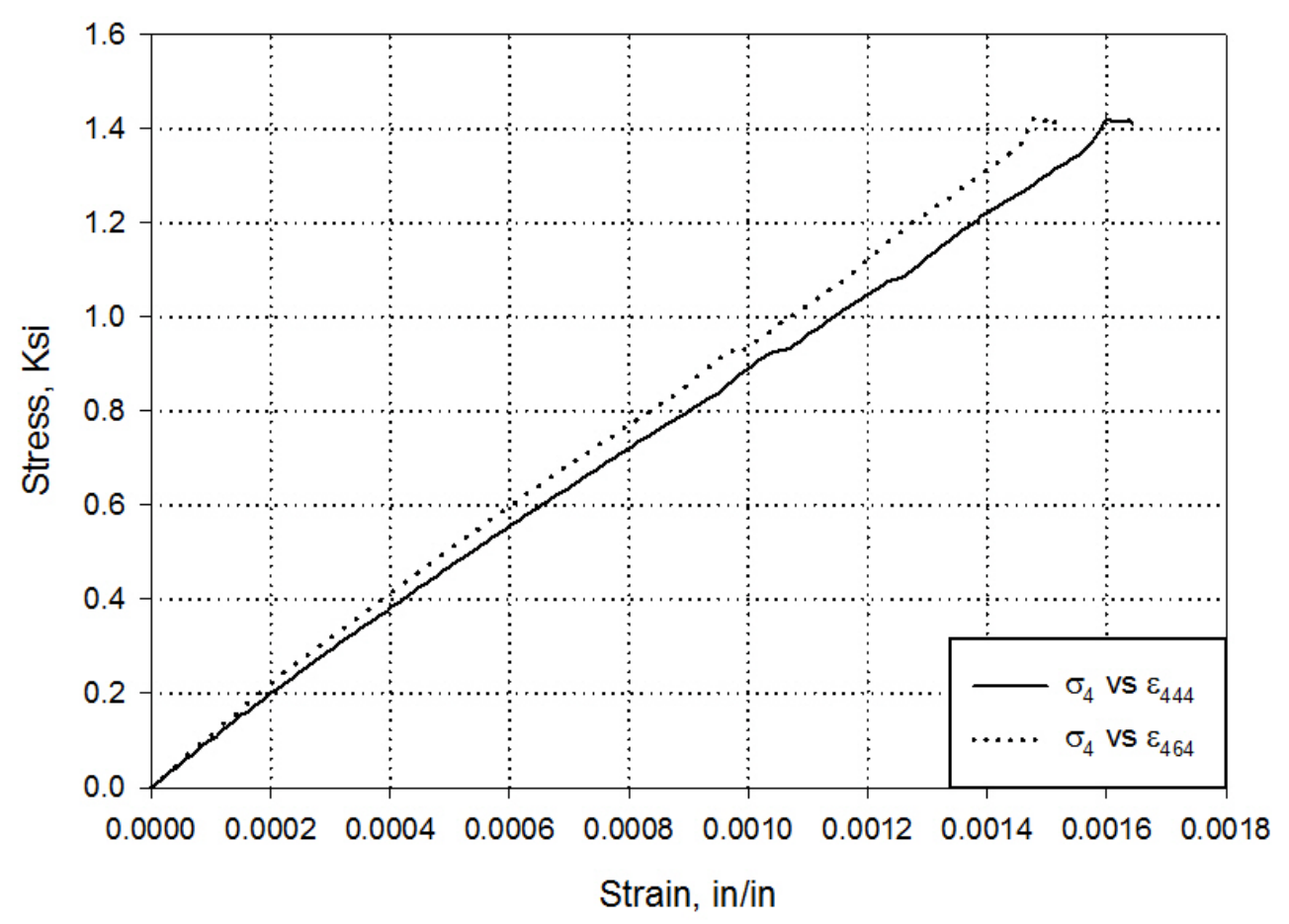

Strain gauge $\mathrm{S}_{630}$ was installed at a section 6 in. (in the $\mathrm{x}$-direction) from the point load. This section was chosen for its high shear and flexural stresses. It is unlike the section located $18 \mathrm{in}$. from the support, which was instrumented with rosette $R_{712}$. That location has a high shear stress and low flexural stress. The stress-strain curve for the location of $\mathrm{S}_{630}$ is shown in Figure 60. 
Figure 60. Calculated stress-strain curve at $\mathrm{S}_{630}$.

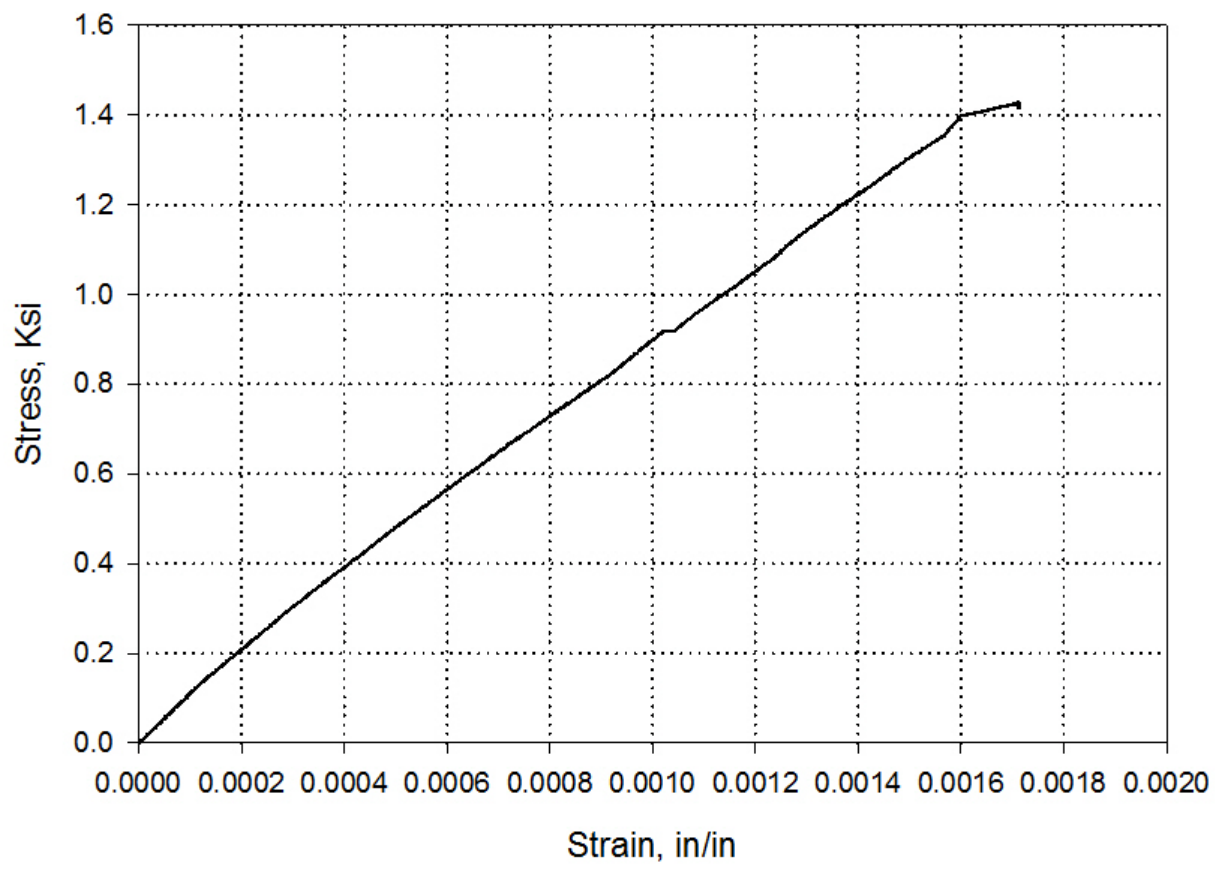




\section{Test \#2 - Single Beam, Improved Batch}

This test was carried out on a $22 \mathrm{ft}-6 \mathrm{in}$. single I-beam from the improved batch of thermoplastic material. The section consisted of two nonsymmetrical T-beams bolted web-to-web to form a symmetric I-shaped section.

The beam was subjected to two point loads, $\mathrm{P}_{3}$ and $\mathrm{P}_{5}$, at a distance $\mathrm{L} / 3$ from the south and north supports, respectively. In order to control the failure mechanism of the beam and protect the actuators, the application of actuator loads was displacement-controlled, instead of force-controlled. The test setup is shown in Figure 61.

Figure 61. Test \#2 setup.

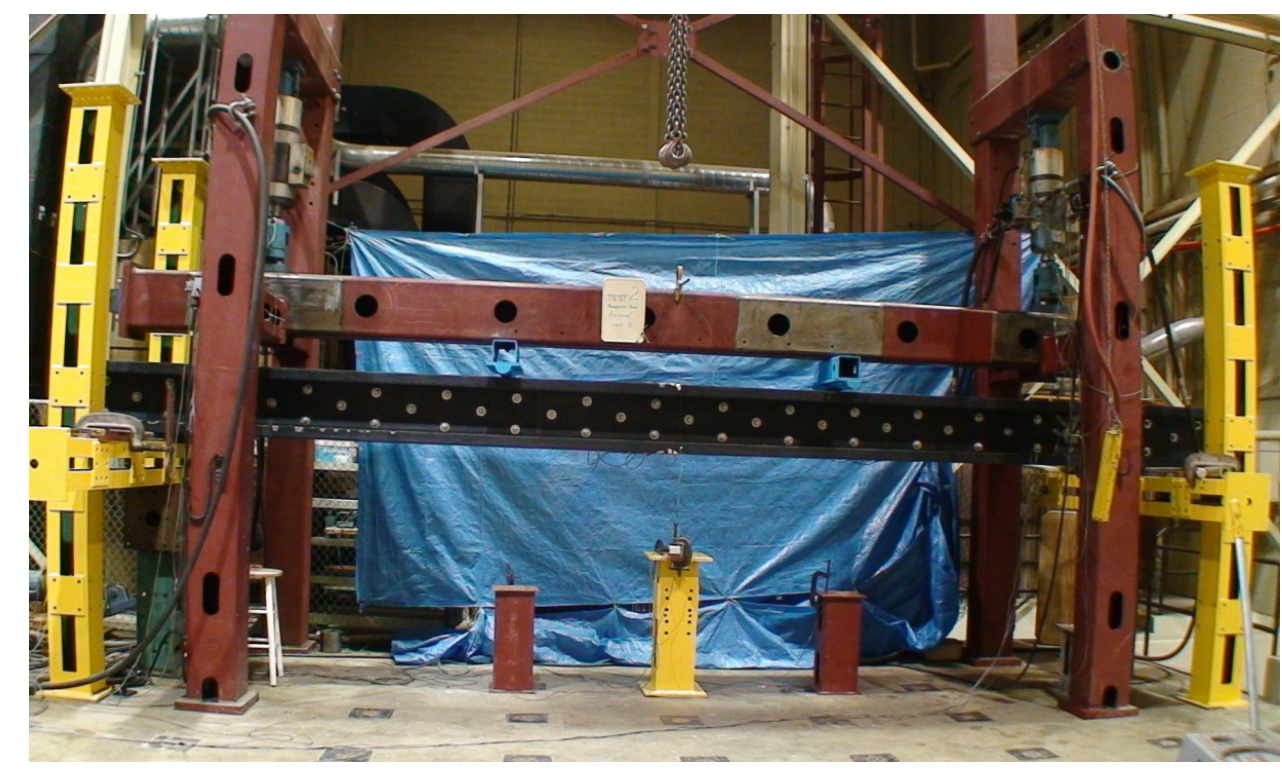

The beam was subjected to three cycles of loading and unloading at a constant actuator displacement rate of 0.83 in. per minute. Each run was set to load the beam to the maximum actuator stroke and remove the load at the same rate, such that the load reached zero at the end of each cycle. The two measured actuator loads, $\mathrm{P}_{3}$ and $\mathrm{P}_{5}$, are plotted against time in Figure 62. The two time histories are very similar.

The load values in Figure 62 are surprisingly high-more than double the magnitude of the corresponding maximum values in the two other singlebeam tests in this report. Since the beam's properties and behavior are very similar in every other way to the other single beams, the difference in these load values is most likely due to a testing error, such as an incorrect 
sensitivity assignment for the actuator load cells. For the sake of thoroughness, however, these load values have been used in stress calculations for the rest of this section. All other measurements (strain and displacement) taken during the test seemed reasonable, when compared to the other tests in this report.

Figure 62. Load versus time.

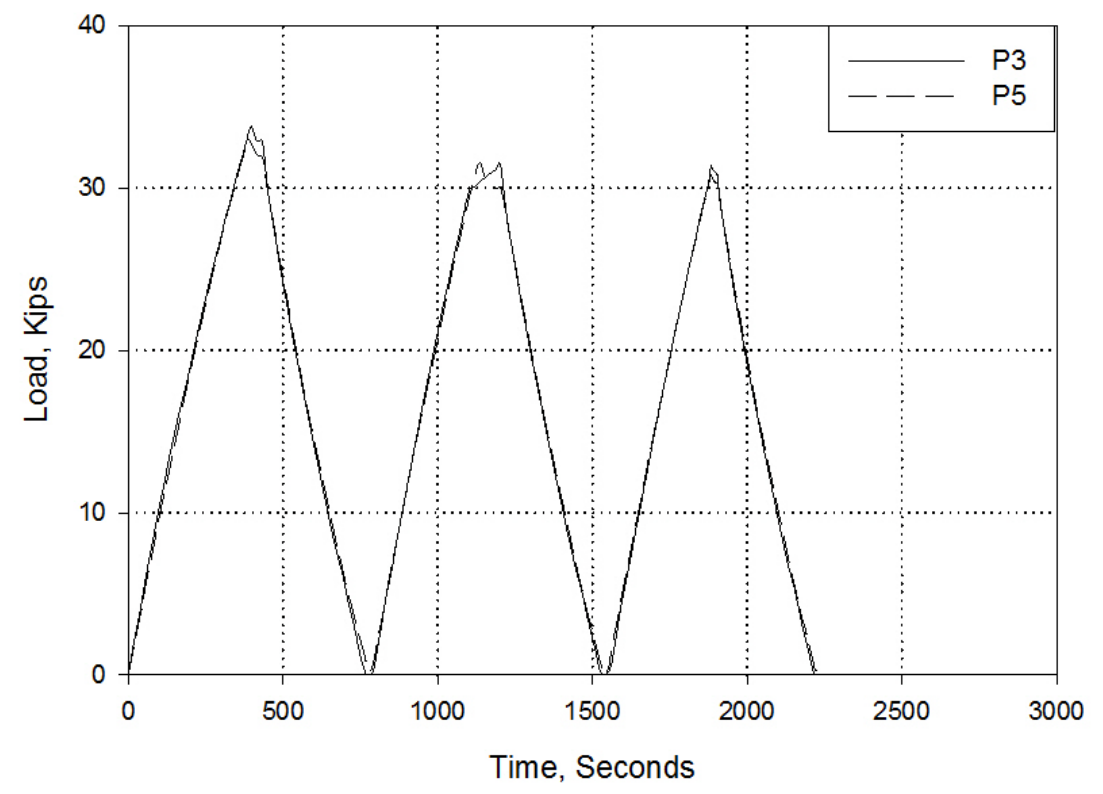

The beam was instrumented with four displacement gauges. Displacement gauge $\mathrm{D}_{330}$ was placed $\mathrm{L} / 3$ from the south support (beneath point load $\mathrm{P}_{3}$ ). $\mathrm{D}_{530}$ was located $\mathrm{L} / 3$ from the north support (beneath point load $\mathrm{P}_{5}$ ). The deflections at these two points were expected to be nearly identical. Two displacement gauges were installed at midspan. One displacement gauge, $\mathrm{D}_{430}$, was aligned with the plane between the two T-beam webs. Another gauge, $\mathrm{D}_{400}$, was installed at the east edge of the beam's bottom fiber.

Figure 63 shows that the deflections measured with $\mathrm{D}_{400}$ and $\mathrm{D}_{430}$ are very close, which indicates very little rotation in the beam about its x-axis during loading. Also, the deflection values at $\mathrm{D}_{330}$ and $\mathrm{D}_{530}$ are close, as expected. The difference between midspan and third-span deflections is also close to what one would expect from a flexural member. 
Figure 63. Displacement versus time.

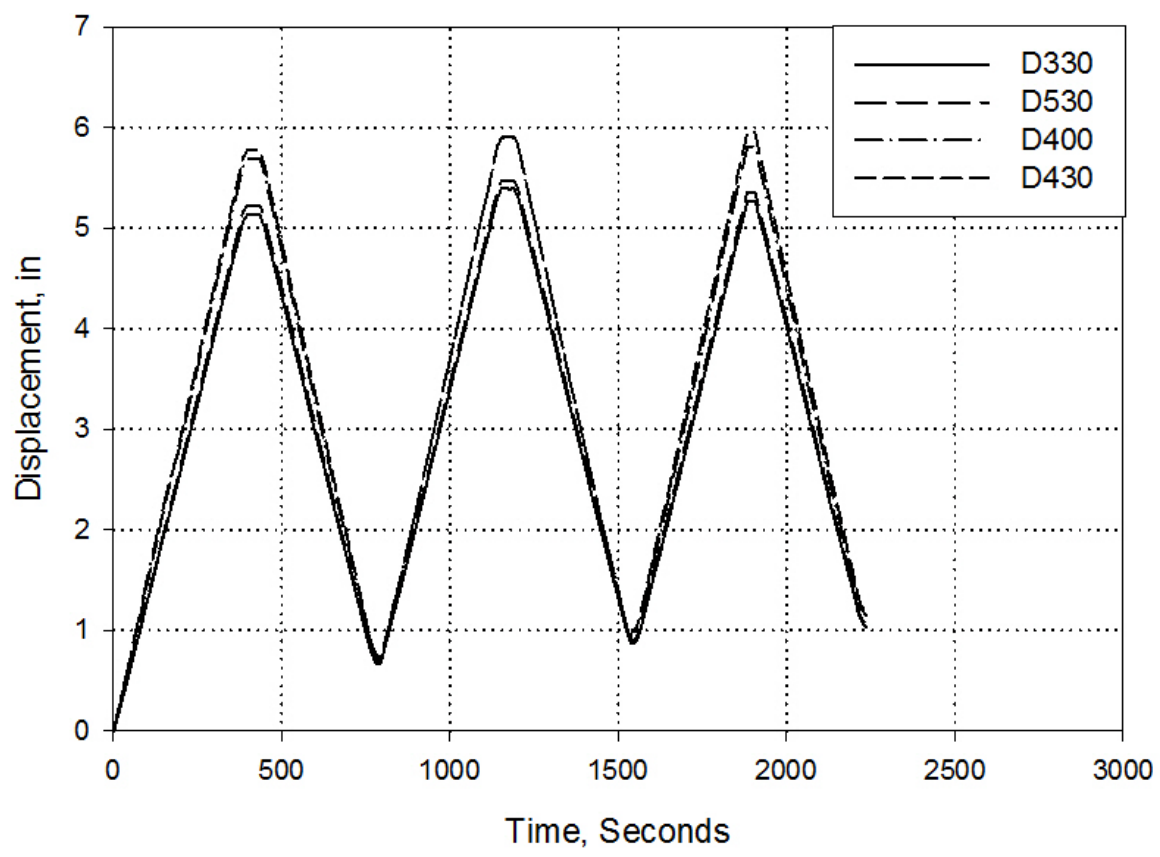

The maximum deflection in the beam was expected at midspan, while the critical section of the beam for flexural strength was expected somewhere near one of the point loads. Strain gauge $\mathrm{S}_{630}$ was installed at a section 6 in. (in the $\mathrm{x}$-direction) outside one of the point loads. This section was chosen for its high shear and flexural stresses. The strain time history for the $\mathrm{S}_{630}$ is shown in Figure 64.

Figure 64. Measured strain at $\mathrm{S}_{630}$, near the actuator.

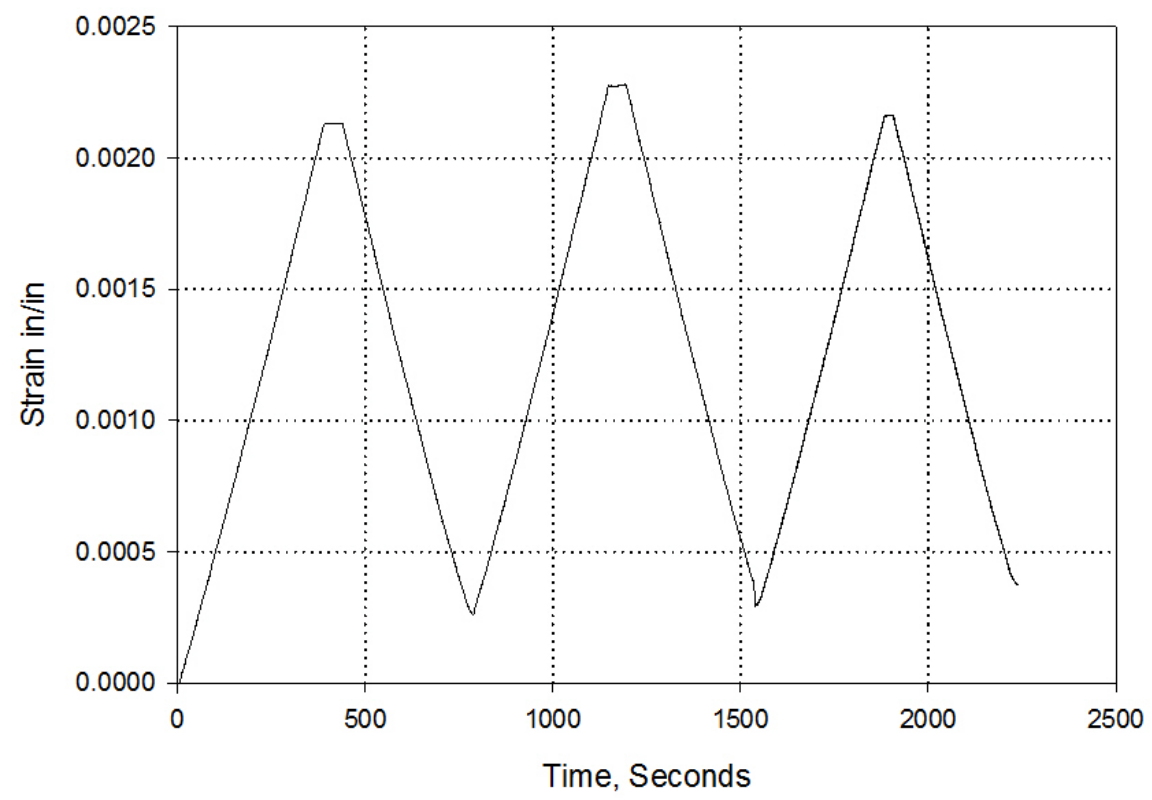


The bottom surface of the beam was instrumented at midspan with three strain gauges: $\mathrm{S}_{400}, \mathrm{~S}_{420}$, and $\mathrm{S}_{460}$. Measured strains at the bottom fiber of the beam's midspan section are shown in Figure 65. During the second loading cycle, the signal from $\mathrm{S}_{460}$ was lost, but it was recovered during the third loading cycle. $\mathrm{S}_{460}$ appears to have recorded unexpectedly small strains, which may be a result of poor bonding between the beam and strain gauge. The strains measured with $S_{400}$ and $S_{420}$ are close to $S_{630}$, implying that curvature, and therefore moment, at midspan and third-span locations is approximately equal, as expected.

Figure 65. Measured strains at midspan bottom fiber.

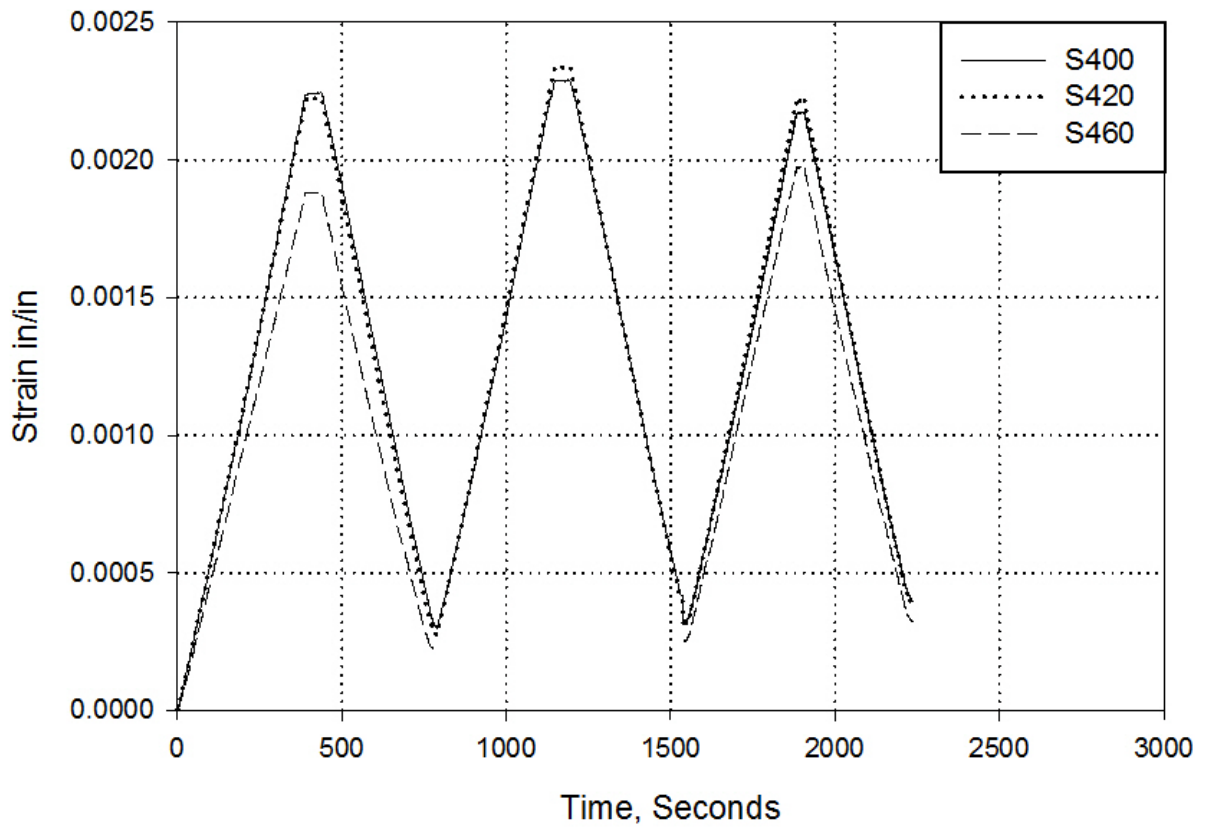

The top surface of the beam was instrumented at midspan with two strain gauges, $S_{444}$ and $S_{464}$. The strains measured with gauges $S_{444}$ and $S_{464}$ are shown in Figure 66. A comparison of the magnitudes of strain values at the top and bottom fibers of the beam will show some skew between top and bottom strains. This difference implies that the beam flexed about a neutral axis which occurred above the section midheight. 
Figure 66. Measured strain at midspan top fiber versus time.

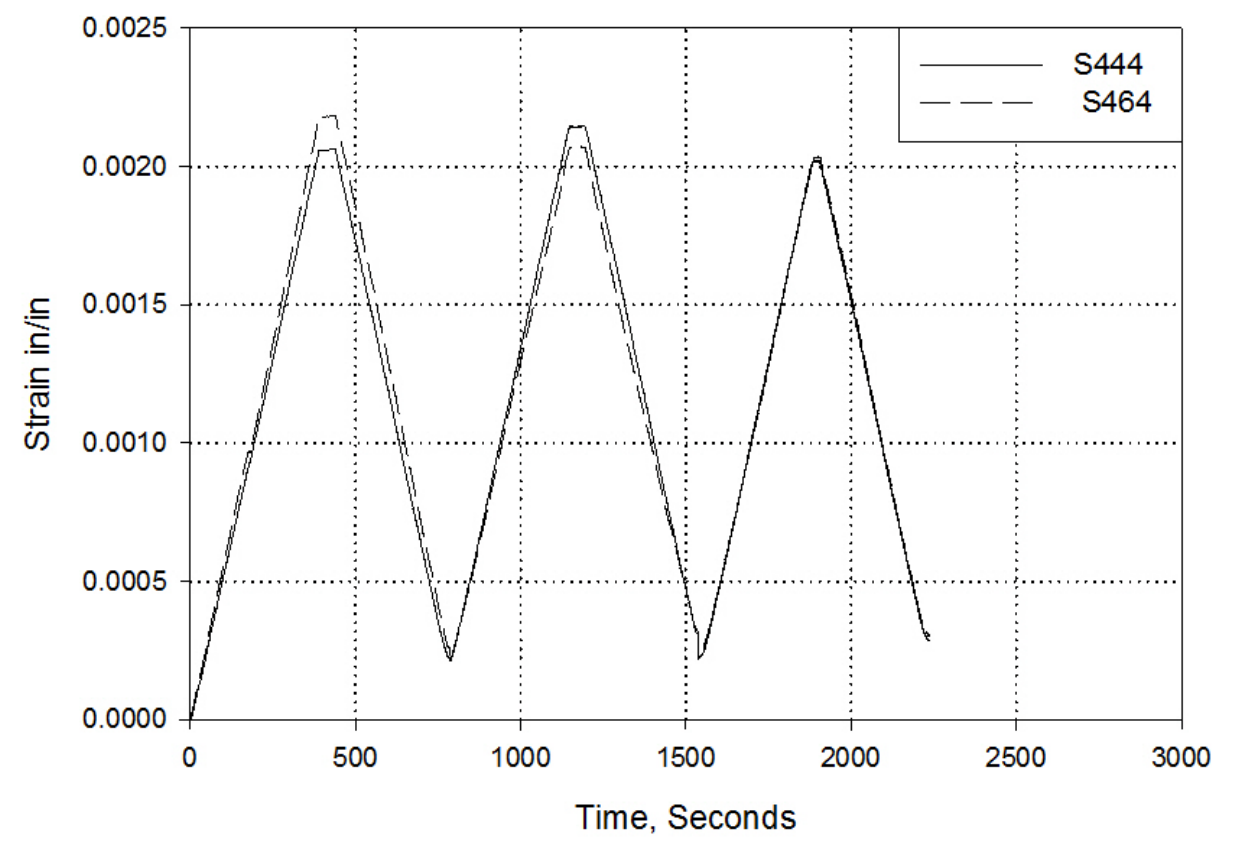

A rosette of strain gauges, $\mathrm{R}_{712}$, was installed at the section midheight, 18 in. from the north support. This was a location with high shear stress and low flexural stress. The diagonal strain gauge $\left(\mathrm{R}_{\mathrm{d} 712}\right)$ recorded the highest values, as expected, while the flexural-induced horizontal strain $\left(\mathrm{R}_{\mathrm{h}}{ }_{12}\right)$ was small but nonzero, which implies that the beam neutral axis was not at the section midheight. The vertical strain $\left(\mathrm{R}_{\mathrm{v} 712}\right)$ was the smallest of all those recorded by the rosette (approximately zero). Figure 67 shows the strain time histories recorded with all three gauges in the rosette. 
Figure 67 . Strains measured with $\mathrm{R}_{712}$ versus time.

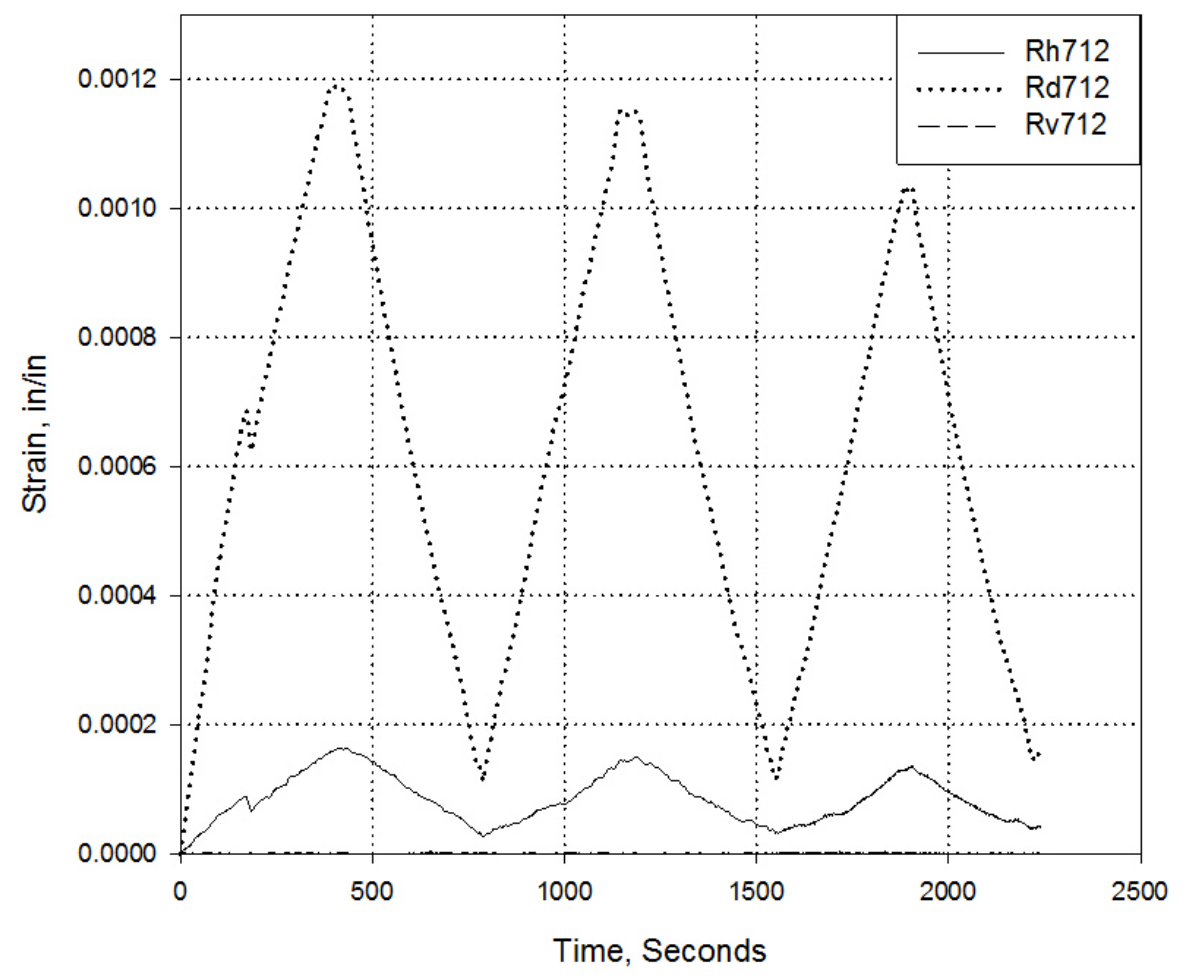

The shear stress-to-point load relationship calculated from the strains measured with the gauge rosette $R_{712}$, with a maximum estimated shear stress of 0.326 ksi, is shown in Figure 68.

Figure 68. Shear stress at $R_{712}$ versus point load $P_{5}$.

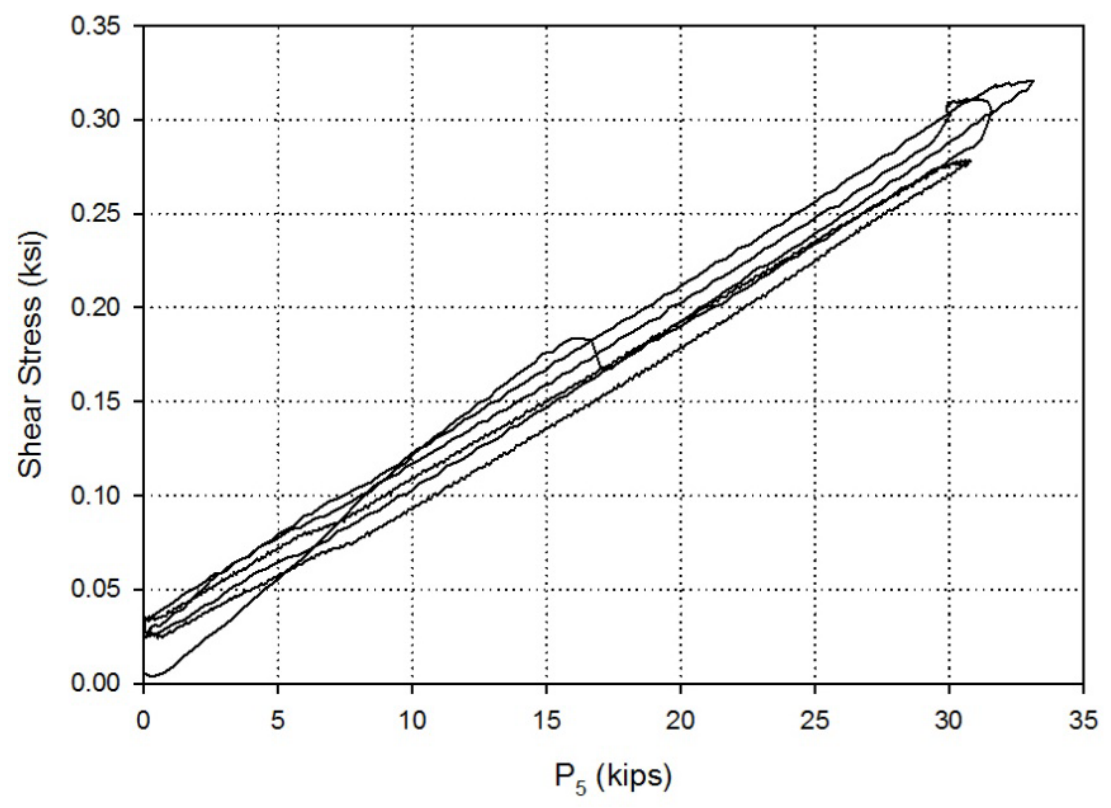


In Figure 69, the strains measured with $\mathrm{S}_{420}$-at the bottom fiber of the midspan section of the beam-are plotted against the corresponding stress, which was calculated from the measured loads and the section properties of the beam. The stress-strain curves display hysteretic behavior.

Figure 69. Stress-strain curves at midspan bottom fiber.

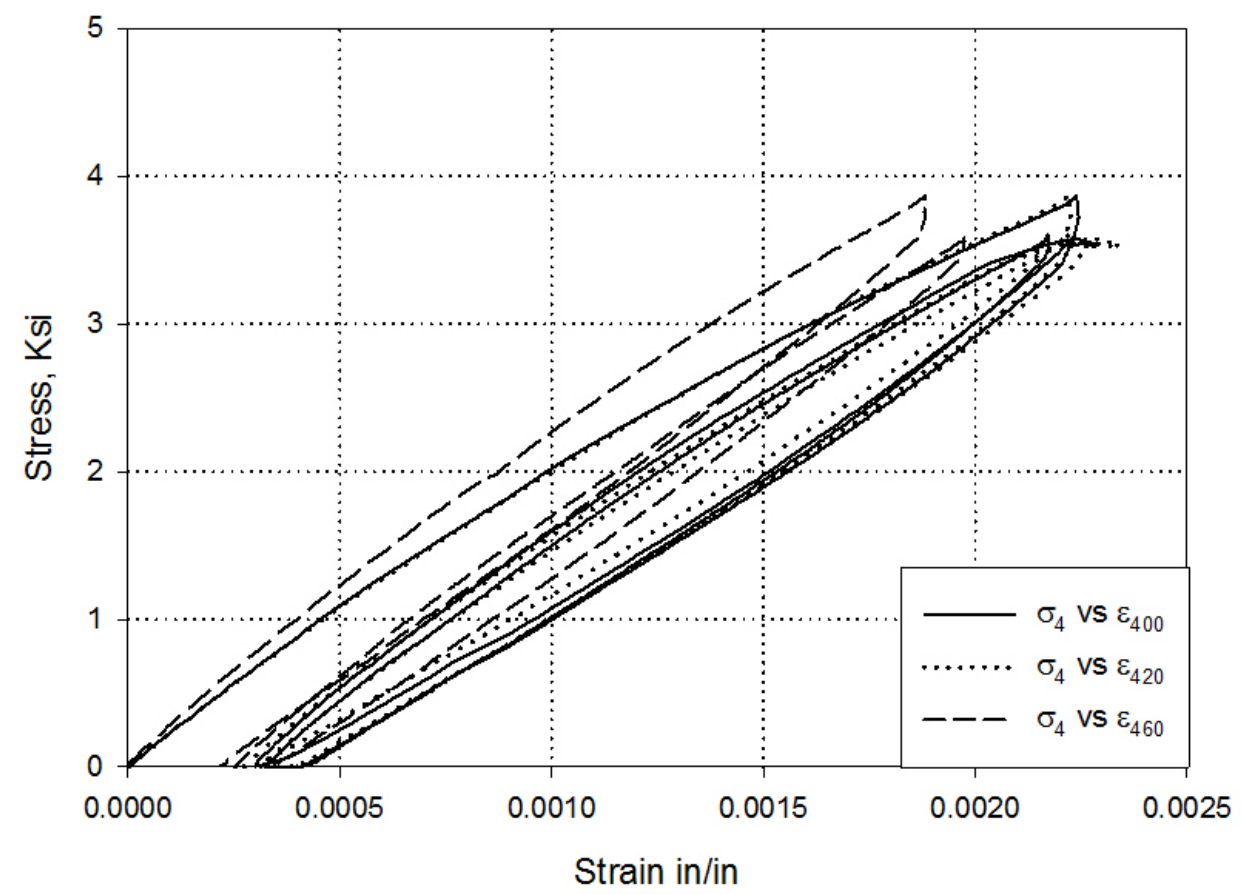

In Figure 70, the strains measured with $\mathrm{S}_{444}-$ at the top fiber of the midspan section of the beam-are plotted against the corresponding stress, as calculated in Figure 69.

Strain gauge $\mathrm{S}_{630}$ was installed at a section 6 in. (in the $\mathrm{x}$-direction) north of the point load $P_{5}$. This section was chosen for its high shear and flexural stresses. It is unlike the section, located 18 in. from the north support, which was instrumented with rosette $R_{712}$. That section has a high shear stress and low flexural stress. The stress-strain curve for the location of $\mathrm{S}_{630}$ is shown in Figure 71. 
Figure 70. Magnitude of stress-strain curves at midspan top fiber.

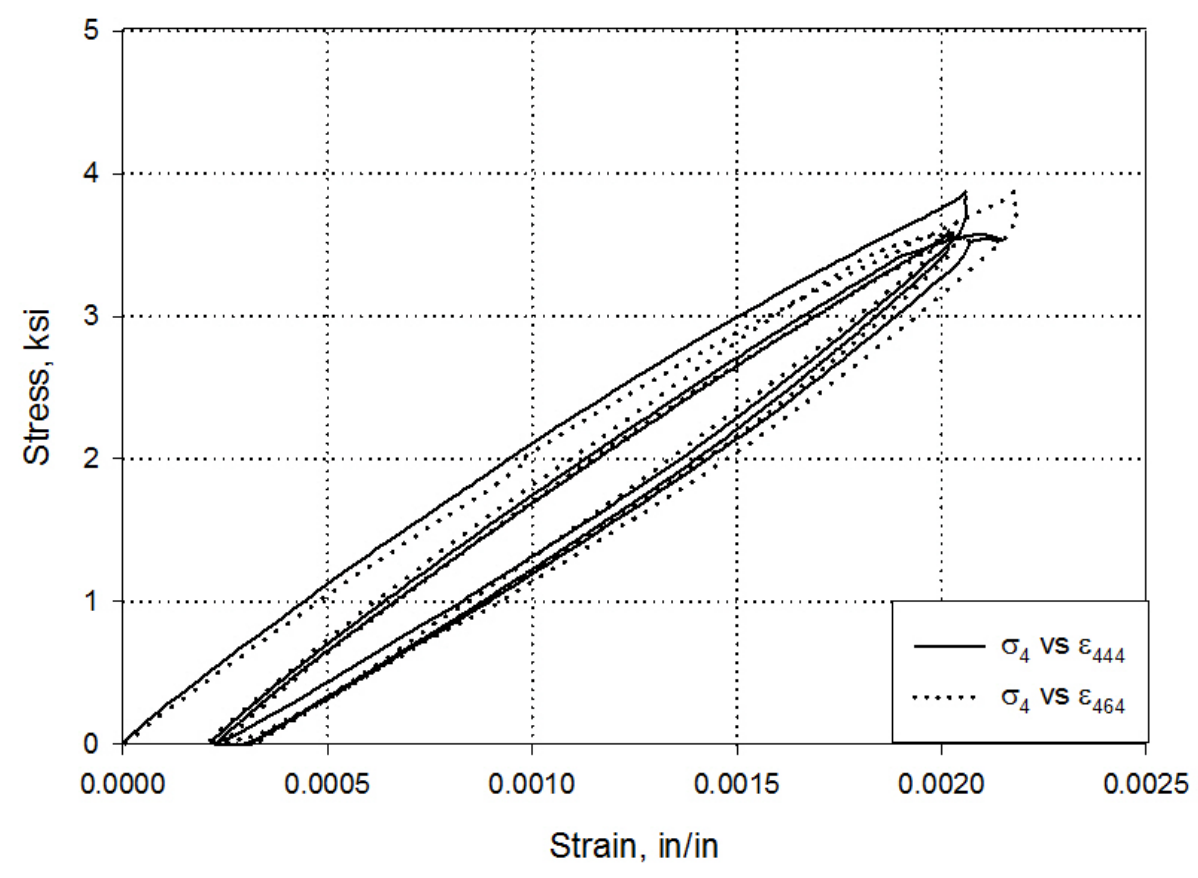

Figure 71 . Stress-strain curve at $\mathbf{S}_{630}$.

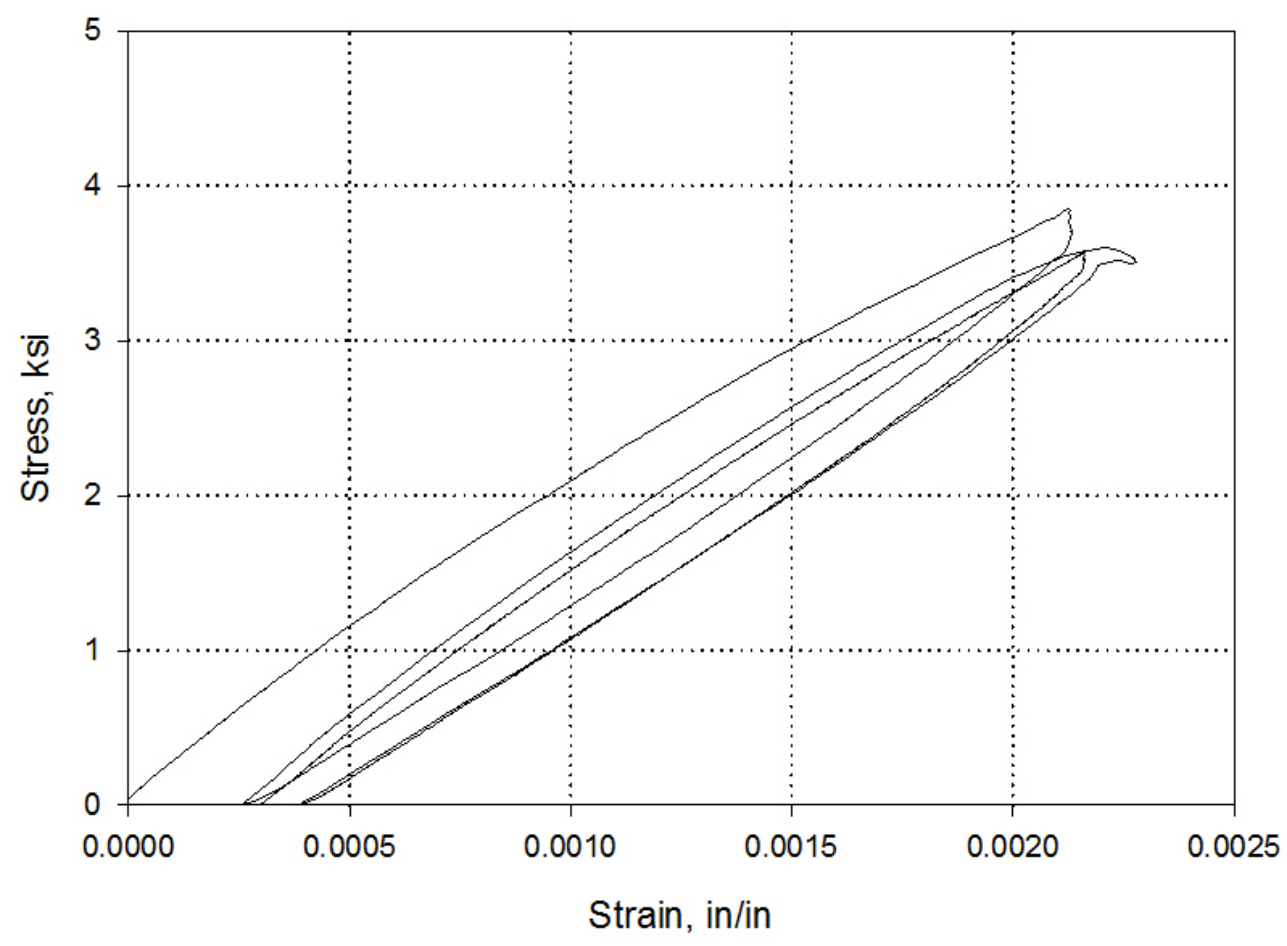




\section{Test \#3 - Single Beam, Original Batch}

This test was carried out on a $22 \mathrm{ft}-6 \mathrm{in}$. single I-beam from the original batch of thermoplastic material. The section consisted of two nonsymmetric T-beams bolted web-to-web to form a symmetric I-shaped section. The purpose of this test was to study the behavior of the specimen and the effect of increases in loading rate on this behavior.

During each loading cycle, the beam was loaded to the maximum stroke of the actuator. at a rate of 8.3 in. per minute. After a short hold, the beam was unloaded at the same actuator displacement rate until the actuator force was equal to zero. The specimen lasted for only one full load cycle. During the second load cycle, the specimen underwent brittle failure, as discussed later in this section. Figure 72 shows the measured load in each actuator over the duration of the test. At a midspan deflection of 3 in., the average value of the point loads is about $8 \mathrm{kip}$. This shows little noticeable change from the stiffness from Test \# 1 from a 10x deflection rate increase. However, a comparison between two different specimens does not necessarily reflect the effect of loading rate accurately, since the stiffness of the two specimens may be different at the same loading rate.

Figure 72. Load in actuators versus time.

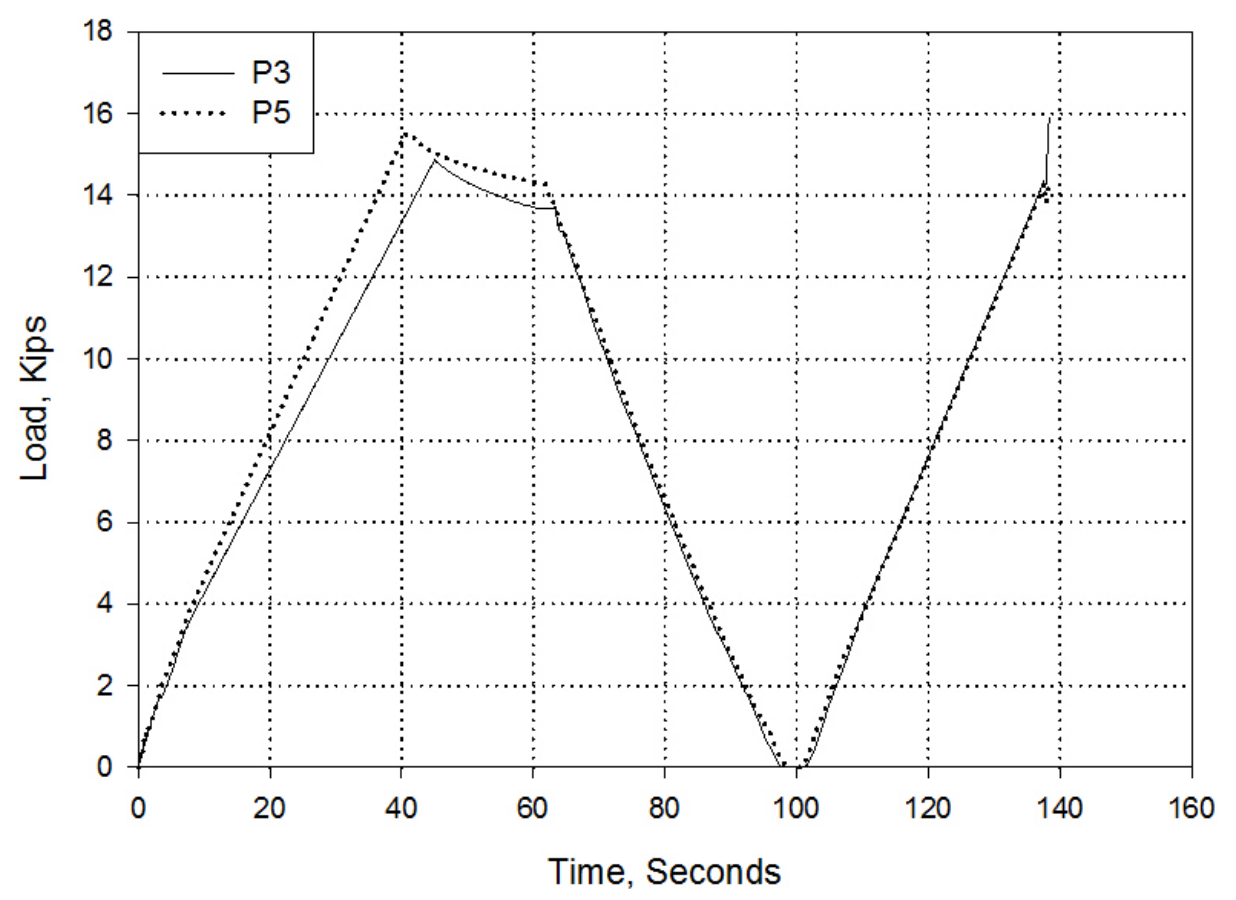


The setup was instrumented with three displacement gauges. Gauges $\mathrm{D}_{430}$ and $\mathrm{D}_{400}$ measured the midspan deflection of the beam at two locations on its bottom flange, while $\mathrm{D}_{435}$ measured the midspan displacement of the steel beam that was used for loading the specimen. Figure 73 shows the displacements measured by all three of these gauges.

The magnitude of the difference between loading beam displacement at midspan and specimen deflection at midspan grows as the input force and specimen displacement increase. The maximum difference of about 1 in. shows how important it is to measure directly the deflections of the specimen. Also, this means that the actual displacement loading rate of the specimen at $\mathrm{L} / 3$ and $2 \mathrm{~L} / 3$ may be significantly different from the displacement rate of the actuators, depending on the test setup (e.g., loading beam stiffness, loading rate). According to Figure 73, the actuator loading rate of 8.3 in. per minute produced a midspan deflection rate of about 9 in. per minute.

Figure 73. Displacement at the center of the beam.

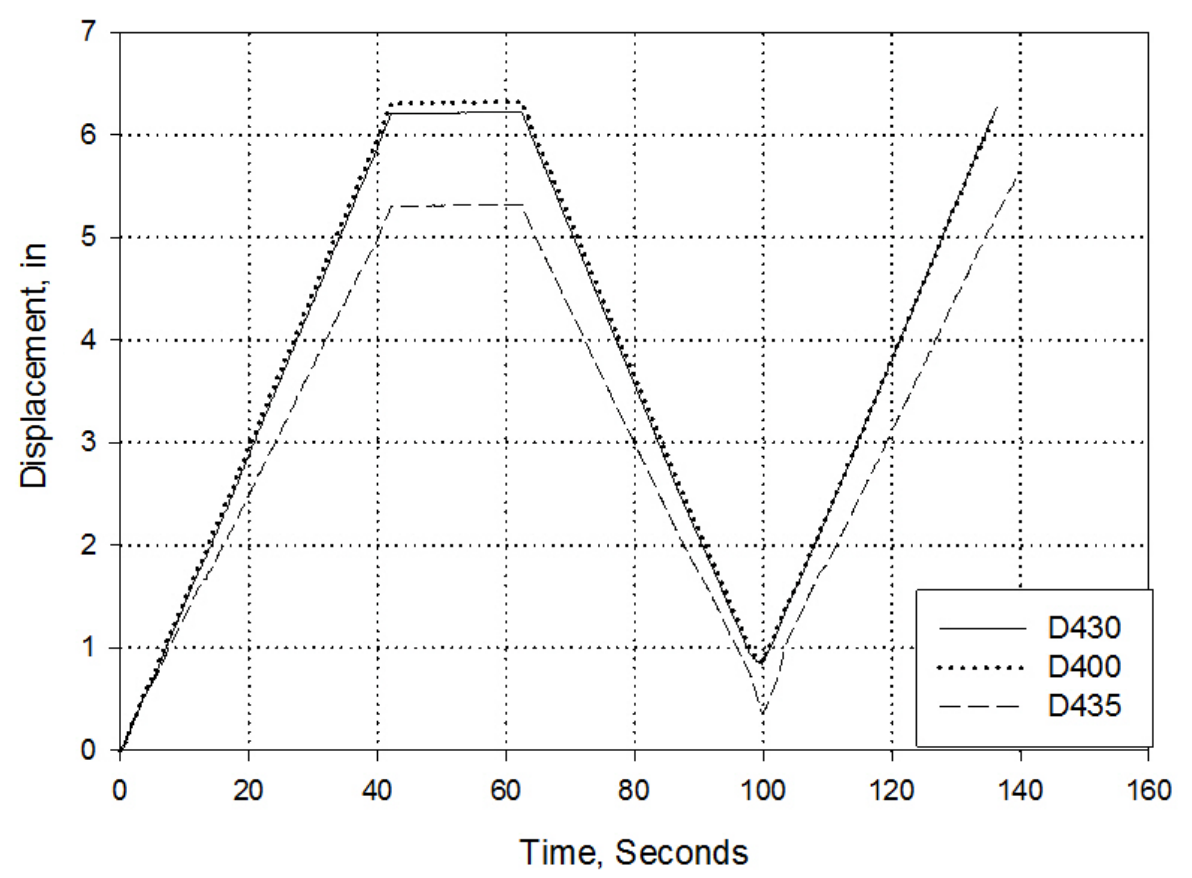

Figure 74 shows the strain time histories recorded at the midspan bottom and top fibers during testing. At midspan, the magnitude of the strain at the top fiber of the specimen is significantly lower than the strain at the bottom fiber. This difference implies that the beam flexed about a neutral axis, which occurred above the section midheight. 
Figure 74. Magnitudes of strain at the midspan top and bottom fibers.

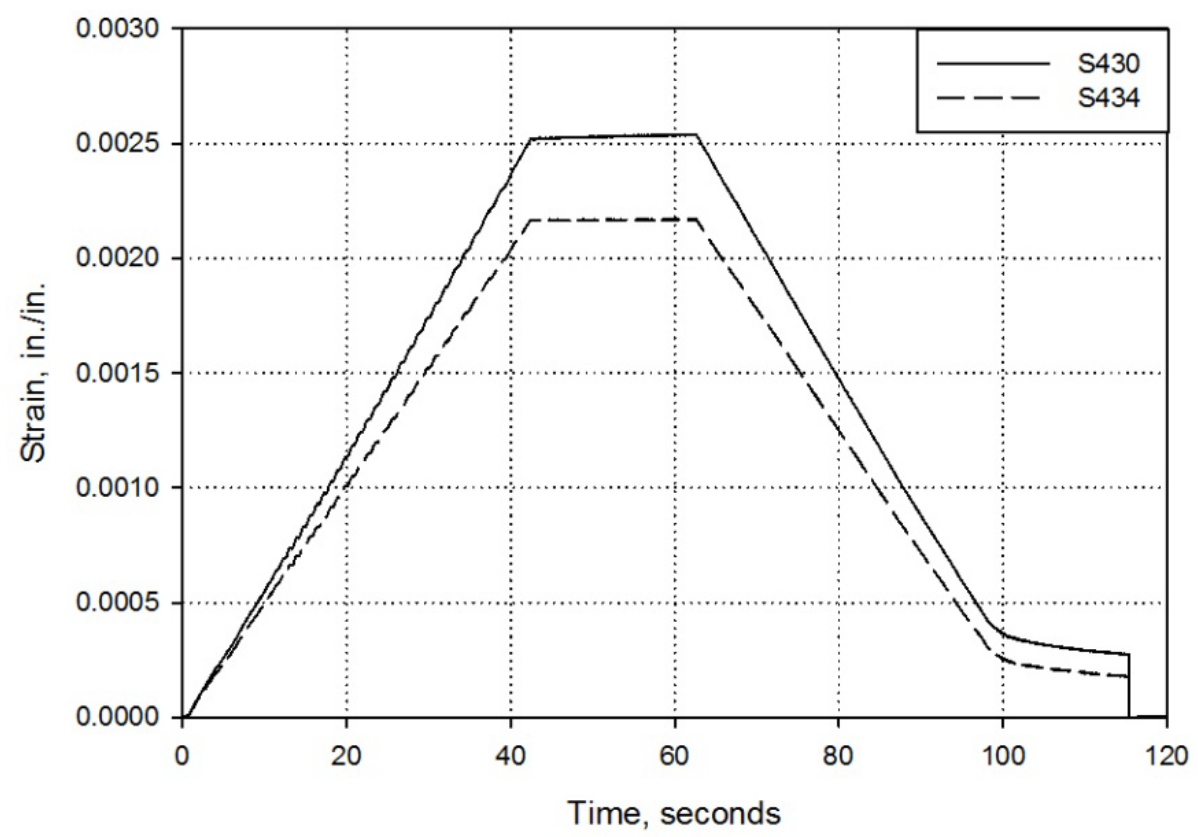

The mechanical properties test results presented earlier in this report show the thermoplastic material to be significantly stiffer in compression than it is in tension. This material property is most likely responsible for the difference in strain magnitudes shown in Figure 74. Using force equilibrium and strain compatibility, one may determine whether the difference in stiffnesses from mechanical tests agrees with the behavior of the beam. In the following equations, " $h$ " is the height of the section, $\varepsilon(x)$ is a linear distribution of strain with $\mathrm{x}=\mathrm{O}$ corresponding to the neutral axis, The depth of the neutral axis is $\mathrm{y}_{\mathrm{NA}}$, and all other variables are commonplace in I-shaped section dimensions.

$$
\begin{gathered}
E_{c}\left[t_{w} \int_{0}^{y_{N A}} \varepsilon(x) d x+\left(b_{f}-t_{w}\right) \int_{y_{N A}-t_{f}}^{y_{N A}} \varepsilon(x) d x\right] \\
=E_{t}\left[t_{w} \int_{0}^{h-y_{N A}} \varepsilon(x) d x+\left(b_{f}-t_{w}\right) \int_{h-y_{N A}-t_{f}}^{h-y_{N A}} \varepsilon(x) d x\right] \\
E_{c}\left[a t_{w} \int_{0}^{y_{N A}} x d x+a\left(b_{f}-t_{w}\right) \int_{y_{N A}-t_{f}}^{y_{N A}} x d x\right] \\
=E_{t}\left[a t_{w} \int_{0}^{h-y_{N A}} x d x+a\left(b_{f}-t_{w}\right) \int_{h-y_{N A}-t_{f}}^{h-y_{N A}} x d x\right]
\end{gathered}
$$


$E_{c}\left[6 \int_{0}^{y_{N A}} x d x+(18-6) \int_{y_{N A}-3}^{y_{N A}} x d x\right]=E_{t}\left[6 \int_{0}^{18-y_{N A}} x d x+(18-6) \int_{18-y_{N A}-3}^{18-y_{N A}} x d x\right]$

$E_{C}\left[9 y_{N A}^{2}-6\left(y_{N A}-3\right)^{2}\right]=E_{t}\left[9\left(h-y_{N A}\right)^{2}+6\left(15-y_{N A}\right)^{2}\right]$

Using equations (18) and (19) below and assuming uniform distribution of material properties over the section, the effective ratio of material compressive and tensile stiffnesses may be approximated for almost any pair of measured strains at $S_{430}$ and $S_{434}$. This estimated ratio " $n$ " is plotted against time in Figure 75. Through most of the first loading cycle, the strain data agrees with the mechanical tests; the thermoplastic material is effectively about 1.3 times stiffer in compression than it is in tension.

$$
n=\frac{E_{c}}{E_{t}}=\frac{y_{N A}^{2}+12 y_{N A}-18}{y_{N A}^{2}-48 y_{N A}+522} \quad(18) ; \quad y_{N A}=\frac{\varepsilon_{\text {top }}}{\varepsilon_{\text {top }}-\varepsilon_{\text {bottom }}}
$$

Figure 75. Estimated variation of relative compressive and tensile stiffness of thermoplastic, plotted over time.

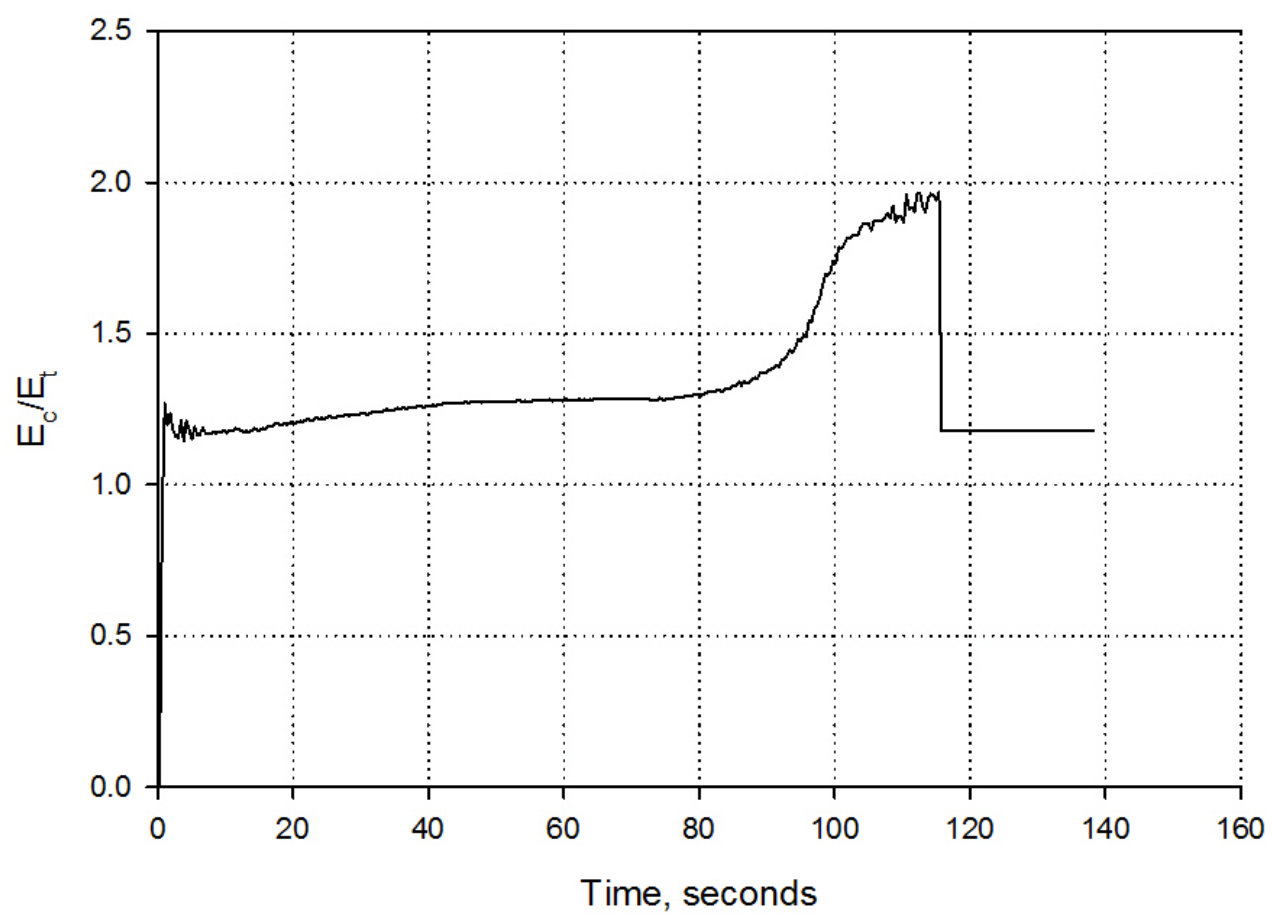


The first two entries in Figure 76 show stress-strain curves at $\mathrm{S}_{430}$ and $\mathrm{S}_{434}$, based solely on strain readings and the thermoplastic material's Young's moduli from mechanical property tests. The final two entries in Figure 76 are hysteretic stress-strain loops determined from the estimated location of the neutral axis, section properties, and point load magnitudes.

The true behavior of the instrumented material is likely closer to the pair of hysteretic loops, based on the loads that must be supported by the beam. Since the strain gauges S430 and S434 were applied to the stiffer external layer of the beam in flexure, it is not surprising that these readings disagree significantly with material tests. The material tests induced and measured behavior of two different thermoplastic materials (voidfilled and void-free) under uniform loading, while this beam test induced behavior of the two materials under some loading gradient and measured only the response in the stiffer material.

Figure 76. Two approximations of stress-strain curves at $S_{430}$ and $S_{434}$.

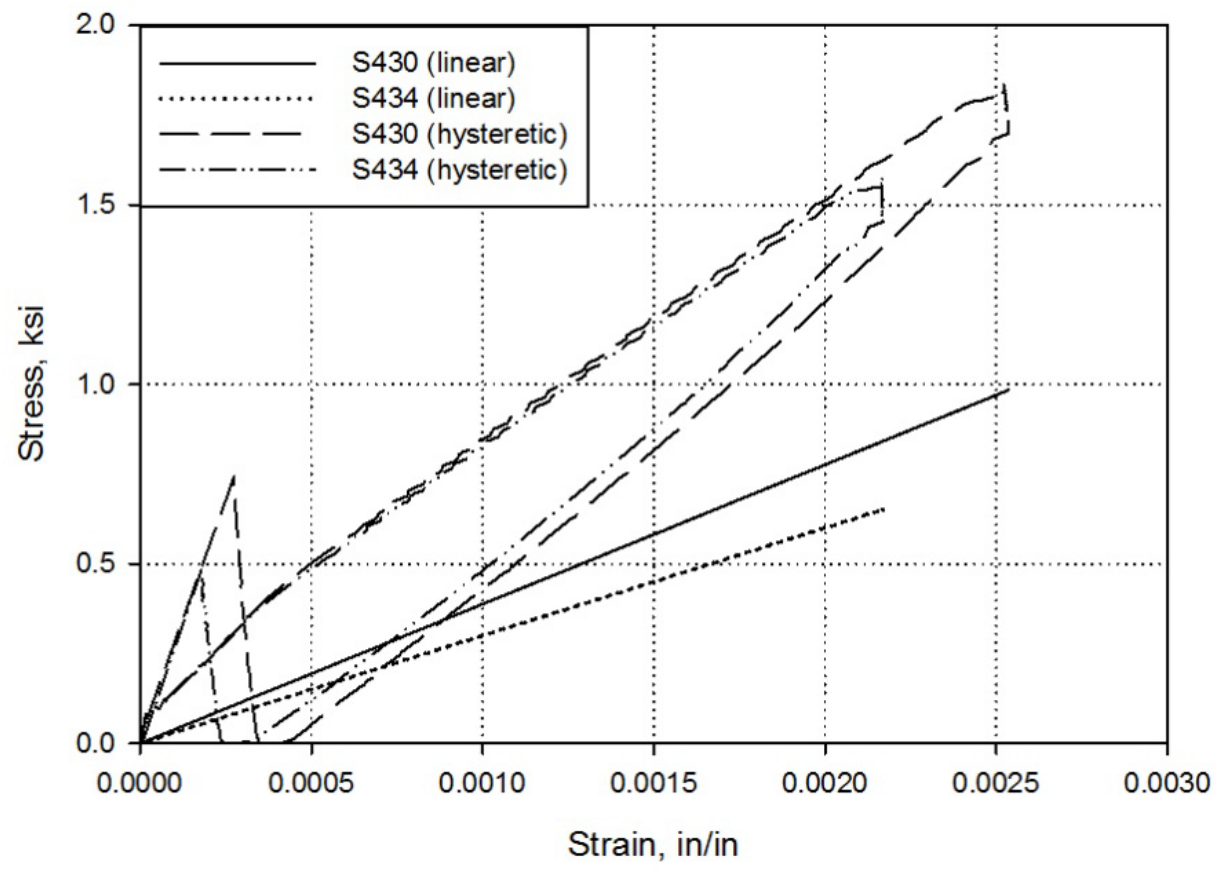

Figure 77 shows the hysteretic loops from Figure 76 with stress-strain curves approximated as in the other tests (assuming the neutral axis to be at the midsection height). The results of the two approaches are reasonably close, showing maximum values within $10 \%$ of one another. The assumption that the beam's neutral axis occurs at the section midheight 
overestimates the tensile stress in the bottom fiber of the beam. Since tensile failure governs flexural capacity, it may be conservative to assume that the neutral bending axis occurs at midsection height in order to estimate ultimate stress for this particular section.

Figure 77. Two approximations of stress-strain curves at $S_{430}$ and $S_{434}$ assuming neutral axis at mid-height.

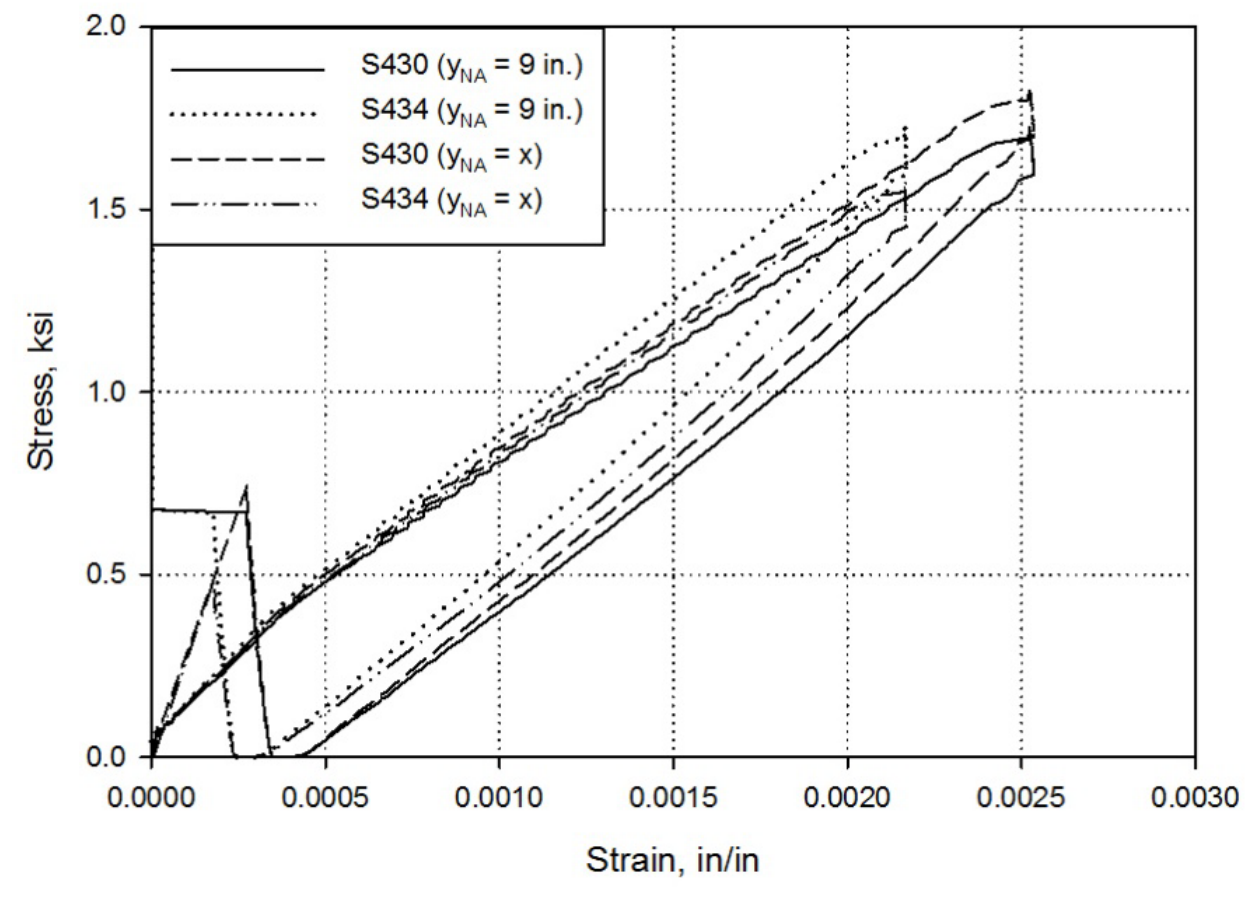

Photos depicting the failure of this specimen are shown in Figure 78Figure 82. 
Figure 78. Specimen after failure, with broken section on floor.

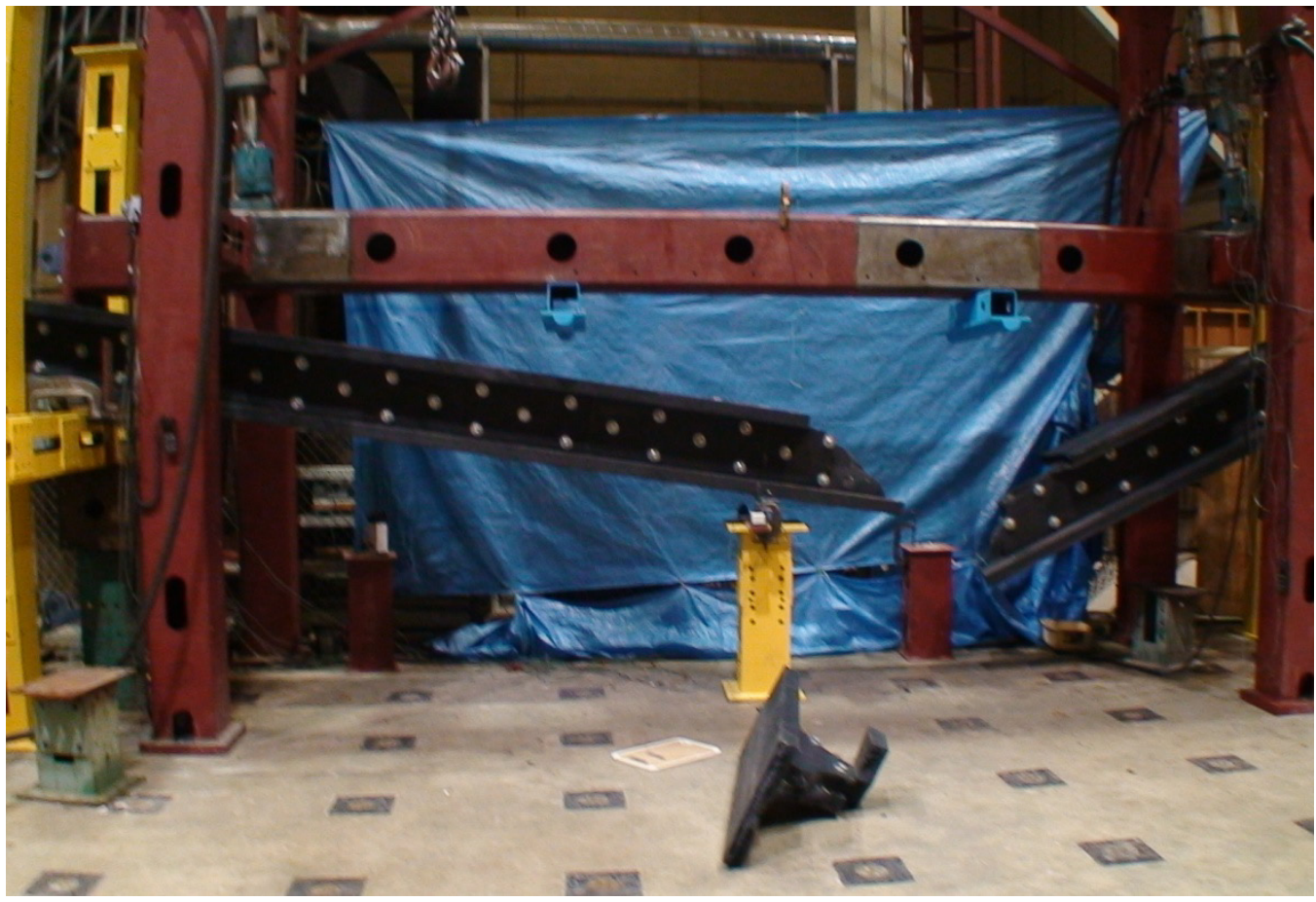

Figure 79. Delamination between webs. Figure 80. Crack through bolt hole and between flange and web.
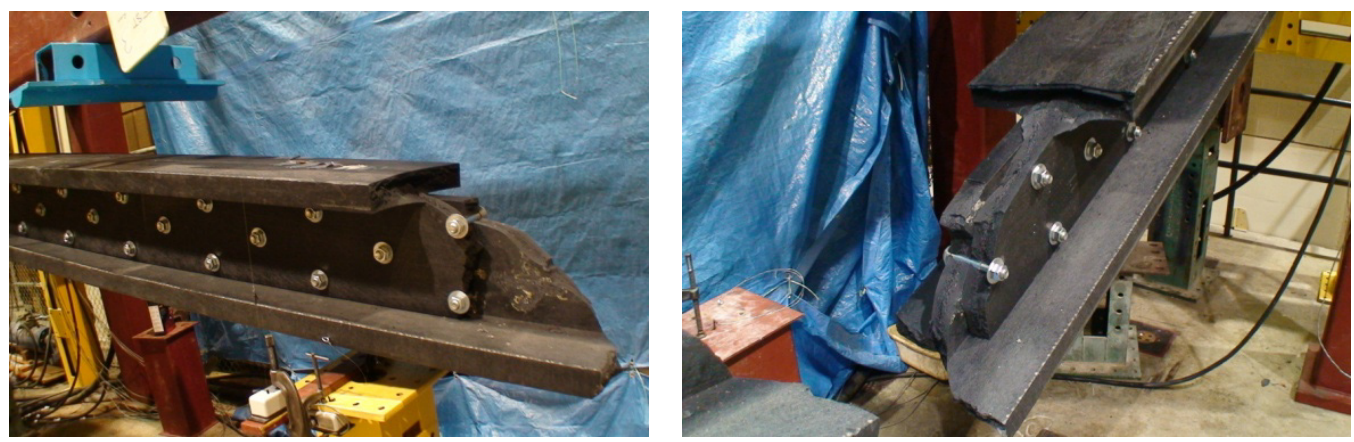

Figure 81. Broken section, top view.

Figure 82. Broken section, west side.
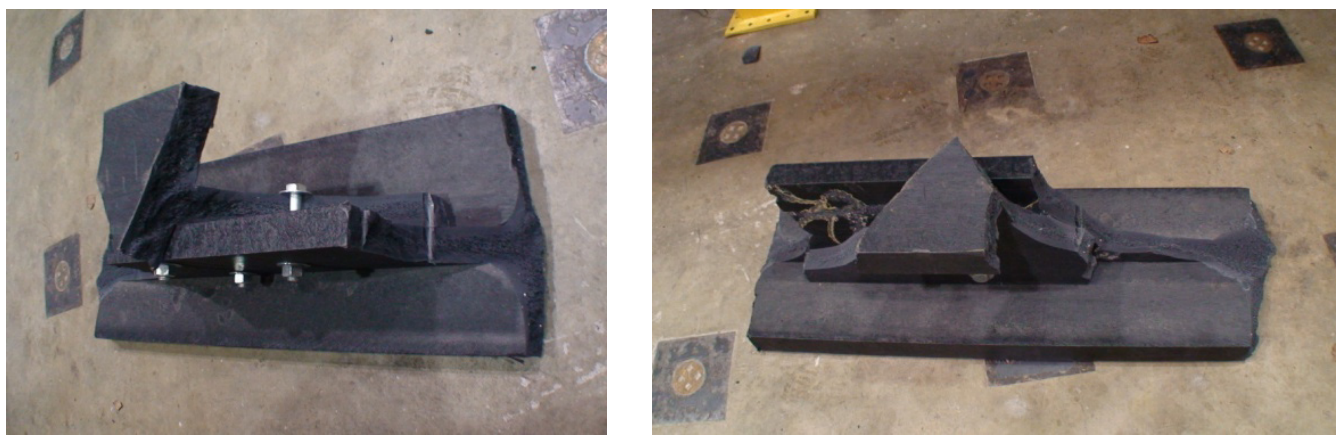


\section{Test \#4 - Double Beam, Original Batch}

This test was carried out on a $22 \mathrm{ft}-6 \mathrm{in}$. II-beam from the original batch of thermoplastic material. The section consisted of two symmetric I-beams, bolted flange tip-to-flange tip, to form a box girder shape. Each symmetric I-beam consisted of two nonsymmetric T-sections bolted web-to-web. The pair of I-beams was also stiffened with a $12 \mathrm{in}$. deep, $12 \mathrm{in.}$ wide, and $12 \mathrm{in.}$ long section of I-beam with 2 in. thick web and flanges. Figure 83 shows three steps in the process of specimen assembly.

Figure 83. Steps in assembling specimen for Test \#4.

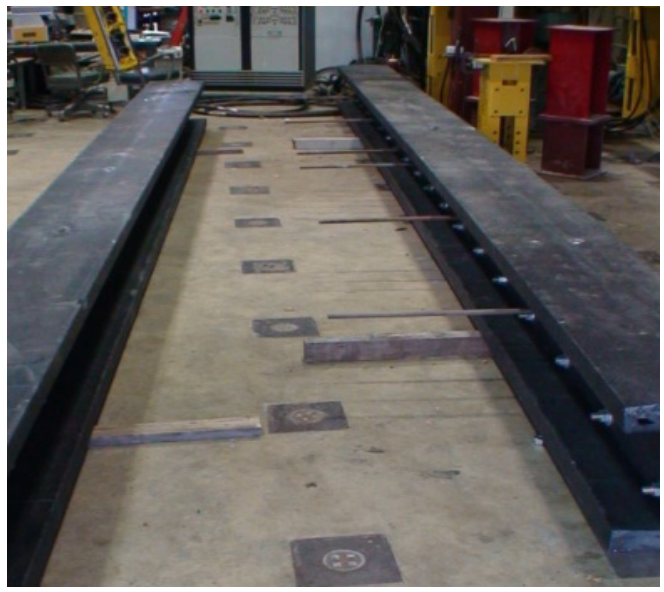

Step 1: Insert tie rods in one I-beam.

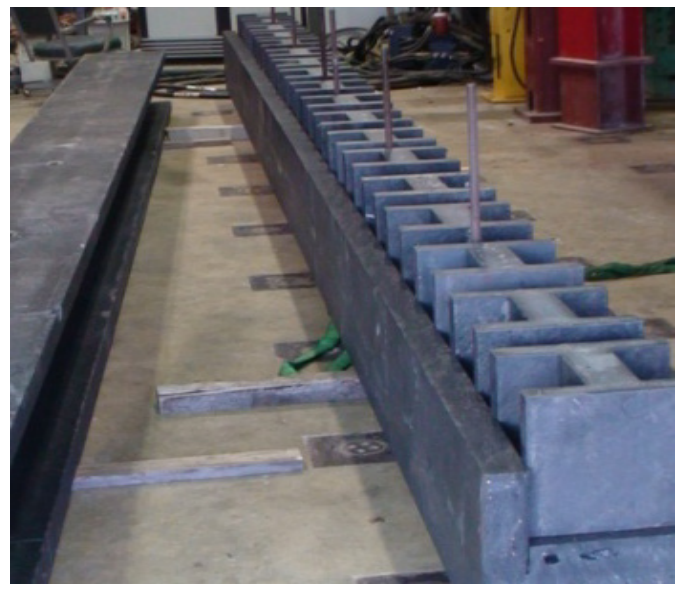

Step 2: Insert stiffeners in one I-beam.

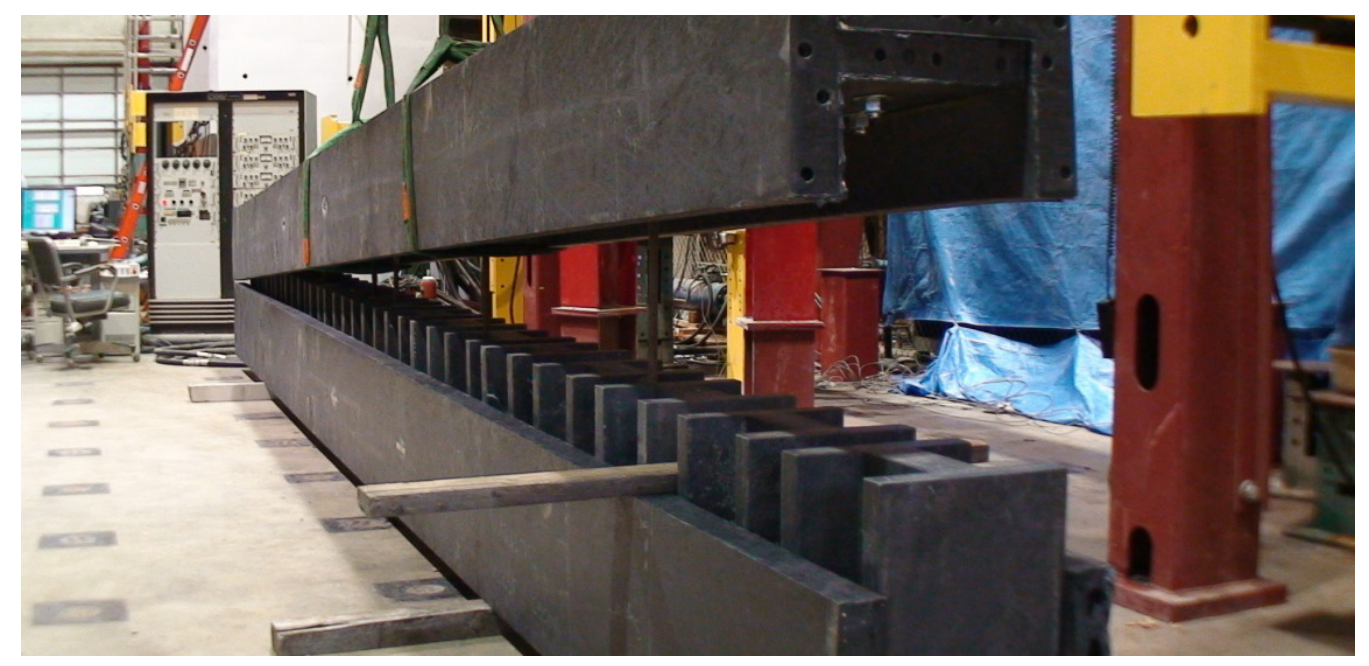

Step 3: Insert other beam.

The distribution of stiffeners is illustrated in Figure 84. The flanges of stiffeners are positioned perpendicular to the webs of the I-beams in the 
specimen (see Figure 83). The stiffeners were spaced 18 in. center-to-center, which left 6 in. of clear space between adjacent stiffeners.

Figure 84. The layout of the stiffeners between the webs of the I-beams.

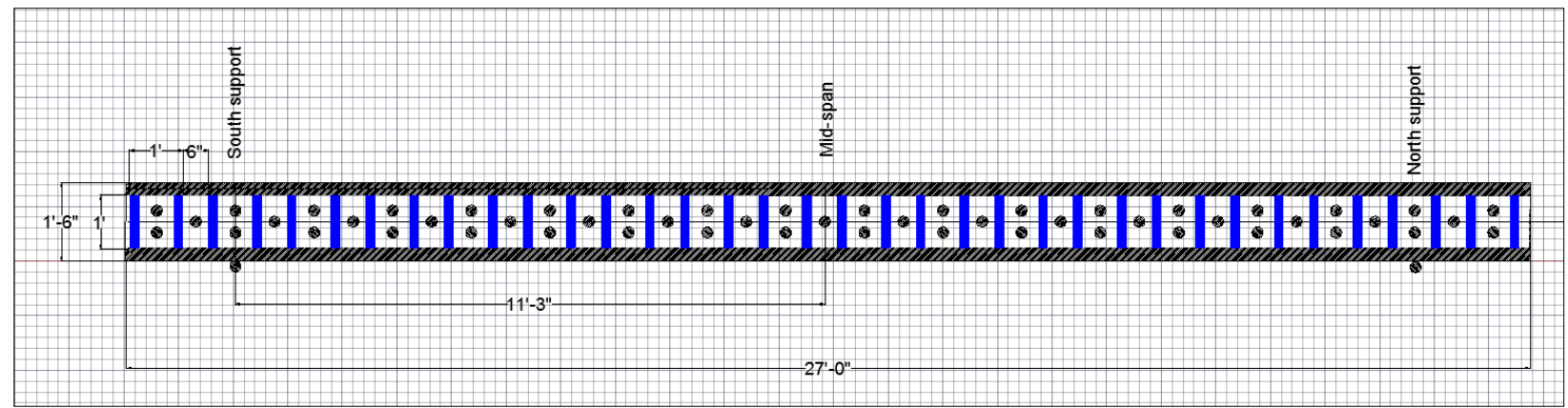

The purpose of this test was to study the behavior of the II-beam specimen and the effect of the displacement loading rate on the performance of that specimen. The testing program consisted of two cycles at an actuator loading rate of $0.8328 \mathrm{in}$. per minute, followed by four cycles at approximately ten times the initial rate. The test setup is shown in Figure 85. The span and loading configuration for this specimen is the same as in Test \#1.

Figure 85. Test \#4 setup.

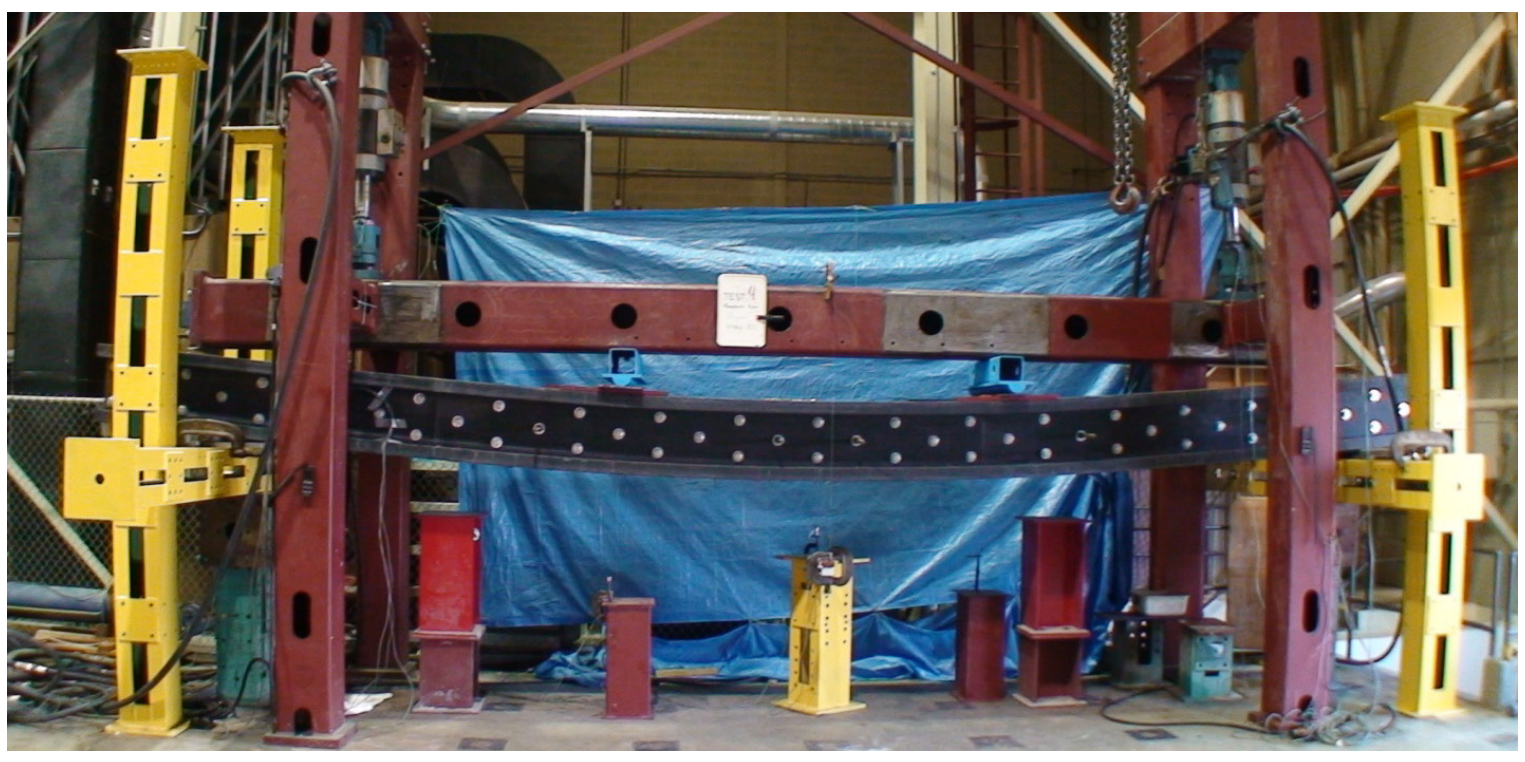

The force applied by each actuator is plotted versus time in Figure 86 and Figure 87. Note the trend of a larger maximum force at higher loading rates, and the apparent force decay over the hold time at each peak displacement. Force decay over time is also apparent in the nonlinearity of 
both the loading and unloading curves, especially during the first two cycles. Apparently, this time-based decay is responsible for a large portion of the rate dependence of the beam stiffness.

Figure 86. Time-variation of point loads.

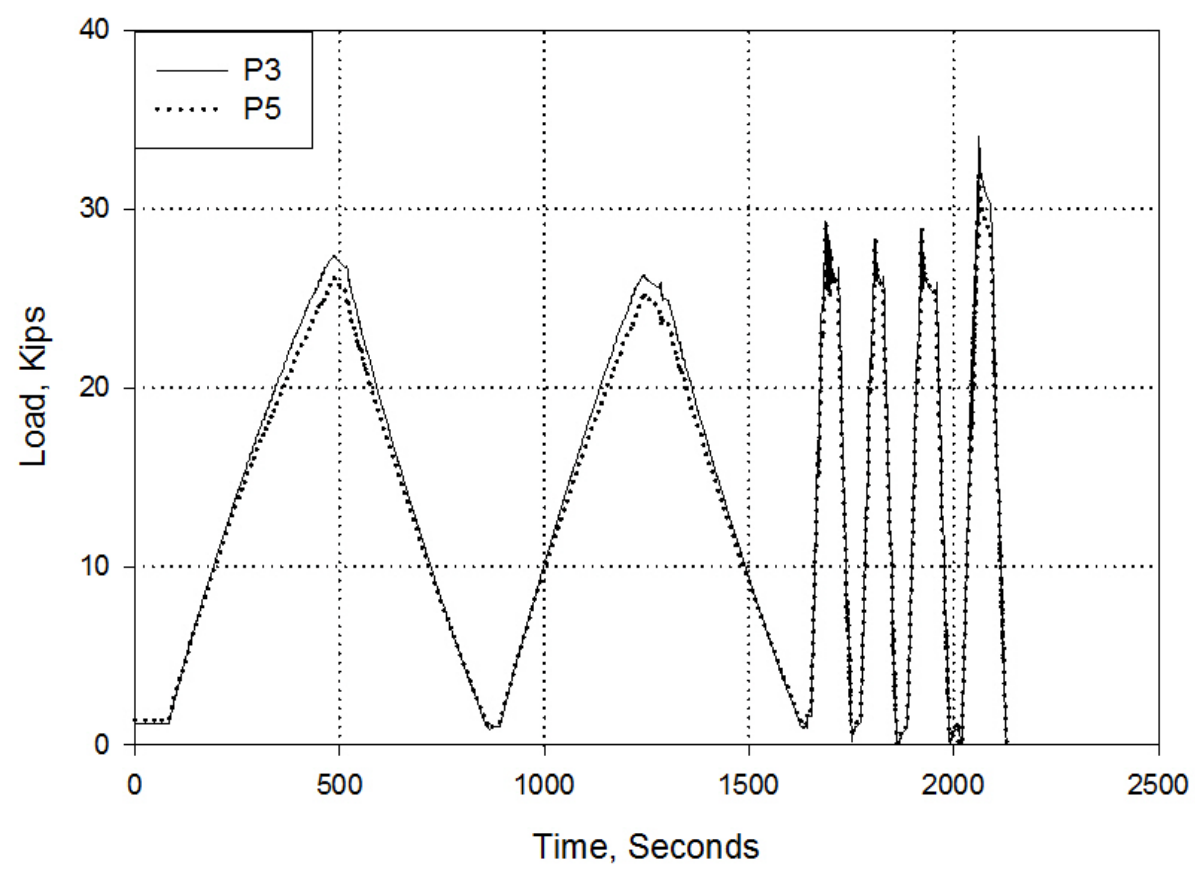

Figure 87. Time-variation of point loads, final four cycles.

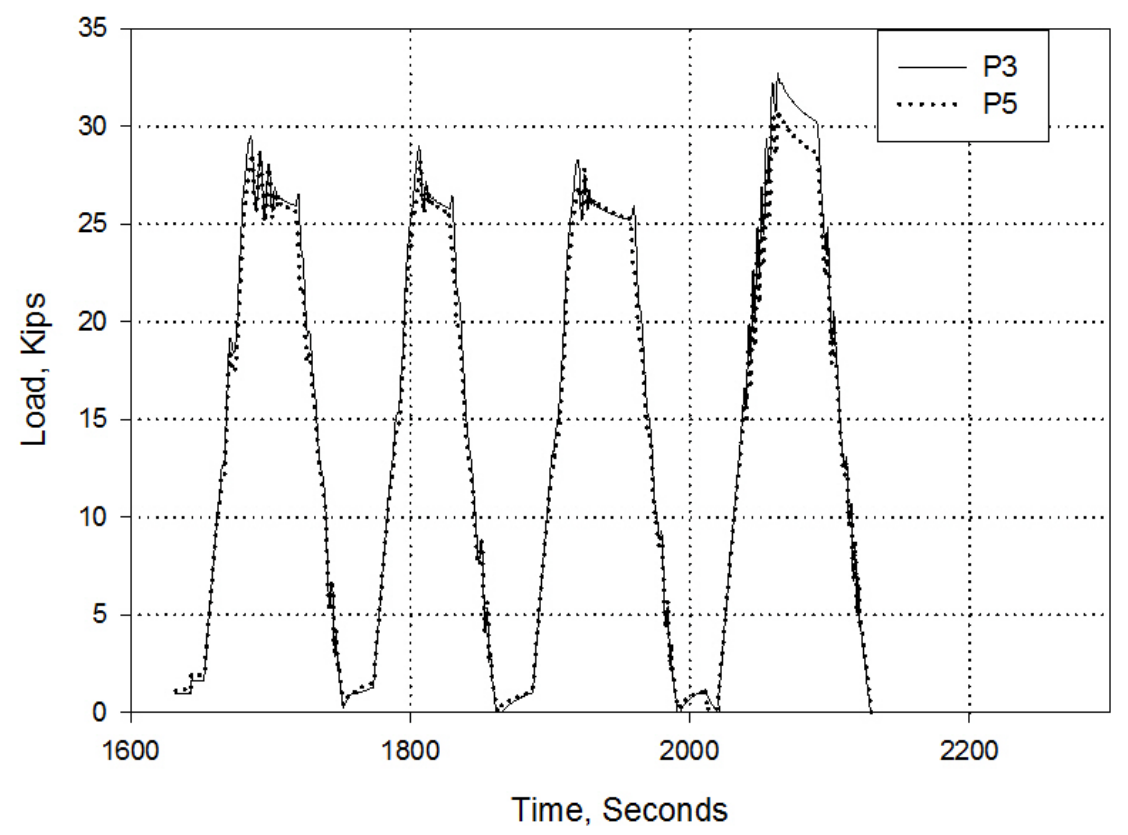


The displacements at loading points are plotted over time in Figure 88 . Note that some residual specimen deformation remains after the load is removed. The readings from $\mathrm{D}_{530}$ appear to have been converted incorrectly from the original voltages, and the $\mathrm{D}_{530}$ values in Figure 89 have been divided by two for the sake of comparison. Displacement $\mathrm{D}_{530}$ will be assumed to be approximately equal to $D_{330}$, since the conversion factor that was used is unknown, and the test video appears to agree with this assumption. Moreover, the distribution of force between actuators seems to be about even. Taken with the assumption of reasonably uniform stiffness over the span of the beam, this implies an approximately even distribution of deflection.

Figure 88. Displacement over time at loading points.

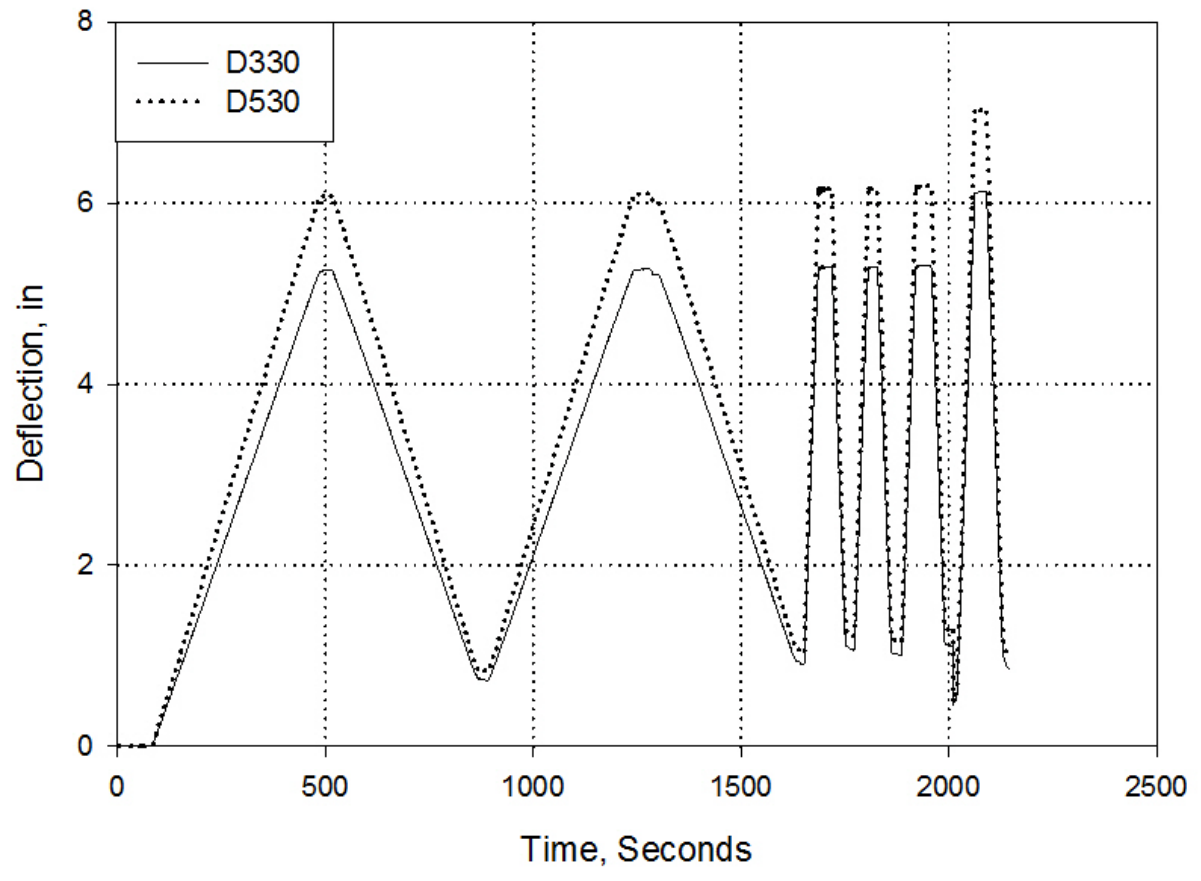


Figure 89. Displacement over time at loading points, final four cycles.

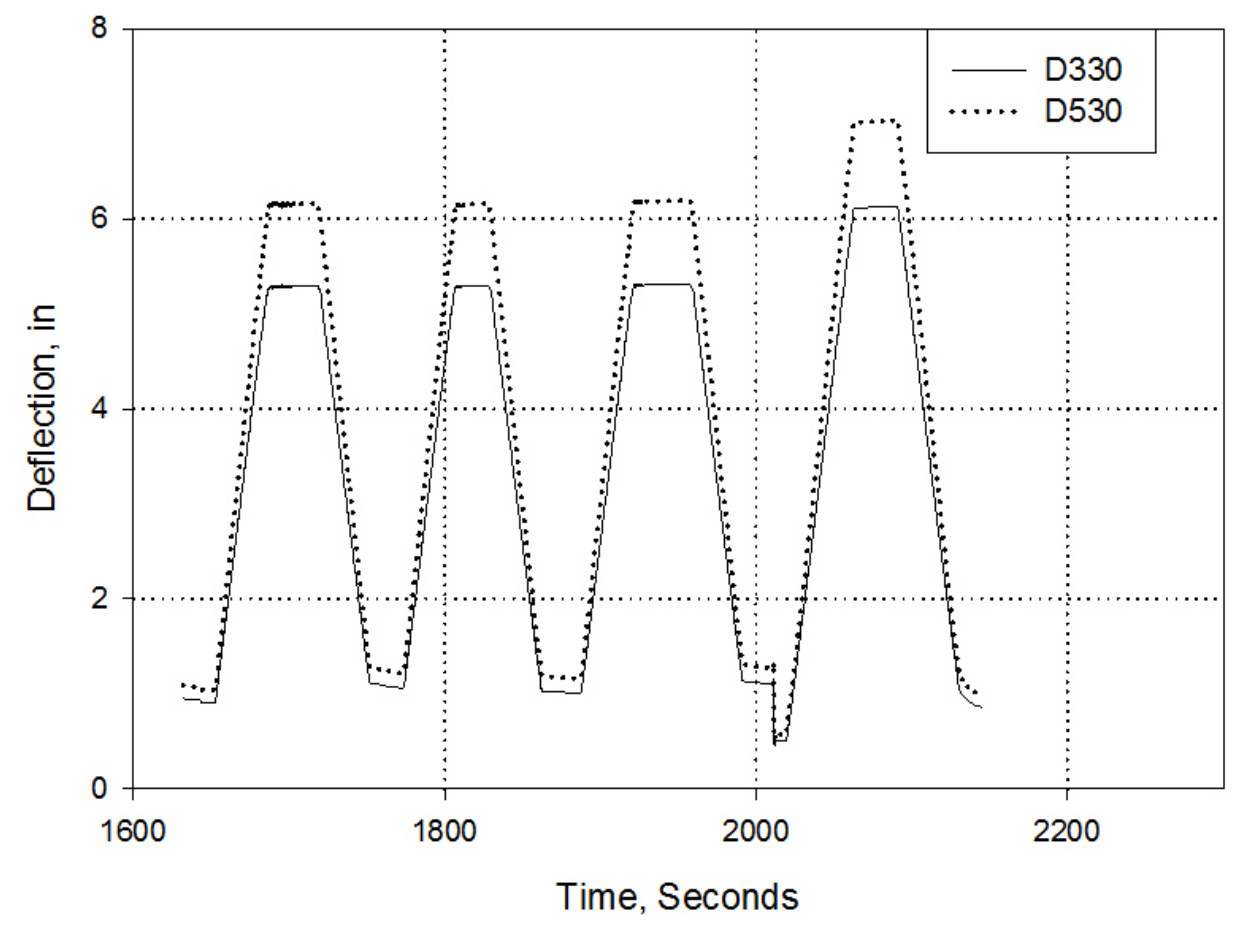

The corresponding displacements over time at midspan are shown in Figure 90 and Figure 91. Residual deformation also appears in this location after removing the load.

Figure 90. Displacement over time at midspan bottom fiber.

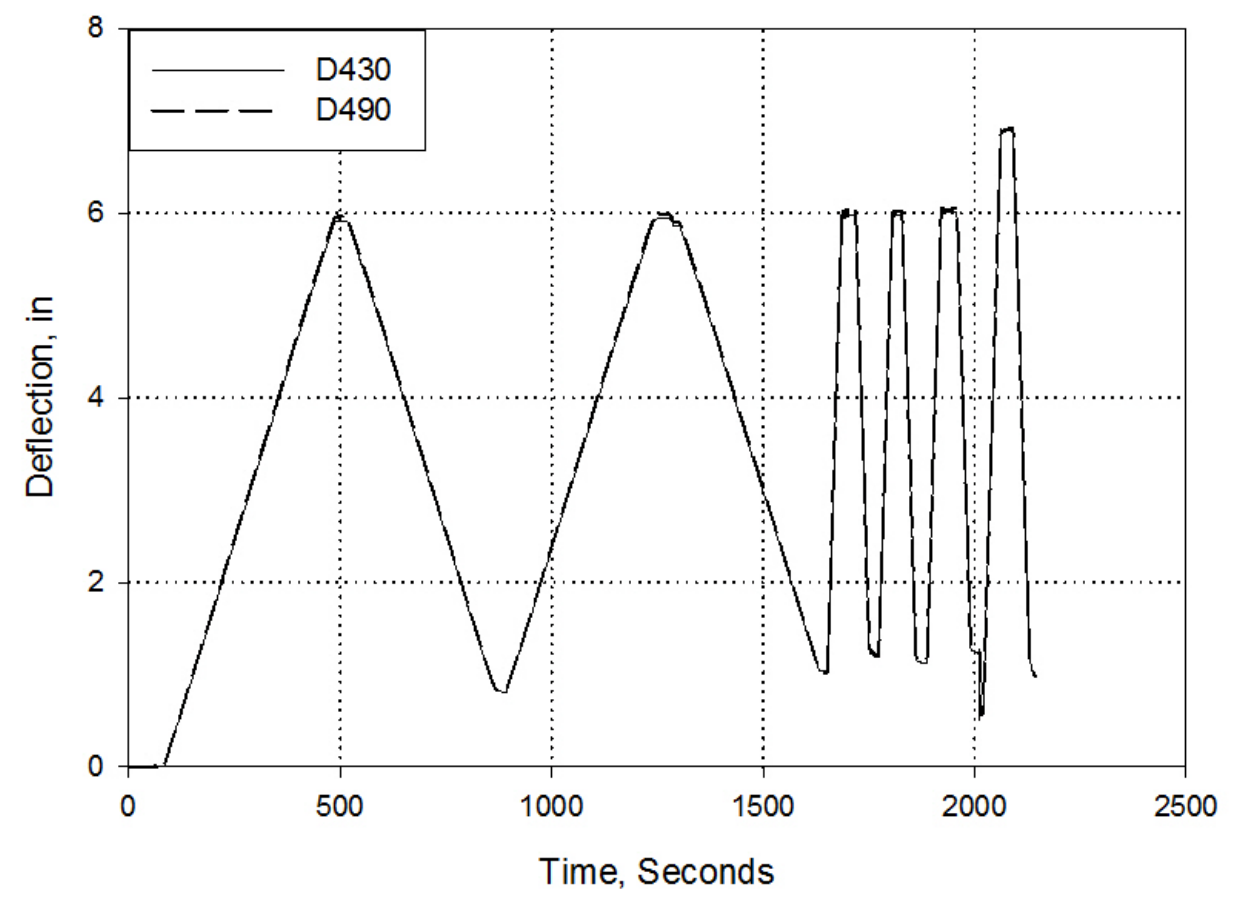


Figure 91. Displacement over time at midspan bottom fiber, final four cycles.

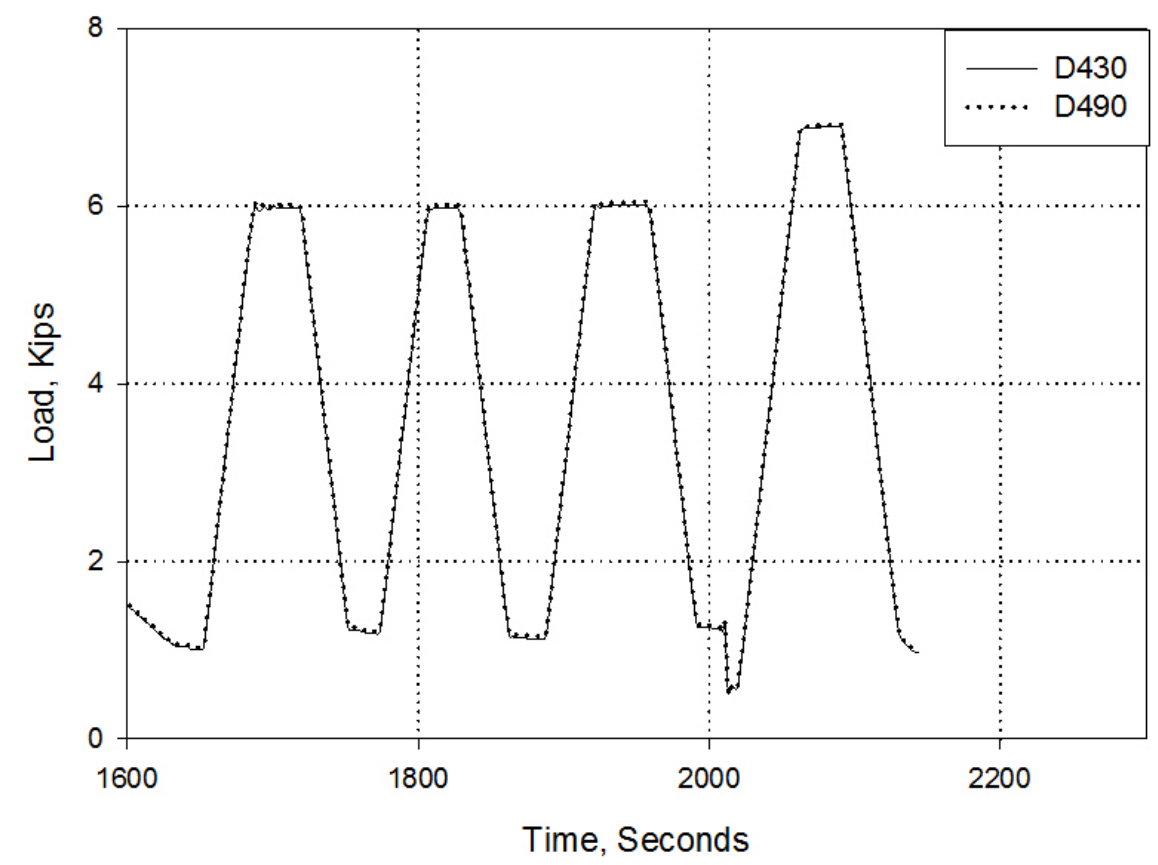

A gauge labeled $\mathrm{D}_{465}$ was attached to the steel loading beam, and the displacement was recorded (Figure 92). The maximum one-inch difference between this displacement and the measured displacements at the $\mathrm{L} / 3$ loading points demonstrates that the loading beam is not rigid enough for its deformation to be neglected. Therefore, it is important to measure all displacements directly from the specimen and to disregard the displacements of the actuators, except as a basis for the general verification of other measurements.

Additionally, it is important to realize that the actual specimen displacement rate at load points may differ significantly from the commanded actuator displacement rate. This difference depends on the stiffness of the loading beam and the amount of force being input into the loading beam, which is a nonlinear function of specimen deflection and deflection rate. If the difference between the prescribed and realized displacement rates is significant, this cannot be accounted for until after the experiment has been performed or unless some feedback correction mechanism is used. The measured midspan deflection rates of the beam specimens will be compared in this report. The midspan deflection rates in this experiment were approximately 0.88 and 8.8 in. per minute, respectively. 
Figure 92. Displacement of the loading steel beam.

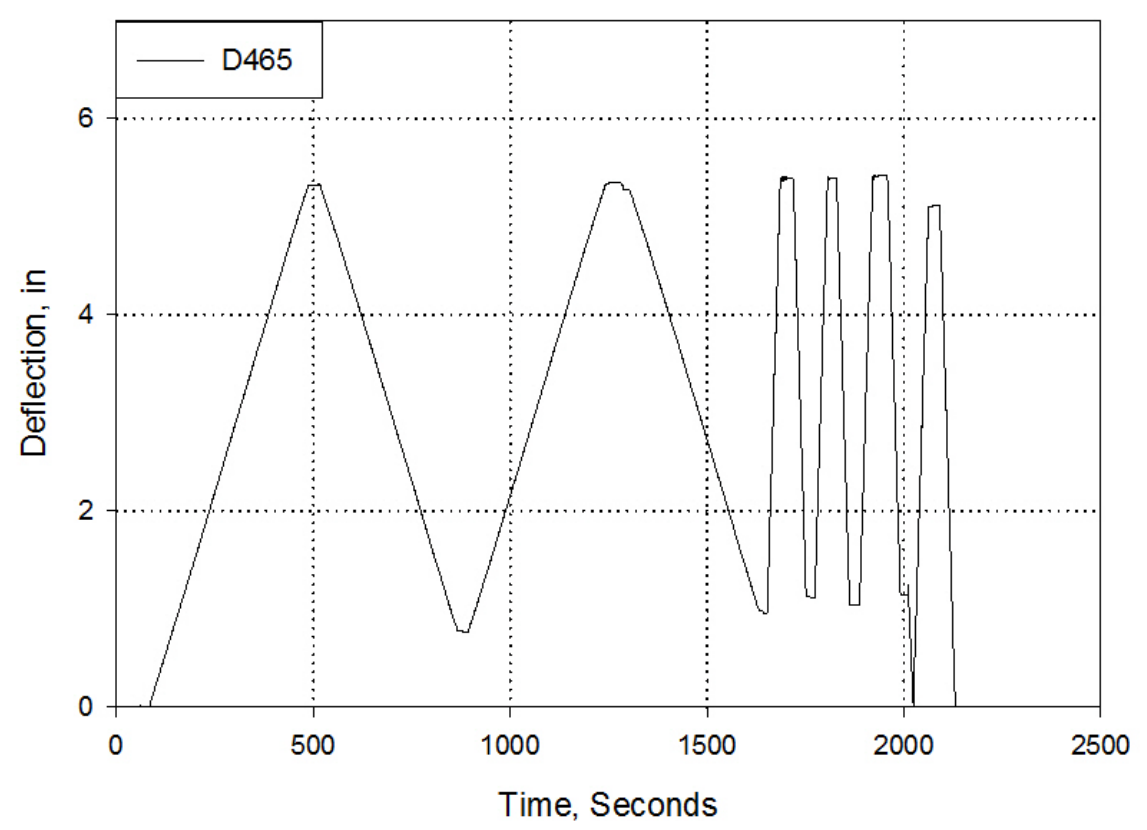

Strain measurements from gauges $\mathrm{S}_{230}$ and $\mathrm{S}_{294}$, located near the point loading $\mathrm{P}_{3}$, are presented in Figure 93. When compared with other strain gauges in this experiment, $\mathrm{S}_{294}$ seems to have recorded unreasonably low values for its position beneath a loading point at $\mathrm{L} / 3$. Since the test video provides no evidence to support the validity of this reading, it is most likely inaccurate. Its inaccuracy may be due to a gauge misalignment, gauge miscalibration, or poor bonding between the gauge and beam surface. The general magnitude of strain readings taken from $S_{230}$, on top of the beam at the same $x$-location, seems more reasonable.

Strains that were recorded near loading point $\mathrm{P}_{5}$ are present in Figure 94. With maximum magnitudes in the neighborhood of 0.002 in./in., the readings from both of these strain gauges seem to make sense and to match the readings at $S_{294}$ fairly closely. 
Figure 93. Strain variation near loading point $P_{3}$.

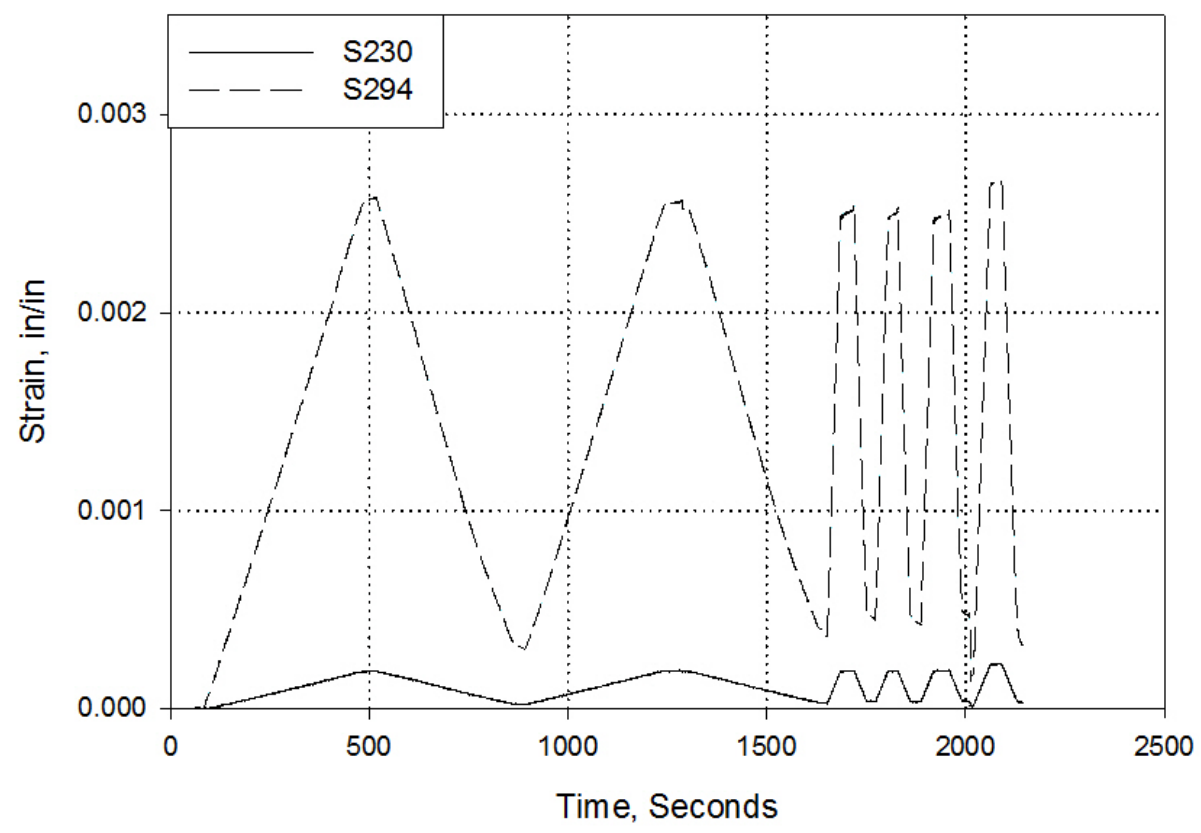

Figure 94. Strain variation near loading point $P_{5}$.

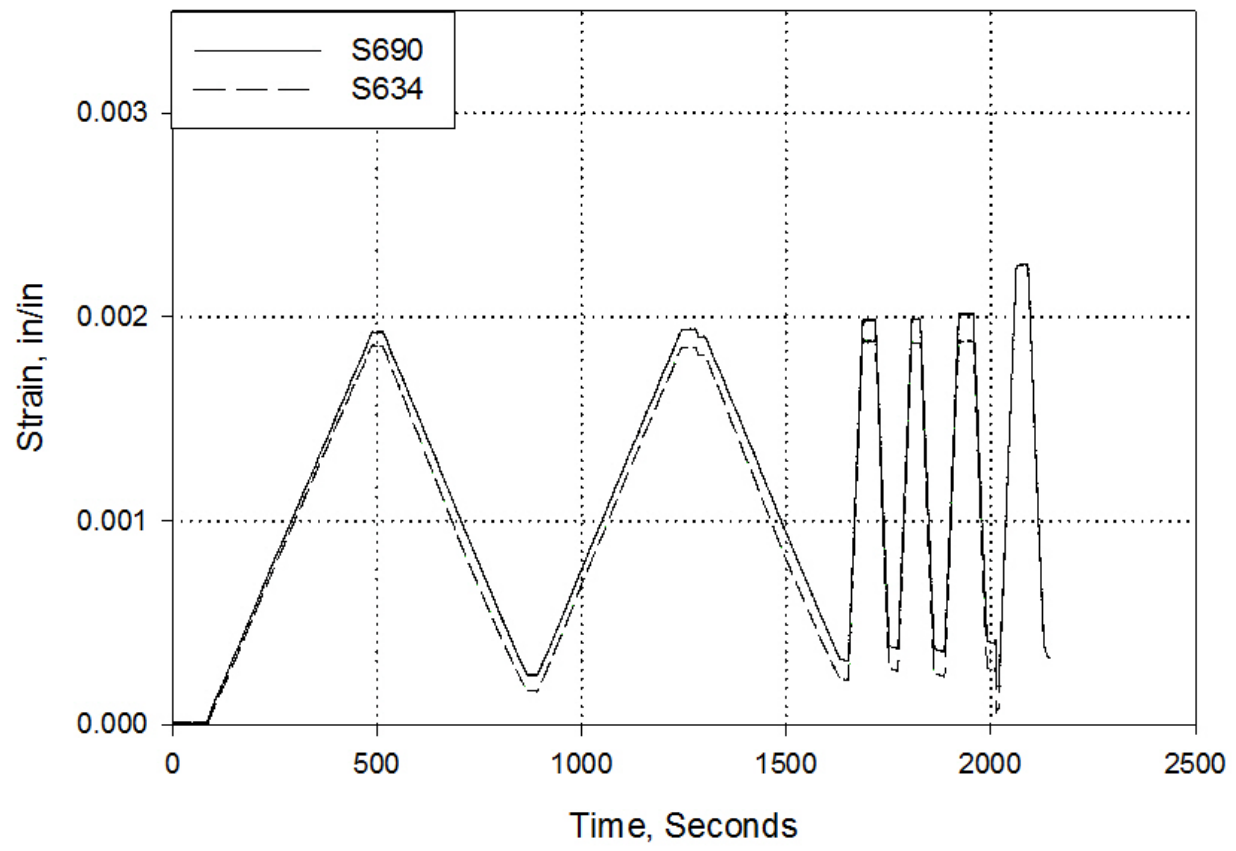


Each of the specimen's I-sections was instrumented at the midspan bottom fiber $\left(\mathrm{S}_{430}\right.$ and $\left.\mathrm{S}_{490}\right)$ and at the midspan top fiber $\left(\mathrm{S}_{434}\right.$ and $\left.\mathrm{S}_{494}\right)$. The maximum strains recorded with $\mathrm{S}_{430}$ were significantly lower than those recorded with $\mathrm{S}_{490}$ (Figure 95). If the beams were nearly identical, wellcoupled, and subject to the same load, the two strain measurements should likewise have been nearly identical. When the relationship between these four strain readings is compared to those in the previous figures, it seems possible that the load was not distributed equally between the two beams. It is also possible that some of the strain gauges recorded bad or inaccurate data. On the other hand, the maximum strains recorded with S434 were approximately the same to those recorded with S494 (Figure 96).

Figure 95. Measured strain at midspan bottom fiber on each I-section.

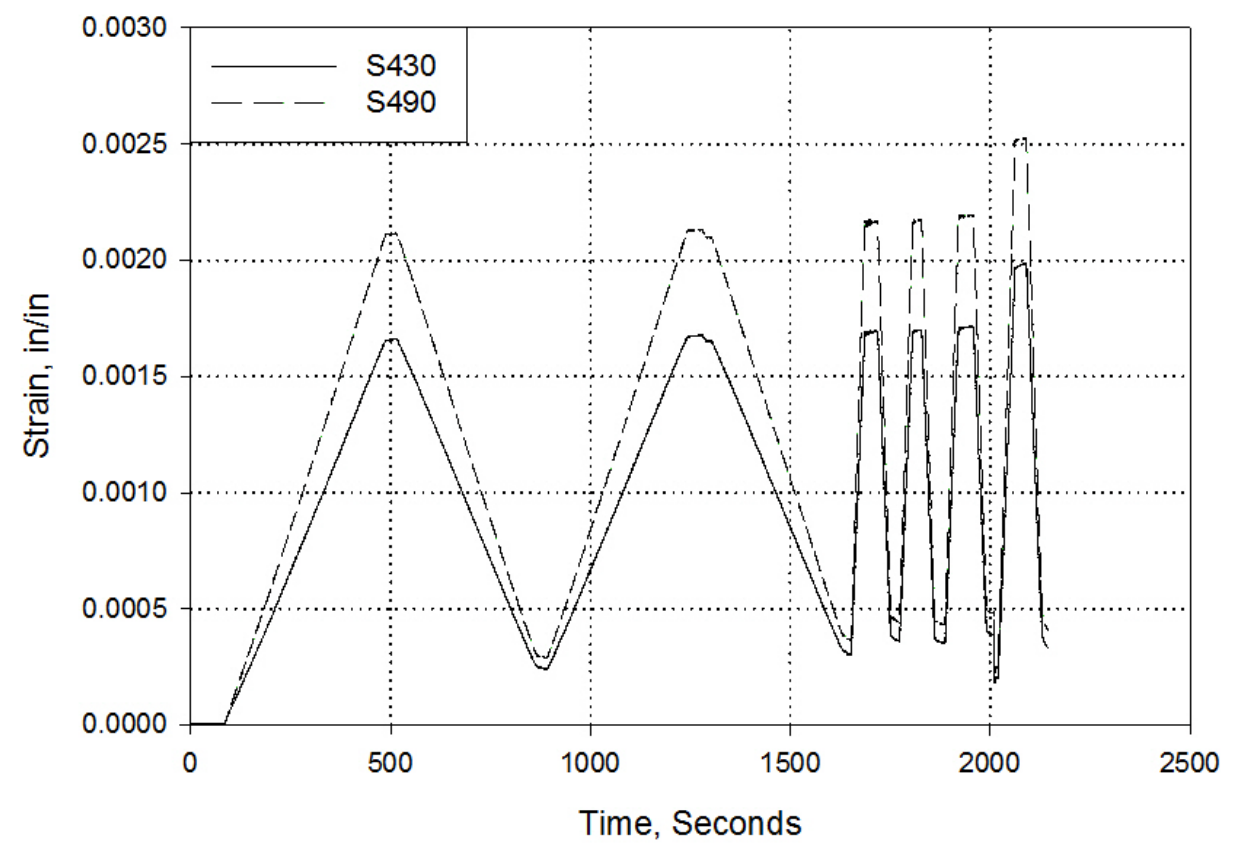


Figure 96. Measured strain at midspan top fiber on each I-section.

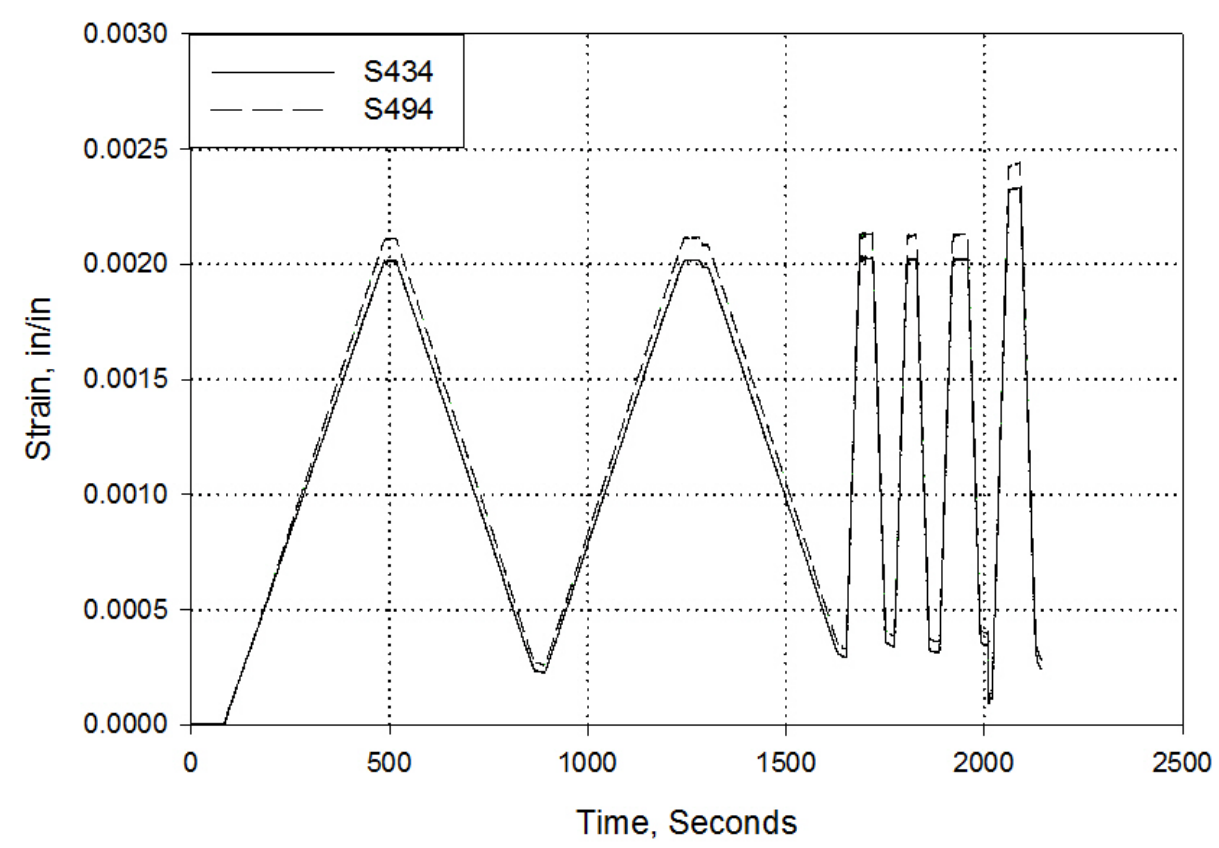

A rosette of horizontal, 45-degree diagonal, and vertical strain gauges was placed $18 \mathrm{in}$. from the support, where shear stresses are high and flexural stresses are low. The readings from this rosette of gauges are plotted in Figure 97.

Figure 97 . Readings from rosette strain gauges.

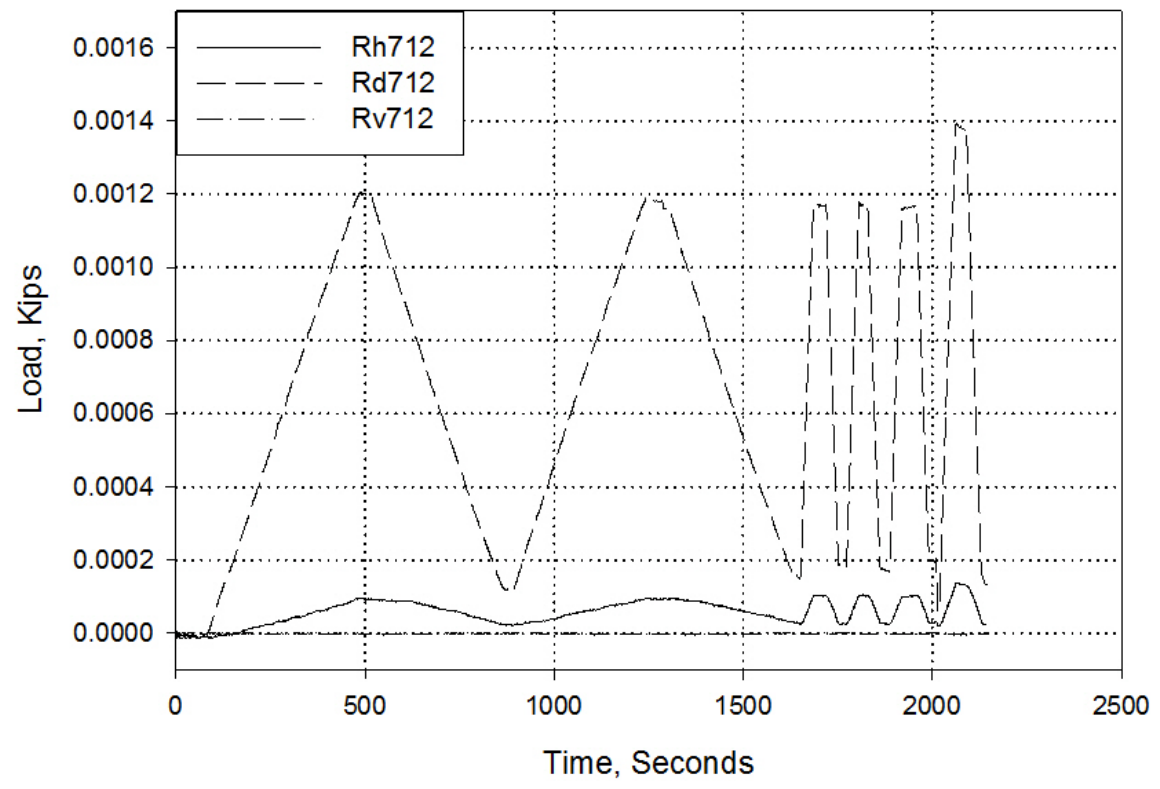

The maximum shear stress derived from the rosette strain gauge readings are shown in Figure 98. The data has been down-sampled to filter out 
measurement noise from $\mathrm{P}_{5}$. The shear stress curve shows hysteretic behavior. The maximum value of about $0.39 \mathrm{ksi}$ appears to agree with the hand calculations in Section 3.5.3 for equal distribution of loading across the two beams.

Figure 98 . $R_{712}$ shear stress plotted over $P_{5}$.

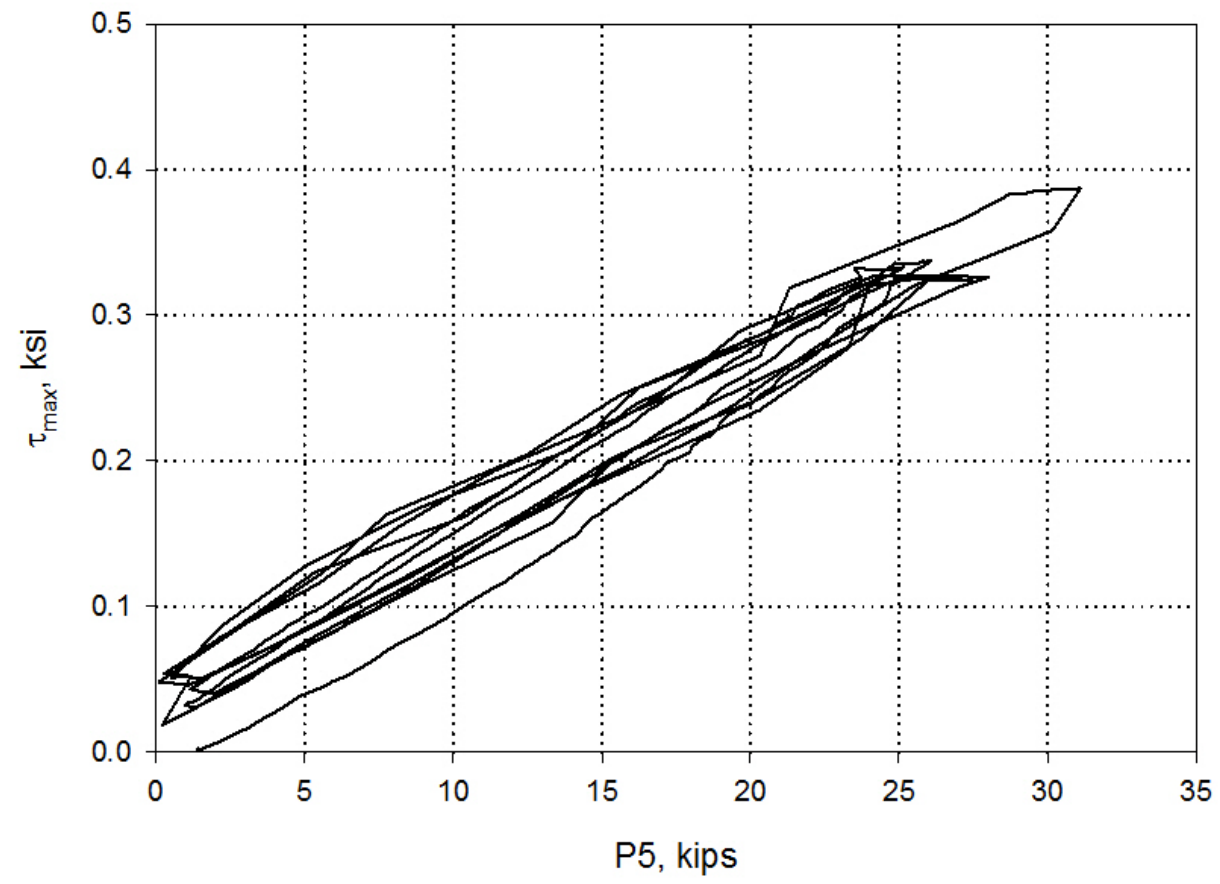

Figure 99-Figure 101 show stress-strain curves for various locations at midspan. The data has been down-sampled to filter out measurement noise from $\mathrm{P}_{5}$, which was used to estimate the stress at each strain gauge location. All these stress-strain curves show similar hysteretic behavior. 
Figure 99. $\mathrm{S}_{430}$ stress-strain curve at midspan bottom fiber.

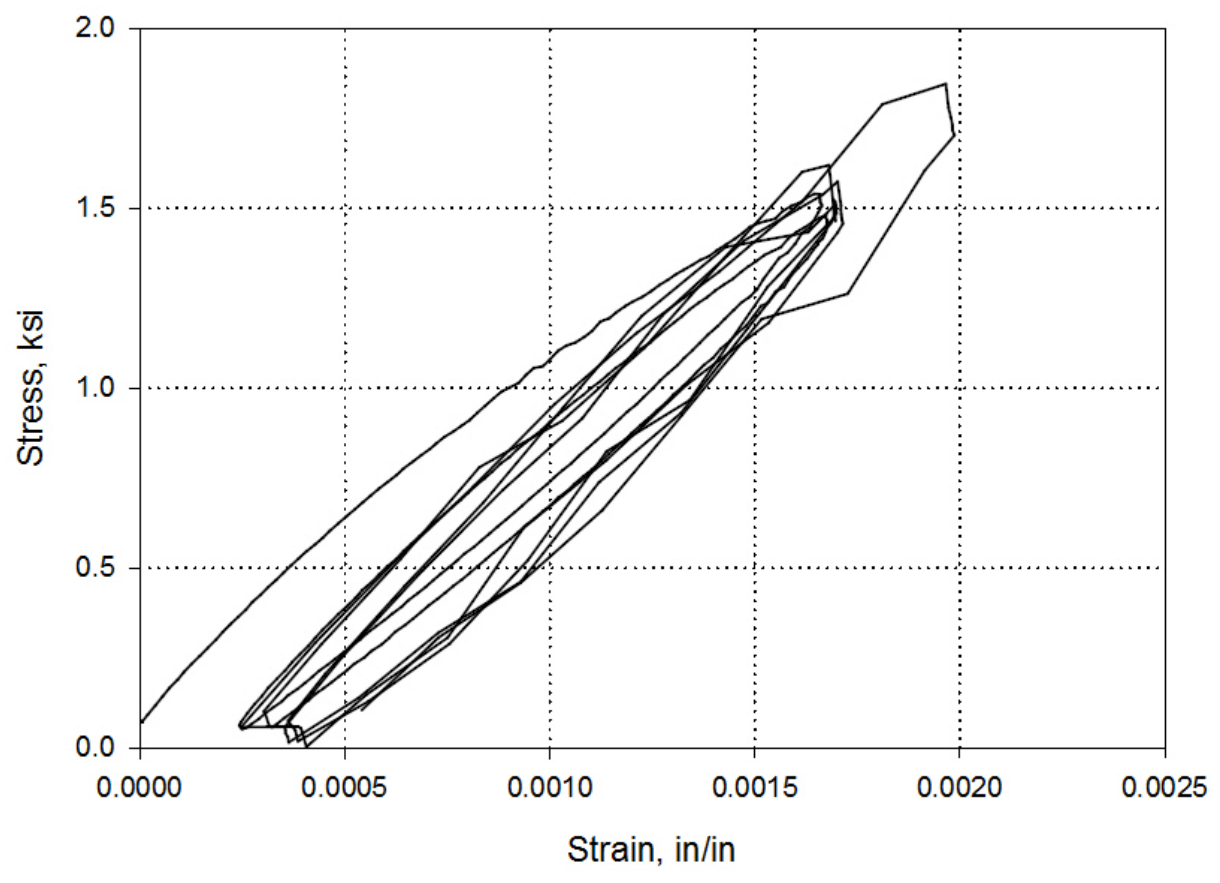

Figure $100 . S_{494}$ stress-strain curve at the midspan top fiber.

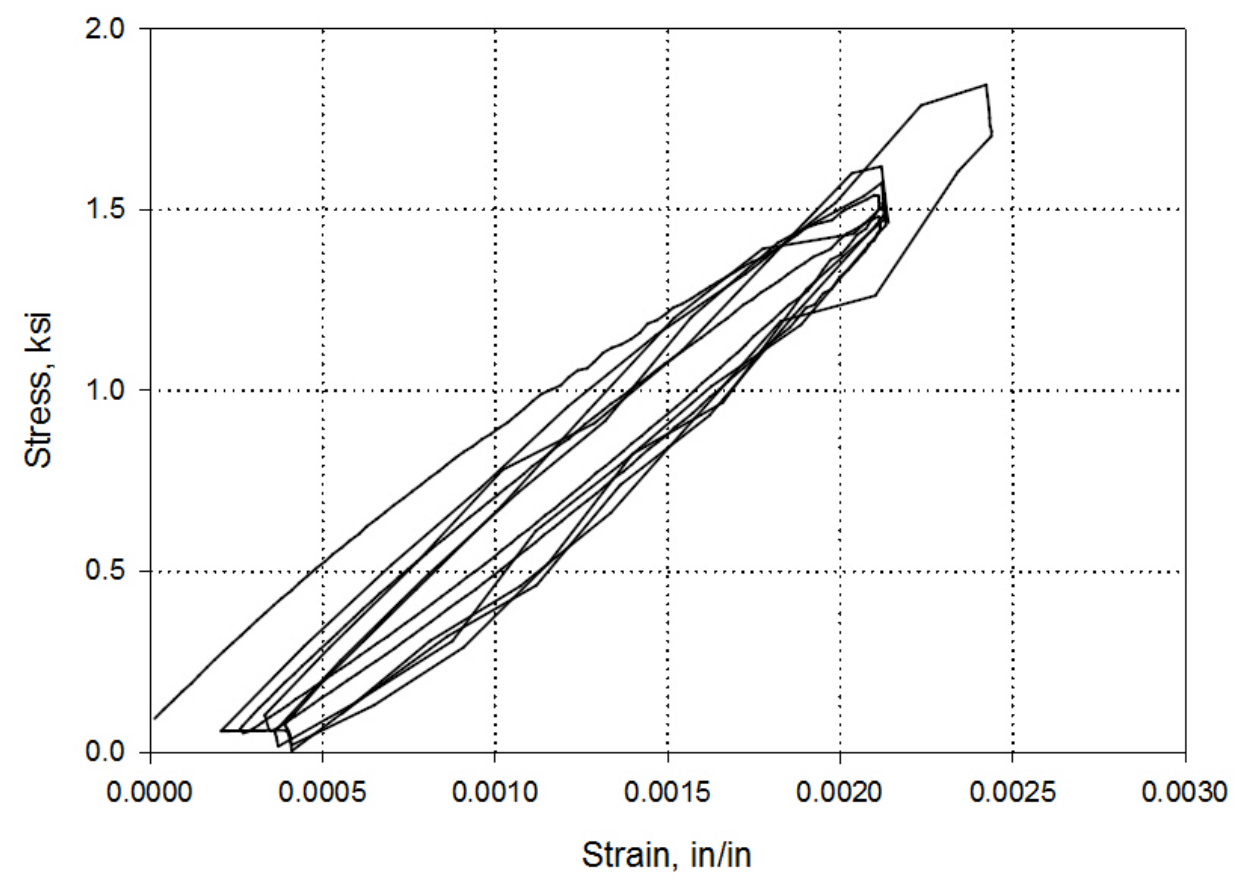


Figure 101. $\mathbf{S}_{490}$ stress-strain curve at midspan bottom fiber.

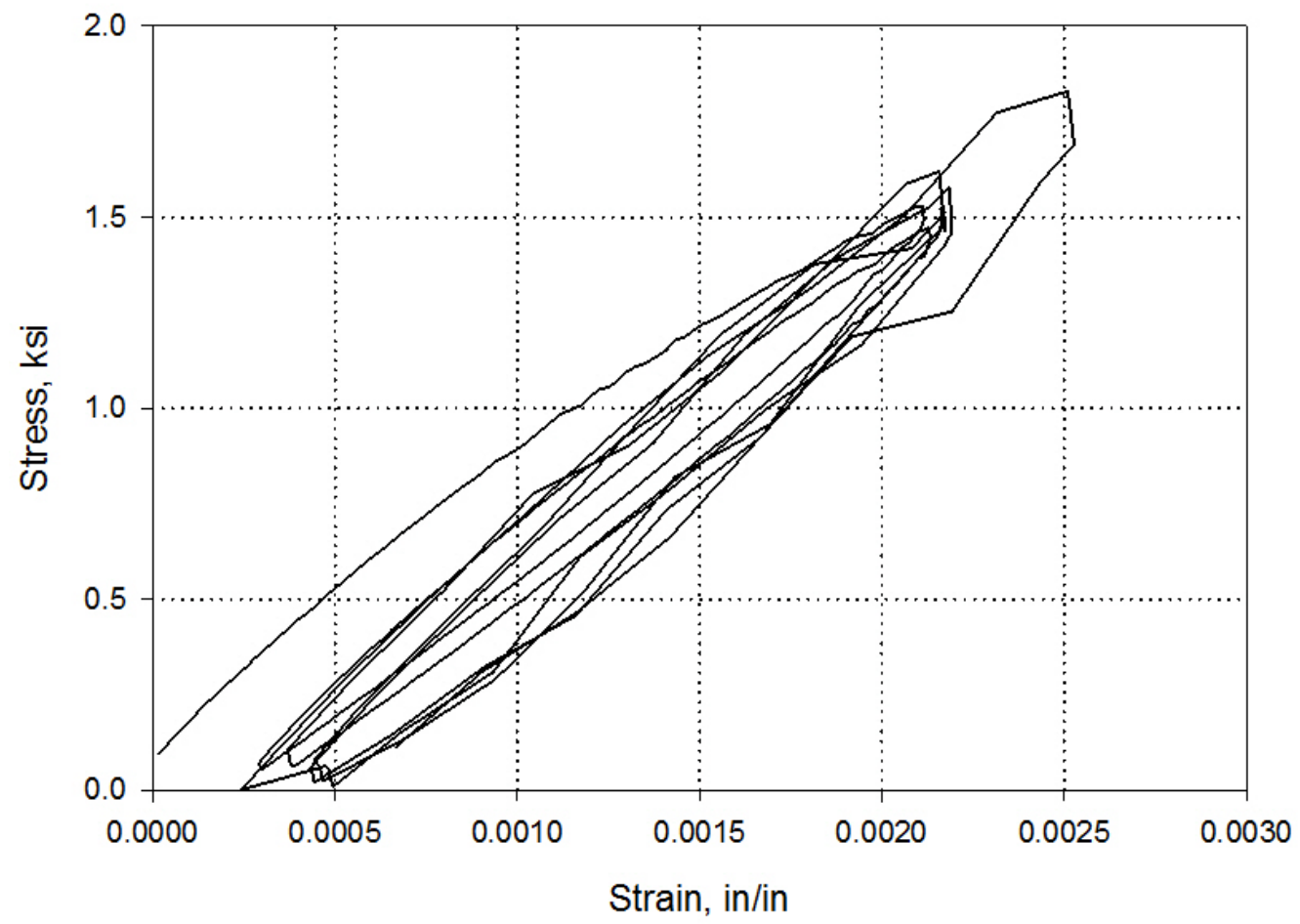

No developing failure modes or even visible cracks were observed in the specimen during loading. The maximum midspan deflection of the specimen was about 7 in. for a 270-inch span. The corresponding deflection-tospan length ratio is about 1:38, which is well beyond the allowable range for use in bridges and other structures. Therefore, the design of this span would generally be controlled by deformation rather than strength for this type of loading. Excessive deformation is shown in Figure 102.

Figure 102. Excessive deformation without failure.

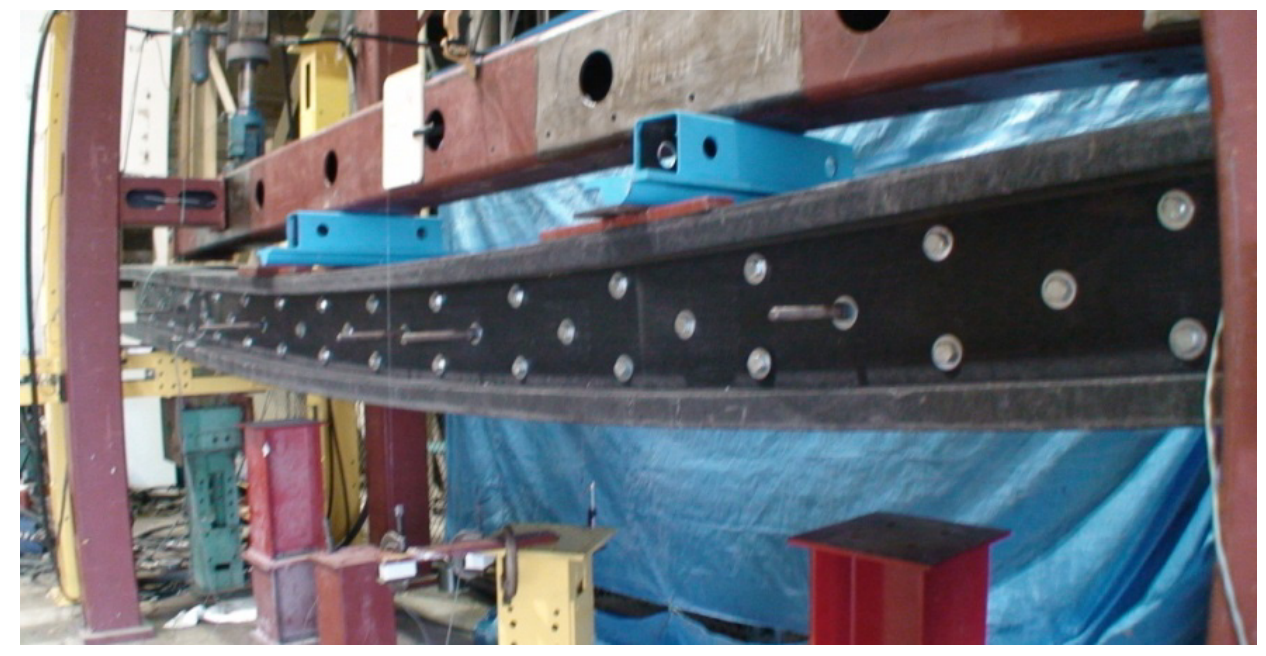


The average stiffness for each measured deflection rate is plotted in Figure 103. Measured deflection rates were calculated from the change in midspan deflection over a given period of time, generally at least $75 \%$ of the loading time in each loading cycle. Average stiffness (Figure 104) was calculated by dividing the change in actuator force (averaged between actuators) over each load cycle by the change in midspan deflection over the cycle, as measured by $\mathrm{D}_{430}$.

Each loading rate produced some distribution of stiffnesses. The number of previous cycles may also have some effect on the stiffness of the specimen, since all of the values in Figure 103-Figure 106 were obtained from serial load cycles on a single beam.

Figure 103. Effect of midspan deflection rate on specimen stiffness.

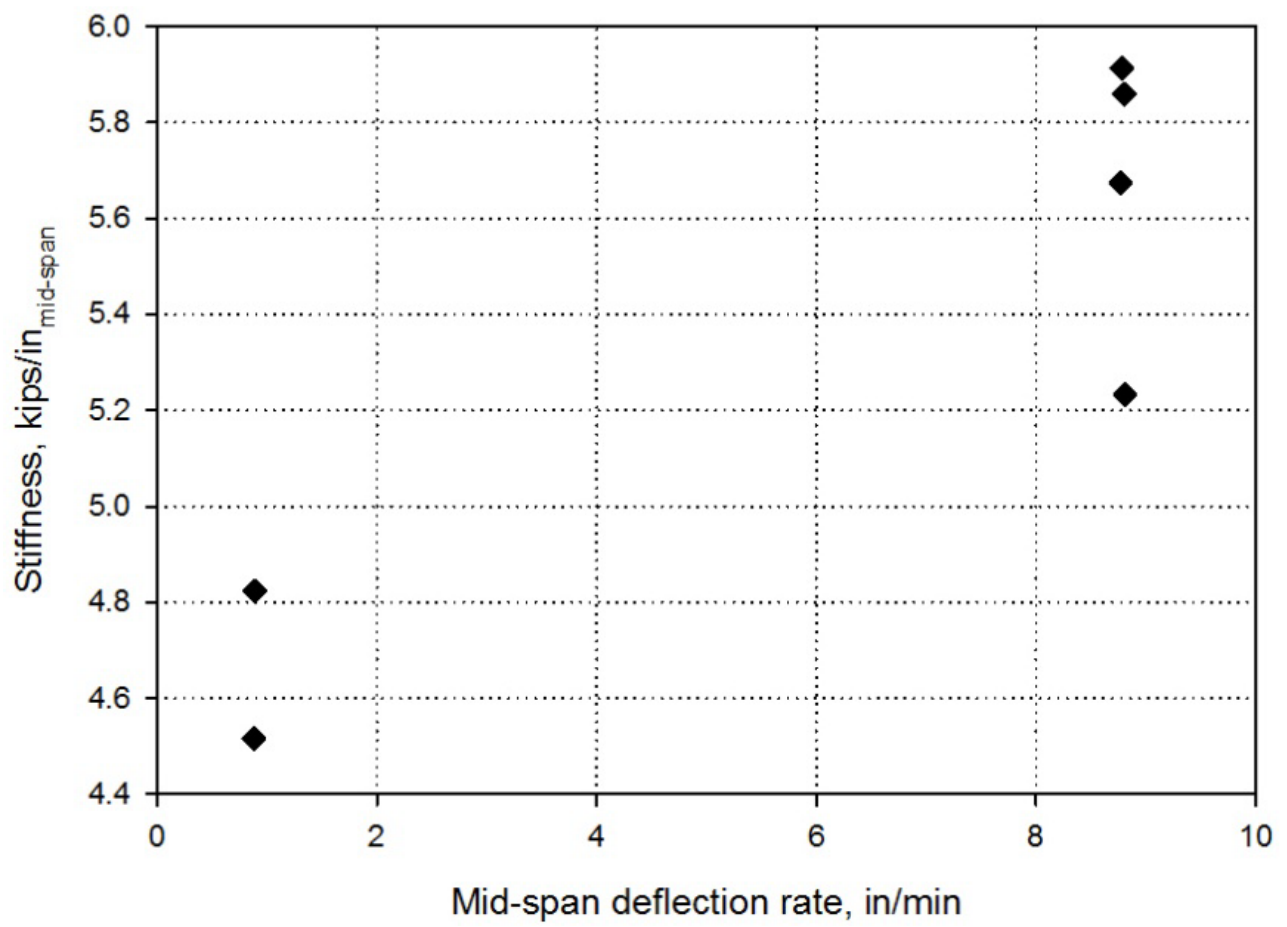


Figure 104. Effect of average midspan deflection rate on average specimen stiffness.

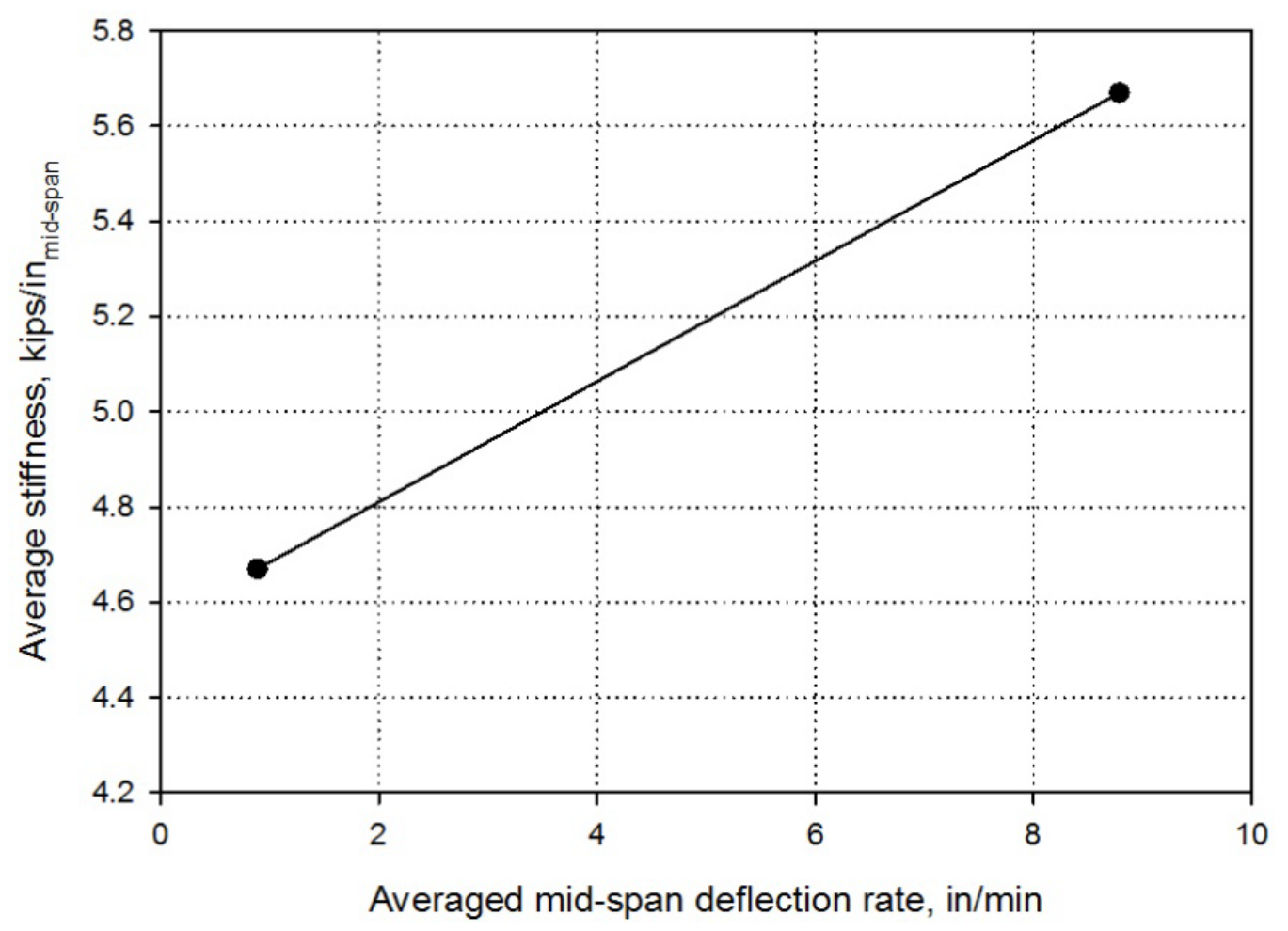

In Figure 105, the midspan deflection rate was normalized to the lowest rate of about $0.88 \mathrm{in}$. per minute, and the load was normalized to the corresponding maximum load. In Figure 106, the midspan deflection rate and maximum load values are normalized to the lowest average values. 
Figure 105. Effect of normalized midspan deflection rate on normalized specimen stiffness.

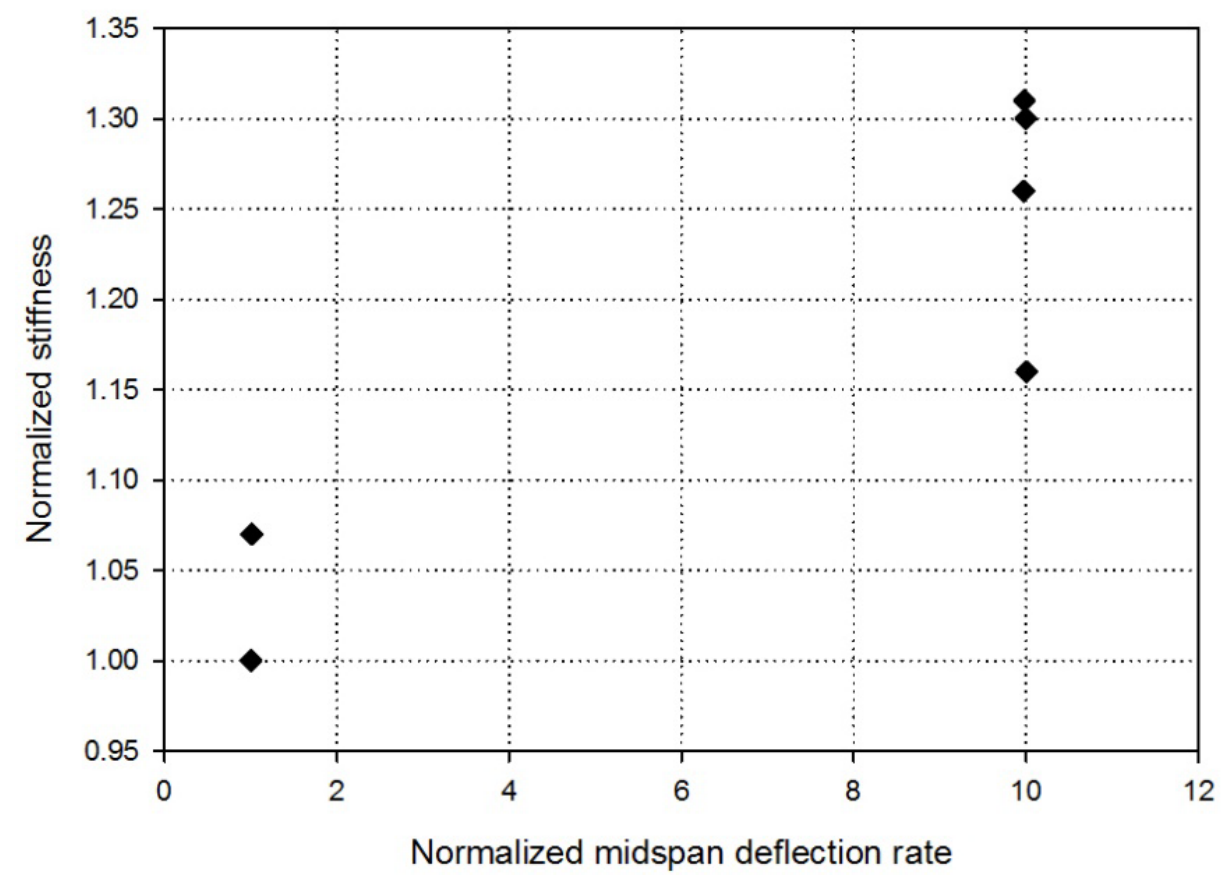

Figure 106. Effect of normalized average midspan deflection rate on normalized average specimen stiffness.

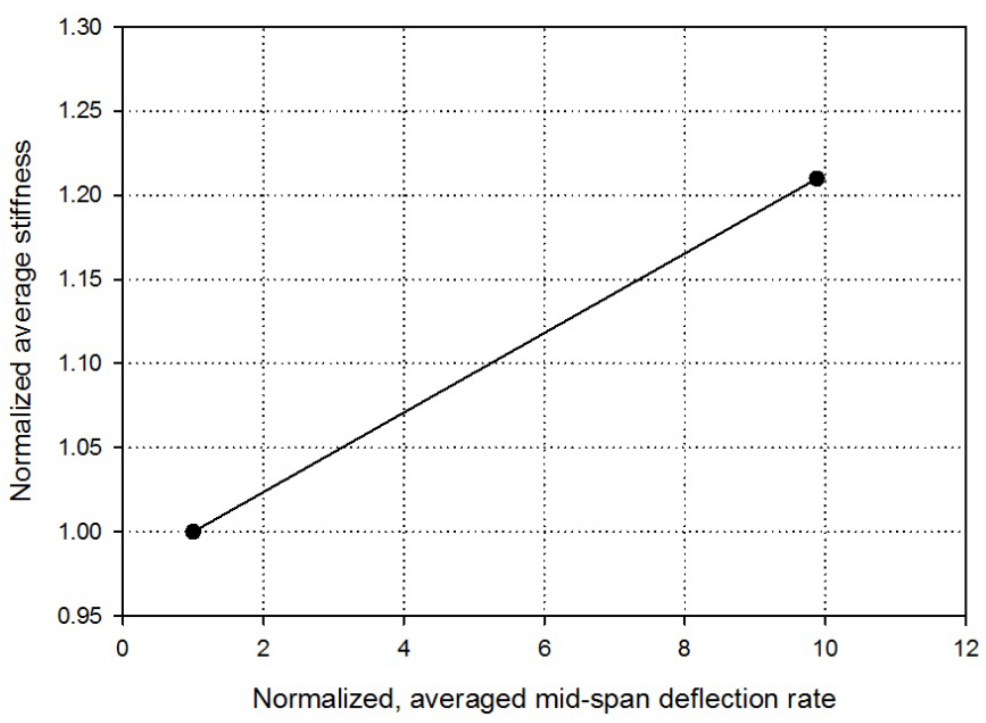




\section{Test \#5 - Double Beam Improved Batch}

This test was carried out on a $22 \mathrm{ft}-6 \mathrm{in}$. II-beam (double beam) from the improved batch of thermoplastic material. The II-beam consisted of two symmetric I-beams bolted flange tip-to-flange tip to form a box girder shape. Each symmetric I-beam used consisted of two nonsymmetric T-sections bolted web-to-web. The pair of I-beams was also stiffened with a $12 \mathrm{in.} \mathrm{deep,} 12 \mathrm{in}$. wide, and $12 \mathrm{in}$. long section of I-beam with $2 \mathrm{in}$. thick flanges. Figure 83 in the previous section shows the assembly process of a II-beam specimen.

The objective of this test was to load the stiffened double beam until failure. The double beam in this test was identical to the specimen described in Test \#4, except the beams were chosen from the improved batch. This specimen was also preloaded with dead weight in order to work around the force and stroke limits of the actuators. An additional dead weight preload of 37.7 kips was hung near the loading points of the actuator such that the added preload was distributed approximately evenly between the loading points, at about 18.85 kips per side. Figure 107 shows the Test 5 setup.

Figure 107. Setup of Test \#5.

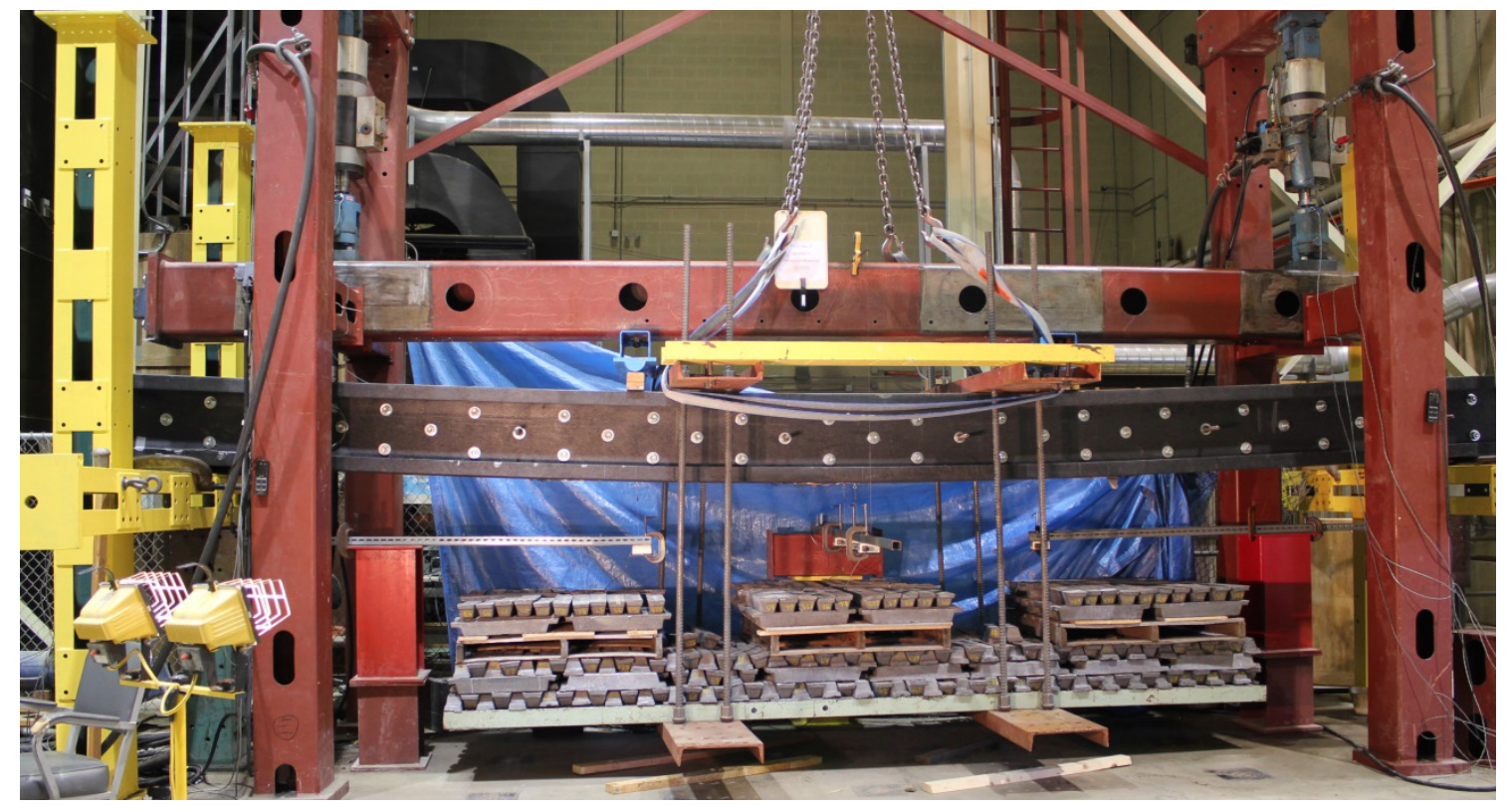

Initially, the preload was suspended from the crane. After gradually lowering the crane boom to apply the preload, the actuator loading protocol was initiated. Each full load cycle consisted of the following steps: 
1. Apply preload using overhead crane.

2. Apply displacement-controlled loading from actuators to maximum actuator stroke.

3. Unload actuators in displacement-controlled manner.

4. Remove preload with overhead crane.

The displacement and strain data discussed in this section resulted from the combined gravity and actuator loads imposed on the specimen, while the actuator load cells only recorded the time histories of actuator forces. Figure 108 shows actuator-only force time histories, with two cycles concatenated, (i.e., placed one immediately after the other). The time that separates applications of actuator loads in the figure is not necessarily what occurred in the lab. All time histories in this section are similarly concatenated.

Figure 108. Actuator-only load time histories.

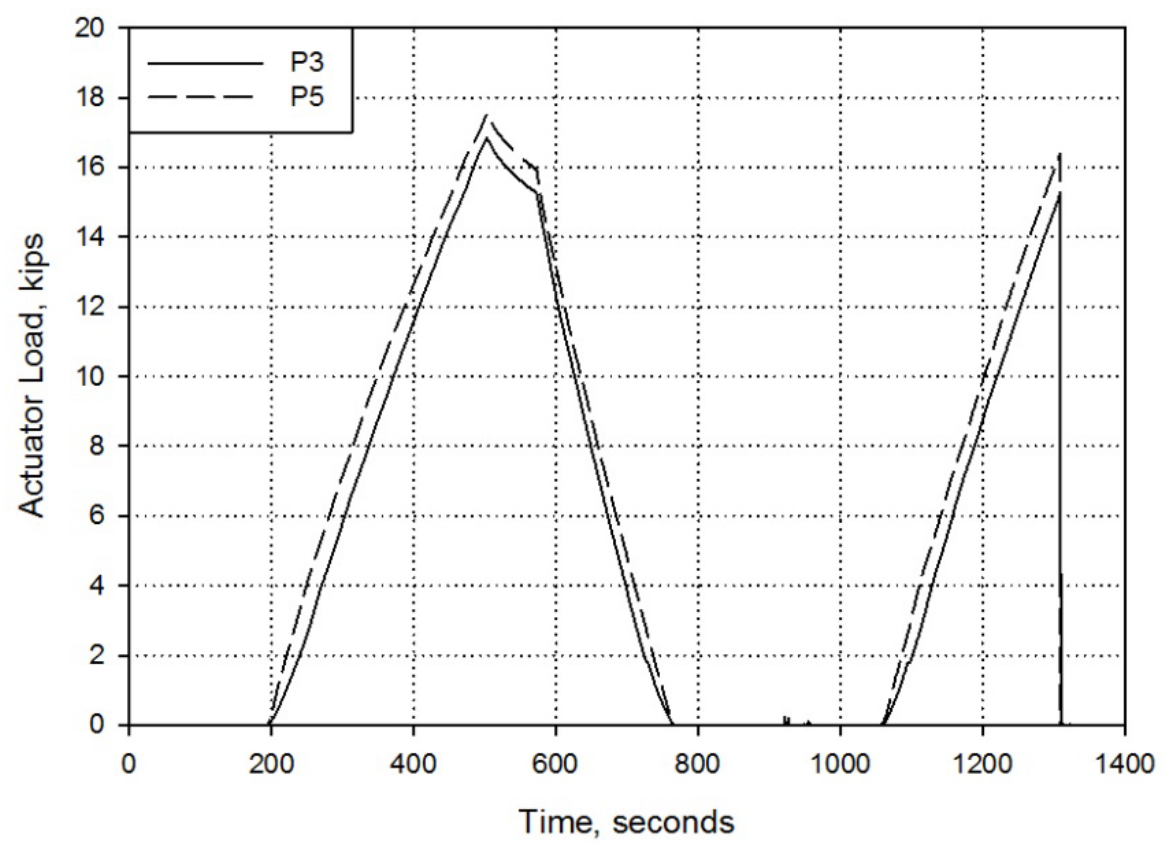

The loading of the specimen over time may be approximated as Figure 109, where the recorded actuator force time histories are offset above the dashed horizontal line ( $\mathrm{P}=18.85 \mathrm{kips})$, and the loading curve under the line is approximated from the known magnitude of the specimen preload and the measured displacement $\mathrm{D}_{330}$. The application and removal of the preload did not necessarily proceed as shown in the diagram. The loading rate of the beam varies significantly throughout this test. 
Figure 109. Approximated total force time histories (preload and actuators).

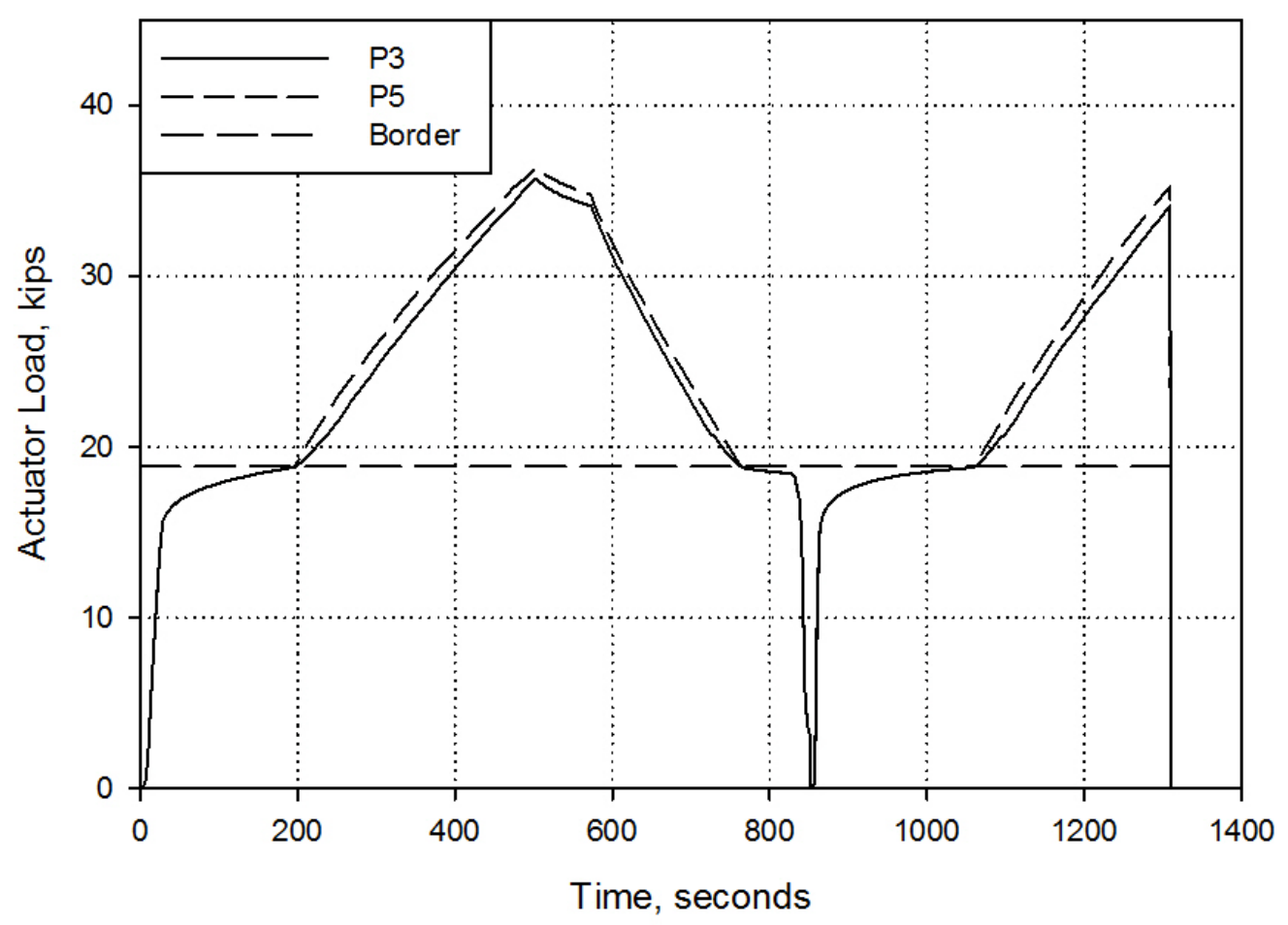

After preloading, the actuators were used to load the specimen in the displacement-control mode. During unloading, the actuators were commanded to unload the beam at a constant displacement rate until the actuator load was o kips. Figure 110 and Figure 111 show that beam deflection under the preload was greater after actuator loading than before actuator loading.

The midspan specimen deflection in each beam was measured $\left(\mathrm{D}_{430}\right.$ and $\mathrm{D}_{490}$ ) and is shown in Figure 111. The measured deflections are very close to one another until after the second application of the preload with the overhead crane. One of the displacement sensors may have been bumped out of alignment during the application of the preload. If the preload was applied unevenly, one would expect to see a difference in deflection at the loading point as well. This difference does not appear. The test video contains no visible evidence of a difference in the midspan deflections of the two I-beams. 
Figure 110. Load point displacement under both loading actions.

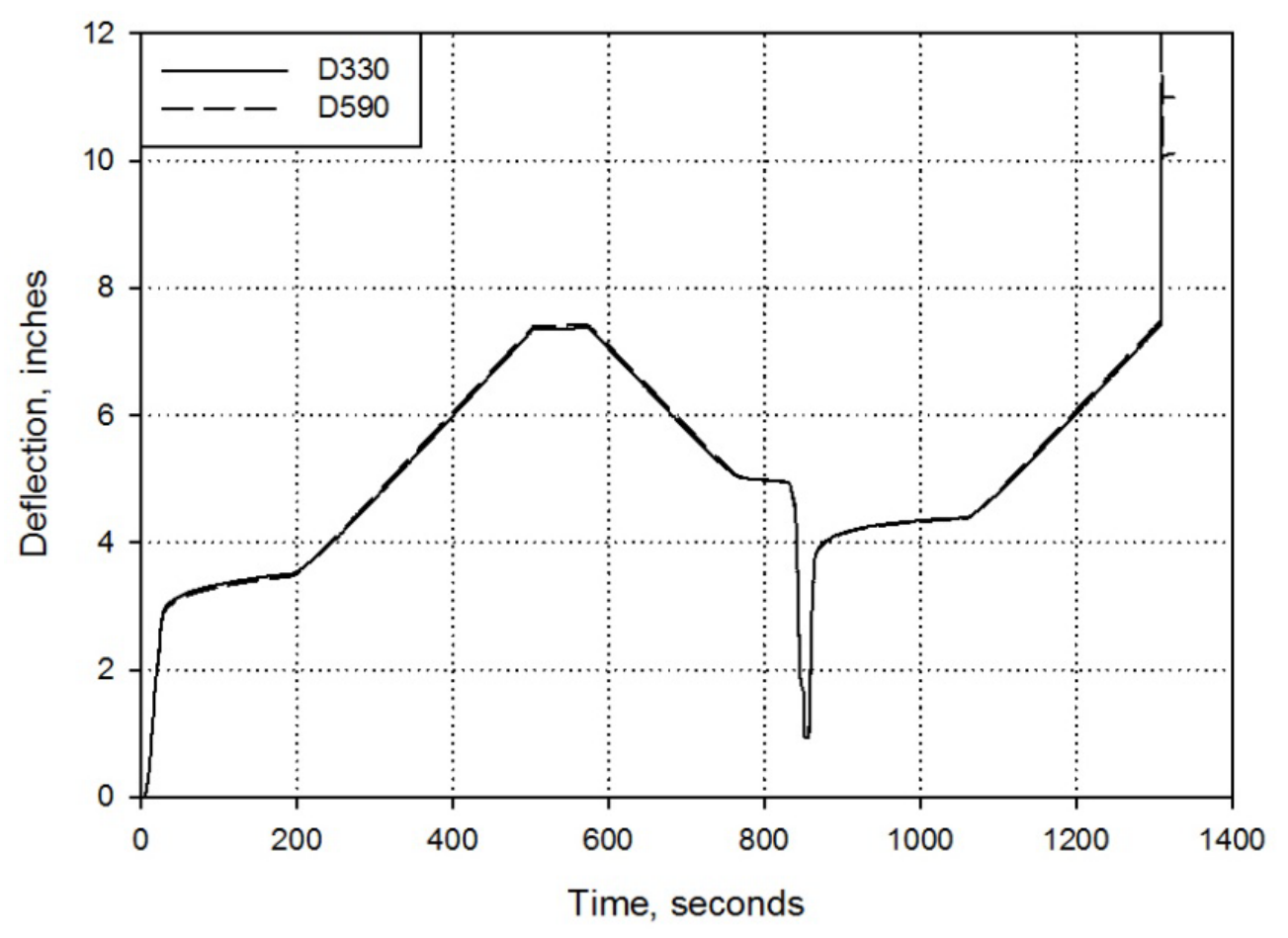

Figure 111. Midspan displacement under both loading actions.

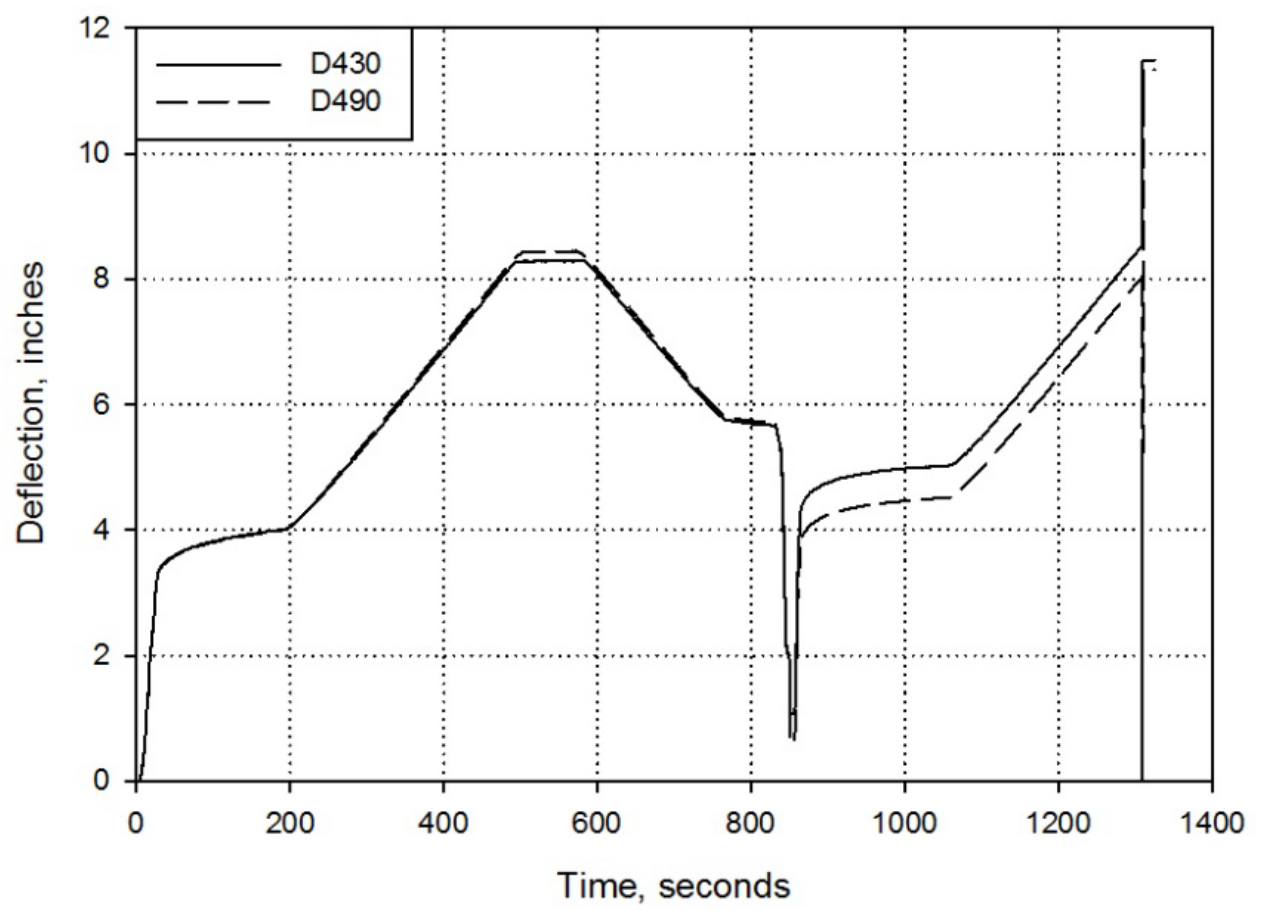

The measured strains under each actuator are shown in Figure 112. Apparently, gauge $\mathrm{S}_{230}$ did not record good data. The readings from $\mathrm{S}_{230}$ follow 
closely the trend from $\mathrm{S}_{294}$, which appears to have returned reasonable data, and the two strain gauge readings are off by a factor of almost exactly 10. Nevertheless, when the strain values from $S_{230}$ are multiplied by 10 , the resulting curve is comparatively noisy (Figure 113). This is likely a result of comparatively low voltage levels in the original $\mathbf{S}_{230}$ reading (i.e., bad or unreliable data).

Since these strain readings are taken from different I-sections and fiber locations, it is difficult to describe or compare directly the local behavior of the two I-sections. However, if each beam can be assumed to flex about a neutral axis at about the same section depth, the curvature in both beams and at each load point appears to be approximately equal over time.

Figure 112. Strain time histories under both loading actions.

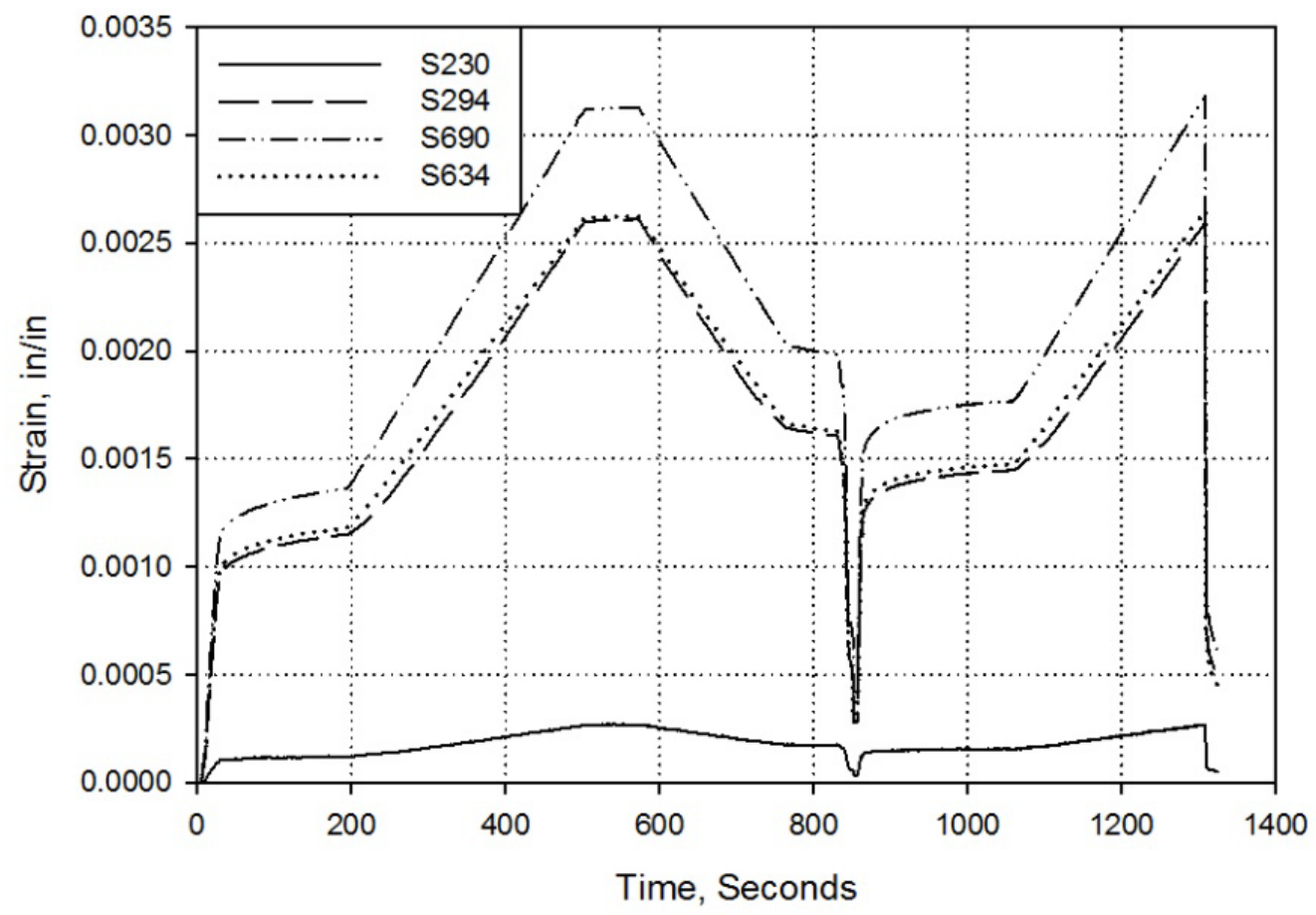


Figure 113. Strain time histories with $S_{230}$ multiplied by 10 .

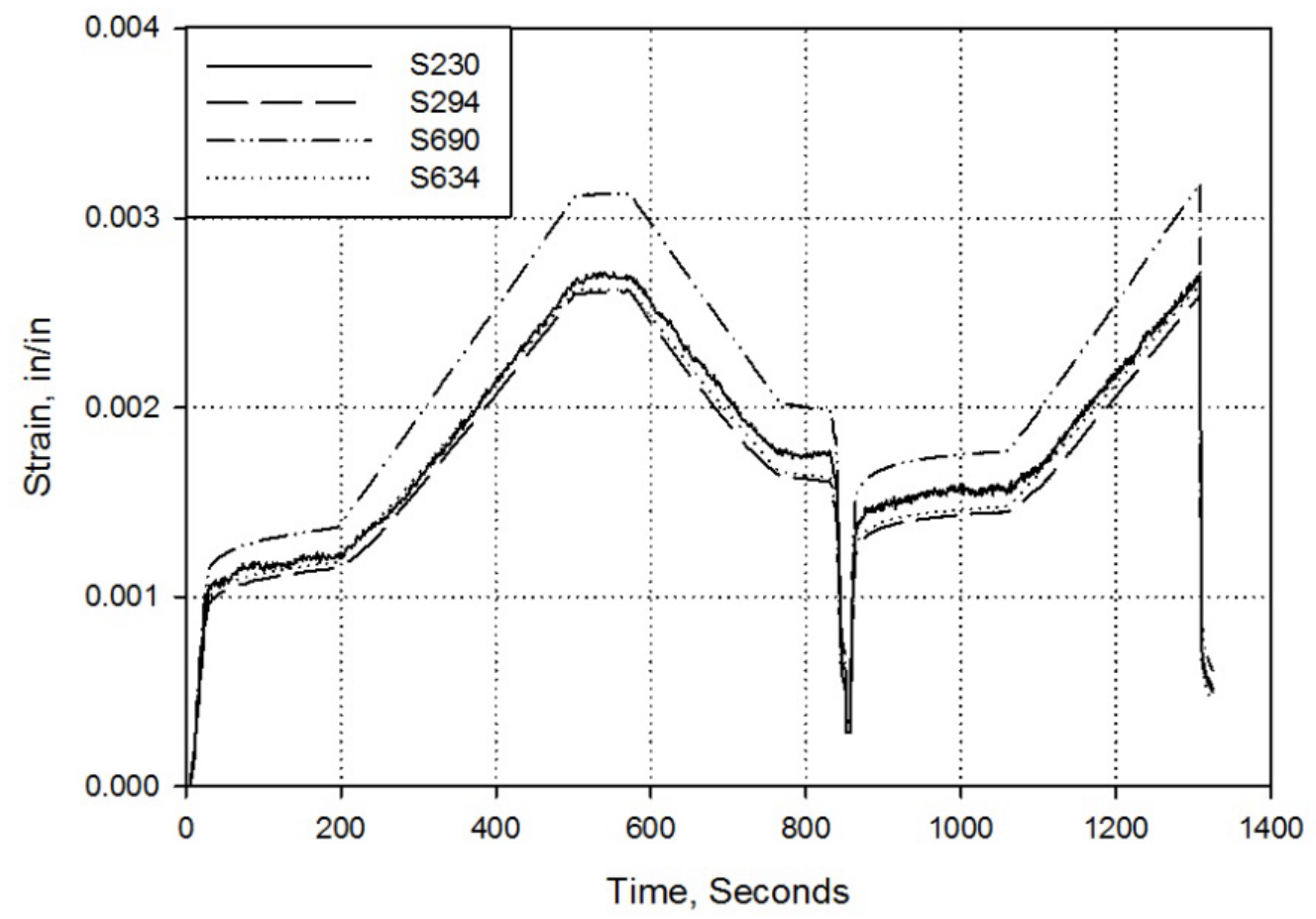

Each of the specimen's I-sections was instrumented with strain gauges at the midspan top and bottom fibers. Gauges $\mathrm{S}_{430}$ and $\mathrm{S}_{490}$ were used to measure strain at the bottom fiber of each I-section, while $\mathrm{S}_{434}$ and $\mathrm{S}_{494}$ measured strain at the respective top fibers (Figure 114). A substantialbut approximately proportional-difference is apparent between the top and bottom strains in each I-section. Also, each of the top and bottom strains in one I-section appear to be proportionally greater than the corresponding strains in the other I-section. These two phenomena imply that each beam flexed about a neutral axis at approximately the same section depth, but the curvature at midspan is greater in one beam than it is in the other.

This finding does not necessarily mean that one beam is globally stiffer than another. Curvature is a function of local, or instantaneous, flexural stiffness. Therefore, the midspan section of one beam may be significantly stiffer than the other, but this relative stiffness may not hold true over the span of the specimen. The stiffness over the span of the section is what determines midspan deflection.

A rosette of three strain gauges-horizontal, diagonal, and vertical-was placed at the midheight of the web, $18 \mathrm{in}$. from the north support. While 
the horizontal and vertical gauges measured small strains, the diagonal gauge returned significant strain with a maximum value of $0.0019 \mathrm{in} . / \mathrm{in}$. as shown in Figure 115.

Figure 114. Measured strain at midspan bottom fiber of specimen.

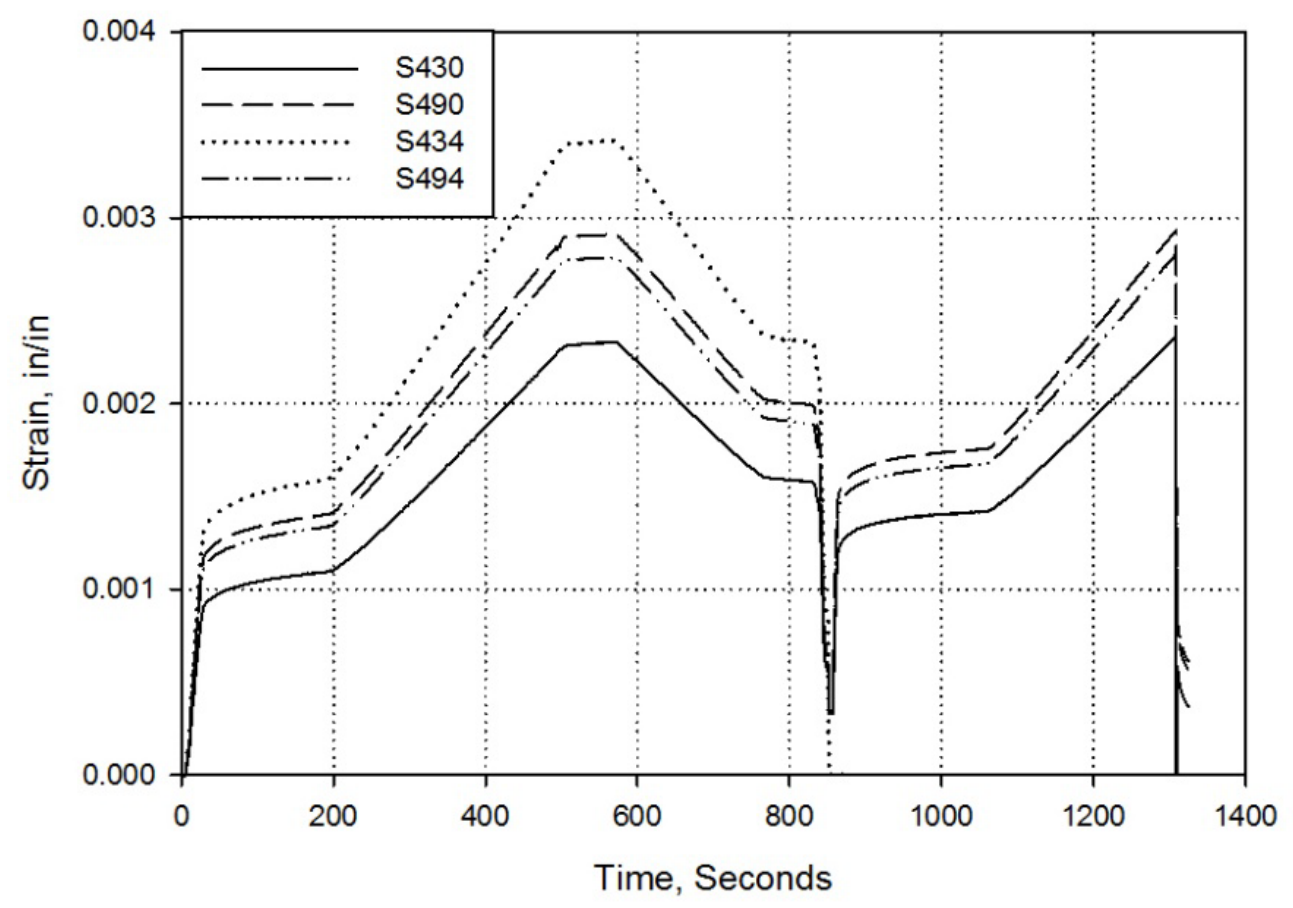

Figure 115 . Strain values measured by the rosette $R_{712}$.

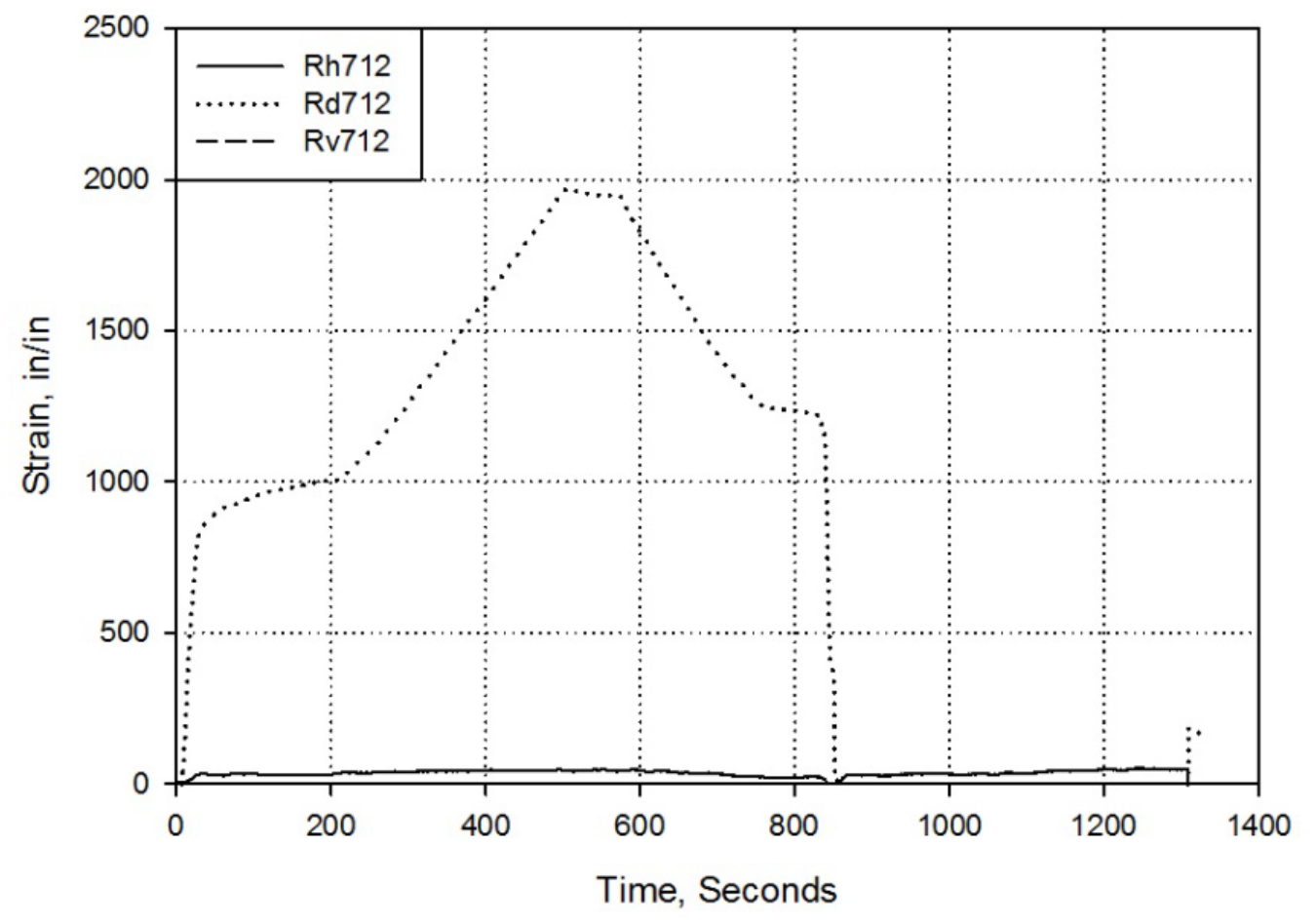


The shear stress at gauge rosette $\mathrm{R}_{712}$ can be approximated by using measured rosette strains and the material properties which were determined from mechanical testing. The calculated stresses are plotted against time in Figure 116, against measured $\mathrm{P}_{5}$ in Figure 117, and against approximated $\mathrm{P}_{5}$ in Figure 118. It is important to note that the specimen is neither linear nor elastic, and it displays some behavior similar to a viscous fluid (deflection rate-dependent force generation and time-dependent deflection under constant force). Therefore, the accuracy of shear stresses calculated from measured strains is uncertain. Below the horizontal dashed line denoted as "Border" in Figure 118, it is evident that the approximated loading curve from Figure 118 may not be a very accurate representation of the actual preloading procedure, but it does serve to provide the proper $y$ axis offset.

Figure 116. Calculated shear stresses at $\mathrm{R}_{712}$ over time.

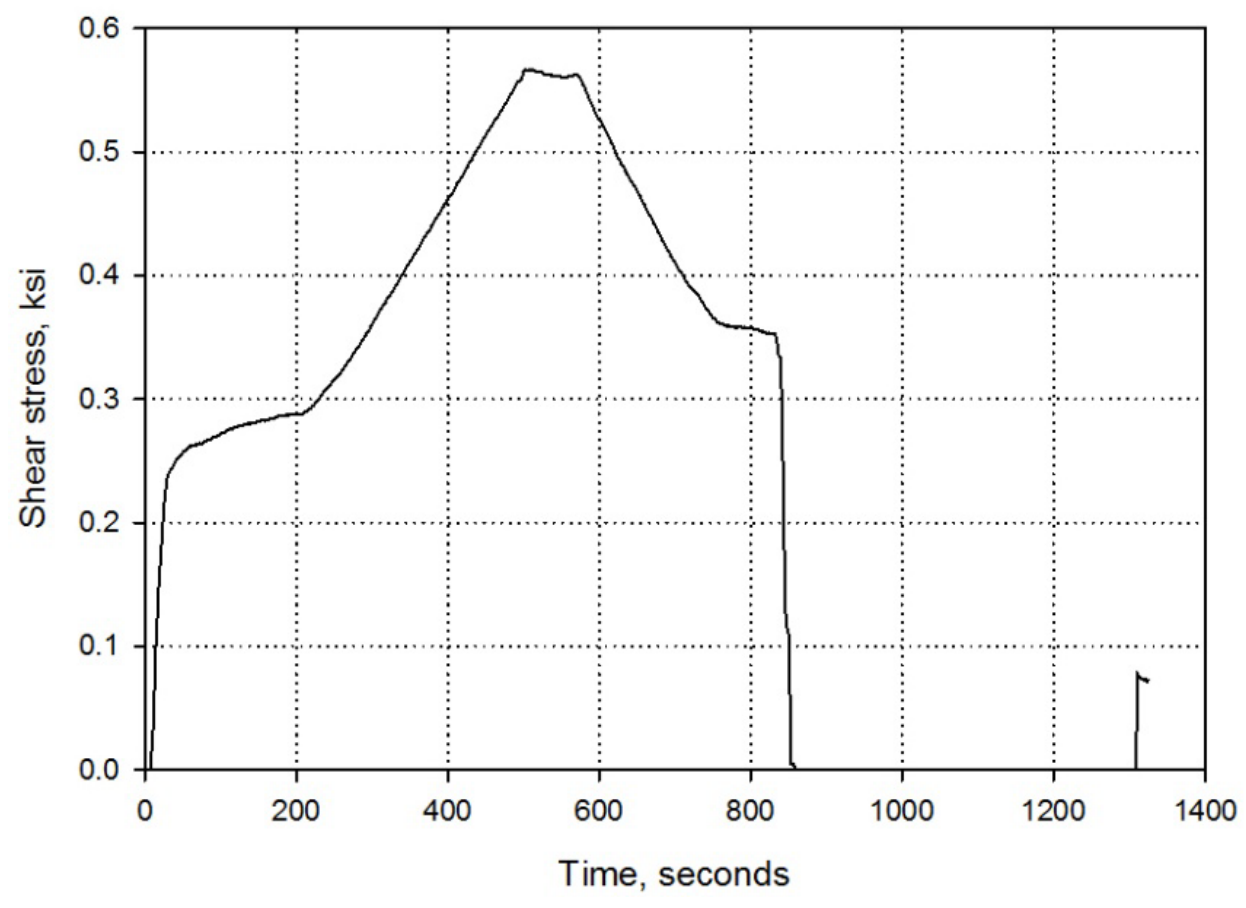


Figure 117. Actuator point load $P_{5}$ versus calculated shear stresses at $R_{712}$.

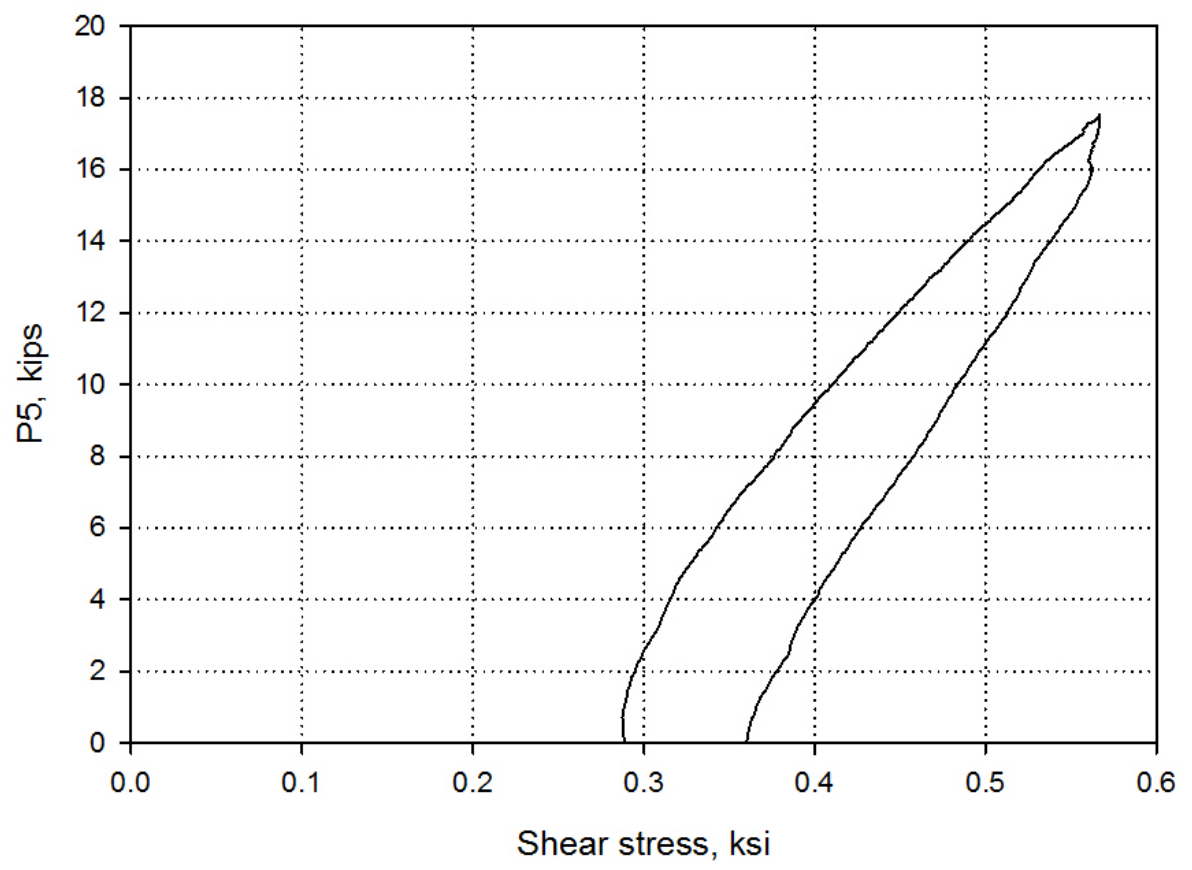

Figure 118. Approximate total point load $P_{5}$ versus calculated shear stresses at $R_{712}$.

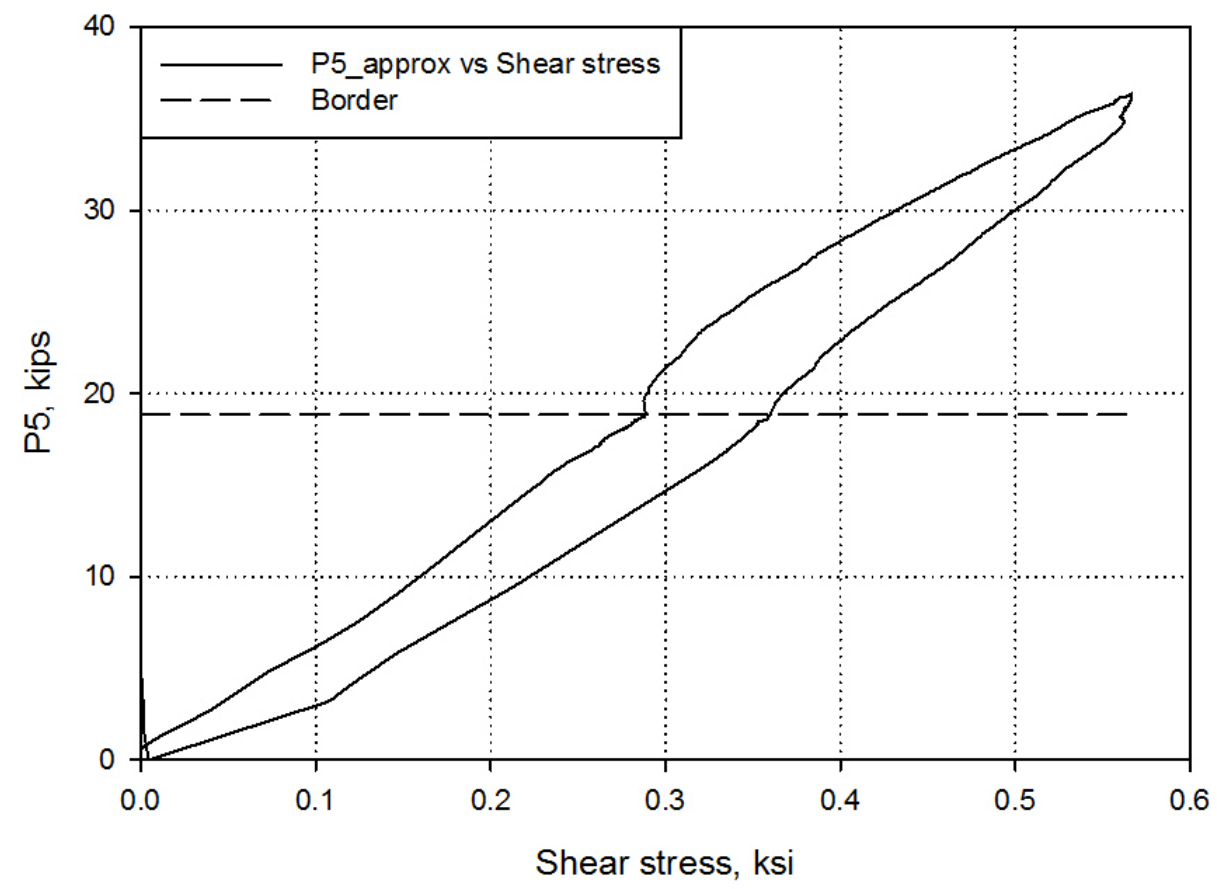


Figure 119 shows the approximate magnitudes of bending stresses versus measured strains at the midspan extreme fibers during the first load cycle. The magnitudes of bending stresses were calculated from approximate section properties (assuming the neutral axis to occur at midsection height) and moments at midspan. The moments at midspan were calculated from the loading curves in Figure 119.

Figure 119. Approximate magnitude of bending stress versus strain at midspan.

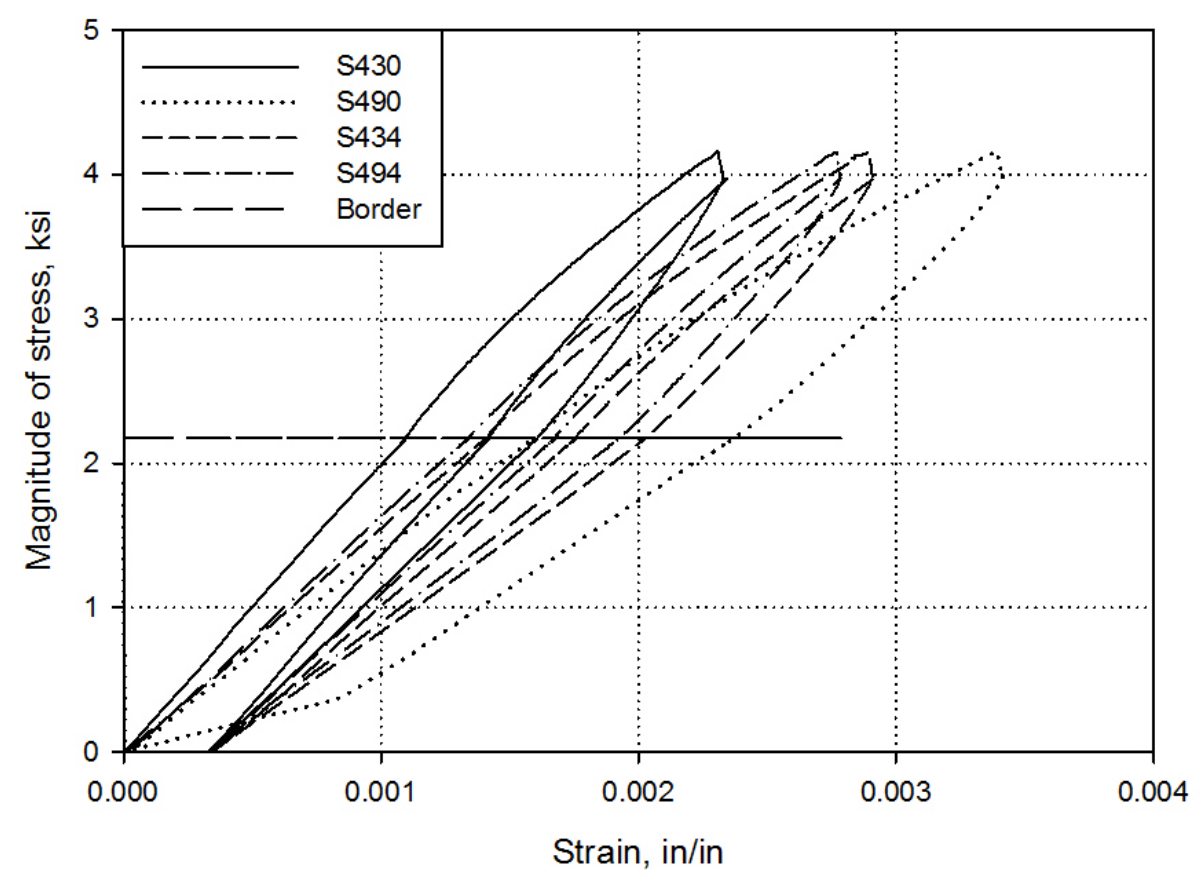

Figure 120 shows the specimen after failure. The specimen underwent sudden, brittle failure during the second load cycle, at a load that was lower than the peak during the first cycle. The maximum deflection of the specimen during the first cycle and at failure was a little more than 7 in. 
Figure 120. Brittle failure of the specimen.

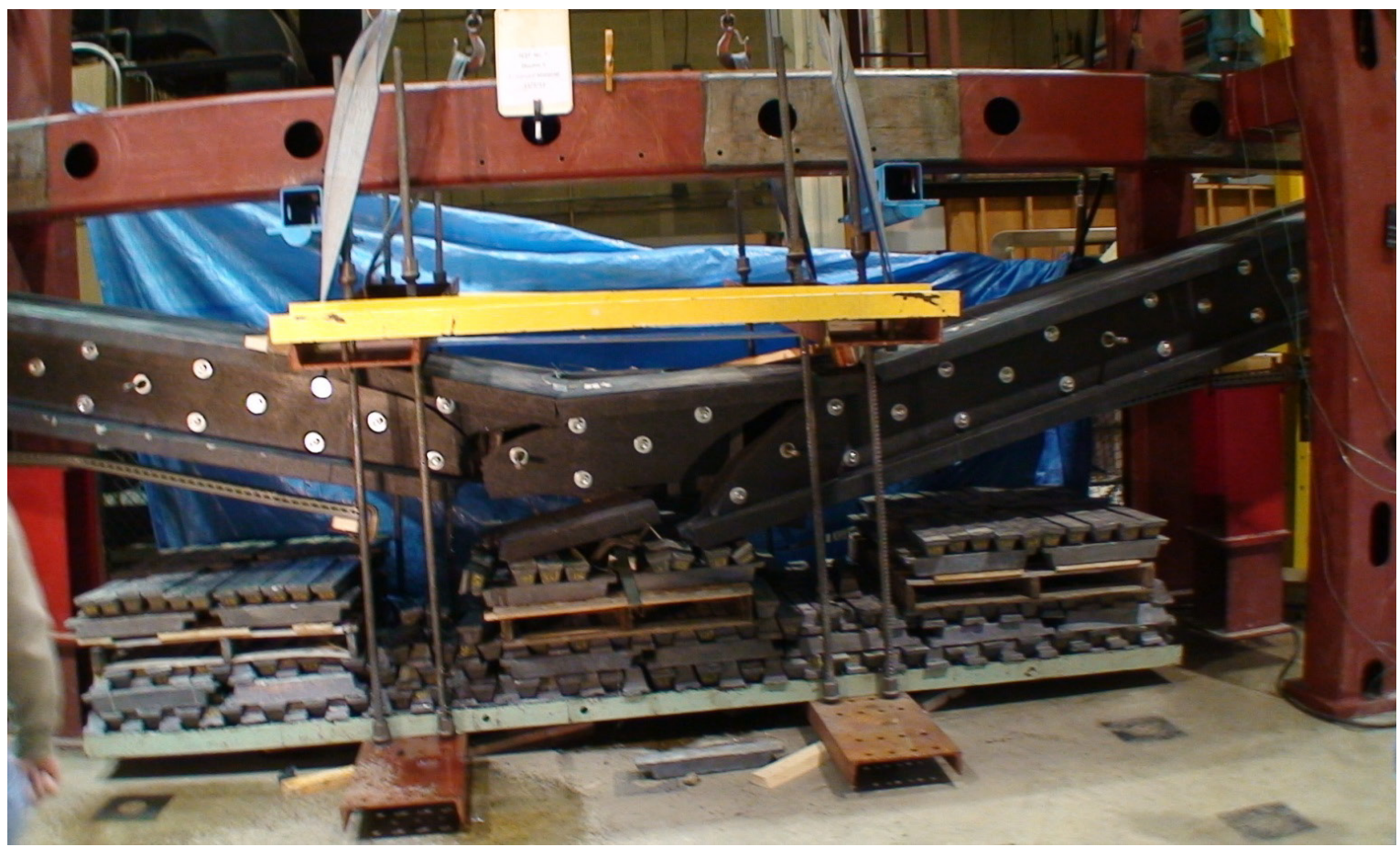

Figure 121-Figure 124 show several views of the failure that was initiated between the two actuators in the region of approximately constant flexural stress. One crack appears to have initiated in the bottom flange and then propagated diagonally through the web and top flange. The other crack initiated in the bottom flange and continued vertically part-way through the web before splitting into a "Y-crack" and entering the top flange, with one branch of the Y-crack passing through a bolt hole. Other cracks did not show a tendency to pass through bolt holes.

Figure 121. Side view of failed specimen, looking west.

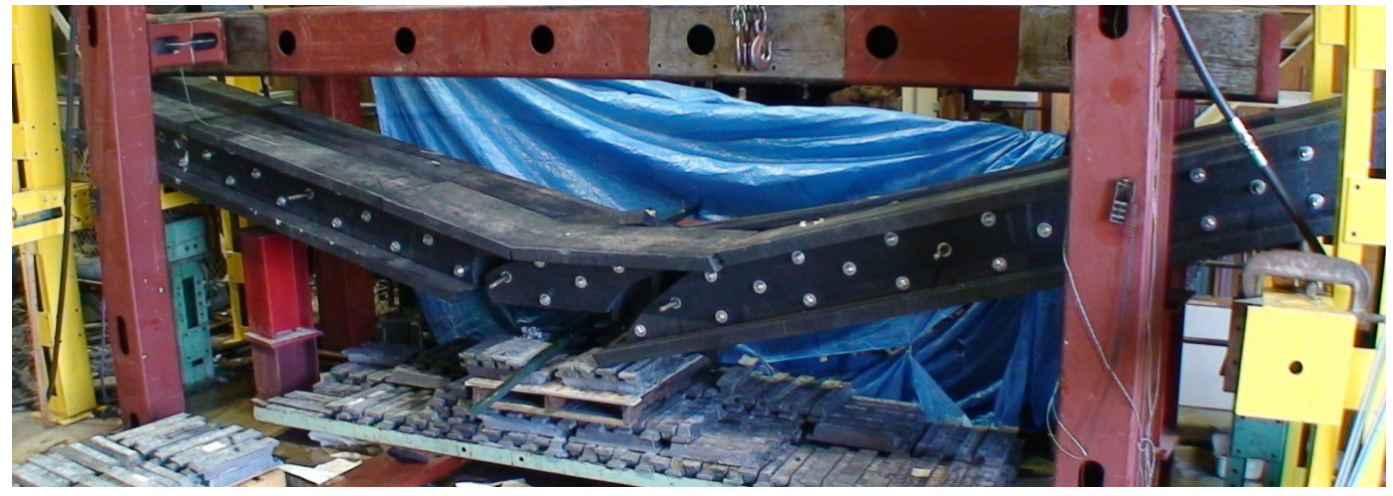


Figure 122. Oblique view of specimen, cracks in top flange are visible.

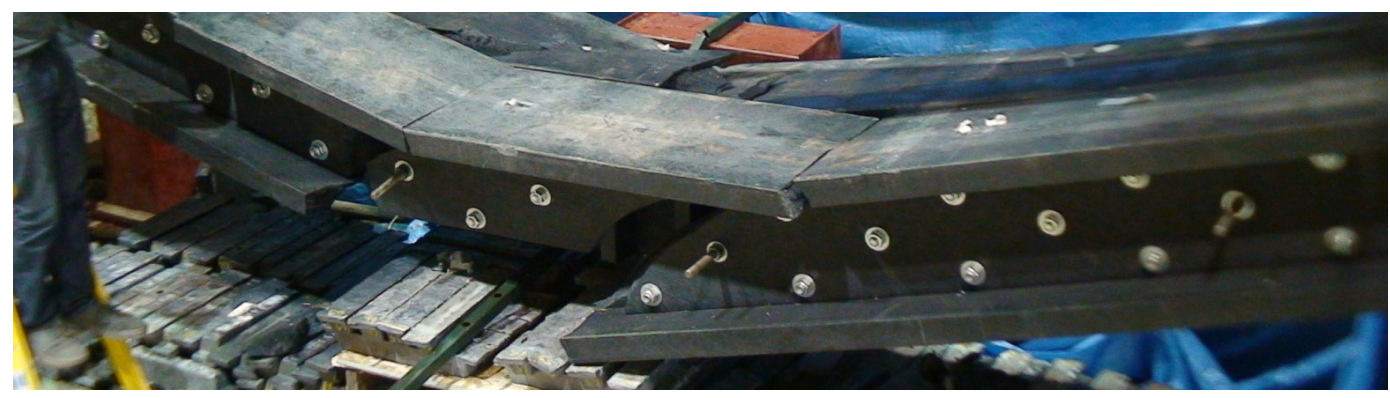

Figure 123. Cracks in the web.

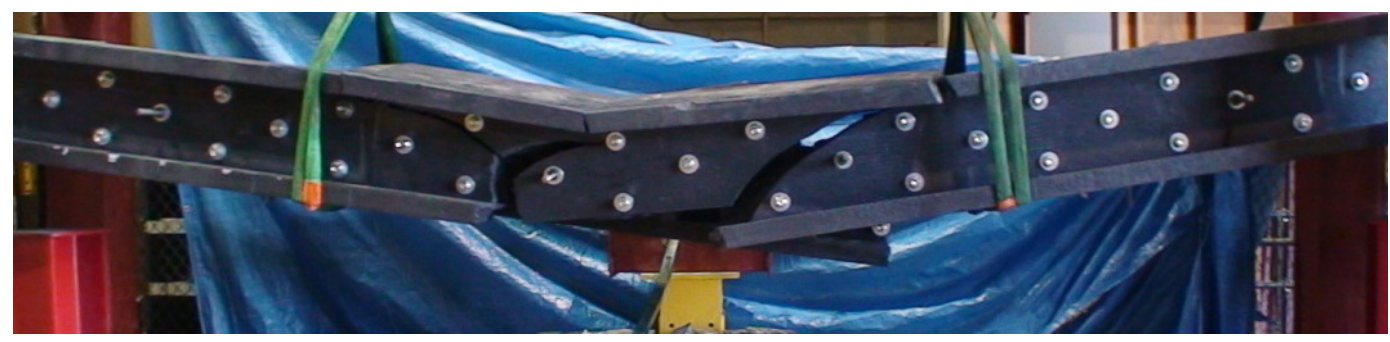

Figure 124. Longitudinal view, looking north.

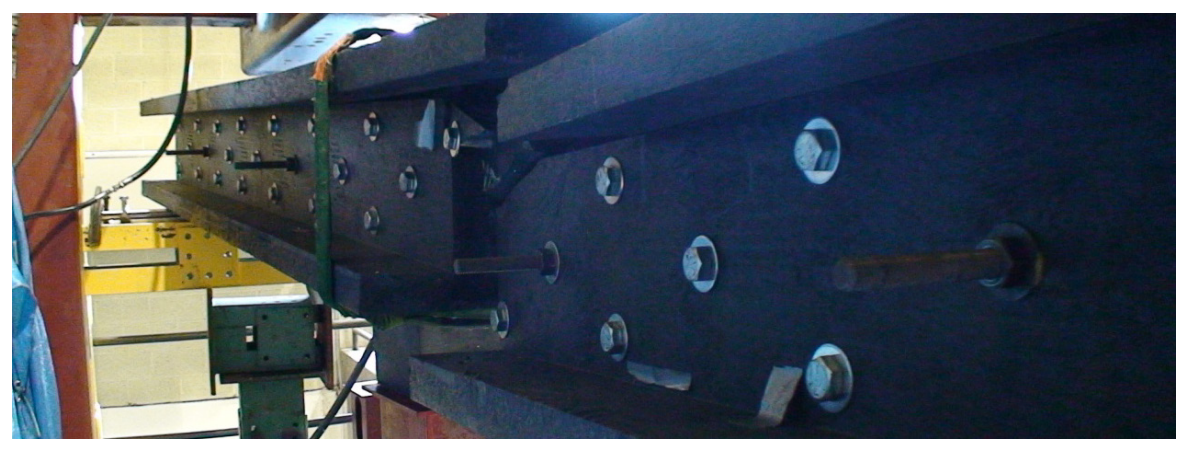

More photos depicting the brittle failure of this specimen are presented below. Figure 125 shows web-flange delaminating, Figure 126 shows cracks in the top flange,

Figure 127 shows the separation surface between the flange and web, and Figure 128 shows fragments which became airborne during failure. 
Figure 125. Flange-web delamination.

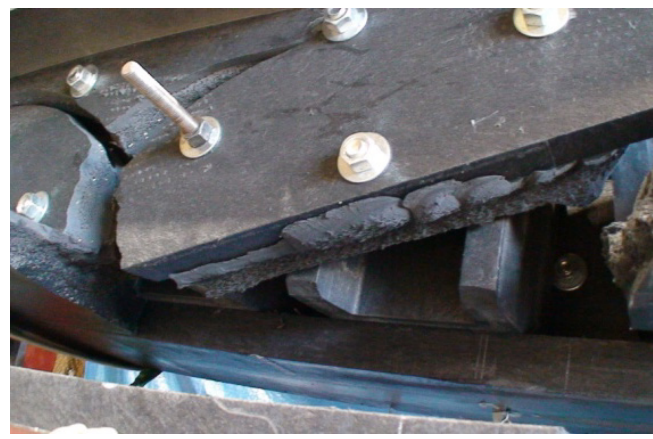

Figure 127. Separation surface between flange and web, shown on flange.

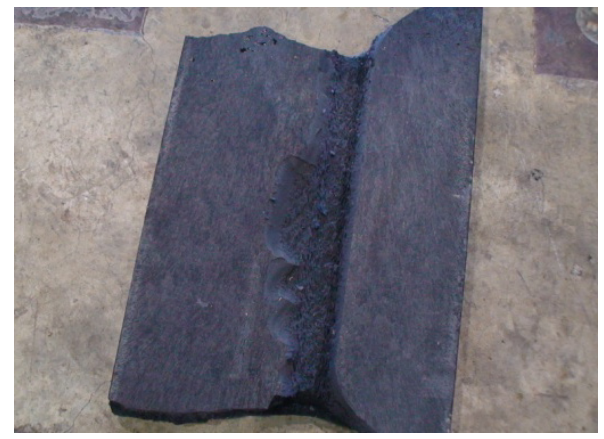

Figure 126. Cracks in the top flange.

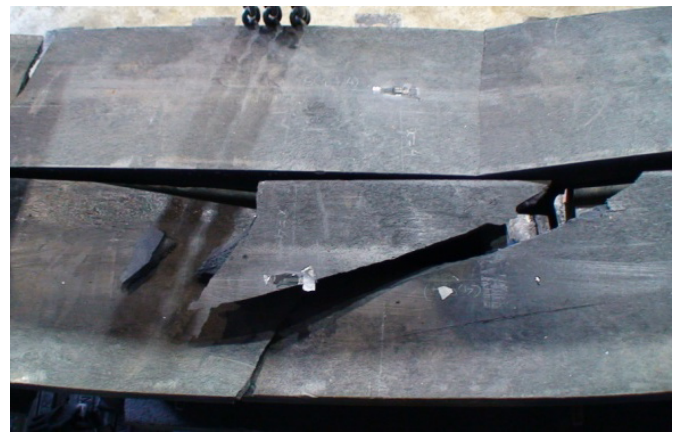

Figure 128. Fragments that became airborne due to brittle failure.

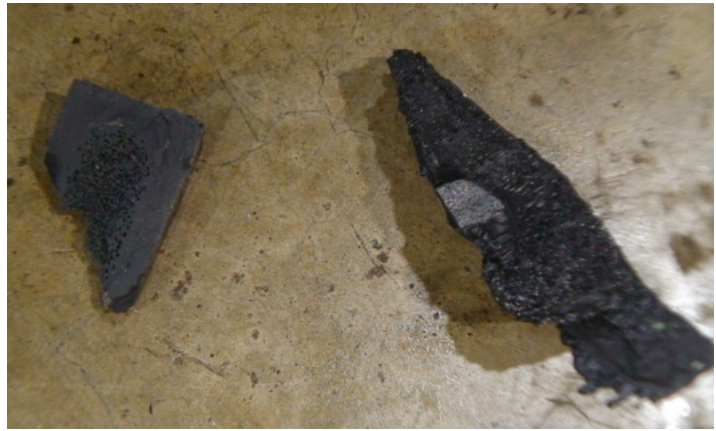

A summary of the significant cracks in the middle section is shown in Figure 129.

Figure 129. Crack survey.

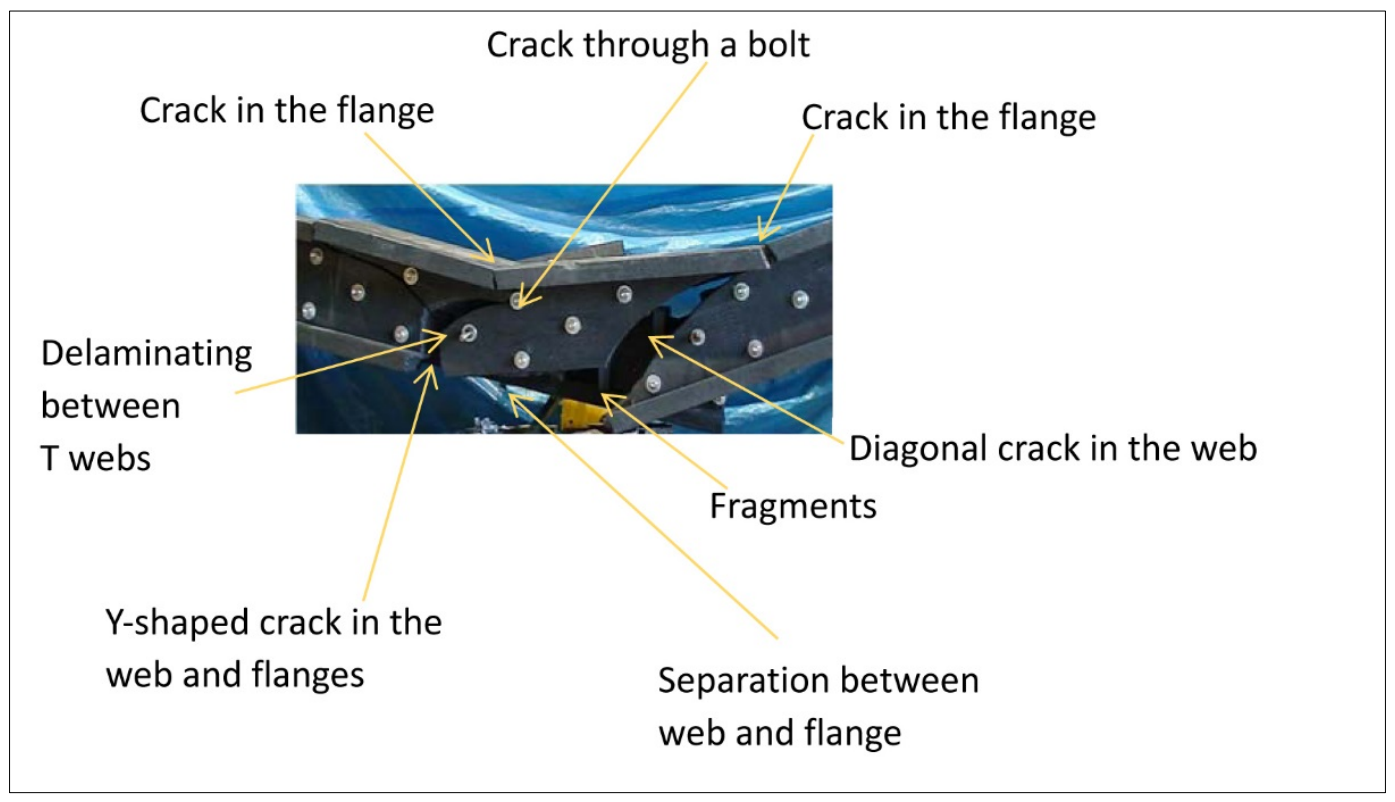




\section{Conclusions and Recommendations}

\subsection{Test summaries and conclusion}

\subsubsection{Load testing}

The original batch of material contained a void-filled core layer, sandwiched between two void-free exterior layers. Two specimens were prepared from this material, based on layer orientation. With layers loaded in parallel, the average compressive strength of the original batch was 4.49 ksi. Tests with this loading orientation were dominated by a delamination and buckling failure mode. With layers loaded in series, the average compressive strength of the original batch was $4.31 \mathrm{ksi}$. Tests with this loading orientation were dominated by a crushing failure mode in the void-filled middle layer. Since the specimen failure mode differed by layer orientation, the ultimate load of the two specimen types are not directly comparable to one another.

Two specimens were also prepared with the second, improved batch of thermoplastic material. When layers were loaded in parallel, the core layer had noticeably fewer voids and provided about $6 \%$ capacity improvement. No significant capacity improvement occurred in specimens that were loaded with layers in series.

All tensile specimens were loaded with layers in parallel. The improved batch provided only about a $1 \%$ increase in tensile strength. At a loading rate of $0.1 \mathrm{in}$. per minute, the average tensile strength across the two batches was $2.25 \mathrm{ksi}$. This value increased by about $19 \%$ with a tenfold increase in the $\mathrm{C} / \mathrm{H}$ loading rate (one test).

\subsubsection{Flexure testing}

Effectively, the thermoplastic beams in this project were composed of two different materials, the void-free external layer and the void-filled core. During material properties testing, approximately uniform loading was imposed over the entirety of the loading surface. Since these specimens contained two discreet material types, the results of these tests cannot be used directly to predict the behavior of a beam under flexure.

However, material compression tests were performed with layers in parallel and layers in series, which provides two linearly independent specimen 
stiffness equations. With approximate layer thicknesses for each specimen, these equations may be solved for the average stiffnesses of both the voidfree and void-filled material (two different materials), which would allow compressive strain gauge readings (void-free layer) from beam tests to be compared directly with mechanical compression testing results. Incorporation of this information would contribute to understanding the behavior of these beams. However, loading curves for many of the compression specimens were not available, and tension testing with layers in series was not performed during this project. This type of tension specimen may be difficult to fabricate.

In the beams that were tested under flexure during this project, only the void-free layer could be instrumented, and the two materials are subjected to different stress and strain gradients with different maxima. Fortunately, the extreme flexural fibers of the beams in this project were composed of the stiffer and stronger void-free layer, making this part of the beam very effective in flexure.

\subsubsection{Material properties testing}

During material properties tests, the material was found to be about $30 \%$ stiffer in compression than in tension, resulting ostensibly in the bending of beams about noncentroidal neutral axes. In other words, higher compressive stiffness appeared to result in larger strains at extreme tensile fibers and larger stresses at extreme compression fibers. Failure of beams was still dominated by flexural tension, which agrees with the higher compressive strengths found in mechanical tests.

The thermoplastic material displayed viscoelastic properties, with greater stiffness at higher deflection rates as well as load decay under both constant and ramped deflections, which implies time-dependent deflection under constant load. The beams also tended to retain residual deformations after each load cycle. Sources which were discussed in the literature review for this project reported residual deformations in similar beams to dissipate over time. Therefore, the "final" deflection and rebound due to long-term loading and load removal may occur well after a load is applied or removed, but "final" deflection and rebound were not covered in this project. 


\subsubsection{Failure testing}

In two flexural tests to beam failure, sudden tensile fracture appeared to initiate between loading points in the bottom flange and proceed quickly through the web near loading points. Failure generally occurred during repeated load cycles, and at lower loads than the maxima from previous load cycles, implying that strength loss occurred during load cycles where failure did not occur.

In two tests to beam failure, it was found that sudden, brittle fracture occurred at ultimate strength. However, excessive deflection greater than L/45 (i.e., serviceability failure) preceded brittle fracture. This may not hold true for high-intensity, high-rate loads, since beam deflection is timeand load-dependent. Moreover, beam strength appeared to be reduced over repeated near-capacity loading.

\subsubsection{Conclusion}

Summaries of the load and displacement results at the center of the beams and the flexural and shear stresses are provided in Table 33 and Table 34, respectively. Based on the results from these experiments, the use of a capacity reduction factor between 0.5 to 0.6 is advisable for the strength design of this type of cross section, in both tension and compression. This large reduction is a result of the sudden, brittle failure modes experienced by thermoplastic beams under ultimate loading conditions. The strength of the material also contains a considerable amount of scatter, which contributes to the necessity for a large reduction in strength.

\subsection{Recommendations}

There are six recommendations to be considered as a result of this work, as listed below:

1. Further testing should be performed to determine the compressive stiffness of the two thermoplastic materials, using a multiple orientation-based approach. In addition, testing one material type at a time to determine the tensile strength is recommended, since the multiple orientation-based approach was not practical.

2. The shear strength of these types of thermoplastic I-beams should be investigated further, since a void-filled core is expected to have significant implications that this project was unable to test. 
3. The shear strength of thermoplastic beams such as these may likely be based on 0.6 times the tensile strength of the material, as is the case with steel, but shear tests must be carried out to verify this figure.

4. More testing may be required at very high loading rates to determine how this type of beam reacts to high-intensity, high-rate loading as well as cyclic near-capacity loading. Also, beam behavior under very highrate, long-term loads (e.g., traffic parked on a bridge or soil-bearing roofing beams) should be investigated further.

5. The capacity reduction factor for strength design of this type of cross section is recommended to be between 0.5 to 0.6 , in both tension and compression. Of course, statistical analysis of a larger population of specimens (from more batches) is required to determine exactly what strength reduction factor should be used.

6. Further experimentation and more accurate characterization of material behavior is unlikely to change the required safety factor for this material, but it may result in better estimates of the properties of discreet material layers which exist within the section as well as their effect on flexural strength. With better material property estimates, structures that use beams such as these could be significantly more efficient, while maintaining conservatism in the design process. 
Table 33. Measured loads and displacement at the center of the specimens.

\begin{tabular}{|c|c|c|c|c|c|c|c|c|c|c|}
\hline 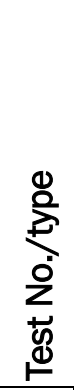 & & 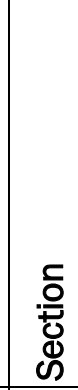 & 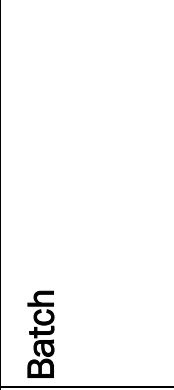 & 亨 & 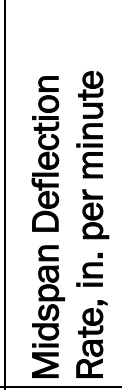 & 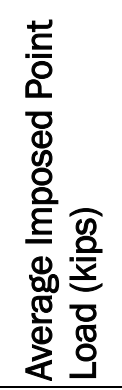 & 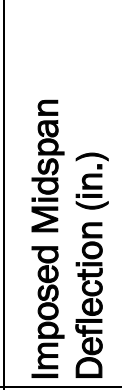 & 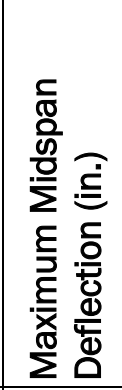 & 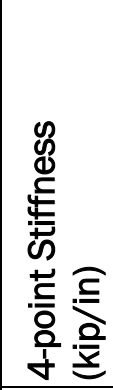 & 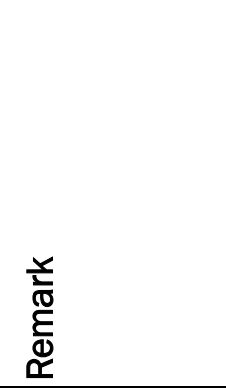 \\
\hline \multirow{3}{*}{$\begin{array}{l}\bar{\pi} \\
\frac{.}{\mathbb{Z}} \\
\frac{\pi}{\pi} \\
\frac{\pi}{<}\end{array}$} & $\begin{array}{l}\text { Hand } \\
\text { calculation }\end{array}$ & I & Improved & 1 & N/A & 17.33 & 4.93 & 4.93 & 3.5 & \\
\hline & SAP2000 & I & Improved & 1 & N/A & 14.33 & 4.00 & 4.00 & 3.6 & $\begin{array}{l}\text { 3" Auto-mesh } \\
\text { (polygonal) }\end{array}$ \\
\hline & SAP2000 & II & Improved & 1 & N/A & 29.98 & 4.00 & 4.00 & 7.5 & $\begin{array}{l}" \text { \& } 2 " \\
\text { square } \\
\text { meshes }\end{array}$ \\
\hline \multirow{5}{*}{ 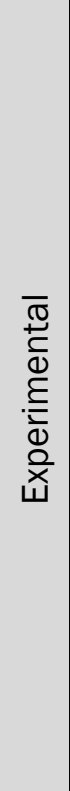 } & 1 & 1 & Original & 1 & 0.92 & 12.7 & 4.7 & 4.7 & 2.7 & \\
\hline & 2 & 1 & Improved & $\begin{array}{l}1 \\
2 \\
3\end{array}$ & \begin{tabular}{|l|}
0.88 \\
0.88 \\
0.89
\end{tabular} & $\begin{array}{l}33.9 \\
31.6 \\
31.3\end{array}$ & $\begin{array}{l}5.7 \\
5.2 \\
5.0\end{array}$ & $\begin{array}{l}5.7 \\
5.9 \\
5.9\end{array}$ & \begin{tabular}{|l|}
5.9 \\
6.1 \\
6.3
\end{tabular} & $\begin{array}{l}\text { Load cell } \\
\text { conversion } \\
\text { error likely }\end{array}$ \\
\hline & 3 & 1 & Improved & $\begin{array}{l}1 \\
2\end{array}$ & $\begin{array}{l}8.94 \\
8.96\end{array}$ & $\begin{array}{l}15.0 \\
16.0\end{array}$ & $\begin{array}{l}6.3 \\
5.4\end{array}$ & $\begin{array}{l}6.3 \\
6.2\end{array}$ & \begin{tabular}{|l|}
2.4 \\
3.0
\end{tabular} & Brittle failure \\
\hline & 4 & II & Original & $\begin{array}{l}1 \\
2 \\
1 \\
2 \\
3 \\
4\end{array}$ & $\begin{array}{l}0.88 \\
0.89 \\
8.77 \\
8.80 \\
8.78 \\
8.81\end{array}$ & $\begin{array}{l}26.8 \\
25.0 \\
28.6 \\
28.6 \\
29.3 \\
33.3\end{array}$ & \begin{tabular}{|l|}
5.9 \\
5.2 \\
5.0 \\
4.9 \\
4.9 \\
6.4
\end{tabular} & $\begin{array}{l}5.9 \\
6.0 \\
6.0 \\
6.0 \\
6.0 \\
6.9\end{array}$ & \begin{tabular}{|l|}
4.5 \\
4.8 \\
5.7 \\
5.8 \\
6.0 \\
5.2
\end{tabular} & \\
\hline & 5 & II & Improved & \begin{tabular}{|l}
1 \\
2 \\
\end{tabular} & $\begin{array}{l}\text { N/A } \\
\text { N/A }\end{array}$ & $\begin{array}{l}36.1 \\
34.7 \\
\end{array}$ & $\begin{array}{l}8.3 \\
6.7 \\
\end{array}$ & $\begin{array}{l}8.3 \\
8.3 \\
\end{array}$ & \begin{tabular}{|l|}
4.3 \\
5.4
\end{tabular} & Brittle failure \\
\hline
\end{tabular}


Table 34. Measured flexural stresses at the center of the beam and the shear stress at $18 "$ in from the support.

\begin{tabular}{|c|c|c|c|c|c|c|c|c|c|c|}
\hline \multicolumn{2}{|l|}{ 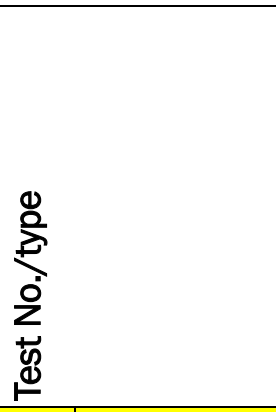 } & 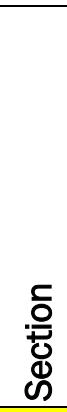 & $\begin{array}{l}\frac{1}{0} \\
\mathbb{\pi} \\
\infty\end{array}$ & 号 & 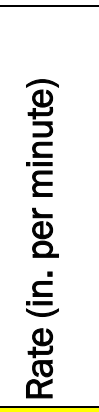 & 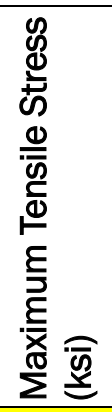 & 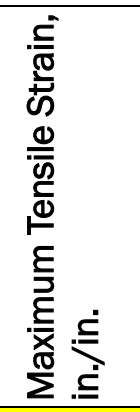 & 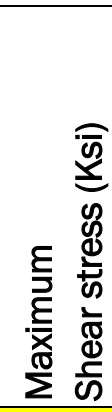 & 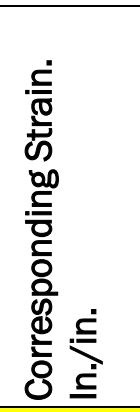 & 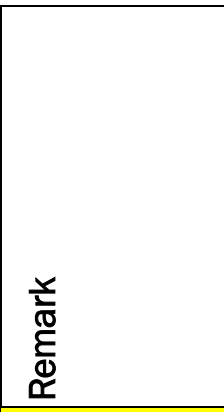 \\
\hline \multirow{3}{*}{$\frac{\frac{0}{0}}{\frac{2}{d \sigma}}$} & $\begin{array}{l}\text { Hand } \\
\text { calculation }\end{array}$ & I & Improved & 1 & N/A & 2.0 & N/A & 0.42 & $\mathrm{~N} / \mathrm{A}$ & \\
\hline & SAP2000 & I & Improved & 1 & $\mathrm{~N} / \mathrm{A}$ & 1.9 & N/A & 0.28 & $\mathrm{~N} / \mathrm{A}$ & $\begin{array}{l}\text { 3" Auto- } \\
\text { mesh } \\
\text { (polygonal) }\end{array}$ \\
\hline & SAP2000 & II & Improved & 1 & $\mathrm{~N} / \mathrm{A}$ & 2.3 & $\mathrm{~N} / \mathrm{A}$ & 0.22 & $\mathrm{~N} / \mathrm{A}$ & $\begin{array}{l}3 " \& 2 " \\
\text { square } \\
\text { meshes }\end{array}$ \\
\hline \multirow{5}{*}{ 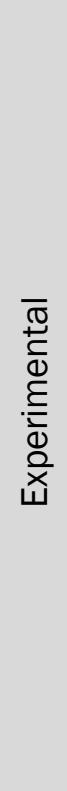 } & 1 & 1 & Original & 1 & 0.92 & 1.43 & 0.0018 & 0.36 & 0.0012 & \\
\hline & 2 & 1 & Improved & $\begin{array}{l}1 \\
2 \\
3\end{array}$ & $\begin{array}{l}0.88 \\
0.88 \\
0.89\end{array}$ & 3.60 & 0.0022 & 0.32 & 0.0012 & $\begin{array}{l}\text { Load cell } \\
\text { conversion } \\
\text { error likely }\end{array}$ \\
\hline & 3 & 1 & Original & $\begin{array}{l}1 \\
2\end{array}$ & $\begin{array}{l}8.94 \\
8.96\end{array}$ & 1.84 & 0.0025 & N/A & N/A & Brittle failure \\
\hline & 4 & II & Original & $\begin{array}{l}1 \\
2 \\
1 \\
2 \\
3 \\
1\end{array}$ & $\begin{array}{l}0.88 \\
0.89 \\
8.77 \\
8.80 \\
8.78 \\
8.81\end{array}$ & 1.91 & 0.0020 & 0.39 & 0.0014 & \\
\hline & 5 & II & Improved & $\begin{array}{l}1 \\
2\end{array}$ & $\begin{array}{l}\text { N/A } \\
\text { N/A }\end{array}$ & 2.08 & 0.0022 & 0.58 & 0.0020 & Brittle failure \\
\hline
\end{tabular}




\section{References}

Assis, George F. 2010. "Applying Recycled Plastic Lumber Technology to Short-Span Bridges." STRUCTURE Magazine, October 2010: 8-9.

ASTM D6109. 2013. "Standard Test Methods for Flexural Properties of Unreinforced and Reinforced Plastic Lumber and Related Products." West Conshohocken, PA: ASTM International.

ASTM D638. 2014. "Standard Test Method for Tensile Properties of Plastics." West Conshohocken, PA: ASTM International.

Commander, Brett C., and Henry Diaz-Alvarez. June 2010. Field Testing and Load Rating of the World's First Thermoplastic Bridge: Bridge T-8518, Camp Mackall, Fort Bragg, North Carolina. ERDC/GSL TR-10-19. Vicksburg, MS: Engineer Research and Development Center, Geotechnical and Structures Laboratory (ERDC-GSL).

Fink, Bruce K., John W. Gillespie Jr., and Nuri B. Ersoy. 2000. Thermal Degradation Effects on Consolidation and Bonding in the Thermoplastic Fiber-Placement Process. ARL-TR-2238. Aberdeen Proving Ground, MD: Army Research Laboratory.

Koch, Gerhardus H., Michiel P.H. Brongers, Neil G. Thompson, Y. Paul Virmani, and J.H. Payer. 2002. Corrosion Costs and Preventive Strategies in the United States. FHWA-RD-01-156. Houston, TX: NACE International.

Lampo, Richard G., Steven Sweeney, James Wilcoski, Vincent Hock, Vincent Chiarito, Henry Diaz-Alvarez, and Thomas Nosker. 2009. "Thermoplastic Composites as Degradation-Resistant Material Systems for Timber Bridge Designs.” In Proceedings of 2009 DoD Corrosion Conference, held in Washington DC, August 2009.

Lampo, Richard G., Barry K. Myers, Karl Palutke, and Darryl M. Butler. 2011. Remote Performance Monitoring of a Thermoplastic Composite Bridge at Camp Mackall, NC: Final Report on Project Fo8-AR13, Task A-Thermoplastic Composite Bridges. ERDC/CERL TR-11-43. Champaign, IL: Engineer Research and Development Center-Construction Engineering Research Laboratory (ERDCCERL).

Lampo, Richard G., Thomas J. Nosker, George Nagle, Sarah B. Nemeth, Karl Palutke, and Lawrence Clark. Forthcoming. Demonstration of Thermoplastic Composite I-Beam Design Bridge at Camp Mackall, NC: Final Report on Projects FYo8-16 and FYo9-31 for Installation Technology Transition Program. Champaign, IL: ERDC-CERL.

Qi, H.J., and M.C. Boyce. 2005. "Stress-strain Behavior of Thermoplastic Polyurethanes." Mechanics of Materials 37(8): 817-839. 
Sheldon, Jim. 2012. R\&D Testing of Deckboard Samples for US Army Corp of Engineering Construction Engineering Research Laboratory of Champaign, IL. PFS Test Report: \#12-007. Cottage Grove, WI: PFS Corporation.

Uddin, Nassim, and Abdul Moeed Abro. 2007. Design and Analysis of Thermoplastic Composite Bridge Superstructures. UTCA Report 05228. Tuscaloosa, AL: University Transportation Center for Alabama. 


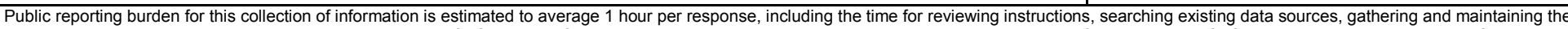

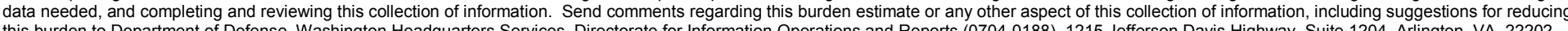

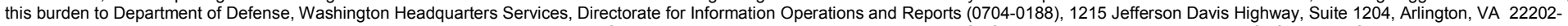

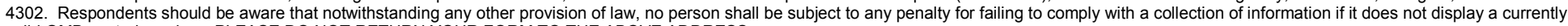
valid OMB control number. PLEASE DO NOT RETURN YOUR FORM TO THE ABOVE ADDRESS.
1. REPORT DATE (DD-MM-YYYY)
June 2017

\section{REPORT TYPE}
Final Technical Report

\section{TITLE AND SUBTITLE}

Full-Scale Testing of Thermoplastic Composite I-Beams for Bridges

5b. GRANT NUMBER

5c. PROGRAM ELEMENT NUMBER

6. AUTHOR(S)

Ghassan K. Al-Chaar, Steven C. Sweeney, Richard G. Lampo, and Marion L. Banko

\section{5d. PROJECT NUMBER}

5e. TASK NUMBER

2DB01B

5f. WORK UNIT NUMBER

\section{PERFORMING ORGANIZATION NAME(S) AND ADDRESS(ES)}

U.S. Army Engineer Research and Development Center (ERDC)

Construction Engineering Research Laboratory (CERL)

8. PERFORMING ORGANIZATION REPORT NUMBER

PO Box 9005

Champaign, IL 61826-9005

ERDC/CERL TR-17-18

\section{SPONSORING / MONITORING AGENCY NAME(S) AND ADDRESS(ES)}

Office of the U.S. Army Assistant Chief of Staff for

Installation Management

600 Army Pentagon

Washington, DC 20310

10. SPONSOR/MONITOR'S ACRONYM(S)

OACSIM

\section{DISTRIBUTION / AVAILABILITY STATEMENT}

Approved for public release. Distribution is unlimited.

\section{SUPPLEMENTARY NOTES}

\section{ABSTRACT}

Bridges are essential to access remote training areas on military installations. Department of Defense (DoD) elements are responsible for maintaining these bridges, which are experiencing significant deterioration of current steel and wood construction. Polymer composite materials that are resistant to corrosion and rot have been demonstrated as beneficial replacements; however, the structural capacity and design considerations for future applications is not known. Structural performance tests were conducted on commercially available, thermoplastic polymer composite I-beams at U.S. Army Corps of Engineers, Engineer Research and Development Center-Construction Engineering Research Laboratory (ERDC-CERL).

Finite element models of the I-beams were used to predict the behavior of the beams and estimate maximum load, displacement, and shear at failure. Then, tests were conducted on actual beams. The thermoplastic beams displayed sudden, brittle failure modes under ultimate loading conditions. The thermoplastic material displayed viscoelastic properties, greater stiffness at higher deflection rates, and load decay under constant and ramped deflections, implying time-dependent deflection under constant load. The beams retained residual deformations after each load cycle.

Therefore, a large capacity-reduction factor is advisable for future strength designs. Follow-on developmental work is recommended that refines material property estimates to create higher efficiency during the design process, yet maintains conservatism.

\section{SUBJECT TERMS}

Thermoplastic composites, Corrosion resistant materials, Structural engineering, Bridges, Materials-Dynamic testing

16. SECURITY CLASSIFICATION OF:
\begin{tabular}{l|l|l|}
\hline $\begin{array}{c}\text { a. REPORT } \\
\text { Unclassified }\end{array}$ & $\begin{array}{c}\text { b. ABSTRACT } \\
\text { Unclassified }\end{array}$ & $\begin{array}{c}\text { c. THIS PAGE } \\
\text { Unclassified }\end{array}$ \\
\hline
\end{tabular}

17. LIMITATION
OF ABSTRACT
UU
130

\begin{tabular}{|l|}
\hline $\begin{array}{l}19 a . \quad \text { NAME OF RESPONSIBLE } \\
\text { PERSON }\end{array}$ \\
\hline $\begin{array}{c}\text { 19b. TELEPHONE NUMBER (in- } \\
\text { clude area code) }\end{array}$ \\
\hline
\end{tabular}

Standard Form 298 (Rev. 8-98)

Prescribed by ANSI Std. 239.18 